\title{
Behavioral toxicity of medicinal drugs
}

Citation for published version (APA):

Ramaekers, J. G. (1998). Behavioral toxicity of medicinal drugs. [Doctoral Thesis, Maastricht University]. NeuroPsych Publishers. https://doi.org/10.26481/dis.19981119jr

Document status and date:

Published: 01/01/1998

DOI:

10.26481/dis.19981119jr

Document Version:

Publisher's PDF, also known as Version of record

\section{Please check the document version of this publication:}

- A submitted manuscript is the version of the article upon submission and before peer-review. There can be important differences between the submitted version and the official published version of record.

People interested in the research are advised to contact the author for the final version of the publication, or visit the DOI to the publisher's website.

- The final author version and the galley proof are versions of the publication after peer review.

- The final published version features the final layout of the paper including the volume, issue and page numbers.

Link to publication

\footnotetext{
General rights rights.

- You may freely distribute the URL identifying the publication in the public portal. please follow below link for the End User Agreement:

www.umlib.nl/taverne-license

Take down policy

If you believe that this document breaches copyright please contact us at:

repository@maastrichtuniversity.nl

providing details and we will investigate your claim.
}

Copyright and moral rights for the publications made accessible in the public portal are retained by the authors and/or other copyright owners and it is a condition of accessing publications that users recognise and abide by the legal requirements associated with these

- Users may download and print one copy of any publication from the public portal for the purpose of private study or research.

- You may not further distribute the material or use it for any profit-making activity or commercial gain

If the publication is distributed under the terms of Article $25 \mathrm{fa}$ of the Dutch Copyright Act, indicated by the "Taverne" license above, 


\section{BEHAVIORAL TOXICITY OF MEDICINAL DRUGS}


O JG Ramaekers, Maastricht 1998

Production: Datawyse U University Press Masasticht

ISBN $\quad 90.75579 .07-1$

NUGI $\quad 716,744,746$

Newropsych Publishers is a non-profit organization which aims at promoting the science of Brain \& Behcuvor and irmproving the application of products of this science in health care and education. Neuropsych Publishers acconplishes these aims by publishing books, dissertations and other products of scientific activity, dissemination of educational materials and publication of tests, assessment scales and other psychometric instruments in the field of Neuropsychology, Neuropsychiatry and other areas within the domain of Brain \& Behavior.

Postal address:

Neuropsych Publishers

Departmen of Psychany and Neuropsychology

Section Neuropsychology and Psychobiology

University of Masastricht

P.O. Box 616

NL 6200 MD M.astricht

The Netherlands 


\title{
BEHAVIORAL TOXICITY OF MEDICINAL DRUGS
}

\author{
PROEFSCHRIFT
}

ter verkrijging van de graad van doctor

aan de Universiteit Maastricht

op gezag van de Rector Magnificus,

Prof dr AC Nieuwenhuijzen Kruseman, volgens het besluit van het College van Decanen, in het openbaar te verdedigen op donderdag 19 november 1998 om 14.00 uur

door

JOHANNES GERARDUS RAMAEKERS 


\section{Promotoren}

Prof dr J Jolles

Prof dr JF O'Hanlon

\section{Beoordellingscommissie}

Prof dr H Merckelbach (voorzitter)

Prof dr M Ansseau (Universiteit Luik)

Prof dr JF Orlebeke (Vrije Universiteit Amsterdam)

Prof dr HM van Praag

Prof dr HAJ Struyker-Boudier

The research deseribed in the dissertation was conducted at the Institute for Human Psychopharmacology, Maastricht University, Maastricht. The studies were funded by: F Hoffman-La Roche, Basle ( $\mathrm{Ch} \mathrm{3,6),} \mathrm{Knoll} \mathrm{(Boots)} \mathrm{Pharmaceuticals,} \mathrm{Nottingham}$ (Ch 4) and Synthelabo Recherche, Paris (Ch 5,7).

The financial support from Schering-Plough BV, Maarssen, Astra Charnwood, Loughborough (main sponsors), Boeluringer Ingelheim, Alkmaar, Synthelabo Recherche, Paris, Nourypharma, Oss, and the Institute for Human Psychopharmacology for the publication of this thesis is greattully acknowledged. 


\section{CONTENTS}

1 General Introduction

2 Behavioral toxicity of medicinal drugs: practical consequences, incidence, management and avoidance

Abstract

Definition

Epidemiological studies

Experimental studies and case reports

Management and avoidance

Conclusion

3 Effects of moclobemide and mianserin on highway driving, psychometric performance and subjective parameters, relative to placebo

Abstract

Introduction

Material and methods

Results 54

Discussion

4 A comparative study of acute and subchronic effects of dothiepin, fluoxetine and placebo on psychomotor and actual driving performance

Abstract

Introduction

62

Material and methods

Results

Discussion

5 A study of the pharmacodynamic interaction between befloxatone and ethanol on performance and mood in healthy volunteers

Abstract 79

Introduction 80

Material and methods 81

Results 84

Discussion 
6 Considering the cylochrome P450 system as determining combined effects of antidepressants and benzodiazepines on actual driving performance of depressed outpatients

Abstract

Introduction

Material and methods

Results

Discussion

7 Psychomotor, cognitive, extrapyramidal and affective functions of healthy volunteers during subchronic treatment with an atypical (amisulpride) and a classic (haloperidol) antipsychotic

Abstract

Introduction

Material and methods

Results

Discussion

8. Antihistamine effects on actual driving performance in a standard test: a Sumnary of Dutch experience

Abstract

Introduction.

The common method

Results

Discussion

Conclusions

9 General discussion

Summary

Samenvating

Dankwoord 


\section{CHAPTER 1}

\section{GENERAL INTRODUCTION}

\section{Side effects of medicinal drugs}

The choice to prescribe a particular drug should be made in the light of possible behavioral effects of available drug therapies. Medicinal drugs of course are intended to ameliorate symptoms and/or to cure a disease. Yet besides a therapeutic effect, they can also have disadvantages that can limit their clinical usefulness. These include primary toxic reactions such as cardiotoxicity, liver or kidney injury, bone marrow depression but also a range of CNS side effects such as sedation, sleep disturbances, motor and emotional disturbances and lethargy. The term side effects is often used in the literature to describe reactions that are subordinate to the therapeutic response and implies that these may not be severe. Yet, at the behavioral level these side effects may cause impairment of thought processing, attentional deficits, indecisiveness or psychomotor impairment. In many patients, these behavioral deficits are even superimposed on preexisting ones. Consequently, past and present researchers in the field of psychopharmacology have repeatedly pointed out that CNS side effects can reduce a patients' ability to cope with the psychomotor, intellectual, and cognitive demands of everyday living. Such detrimental drug effects on human performance have been described in terms of behavioral toxicity since the sixties (Cole, 1960; Fingl \&Woodbury, 1964; Dimascio \& Shader, 1968; Hindmarch \& Kerr, 1992; O'Hanlon \& Freeman, 1995).

\section{Behavioral roxicity: problem definition}

Each year many new drugs are introduced to the marked. Their registration in various countries is contingent upon their demonstrated efficacy in large, well-controlled clinical trials. Unfortunately, it is not so common to investigate the effects of new agents on everyday performance even though impairment can sometimes be expected beforehand on the basis of their specific pharmacological characteristics. Still, the proffle of behavioral side effects of a medicinal drug is of crucial importance for the well-being and safety of their users. Particularly in ambulant patients who continue 
their daily activities within a social, domestic, work and traffic environment. Their use of medicinal drugs such as benzodiazepines and tricyclic antidepressants has been shown to more than double their risk of involvement in injurious falls, and occupational and traffic accidents (For a review see Chapter 2). Traffic accidents resulting in 50,000 fatalities and 1,5 million injuries cost European society over 70 billion ECU (De Gier, 1995). The contribution of medicinal drugs is currently unknown but may be substantial since an average of $10 \%$ of the adult population is using them at any given time. At a very conservative estimate, if $10 \%$ of the adult population is driving under the influence of behaviorally toxic drugs, thus incurring twice the risk of being involwed in a traffic accident, those drugs are causing 4,500 death, 135,000 injuries and 6,3 billion ECU damage to society each year (De Gier, 1995).

The relative lack of interest in behavioral toxicity of medicinal drugs is even more surprising given the fact that the extent of performance impairment varies greatly between them, even if they belong to the same therapeutic class. Many novel drugs that have been introduced to the market over the recent years, produce less behavioral side effects than their predecessors because of their more selective activities within the brain. Sometimes, the difference in the level of behavioral toxicity is their only distinction. Clearly, information pertaining to such differences would provide physicians with a better rationale for choosing a particular drug. The amount of drug related accidents would reduce dramatically if only the least impairing drugs were to be prescribed. Even if a severely impairing drug has to be prescribed by lack of a better alternative, the recognition of its potential effects on performance could increase the patients' awareness of those situations in which these would pose the biggest risk to his or her safety (e.g traffic). Behavioral toxicity of medicinal drugs should therefore always be assessed in experimental performance studies before they enter the market, in the same way that their efficacy is always evaluated in clinical trials. Studies presented in the current thesis seek to establish the behavioral toxicity profiles of medicinal drugs.

\section{Assessment of behavioral toxicity}

Determination of a drugs' level of behavioral toxicity has mostly been based on information provided by the field of psychopharmacology, a distinct coalescence of behavioral pharmacology, biological psychiatry and experimental psychology. Over 
the last 30 years this discipline has aided in the development of more efficacious drugs and in the identification of their adverse behavioral side effects. Psychopharmacologists have devised a large number of experimental performance tasks for measuring the behavioral effects of medicinal drugs. These include laboratory tests of specific psychomotor and cognitive skills such as response speed, motor coordination, attention, logical reasoning and memory as well as performance measurements in real-life situations (Wittenborn, 1987; Wesnes et al, 1987; Parrot, 1.987).

Performance studies presented in the current thesis have employed both types of tasks for measuring behavioral toxicity. However, particular emphasis was given to the application of a real-life, over-the-road test for assessing driving performance under the influence of drugs. That test evolved from studies of driver fatigue conducted in the USA during the seventees (O'Hanlon \& Kelley, 1977). It was first applied in a limited pilot study for showing the effects of diazepam $10 \mathrm{mg}$ (O'Hanlon et al, 1981). It was standardized thereafter (O'Hanlon, 1984) and has repeatedly been applied to measure drug effects on driving.

The test involves driving over a $100 \mathrm{~km}$ circuit on a primary highway while attempting to maintain a constant speed $(95 \mathrm{~km} / \mathrm{h})$ and steady lateral position between the delineated boundaries of the right slower traffic lane. Subjects perform the test in the company of a licenced driving instructor who can intervene if necessary by using redundant controls at his position at the front passengers seat. An electro-optical device mounted at the back of the vehicle is used to measure lateral position of the vehicle relative to the paint-stripe delineation. The primary performance measure of road tracking ability is standard deviation of lateral position (SDLP), an index of "weaving".

\section{Outline of this thesis}

Chapter 2 offers a working definition of behavioral toxicity and reviews epidemiological surveys, experimental performance studies and case reports of behavioral toxicity. The chapter ends with recommendations for minimizing its occurrence. After this general overview, a series of experimental performance studies concerning the comparative behavioral toxicity of medicinal drugs is presented. Their purpose is to assess the toxic effects of medicinal drugs on human performance and how these differ between them. Study drugs include antidepressants, antipsychotics and antihistamines. 
Studies on the behavioral toxicity of antidepressants are presented in Chapters 3-6. The acute and subchronic effects of novell antidepressants (fluoxetine, moclobemide and befloxatone), traditional antidepressants (dothiepin, mianserin) and ethanol, were compared to those of placebo in three, double-blind, cross-over studies involving healthy volunteers. Performance measures included a range of laboratory tests of psychomotor and cognitive function as well as actual driving tests. In another study, parallel groups of depressed outpatients received either moclobemide or fluoxetine, double blind, for 6 weeks. Chronic users of benzodiazepines were allowed to continue them as comedication. The effect of antidepressant use and benzodiazepine comedication on the patients" driving ability was measured in the standard over-theroad driving test.

A comparative study of the behavioral toxicity of antipsychotics is presented in Chapter 7. Healthy volunteers were treated with repeated therapeutic doses of an atypical antipsychotic (amisulpride), a classic antipsychotic (haloperidol) and placebo according to a cross-over, double blind design. Performance effects were measured using objective and subjective tests of affective, cognitive, extrapyramidal and psychomotor functions.

The behavioral toxicity of antihistamines is reviewed in Chapter 8. Results from a number of cross-over, double-blind studies comparing the acute and subchronic effects of "sedating" first generation antihistamines (diphenhydramine, triprolidine, clemastine) and "non-sedating" second generation antihistamines (loratadine, terfenadine, cetirizine, ebastine, mizolastine) on actual driving performance of healthy volunteers are presented and discussed.

This dissertation concludes with a general discussion of results from the studies and recommendations concerning further research on behavioral toxicity.

\section{References}

Cole JO (1960). Behavioral toxicity. In: Uhr L, Miller JG, eds. Drugs and behavior. New-York, John Wiley \& Sons, 375.

De Gier JJ (1995) Drugs other than alcohol and driving in the European Union. Technical Report, Institute for Human Psychopharnacology, Maastricht University, 95-54.

Dimascio A, Shader RI (1968). Behawional toxicity of psychotropic drugs: I Definition, II Toxic effects on psychomotor functions. Cont Med, 617-620.

Fingl E, Woodbury DM. General principles. In: Goodman LS, Gilman A, eds. The pharmacological basis of therapeutics, 3rd ed. New York: MacMillan, 1. 
Hindmarch I, Kerr J (1992). Behavioural toxicity of antidepressants with particular reference to moclobemide. Psychopharmacology 106: \$49-555.

O'Hanlon JE, Kelley GR (1977). Comparison of performance and physiological changes between drivers who perform well and poorly during prolonged vehicle operation. In: Macke EE, ed. Vigilance : theory, operational performance and physiological correlates. Nex-York, Plenum Press, 87-110.

O'Hanlon JF, Haak $T$, Blaauw GJ, Riemersma JBI (1982). Diazepam impairs lateral position control in highway driving. Sicience 217: 79-82.

O'Hanlon JF (1984) Driving performance under the influence of drugs: rationale for, and application of, a new test. Br Clin Pharmacol 18: 121s-130s.

O'Hanlon JF, Freeman H (1995). Categorizing the behavioral toxicities of antidepressants. $\mathrm{Br}$ I Psychiatry 166: 421-423.

Parrot AC (1987) Assessment of psychological performance in applied situations. In: I Hindmarch, P Stonier (eds), Human Psychopharmacology; measures and methods. Vol I. John Wiley \& Sons, Chichester, New York, Brisbane, pp $93-111$

Wesnes K, Simpson P, Chrismas L (1987) The assessment of human information-processing abilities in psychopharmacology. In: I Hindmarch, P Stonier (eds). Human Psychopharmacology; measures and methods. Vol 1. John Wiley \& Sons, Chichester, New York, Brisbane, pp 79-92

Wittenborn JR (1987) Psychomotor tests in psychopharmacology. In: I Hindmarch, P Stonier (eds), Human Psychopharmacology; measures and methods. Vol 1. John Wiley \& Sons, Chichester, New York, Brisbane, pp 69-78 


\title{
CHAPTER 2
}

\section{BEHAVIORAL TOXICITY OF MEDICINAL DRUGS: Practical Consequences, Incidence, Management and Avoidance}

\begin{abstract}
This article offers a working definition of behavioral toxicity and reviews data from epidemiological surveys, experimental studies and case reports that demonstrate the behavioral toxicity of anxiolytics, hypnotics, antidepressants, antipsychotics and antihistamines. Epidemiological research indicates that the use of such sedative drugs increases the risk of becoming involved in injurious accidents. Experimental studies likewise demonstrated the adverse effects of sedative drugs on the performance of healthy volunteers and patients in a range of laboratory tests designed to measure psychomotor and cognitive function, and in real-life tests measuring over-the-road driving performance. These studies furthermore indicate that behavioral toxicity varies widely between drugs depending on dose, dosage regimen, treatment duration, pharmacokinetics and mechanisms of action. Case reports indicate the existence of unusual drugs reactions such as aggression, paranoia, social withdrawal or lack of motivation, that are sometimes are more debilitating than sedation.

A number of recommendations are offered for minimizing behavioral toxicity; i.e avoidance of drug interactions, adjustment of drug regimens to an individual response, nocturnal administration of sedative drugs and patient education on ways to avoide accidents. Much of this information can be gained from experimental research comparing individual drug effects on performance. Unfortunately most studies only pertain to drugs used in psychiatry. Yet, in the interest of the patient, it should be the responsibility of drug manufactures and regulators to always identify problematic drugs.
\end{abstract}

JG Ramaekers. Drug Safety 18:189-208,1998 


\section{BEHAVIORAL TOXICITY : DEFINITION}

Medicinal drugs may beneficially affect the behavior of individuals. They may however also alter behavior in ways that are deleterious to a person. This latter phenomenon has been called "behavioral toxicity" (Cole, 1960; Fingl \& Woodbury, 1965; Dimascio \& Shader, 1968; Hindmarch \& Kerr, 1992; O'Hanlon \& Freeman, 1995).

Cole (1960) was the first to describe behavioral toxicity in humans. To him the term included 'adverse' subjective mood changes and 'decrements in objective performance' that resulted from drug ingestion. According to Fingl \& Woodbury (1965) this description of behavioral toxicity was too general. They subsequently redefined the term to include "... suppression of normal anxiety, reduction in motivation, impairment of memory and learning, distortion of judgement, impairment of reflexes, motor incoordination, non-purposive or inappropriate behavior, and other effects of drugs on mood, behavior, and psychological and psychometric functioning". Both descriptions concentrate on the outcome of behavioral toxicity and do not make restrictions as to its cause. Yet a distinction should be made between behavioral changes that result directly from a drugs' action and those that result indirectly from non-behavioral effects such as akathisia, parkinsonism, drug allergies, hepatotoxicity or cardiotoxicity (Halliday, 1967; Dimascio \& Shader, 1967). The relevance of this distinction is reflected in later descriptions of behavioral toxicity. Dimascio \& Shader (1967) noted that behavioral toxicity only includes those adverse behavioral changes that arise "from direct pharmacological action". Likewise, Hindmarch \& Kerr (1992) postulate that behavioral toxicity arises whenever a medicinal drug "directly interferes with and/or impairs psychological abilities necessary for optimal performance".

Dimascio \& Shader (1967) furthermore argued that behavioral toxicity should only include drug induced changes that are "as universally as possible accepted as being adverse or undesirable"; i.e sedation would not be included in the term, while excessive sedation would, mood dampening would not be included but depression inducing would. They realized however that such a restriction was problematic in that it inherently involved the assessment and the judgement of the intensity of drug induced changes. Today, qualification of behavioral toxicity no longer depends on the severity of changes brought about by a drug, but the notion that these vary between different drugs and doses of the same ones is generally accepted (Hindmarch \& Kerr, 
1992; Streufert \& Gengo, 1993; O'Hanlon \& Freeman, 1995). Assessments of behavioral toxicity furthermore evolved from observational, subjective ratings of a patients' behavioral status to more sophisticated measurements based on task performance in controlled, experimental settings. The latter are less subject to bias and provide objective means for discriminating between levels of behavioral toxicity (Streufert \& Gengo, 1993).

It has been suggested that the broad range of drug effects on human functioning that are encompassed by behavioral toxicity, can be classified as disruptive, inhibitory and provocative (O'Hanlon, 1996). Disruptive drug effects are those that pertain to impairment of speed and organization of behavior, such that the individual becomes inefficient and the possibility of making errors in ordinary tasks increases. Sedation is probably the most common CNS side effect that causes this type of performance impairment. It is produced by a wide variety of drugs, which through a variety of mechanisms reduce overall arousal (Linnoilla, 1986). Inhibitory reactions, such as indifference, social withdrawal or apathy, limit a person's ability to attain a certain goal by reducing the motivation to initiate or sustain certain behaviors. Provocative effects of a drug lead to aberrant behavior that is socially unacceptable or dangerous; e.g aggression, hallucination or paranoia. Any of these effects can have a very pervasive influence upon the way an individual functions within the human society and consequently, the manner in which society treats the individual. The afflicted individual would be less likely to achieve normal goals and avoid predictable sanctions than before taking the drug or while taking an equally efficacious alternative without the impairing side effect.

The term "behavioral toxicity" thus has been interpreted in various ways by various researchers. In an attempt to integrate these views and in order to define the scope of the current review this author arrived at the following working definition of behavioral toxicity:

Behavioral toxicity is fundamentally a reversible, pharmacological, drug-induced disruption of neuropsychological processes controlling behavior. The existence of behavioral toxicity can be inferred by certain changes in the individual's behavior while taking the drug; or, by certain differences in his/her behavior between periods when the individual uses that drug and a therapeutically equivalent alternative lacking the same behaviorally toxic effect. Changes and differences will imply that the behaviorally toxic drug inhibits or reduces the efficiency of 


\section{normal behavior, and/or causes aberrant behavior, in a manner reducing the individual's ability to obtain benefits and avoid sanctions within the society.}

The reminder of this article reviews epidemiological and experimental studies of the behavioral toxicity of medicinal drugs, indicates what is known about its underlying pharmacological mechanisms, and provides insights for its management. The review will be restricted to those drugs that have been implicated most frequently as causing behavioral toxicity; i.e anxiolytics, hypnotics, antidepressants, antipsychotics and antihistamines. Other drug classes will only briefly be mentioned.

\section{EPIDEMIOLOGICAL STUDIES}

Perhaps the strongest evidence supporting the present concept of behavioral toxicity comes from a host of epidemiological surveys. These convincingly show that patients taking a variety of medicines often suffer performance deficits responsible for their injuries and deaths in several common situations. This breakthrough was mainly enabled by epidemiologists' simultaneous access to computer records of prescription and accident histories from sometimes several hundreds of thousands of patients (eg Neutel, 1995; Neutel et al, 1995).

Three types of design have been used for associating injurious accidents and the use of medicines; i.e cross-sectional, case-control and cohort designs. Cross-sectional designs relate subject's medication use at a particular moment in time to their history of sustained injuries. The odds-ratio (OR) is used as the measure of association to estimate the likelihood of medication use among those involved in an accident as compared to those who were not. However in cross-sectional designs, the temporal sequence of the events can not definitely be established, and some medication might be used as a consequence of the accident. The predictive validity of results from this type of study is consequently rather limited. In case-control and cohort designs the temporal relation between medication use and accidents is fixed. Case-control studies compare the frequency of prior medication use for persons who sustained injuries (cases) with that in persons without adverse outcomes (controls). An increased frequency among the cases indicates a positive association and a higher OR. In cohort designs, classified groups of medication users and matched non-users are, prospectively or in retrospect, 
followed over time to calculate their frequencies of accident inwolvement. Higher rates of accident involvement among users indicate a higher risks relative to non-users. The drug users' frequency of involvement in injurious accidents, relative to that of the nonusers, is used as a measure of association expressing their relative risk (RR). Thus, case-control and cohort designs are clearly best suited for establishing causal relations between drugs and accidents.

Table 1 summarizes the particular drugs or drug classes that have been indicated in epidemiologal studies to increase the risk on injurious falls, traffic accidents and occupational accidents. Results of these studies will be discussed in detail below. Generally, relationships have been found most frequently for those psychoactive drugs that were not only most frequently used during the survey periods (usually 5-10 yrs before their publication dates), but also the ones suspected of causing accidents beforehand. Thus, the benzodiazepines (BZDs) and tricyclic antidepressants (TCAs) are commonly cited as causal factors of accidental injury. Likewise, surveys not listed in the table have shown greater use of medical services by BZD users (Oster 1990, 1991), and a greater incidence of TCA and BZD use among perpetrators as compared to victims of accidents (Currie et al, 1995). This does not mean however, that the use of some more recent, less used or less notoriously impairing drugs is not also a cause of accidents. It should also be noted that RRs and ORs given in Table 1 only reflect the overall risks associated with particular drugs, since many of them were prescribed to patients in varying doses. Many of these surveys however demonstrated that the users' risk further increases with the drugs' prescribed doses and the number of different drugs taken concurrently.

\section{Falls}

Besides death, hip fracture is the most serious consequence of falls in the elderly. About one third of non-institutionalized elderly over 65 experience one or more injurious falls and their probability of falling increases as they grow older (Tinetti, 1988; Blake et al, 1988; Campbell, 1989). The use of psychoactive medication in general has been shown to significantly contribute to their risk of falling (Tinetti et al., 1988; Blake et al, 1988; Campbell et al, 1889; 1990; Cwikel 1992; Sheahan et al, 1995).

Ray et al (1987) demonstrated that the association between falls and use of psychoactive drugs was more pertinent to some drugs and less to others. Elderly users 
Table 1 Summary of epidemiological studies indicating drug users' enhanced RROR of beconing involved in injurious falling, traffic and occupational accidents.

\begin{tabular}{|c|c|c|c|c|c|c|}
\hline A uthors & Desăgr & $\begin{array}{l}\text { No subjects } \\
\text { and comtatis }\end{array}$ & Age & $\begin{array}{l}\text { Arectidethit } \\
\text { Mighury }\end{array}$ & Drutss & $\begin{array}{l}\mathrm{RE} / \mathrm{OW} \\
(9500 \mathrm{C})\end{array}$ \\
\hline Ray at a $(1987)$ & Case-Control & $1021-5606$ & $>65$ & $\begin{array}{l}\text { lfip } \\
\text { frosturs }\end{array}$ & 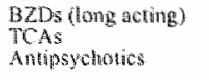 & $\begin{array}{l}1.8(1.3-3.4) \\
1.9(1.3-2.83) \\
2.0(1.6-2.65)\end{array}$ \\
\hline Granck ot at (1987) & Case-Control & $184-184$ & 365 & Fin & 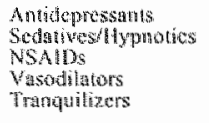 & $\begin{array}{l}2.6(1.1-6.0)^{4} \\
2.6(1.2-6.5) \\
2.4(0.9-6.5) \\
2.1(1.1-4.1) \\
1.8(0.8-9.6)\end{array}$ \\
\hline Ray ex al (190) & Case-Control & $4501-24041$ & $>65$ & Hu fracture & TCAs & $1.6\left(\frac{1}{2}, 4-1.0\right)$ \\
\hline funnming at a (1091) & Cross-Sectional & $108-1250$ & 265 & Mullipale fands & Diazegam & $9.7(1.5-9.3)$ \\
\hline shom atal (1992) & Case-Control & $4500-2404$ & 265 & $\begin{array}{l}\text { Hitp } \\
\text { tritelutur }\end{array}$ & Oproid analgeses & $1.6(1.4-1.3)$ \\
\hline $\begin{array}{l}\text { Cumpring } \\
\text { Klineberg }\end{array}$ & Cuse-Contrel & $209-207$ & $>65$ & Hop Irracture & $\begin{array}{l}\mathrm{BZD} \\
\text { Tontazepun }\end{array}$ & $\begin{array}{l}1.6(1.0-2.5) \\
3.8(1.6-8.9)\end{array}$ \\
\hline $\begin{array}{l}\text { Rutlazer and } \\
\text { Lipsitz (1903) }\end{array}$ & $\begin{array}{l}\text { Proppentive } \\
\text { Cohorl }\end{array}$ & $228-407$ & 370 & Falls & TCAs + SSTHS & $1.8(0.9-3.7)$ \\
\hline Ryymänen el al (1993) & Case-Comtrol & $380-342$ & $>65$ & Fetils & $\begin{array}{l}\text { A2Ds } \\
\text { Antidepressunts } \\
\text { Antipsychotics }\end{array}$ & $\begin{array}{l}2.2(1.2-4.2) \\
2.2(1.2-3.9) \\
4.4(1.6-11.9)\end{array}$ \\
\hline $\begin{array}{l}\text { Malmivanatat a } \\
\text { (1993) }\end{array}$ & $\begin{array}{l}\text { Prospective } \\
\text { Cohor }\end{array}$ & $2164-17354$ & $>20$ & folls & $\begin{array}{l}\text { Anxiolytios } \\
\text { Antipsychotos }\end{array}$ & $\begin{array}{l}1.7(1.4-2.6) \\
2.0(1.4-3.0)\end{array}$ \\
\hline $\begin{array}{l}\text { Linhenstain ath al } \\
(1094)\end{array}$ & Case-Contro: & $129-324$ & $>6,5$ & $\begin{array}{l}\text { Hip } \\
\text { Tracture }\end{array}$ & $\begin{array}{l}\text { Antidepressemts } \\
\text { Bzys }\end{array}$ & $\begin{array}{l}2.7(1.0-8.4) \\
2.1(1.1-3.19)\end{array}$ \\
\hline Neufct a al $(1995)$ & $\begin{array}{l}\text { Prospertive } \\
\text { Golnor }\end{array}$ & $\begin{array}{l}225796 \\
98000\end{array}$ & 320 & Fat & 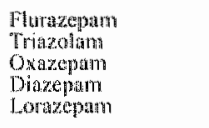 & $\begin{array}{l}4.2(2.4-5.1)^{3} \\
3.5(2.6-6.7) \\
3.0(1.7-5.2) \\
3.0(1.6-5.6) \\
2.7(2.0-4.4)\end{array}$ \\
\hline lord et al $(1005)$ & $\begin{array}{l}\text { Prospective } \\
\text { Colwer }\end{array}$ & $76 \cdot 338$ & 36.5 & $\begin{array}{l}\text { Mulitiple } \\
\text { fall: }\end{array}$ & 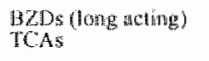 & $\begin{array}{l}2.0(1.5-2.6) \\
2.8(2.0-3.6)\end{array}$ \\
\hline 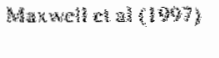 & 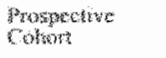 & 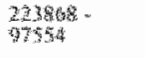 & $x_{1}$ & F程基 & 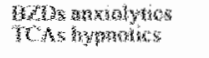 & 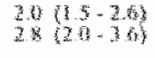 \\
\hline 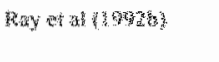 & 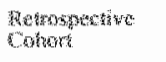 & SALB. & $\triangle x_{3}$ & 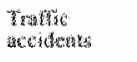 & 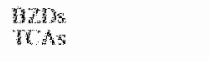 & 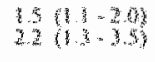 \\
\hline 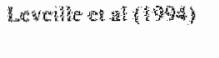 & 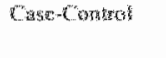 & 2. $34-2$ & stest & 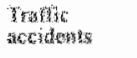 & 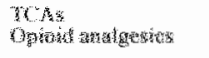 & 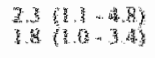 \\
\hline 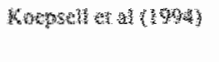 & hasedontar & $234-4,4$ & 305 & 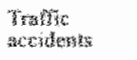 & 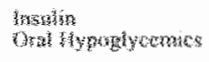 & 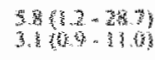 \\
\hline M & 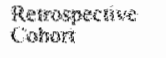 & 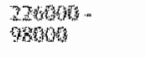 & 34 & 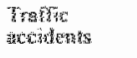 & 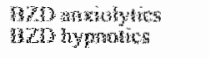 & 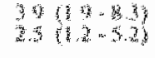 \\
\hline 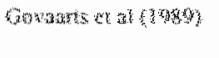 & Chost-Seotrom? & $130-3065$ & $\left.\cos ^{3}\right)$ & 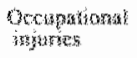 & $3 \mathrm{WO}$ & $25(4)$ \\
\hline Whandine at at & $\sin \pi^{\alpha}-\sin 20$ & $394-578$ & $x^{3} 3$ & 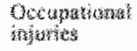 & 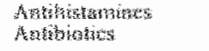 & 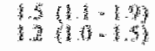 \\
\hline
\end{tabular}

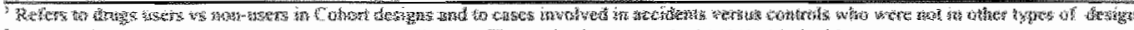

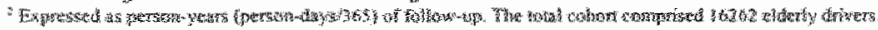

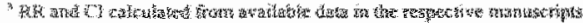

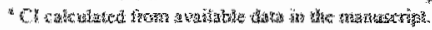


of long-acting BZD hypnotics or anxiolytics, antipsychotics and TCAs were found to be $1.8-2.0$ times more likely to suffer from hip fractures, relative to their controls. In contrast, usage of short-acting hypnotics and anxiolytics was not associated with increased risk. The latter category included drugs with an elimination half-life of 24 hrs or less and predominantly consisted of chloral hydrate and the antihistamines, diphenhydramine and hydroxyzine. The use of short-acting BZDs was still too infrequent for evaluation at the time of this survey.

Subsequent epidemiological studies generally confirmed the higher fall frequency among users of BZDs, antipsychotics or TCAs (Granek et al, 1987; Ray et al, 1991; Ryynamen et al, 1993; Lichtenstein et al, 1995, Malmivaara, 1995). Others differentiated between effects of short and long acting BZDs. Lord et al (1995) found higher falling rates among 13 users of long acting BZDs but not among 23 users of shorter acting oxazepam or temazepam, as compared to non-users. In contrast, use of temezapam was more frequent among 29 cases with hip fracture, as compared to their controls, in another study (Cumming and Klineberg, 1993). Clearly the numbers of participants in these studies were too low for calculating reliable risk estimates for these individual drugs. A study conducted by Neutel et al (1995) is more definitive. It included 225,796 users of BZD medication and 98,000 controls. These investigators only included fall related hospitalizations within three weeks of a first prescription for calculating the RR of BZD users, as compared to non-users. It is evident from clinical trials that adverse events are generally more likely to occur shortly after a first prescription than during chronic use of a drug. Yet most epidemiological surveys have failed to consider chronicity as a factor determining RR. This one did not. It demonstrated that the frequencies of hospitalization for fall related injuries among users of oxazepam and triazolam were comparable to those among users of long-acting BZDs, and about three times higher as in non-users.

Selective Serotonin Reuptake Inhibitors (SSRIs) have largely replaced TCAs as the antidepressants of first choice and the former are generally less sedative than the latter. So far, only one survey has been undertaken to compare the separate relationships between SSRIs and TCAs with falls (Ruthazer and Lipsitz, 1993). Although the use of any antidepressant by patients of both sexes was marginally related to the occurrence of falling accidents $(R R=1.84 ; p=.09$ ), women using antidepressants had significant higher fall rates then their controls. Among them a 
larger percentage of those taking the SSRIs (53\%) fell as compared to those taking TCAs $(14 \%)$.

Other drug classes implicated as causing hip fracture or falls include opioid analgesics (Shorr et al, 1992), nonsteroidal anti-inflammatory drugs (NSAIDs) and vasodilators (Granek et al, 1987) The former investigators indicated that their results might have been largely expected from the opioids' sedative properties in general and the previously demonstrated tendency of opioids to impair their users' balance and coordination in experimental studies. The association between NSAID use and falling accidents, is more surprising. Though these drugs are known to possess CNS activity, it usually occurs after high doses. Granek et al (1987) did not mention whether her cases received large doses, but their frequent complaints of adverse events like sedation, dizziness, blurred vision, confusion, vertigo and syncope suggests that many of them did. Alternatively, the possibility of confounding by indication (i.e an over representation of persons afflicted with arthritis among those taking NSAIDs) can not be excluded. The association involving vasodilators may be attributable to orthostatic hypotension that is a common side effect of all these drugs.

With three exceptions, all epidemiological studies on drug-related falls have involved elderly patients. This does not necessarily mean that the problem of drug related falls is confined to the elderly. This was clearly demonstrated by Neutel et all (1995) and Maxwell et al (1997). They observed that there is an increased risk of falling after a first BZD prescription for all patients above the age of 20 . Falling rates remained fairly stable up to about age 60 and began to rise sharply beyond the age of 70. Likewise, Malmivaara et al (1995) observed a significant elevation in the relative frequency of drug related falls in all adult age groups, but more so in the elderly.

\section{Traffic accidents}

Ray et al (1992) demonstrated that BZDs and TCAs, but not opioid analgesic and antihistamines, increase the risk of involvement in motor vehicle crashes for elderly drivers. In a later survey, also conducted in the USA, Leveille et al (1995) failed to confirm these findings in users of BZDs and opioids. The conflicting results for $\mathrm{BZD}$ users are easily explainable. Whereas Ray et al specifically excluded patients using BZD hypnotics from their sample, preferring to concentrate on anxiolytic users instead, practically all of those included in Leveille et al's survey were using hypnotics, particularly the short acting triazolam. The conflicting results for users of 


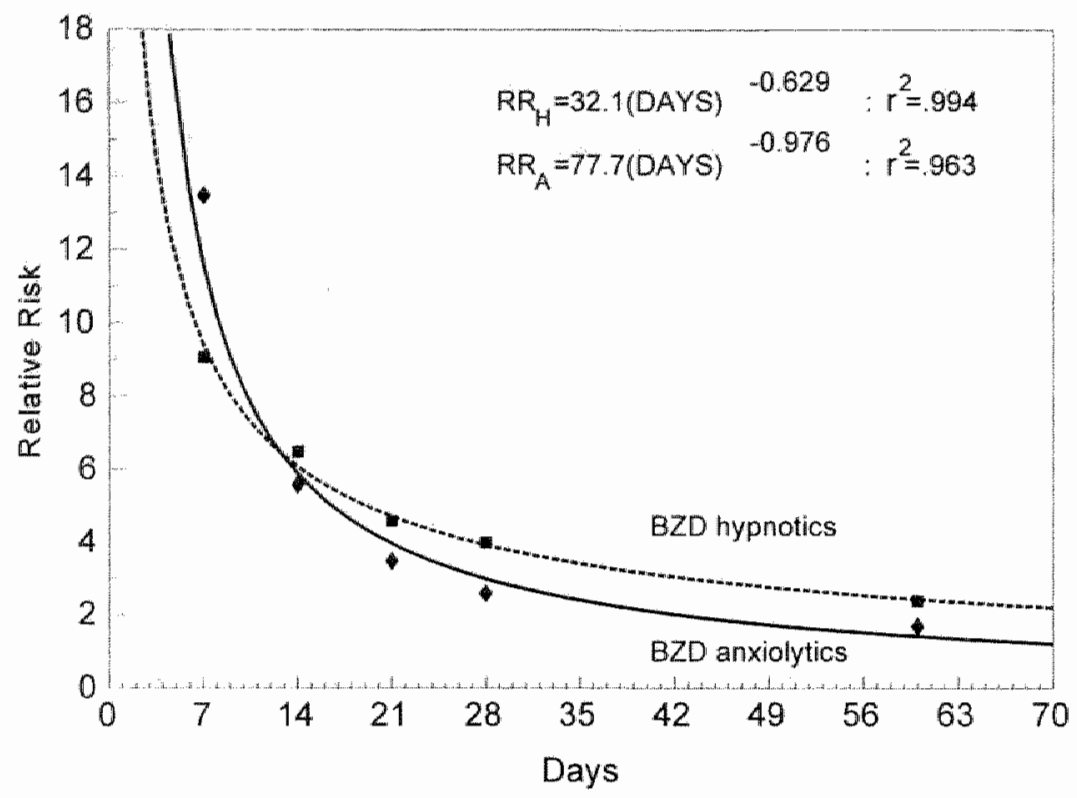

Figure 1 RR of injurious traffic accidents as functions of cumulative elapsed time affer prescription of hyphotics ( $\left.R R_{H}\right)$ and anxiolyrics $\left(R R_{A}\right)$ of the benzodiazepine class (cume estimations based on data from Neutel, 1995]

opioids may be accounted for by the fact that Leveille et al included codeine containing cough medication in their analysis, comprising 19\% of the opioid prescriptions, whereas these were excluded by Ray et al because of their sporadic use in his study sample. Both studies obtained simillar risk estimates in users of TCAs or antihistamines. Yet, the absence of an association with the latter is surprising in the light of experimental data showing that the older "sedating" antihistamines can severely impair driving performance (O'Hanlon \& Ramaekers, 1995). Ray et al did not mention which antihistamines were used in their study sample. The possibility therefore exists that some received an antihistamine of the more recently introduced "non-sedating" generation. In Leveille's sample however," the "sedating" diphenhydramine accounted for $80 \%$ of the antihistamine use. The controversy may be related to the fact that the use of antihistamines in both surveys was ascertained from prescriptions filled at the pharmacy and did not include the vast majority of "sedating" 
antihistamines that are being sold over-the-counter. As a consequence, misclassification of drug exposure in the study samples could have introduced a conservative bias. Neutel (1995) estimated the RR of becoming involved in an injurious accident as a finction of time since their first prescription for most of the adult users of BZDs hypnotics and anxiolytics in Saskatchewan during the period 1979-1986. Her results, shown graphically in Figure 1, demonstrate that the first prescription for a BZD is initially followed by a substantially increased risk of a traffic accident. They also illustrate that this risk diminishes with passage of time as a result of developing tolerance to the drugs' sedative activity. During the first week, the hypnotic users' RR was 9.1, and the anxiolytic users', 13.6. By the end of the second week those RRs declined to 6.5 and 5.6. At the end of one month, the respective values were 3.9 and 2.5. The youngest group (20-39 yrs) of BZD users showed substantially higher rates of hospitalization for traffic accidents than their older counterparts.

In another article, Neutel et at (1995) indicated that for 3 weeks after a first prescription, flurazepam's users were about 5 times, and triazolam's, diazepam's and lorazepams' users about 3 times, more likely to be injured in traffic accidents than nonusers. Among individual drugs, only oxazepan failed to significantly elevate its users" RR. That triazolam elevated the users risk in this survey but not in that by Leveille et al's is probably attributable to a difference in doses taken by the participants. The former data were collected before, and the latter after, the manufacturer had reduced the recommended starting dose from 0.50 to $0.25 \mathrm{mg}$.

Insulin and oral hypoglycemics have also been implicated as causal factors in injurious traffic accidents (Koepsell et al, 1994) This is probably related to the fact that diabetics treated with such drugs commonly experience mild to moderate hypoglycemia causing dizziness, cognitive impaiment and, as a consequence, accidents .

\section{Occupational accidents}

Accidents attributable to medication use in working environments have been reported in two studies. Govaarts et al. (1989) conducted a postal survey of 2795 employees of three Dutch companies (public transportation, clerical and electrotonic fabrication) concerning BZD use and injuries incurred within the preceding 48hrs. Completed questionnaires were received from $62 \%$ of the workers. The replies indicated that $\mathrm{BZD}$ users were 2.6 times more frequently involved in occupational accidents than non- 
users. Gilmore et al (1996) reported significant associations between certain types of occupational injuries and the use of either antihistamines or antibiotics. Open wounds and burns were the most prevalent injuries among the drugs' users. The authors interpreted the relationship involving antibiotics as epiphenomenal. They thought it more likely that the infections requiring antibiotic use were responsible for the accidents than the drugs themselves. However the relationship involving antihistamines was interpreted as causal. This was because at the time of and place the survey was conducted, the workers' medical insurance carrier would only support their use of older (i.e less expensive) sedating antihistamines. The epidemiologists justified their interpretation on the basis of experimental evidence showing that the older drugs possess strongly impairing properties, expected to cause accidents in the workplace.

\section{EXPERIMENTAL STUDIES AND CASE REPORTS}

A wide variety of procedures have been used for assessing the behavioral impairing effects of drugs (reviews: Wittenborn, 1987; Wesnes et al, 1987; Parrot, 1987). The earliest were taken from existing psychometric test batteries, such as the Digit Symbol Substitution Test (DSST) from the Wechsler Adult Intelligence Scale. Other early tests were those developed for diagnosing neurological, ophthalmological and vestibular disorders (e.g respectively Wisconsin Card Sorting, Maddox wing, Body sway tests). Later, "Psychomotor" tests, characterized by contingent motor responding to an imposed discrete or continuous signal, were applied (eg reaction time (RT), tracking and critical flicker/fusion frequency (CFF) tests). "Cognitive" tests were added for measuring, primarily, various mnemonic functions but also deductive reasoning. Finally, tests were developed to measure some aspects of "real life" performance such as driving in a simulator, through staged maneuvers on a course closed to other traffic or on public roads in actual traffic. All of these tests have been applied in single- or multiple dose, double-blind studies, usually with healthy volunteers but sometimes patients. They have followed both parallel group and cross-over designs, most with both placebo- and active drug (i.e verum) controls.

The great advantage of the empirical approach is its ability to determine the intrinsic pharmacological effects of drugs on performance without the confounding factors that always obscure or exaggerate the effect in the natural environment. 
Moreover, experimental studies can be undertaken with drugs in all phases of clinical development and with doses that extend beyond the therapentio range. They are particularly valuable for identifying and controlling problematic drugs. However the empirical approach has limitations as well. All tests employed in experimental studies are more or less artificial. No one knows how to translate the results they provide into the safety relevant performance impairment of patients in their normal daily living activities. There are just enough comparative data from volunteers and patients to know that both experience similar side effects of psychoactive drugs that influence performance (van Laar et al, 1992; O'Hanlon et al, 1995; Ramaekers et al, 1997a), but much less concerning these drugs' therapeutic effects that might improve patients' performance (Freeman \& O'Hanlon, 1995). In short, its not generally possible to predict the net effect of psychoactive drugs on patients' performance from results obtained in experimental studies. Finally, the relatively small numbers (i.e $<30$ ) employed in these studies are generally insufficient for observing extreme or unusual reactions, particular types that involve the inhibition of spontaneous behavior or the provocation of grossly aberrant behavior. Such unusual reactions are only reported in clinical case studies. Though somewhat anecdotal they must be regarded seriously. The phenomena they describe are often the most severe kinds of behavioral toxicity afflicting individual patients. Any review of this topic would be incomplete without mentioning them.

\section{Anxiolytics and hypnotics}

$\mathrm{GABA}$ is a major inhibitory and widely distributed neurotransmitter in the mammalian CNS. It is released by a web of short-axon intemeurons occupying some $40 \%$ of all synapses. BZD ligands affect inhibitory GABA neurotransmission by allosterically modulating the neurotransmitter's ability to open chloride channels at the $G A B A_{A}$ $/ B Z D$ receptor complex. The classic $B Z D$ anxiolytics and hypnotics act as agonists and achieve their anxiolytic, anticonvulsant and sedative effects through potentiation of GABA stimulated chloride flux.

Previous reviews of pharmacodynamic studies employing healthy volunteers and patients have generally shown that BZD agonists can cause severe impairment in tests designed to measure psychomotor and driving performance (Saletu, 1987a; Koelega, 1989; Woods et al, 1992). Among psychomotor tasks, measures of CFF, DSST, tracking, and RT were particularly sensitive to the sedative effects of BZDs. 
They generally indicate that $B Z D$ s cause a reduction in their users' overall speed of information processing and motor response. The practical relevance of psychomotor impairment under the influence of BZDs has been amply demonstrated in a long series of driving studies employing a standardized test (O'Hanlon et al, 1982, 1986, 1995a; O'Hanlon, 1984; O'Hanlon and Volkerts, 1986; Volkerts \& O'Hanlon, 1986; Brookhuis and Borgman, 1988; Van Laar et al, 1992; Volkerts et al, 1991; 1992). The test involves operating a specially instrumented vehicle at a constant speed and with a steady lateral position over a $100 \mathrm{~km}(61 \mathrm{mi})$ circuit on a primary highway in actual traffic. Standard deviation of Jateral position (SDLP), a measure of tracking error, is its primary performance measure. Subjects have included both healthy volunteers and anxious patients and no essential difference was noted to their reactions to the same drugs. Typically their driving performance has deteriorated in a dose-related manner to same day treatment with anxiolytics and on days following hypnotic treatment. Almost all commonly used BZDs have been tested and practically none has failed to seriously impair driving performance. The maximum effect was usually seen after the initial doses. However, it occurred later in series of repeated doses for those BZDs possessing the slowest rates of elimination. The drugs' adverse effects on driving diminished but were still significarit for up to 3 weeks of continual dosing.

Recognition of the detrimental effects of BZDs on performance has led to the development of newer drugs expected to achieve anxiolysis without concomitant sedation. The first was buspirone, a 5-HT $1 \mathrm{~A}$ receptor partial agonist (review: O'Hanlon, 1991; Van Laar et al, 1992). Other new classes of BZD-like drugs acting as partial agonists at the $\mathrm{GABA}_{\mathrm{A}}$ receptor complex such as the cyclopyrollones, zopiclone and suriclone, and the imidazopyridines, such as alpidem, were less successful in achieving that goal. All had detrimental effects on performance similar to those seen for classic benzodiazepines (Fairweather et al, 1992; Balkin et al, 1992; Allain et al, 1995, Roehrs et al, 1994, Vermeeren et al, 1995; O'Hanlon et al, 1995a, O'Hanlon et al, 1995b, Patat et al, 1995a).

BZD agonists are also known to produce anterograde amnesia in healthy volunteers and patients (reviews: Curren, 1986; Woods et al, 1992). It is thought that the specific amnesic effect is somewhat independent of the general sedative effect responsible for psychomotor impairment (Kirk et al, 1990; Derschwitz et al, 1991; Curran et al, 1991; Curran and Birch, 1991; Hommer et al, 1993) and that the former may outlast the latter (Pomara ef al, 1989; Gorenstein, 1994). There is increasing 
evidence that most BZDs primarily affect explicit memory systems involved in recall of specific events, but not implicit memory systems involved in knowledge of language, procedures and motor skills that do not require delliberate recollection (Danion et al, 1989; Weingarter et al, 1992; Curran and Gorenstein, 1993; Polster et al, 1993; Bishop et al, 1996). The practical implication of this specific amnestic effect of BZD may be best illustrated by a number of case reports reviewed by Woods et al. (1992). All patients suffered from transient anterograde amnesia after taking initial doses of midazolam or triazolam. They were perfectly capable of routinely performing their daily, occupational activities while in this state, but they were completely unable to recall any events occurring for up to $24 \mathrm{hrs}$ after ingesting the medication.

Other case reports have related how in anxious but otherwise healthy individuals BZDs impaired cognitive functions to degrees commonly observed in demented patients (review: Starr and Whalley, 1994). Moreover, BZDs occasionally provoked aberrant behavior, such as hostility, and in some cases overt aggression, selfharming behavior and mania (review: Cole and Kando, 1993). The practical importance of these case reports can not easily be disregarded. Similar case reports were the reason for triazolam's forced withdrawal from the market in several countries.

In summary, empirical studies have consistently demonstrated that behavioral toxicity occurs with benzodiazepine administration. Short-acting BZDs affect psychomotor performance in the same way as long-acting BZDs and do not necessarily represent an advantage in avoiding behavioral impairment. Clearly, impairment is less persistent for short-acting BZDs, but this may be irrelevant to patients who receive multiple doses of short acting $\mathrm{BZD}$ anxiolytics for achieving steady state plasma concentrations. Similarly, none of the newer $B Z D$ receptor ligands appear to devoid of behavioral toxicity.

\section{Antidepressants}

Most antidepressants are thought to achieve their efficacy by increasing postsynaptic concentrations of monoamines (Leonard, 1997). TCAs relieve depression by inhibiting the reuptake of NA and 5-HT, whereas other second generation antidepressants such as SSRIs preferably inhibit reuptake of 5-HT. Other antidepressants, such as mianserin and mirtazapine enhance noradrenergic release by blocking presynaptic $\alpha_{2}$ receptors or increase monoamine release by inhibition of MAO-A as with moclobemide. Apart from reversible inhibitors of MAO-A and some SSRIs, most of these antidepressants 
possess binding affinities for postsynaptic adrenergic $\left(a_{1}\right)$ or histaminergic $\left(\mathrm{H}_{1}\right)$ receptors that are though to play a major role in the development of sedation causing cognitive, psychomotor and driving impairment during treatment (Rickelson, 1996; Simons, 1994, Coccaro \& Siever, 1985; Deptula \& Pomara, 1990; Freeman \& O'Hanlon, 1995). TCAs antagonize muscarinic acetylcholine receptors as well, and may cause amnesia (review: Thompson, 1991). Among TCAs, impairment is most pronounced for the tertiary amines (clomipramine, amitriptyline, doxepin, imipramine, dothiepin) and less for secondary amines (desipramine, nortriptyline) that possess very modest anticholinergic activity (review: Riedel \& Van Praag, 1996).

In patients, side effects are predominant and superimposed on behavioral disturbances related to depression itself during the first weeks of treatment. Side effects are expected to dissipate after 2-4 weeks of treatment at about the same time as the therapeutic effect begins (Hobi et al, 1982; Siegfried \& O'Connoly, 1986; Moon \& Davey, 1988; Peselow et al, 1991; Austin et al, 1992). Most studies indicate that tolerance to the acute sedative effects of amitriptyline, mianserin, doxepin and maprotiline on psychomotor and driwing performance develops in both healthy volunteers and patients within 1-3 weeks of treatment (Robbe et al, 1995; Ramaekers et al, 1994; Curran \& Lader, 1986b; Seppälä et al, 1975; Dijen et al, 1989; Stromberg et al, 1988; Moon \& Jesinger, 1991). However, it is doubtful that tolerance completely abolishes the initial deficits or that new deficits fail to emerge during the course of chronic antidepressant therapy. The persistence of certain kinds of impairment has been shown in several empirical studies with both volunteers and depressed patients (Ramaekers et al, 1992, 1995a; Hindmarch et al, 1990; Fairweather et al, 1993a; Hale and Pinninti, 1995). And, as mentioned earlier, epidemiological surveys have shown that patients using antidepressants chronically are at a relatively high risk of becoming involved in various types of accidents. Similarly, specific anticholinergic effects of antidepressants on memory functions seem resistant to tolerance (Sakulsiprong et al, 1991; Spring et al, 1992).

The latest generation of antidepressants, such as the reversible inhibitors of MAO-A, moclobemide and befloxatone, SSRIs or venlafaxine have no or little affinity for histaminergic, adrenergic or muscarinic receptors. This is mainly why therapeutic doses of reversible MAO-A inhibitors have never been shown to adversely affect cognitive and psychomotor function (Ramaekers et, 1992, 1994, 1996a; Patat et al 1995b; Hindmarch \& Kerr, 1992; Allain et al, 1992). Generally, SSRIs have little 
effect on performance as well (Robbe and O"Hanlon 1994, Fairweather et al, 1993a; Hindmarch et al, 1990, Fairweather et al, 1993b). Mild psychomotor and memory impairment is most likely to occur for those possessing some affinity for muscarinic receptors, such as paroxetine and fluvoxamine (Herberg \& Menke, 1981; Hindmarch \& Harrison, 1988; Dijen et al, 1989; Kerr et al, 1992; Robbe \& OHanlon, 1994; Weinstein et al, 1996) or for $\alpha_{1}$ receptors, like nefazodone (Frewer et al, 1993; Van Laar et al, 1995). This is not to say that performance impairment can never occur with the more selective reuptake inhibitors that have no specific affinities for muscarinic, adrenergic or histamine receptors, as in the case of venlafaxine and fluoxetine. Volunteers' performance in actual driving and psychomotor tests remained virtually unaffected by both drugs, but their vigilance, i.e their ability to sustain attention, progressively decreased over respectively 2 and 3 weeks of treatment (Ramaekers et al, 1995b; O'Hanjon et al, 1997). The relevance of this finding is unknown, but it can not be disregarded too soon. Fluoxetine concentrations are known to accumulate over 4-8 weeks (Farid et al, 1991; Newhouse et al, 1996) before steady-state is achieved. Accumulation over time may well account for a belated emergence of adverse events.

The chronic use of SSRIs has been associated with unusual adverse behavioral reactions in a number of case reports. Most of them implicate fluoxetine for the simple reason that it is the most widely prescribed. Anxiety, insomnia and agitation have been most frequently reponted for patients taking fluoxetine (Beasley et al, 1991; 1992; Mander et al, 1994; Meghji, 1994; Coulter and Pillians, 1995; Haenel et al, 1995), sometimes in combination with confusion and amnesia (Betschy and Vandel, 1993; Ruiz, 1994; Singh et al, 1995). Inhibitory reactions, such as apathy, indifference, loss of initiatiwe have been reported in cases taking both fluoxetine and fluvoxamine (Hoehn-Saric et al, 1990) In another case, a 60 year old women retired as a piano teacher when she failed to learn piano pieces and a foreign language in preparation for a trip. Withdrawall of fluoxetine resulted in resuming her career as a plano teacher and learning the language she had been unable to master (Mirow, 1991). Fluoxetine has also been reported to provoke abberant behawior, such as paranoia, hostility and aggression (Mandalos and Szarek, 1990; Grounds et al, 1995). Cessation of fluoxetine resulted in an abatement of the problem which usually retumed on rechallenge.

In summary, experimental data consistently demonstrate that most antidepressants impair psychomotor or memory function, and diminish their users" driving perfomance as measured in a standard driving test. Impaiment is most 
pronounced for antidepressants possessing multiple antagonistic affinities for histaminergic, adrenergic and muscarinic receptors, such as with the TCAs. They generally produce greater sedation than antidepressants with selective affinity for the 5-HT and NA transporters. Yet, even in the absence of sedation, behavioral toxicity can still occur with the latter, as shown by their selective effects on vigilance and the adverse motivational and emotional reactions noted in case reports.

\section{Antipsychotics}

Phenothiazines, such as thioridazine and chlorpromazine were the first $D_{2}$ receptor antagonists used in the treatment of schizophrenia. Most produce profound sedation by blocking dopamine neurotransmission required for sustaining arousal. Additional blockade of histaminergic, anticholinergic and -adrenergic neurotransmission furthermore contributes to the sedative potential of phenothiazines and results in a high prevalence of concentration difficulties, fatigue and daytime sleepiness among users (Bhavnani and Levin, 1996). Studies examining the effects of phenothiazines on psychomotor performance have not often been conducted but those that were, confirm the expected detrimental effects on psychomotor performance and wakefulness (McClelland et al, 1990; Hindmarch, 1994, Wylie et al, 1993; King, 1993; Quigley et al, 1996).

Since their introduction in the fifties these drugs have largely been replaced by more selective and potent dopaminergic drugs such as haloperidol. Like any dopaminergic receptor antagonists, haloperidol also produces sedation responsible for psychomotor impairment observed in empirical studies employing patients or healthy volunteers (review: King, 1993). Yet, sedation produced by selective dopaminergic antipsychotics is less profound and less capable of affecting a variety of mental functions and dependent behaviors, as compared to antipsychotics that block post synaptic receptors within other monoamine systems as well. This was repeatedly demonstrated for the substituted benzamides, which selectively block dopaminergic neurotransmission at $\mathrm{D}_{2} / \mathrm{D}_{3}$ receptors. The first of its kind, sulpiride, only produced minimal psychomotor and cognitive impairment in conventional tests (Liljequist et al, 1975; Bartfai and Wiesel, 1986; McClelland et al, 1990). Therapeutic doses of its successors, remoxepride and amisulpride, consistently impaired psychomotor performance in healthy volunteers, but generally less than subtherapeutic doses of 
chlorpromazine or haloperidol (Fagan et al, 1988; Mattila et al, 1988; 1996; King et al, 1995; Rammsayer and Gallhofer, 1995; Ramaekers et al, 1996b).

Reappraisal of clozapine treatment, has led to the development of a new generation of comparable antipsychotics that, besides affinity for dopaminergic receptors, possess multiple mechanisms of action. Clozapine, rispiridone, olanzepine, seroquel are potent antagonists of the $5 \mathrm{HT}_{2 \mathrm{~A}}$, HI and $\alpha_{1}$ receptor, and, in the case of clozapine and olanzapine, the muscarinic acetylcholine receptor as well. Sertindole, was shown to possess strong antagonistic activity at the $\alpha_{1}$ receptors (Jackson et al, 1994; Leysen et al, 1996; Kinon and Lieberman, 1996). None of these antipsychotics have been properly investigated in studies designed for showing their effects on psychomotor and cognitive function. Yet, in theory all of them should produce deficits in performance comparable to those observed for the earlier phenothiazines. Clozapine, for example, was shown to cause changes in EEG indicative of sedation (Saletu et al, 1987b). Another indication came from a multi-centered, clinical trial evaluating the effectiveness of 5 doses $(1,4,8,12$ and $16 \mathrm{mg})$ of risperidone in over 1300 patients (Peuskens et al , 1995). At the lowest dose, 23.5-28.8 percent of the patients complained of concentration difficulties, increased fatigue, sedation and 19 percent complained of memory problems. At the highest dose these percentages rose to $42-48$ percent and 34 percent respectively.

Antipsychotics may furthermore induce additional inhibitory behavioral reactions, such as psychic indifference, diminished conation, affect and motivation, by blocking central $\mathrm{D}_{2}$ receptors (Levander, 1994; King, 1994). These mental side effects, nowadays referred to as neuroleptic induced deficit syndrome (NIDS; Lader, 1994), are among the most neglected in schizophrenic patients, because of their similarity to the negative symptoms of schizophrenia. As a consequence, the former may easily be mistaken for the latter and go undetected in patients. This apparently confounding situation, contributed to the currently growing belief that the principal action of antipsychotics may be best studied in healthy volunteers (King, 1997). The latter do not suffer negative symptoms and may thus serve as a better sample for establishing the existence of NIDS. As to now, only one group of investigators (Ramaekers at, 1996b) followed this approach for demonstrating NIDS. They treated 17 volunteers for 5 days with either haloperidol $4 \mathrm{mg}$, amisulpride 50 and $400 \mathrm{mg}$ and placebo to investigate their effects on, among others, affective function. The latter was assessed with the Positive and Negative Symptom Scale (PANSS) and Naber's Subjective Well- 
being under Antipsychotics (SWN) scale. Halloperidol, but not amisulpride, significantly elevated negative symptoms, and general psychopathology ratings on the PANSS and reduced feelings of well being on the SWN scale. Since both haloperidol and amisulpride are selective $D_{2}$ receptors antagonists, the absence of negative symptoms during amisulpride treatment was remarkable. It may be explained by evidence suggesting that amisulpride preferably attaches to receptors in the limbic rather than striatal system, whereas haloperidol does not discriminate between regional subpopulations of dopamine receptors (Schoemaker et al, 1997; Perrault et al, 1997).

Perhaps the clearest demonstration of the potentially behaviorally toxic effects of antipsychotics comes from the unethical use of these drugs in numerous cases in former Soviet psychiatry (Koryagin, 1981). Dissenters of the Soviet regime, who were in good mental condition, were frequently confined to special clinics and subjected to psychiatric repression for the political purpose of punishing, restraining and isolating those with anti-Soviet tendencies. Many received high doses of antipsychotics, e.g haloperidol, whille being forced to renounce their beliefs and opinions, and spoke of punishment by "treatment".

In summary, empirical studies have demonstrated the ability of antipsychotic drugs to produce profound sedation and disrupt psychomotor and cognitive function through blockade of central dopaminergic receptors. Their adverse effects on performance may further increase if neurotransmission within other monoamine or cholinergic systems is blocked simultaneously. Other dopamine regulated adverse reactions such as mental disturbances may additionally diminish a patients' ability or motivation to initiate behavior. These adverse reactions seem least likely to occur during treatment with the substituted benzamides, though the amount of comparative data is currently rather limited.

\section{Anthistamines}

Histamine is a neurotransmitter responsible for the maintenance of arousal. First generation antihistamines, such as diphenhydramine, triprolidine, clemastine or clorpheniramine are strong antagonists of muscarinic and $H_{1}$ receptors. All first generation antihistamines induce somnolence and have repeatedly been demonstrated to diminish cognitive, psychomotor and driving performance in healthy volunteers (reviews: Simons, 1994; Rombaud \& Hindmarch, 1994; O'Hanlon \& Ramaekers, 1995). Impaiment might be even of greater clinical significance in patients when the 
allergic disorder per sé adversely affects CNS function, as suggested by studies in which a reduced learning ability of children and young adults with allergic rhinitis exacerbated by diphenhydramine (Vumman et al, 1993; 1996).

Second generation antihistamines are less lipophilic and more slowly cross the blood-brain barrier then their predecessors. Their impairing properties have been extensively assessed using the standardized actual driving test described above, usually after both single and repeated doses up to 4 times those currently recommended (O'Hanlon \& Ramaekers, 1995; Vermeeren et al, 1996). Results of these studies show that the extent to which these antihistamines cause sedation varies with the drug, its dose and the chronicity of dosing. Several (acrivastine, cetirizine and mizolastine) mildly affected driving performance when given at therapeutic doses. Others (ebastine, fexofenadine, loratadine and terfenadine) did not have significant effects after being taken in recommended doses but had at least measurable effects after doses that were twice as high. Mild impaiment is sometimes overcome by coadministering the decongestant sympathomimetic, pseudoephedrine (O'Hanlon \& Ramaekers, 1995; Stanley et al, 1996), but the combination may also be associated with a higher frequency of insomnia and other symptoms of CNS stimulation (Simons, 1994)

Interestingly, nocturnal doses of chlorpheniramine have failed to affect actual driving performance when assessed the next morning (Ramaekers et al, 1997b). This results is somewhat surprising given the fact the drug possesses an elimination half life $(>24$ hrs) long enough to sustain its pharmacological activity for a considerable period over the day. Similarly, as noted before, Ray et al (1987) found no association between the use of antihistamines for promoting sleep (half-lives up to 13 hrs) and the risk of hip fracture in their epidemiological survey. A possible explanation for this discrepancy may come from another study on the effects of sleep on performance of volunteers previously treated with diphenhydramine (Roehrs et al, 1993) Performance was initially impaired, but reversed after a 60 minutes nap. These results suggest that antihistamines specifically activate sleep mechanism which in turn may be reversed by some period of sleep. The mechanism by which this occurs is still largely unknown, but might be mediated by restoring the balance between histamine release and synthesis. Histamine is synthesized in cell bodies located in the posterior hypothalamus and transported to axon terminals throughout the cerebral cortex and limbic system (Schwartz et al, 1994) Transmitter release without reuptake is more or less constant during the waking period but ceases abruptly with the onset of slow-wave sleep. 
Synthesis continues unabated and may even be greater during sleep. Thus histamine availability at the postsynaptic $\mathrm{H}_{1}$ receptors may be greatest shortly after awakening. In that case, antihistamines would be less likely to block histaminergic transmission at this time then others.

In summary, from empirical studies it can be concluded that the second generation antihistamines posses a major adwantage over the first generation in that they produce considerably less behavioral toxicity. The differences between the second generation antihistamines should not be exaggerated but can not be ignored. Regulatory authorities from Europe and the United States have recognized these differences and required appropriate warnings for some of the second generation antihistamines.

\section{Other drigss}

Other classes of drugs are known to cause adverse behavioral reactions in individual cases. It is generally accepted that beta-blockers can cause depression and that frequent adverse events such as fatigue, somnolence and dizziness diminish the patients' "quality of life" (reviews: Patten \& Love, 1994; Gleiter \& Decker, 1996). Anticholinergic agents, opioids, NSAIDS, other antihypertensives and $\mathrm{H}_{2}$ antagonists have all been implicated in disturbance of consciousness and changes in cognition indicative of drug induced delirium or dementia (reviews: Starr \& Whalley, 1994; Carter et al, 1996). Manic reactions have been associated with anti-parkinsonian agents, antimalarials and sympathomimetics (review: Peet \& Peters, 1995).

\section{MANAGEMENT AND AVOIDANCE}

Any solution should start with recognizing the fact some drugs place patients at risk in normal day to day operations or limit their social and cognitive functioning in an unacceptable manner. Much of the epidemiological or empirical evidence cited above has contributed to the currently growing awareness of this problem among physicians. In particular, inappropriate drug prescription in the elderly has received considerable attention from experts in fields of geriatrics and pharmacology. Some (Beers et al, 1991) explicitly identified individual drugs (e.g diazepam, flurazepam, chlordiazepoxide, amitriptyline, propoxephene) that should be totally avoided because 
of their detrimental effects on behavior. Today their list is widely accepted, and was recently used for estimating the amount of inappropriate drug prescribing for elderly living in the American community in the year 1987 (Wilcox et al, 1994). Among the study population, $23,5 \%$ received at least one of the drugs considered inapproprimte, whereas long-term BZDs and amitriptyline were among the most commonly prescribed of the contraindicated drugs. These findings may not be totally relevant to the situation in 1997 since overall patterns of drug prescription are different today. Yet, there is also little reason to assume that physicians are currently more aware of the impairing properties of any of the alternative, more recently developed drugs. To be maximally effective, lists of contraindicated drugs require regular updating for incorporating recently published material, particularly empirical studies identifying problematic drugs before they become widely available. It is therefore of crucial importance for drug manufactures to conduct research for determining whether the drugs they advance through the registration process are in any way behaviorally toxic, and for drug regulators to insure that physicians are properly informed of its results. Physicians should subsequently consider alternative treatments in the light of this research or try to minimize behavioral toxicity when none is available. The following recommendations may be helpful for achieving that goal.

Minimize the number of drugs prescribed to reduce the chances of behavioral toxicity. Various studies have shown that it is common for elderly patients to take seven or eight prescription drugs daly (Lamy et al, 1992; Broderick, 1997). Obviously these patients are at increased risk for experiencing adverse drug reactions (Jones, 1997). Unfortunately, it is not so common for geriatric polypharmacy to be carefully monitored (Stuck et al, 1994; Apparasu \& Fliginger, 1997). The consequence can be severe as illustrated by Larson et al (1988) who identified 35 cases of drug induced cognitive impaiment among 308 out-patients evaluated for suspected dementia. Twenty seven patients were taking at least one drug known to cause cognitive impaiment and the others were taking two or three of such drugs. BZDs were implicated in nearly hal the cases, with antihypertensives and major tranquillizers as the other main offenders. The number of differential drugs prescribed was indicated as a main risk factor in those suffering from drug induced cognitive impaiment as 
compared to the rest of the sample. In all cases cognition improved when these drugs were withdrawn.

- Determine the likelihood of a pharmacokinetic interaction between drugs if polypharmacy can not be totally awoided and adjust treatment accordingly. An increasing body of evidence has shown that drugs which inhibit catabolic enzymes of the cytochrome P450 system cause elevated plasma concentrations of concurrently given drugs depending on the same enzyme for oxidation (Brøsen, 1996). All SSRIs, for example, are inhibitors of CYP2D6 and CYP3A4 and have the potential for causing clinically important interactions with substrates of these particular isozymes i.e, TCAs, BZDs, antipsychotics, $\beta$ blockers and opioids. Moclobemide, in turn, is a potent inhibitor of CYP2C19 implicated in the demethylation of diazepam, and the hydroxylation of its metabolite nordiazepam. The practical implication of such interactions have recently been demonstrated in a number of empirical studies. Combination of fluoxetine or nefazodone with alprazolam resulted in the latter's accumulation in plasma and progressive psychomotor impairment in healthy volunteers (Lasher, 1991, Kroboth et al, 1995). Driving performance of a group of depressed outpatients treated with fluoxetine or moclobemide, deteriorated over 6 weeks of treatment for those using BZD comedication that is metabolized by a cytochrome $\mathrm{P} 450$ isozyme subject to inhibition by their particular antidepressant (Ramaekers et al, 1997a).

- Behavioral impairment may be minimized when drugs are administered in nocturnal doses. Sedating anxiolytics have to be taken in divided daily doses but other psychoactive drugs do not. Residual effects of sedative antidepressants and antihistamines might be reduced or avoided when administered in nocturnal doses. A number of studies (Lader et al, 1986; Allen et al, 1988; Stille \& Herberg, 1989; Ramaekers et al, 1992, 1995b) showed that daytime driving or psychomotor performance during subchronic treatment with nocturnal doses of amitriptyline, dothiepin, mianserin and mirtazapine were was virtually indistinguishable from that during placebo treatment. Similarly, nocturnal administration of the antihistamine chlorpheniramine to healthy volunteers did 
not impair their driving performance when tested the next morning (Ramaekers, 1997b).

Adjust a recommended dose regimen to a patients" individual response to the drug in order to minimize the possibility of behavioral toxicity. In particular elderly are more vulnerable to drug effects than their younger counterparts due to age related decrements in metabolic, psychomotor and cognitive function (Van Boxtel, 1997; Star \& Whalley, 1994). Short periodic evaluations of the latter, before and during treatments are helpful means for establishing and verifying the choice of dose. If the means for objective assessment are not available, much valuable information can be gained from a patient's subjective experience or observations from persons in close contact to him or her.

Educate patients on ways to minimize the risk of becoming involved in injurious accidents. If prescription of potentially impairing drugs can not be avoided patients should be instructed to avoid driving a car or to operate hazardous machinery, in general, and always restrain from these activities whenever they feel unusually sleepy, dizzy, lethargic or otherwise not themselves. The benefit of educating the potential users was shown by a group of investigators (Hegmann et all., 1993) who reported the absence of a significant association between psychoactive drug use and work-related accidents in 1989-90 among employees of the Utah Bacchus Work facility of Hercules Aerospace. This study was undertaken to confirm the effectiveness of medication self-reporting program that was introduced by the plant"s management in 1987. Because of the recognized high-cost of human errors in this workplace, a list of commonly used, potentially impairing OTC and prescription drugs was compiled and distributed to the workers. They were advised the use safer alternatives. If they had to use impairing drugs for lack of better alternatives, the workers were assigned to less hazardous duties. These workers were not only protected from risks associated with the use of impairing drugs, they were also more informed than most about the existence of the risks. 


\section{CONCLUSION}

Behavioral toxicity is rellatively common among medicinal drug users. Results from epidemiological and empirical research all converge on the fact that drugs frequently produce side effects that prevent their users from performing everyday operations in an efficient or normal manner. As a consequence, they are at higher risk of becoming involved in accidents which in tum may lead to injuries and even worse, death. Unfortunately, behavioral toxicity often goes unnoticed by users themselves and their prescribing physician. Clearly, more effort from regulatory authorities is needed for increasing the patients' and physicians' awareness of the detrimental drug effects on behavior in general, and of differences between the effects of different drugs and doses of the same ones in particular. Much of this information can be gained from experimental literature comparing individual drugs' effects on performance. Yet, this is presently incomplete since most research conducted until now pertained to drugs used in psychiatry. Other drug classes have not been properly investigated yet, though many are suspected or known to decrease a patients quality of life. Yet in the interest of the patients, it should be the responsibility of drug manufactures and drug regulators, to always identify a drug's potential for producing side effects that can be conceived as behaviorally toxic.

\section{References}

Allain H, Lieury A, Brunct-Bourgin F, Mirabaud C, Trebon P et al (1992). Antidepressants and cognition: comparative effects of moclobemide, viloxazine and maprotaline. Psychopharmacology 106: $556-561$

Alloin H, Patat A, Lieury A, Le Coz F, Janus C, Menard G, Gandon JM (1995). Comparative study of the effects of zopiclone $(7.5 \mathrm{mg})$, zolpidem, flunitrazepam and a placebo on noctumal cognitive performance in healthy subjects, in relation to pharmacokinetics. European Psychiatry $10: 129 \mathrm{~s} \cdot 136 \mathrm{~s}$

Allen D, Lader M, Curran V (1988) A comparative study of the interactions of alcohol with amitriptyline, fluoxetine and placebo in normal subjects. Progress in Neuropsychopharmacology and Biological Psychiatry 12: 63-80

Aparasu RR, Fliginger SE (1997) Inappropriate medication prescription for the elderly by afficebased physicians. Anmals of Pharmacotherapy $31: 823-829$

Austin MP, Ross M, Murray C, O'Carrol RE, Ebmeier KP et al. (1992). Cognitive function in major depression. Journal of affective Disorders $25: 21-30$

Balkin T. O'Donnell, Wesensten N, McCann U, Belenky G (1992). Comparison of the daytime sleep and perfornance effects of zolpidem versus triazolam. Psychopharmacology 107: 83-88

Bartfai A. Wiesel FA. (1986) Effects of sulpiride on vigilance in healthy subjects. International Joumal of Psychophysiology 4: 1-5 


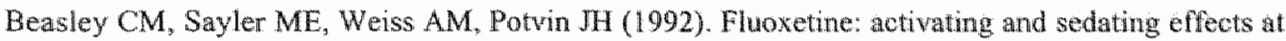
multiple fixed doses. Journal of Climical Psychopharmacology $12: 328-333$

Beasley CM, Sayler ME, Bosomworth JC, Wemicke JF (1991) High dose fluoxetine: efficacy and activating-sedating effects in agitated and retarded depression. Joumal of Clinical Psychophamacology $11: 166-174,1991$

Beers MH, Ouslander JG, Rollinger I, Reuben DB. Brooks J et al. (1991) Explicit criteria for determining inappropriate medication use in nursing homes. Archives of Internal Medicine 151: $1825-1832$

Betschy $G$, Vandel $S$ (1993). Fluoxetine related indifference and akathisia. A case report. Therapic 48: 158-159

Bhavnani SM, Levin GM (1996) Antipsychotic agents: a survey of the prevalence, severity and burden of side effects. Intenational Clinical Psychopharmacology 11:1-12

Bishop KI, Curran HV, Lader M (1996) Do scopolamine and lorazepam have dissociable effects on human memory systems? A dose response study with normal wolunteers. Exxperimental and Clinical Psychopharmacology 4: 292-299

Blake AJ, Morgan K, Bendall MJ, Dallosso H, Ebrahim SBJ et al.(1988) Falls by elderly people at home: Prevalence and associated factors. Age and aging 17:365-372

Broderick E (1997) Prescribing patterns for mursing home residentss in the US. The reality and the vision. Drugs and Aging 1. 1: 255-260

Brookhuis KA, Borgman AE (1988) The effects of some anxiolytics on driving performance. TGO Tijdschrift voorTherapie, Geneesmiddel, en Onderzoek 13:228-231

Bresen K (1996) Are pharmacokinetic drug interactions with the SSRIs an issue? International Clinical Pharmacology 11: 23-27

Campbell AJ, Borrie MJ, Spears GF (1989). Risk factors for falls in a community-based prospective study of people 70 years and older. Journal of Gerontology 44: M $112-117$

Campbell AJ, Bonie MJ, Spears GF, Jackson SL, Browns JS et al.(1990). Circumstances and consequences of falls experienced by a community population 70 years and over during a prospective study. Age and Aging 19:136-141

Carter GL, Dawson AH, Lopert $\mathrm{R}$ (1996) Drug induced delirium. Incidence, management and prevention. Drug Safety 15:291-301

Coccaro EF, Siever LJ (1985) Second generation antidepressants: a comparative review. Journal of Clinical Pharmacology 25: 241-260, 1985

Cole 10 (1960) Behavioral toxicity. In: Uhr L, Miller JG (eds) Drugs and behavior. John Wiley \& Sons, New York, p375

Cole JO, Kando JC (1993) Adverse behavioral events reported in patients taking alprazolan and other benzodiazepines. Journal of Clinical Psychiatry 54: $\$ 49-561$

Coulter DM, Pillians PI (1995). Fluoxetine and extrapyramidal side effects. American Journal of Psychiatry 1152: 122-125, 1995

Cummings RG, Miller JP, Kelsey JL, Davis P, Arken C et al.(1991) Medications and multiple lalls in elderly people: The St Louis OASIS study. Age and Ageing 20:455-461

Cumming RG, Klineberg RJ (1993) Psychotropics, thiazide diuretics and hip fractures in the elderly. The Medical Joumal of Australia 158: 414-417

Cuman HV (1986) Tranquillizing memories: a review of the effects of benzodiazepines on human performance. Biological Psychology 23: 179-213

Curran HV, Lader M (1986) The pharmacological effects of repeated doses of fluvoxamine, mianserin and placebo in healthy human subjects. European Joumal of Clinical Pharmacology 29: $601-607$ 
Curran HV, Shifano F, Lader M (1991) Models of menory dysfunction? A comparison of the effects of scopolamine and lorazepam on memory, psychomotor performance and mood. Psychopharmacology 103:83-90

Curran HV, Birch B (1991) Differentiating the sedative, psychomotor and amnestic effects of benzodiazepines: a study with midazolam and the benzodiazepine antagonist, flumazenil. Psychopharmacology 103: 519-523

Curran HV, Gorengtein G (1993) Differential effects of lorazepam and oxazepam on priming. International Clinical Psychopharmacology 8: 37-42

Currie D, Fashemi K, Fothergill J, Findlay A, Harris A et al. (1995) The use of anti-depressants and benzodiazepines in the perpetrators and victims of accidents. Occupational Medicine $45: 323$ 325

Cwikel J (1987) Falls among elderly people living at home: Medical and social factors in a national sample. Israelian Journal of Medical Science 28: 446-453

Danion JM, Zimmerman MA, Willard-Schroeder D, Grange D, Singer L (1989) Diazepam induces a dissociation between explicit and implicit memory. Psychopharmacology 99: 238-243

Deptula D, Pomara N (1990). Effects of antidepressants on human performance: a review. Joumal of Clinical Psychopharmacology 10: 105-110

Dershwitz M, Rosow CE, Dibiase PM, Zaslavky A (1991) Comparison of the sedative effects of butorphanol and nidazolam. Anesthesiology 74: 717-724

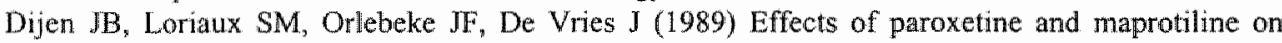
mood, perceptual-motor skills and eye movennents in healthy volunteers. Journal of Psychopharmacology 3: 149-155

Dimascio A, Shader RI (1968) Behavioral toxicity of psychotropic drugs: II Definition II Toxic effects on psychomotor functions. Connecticut Medicine, 32:617-620

Fagan D, Scott DB, Mitchell M, Tiplady B (1991) Effects of remoxipride on measures of psychological performance in healthy wolunteers. Psychopharmacology 105: 225-229

Fairweather DB, Kerr JS, Hindmarch 1 (1992) The effects of acute and repeated doses of zolpidem on subjective sleep, psychomotor performance and cognitive function in elderly volunteers. European Journal of Clinical Pharmacology 43: 597-601

Fairweather DB, Kerr KS, Hartison DA, Moon CA, Hindmarch I (1993a). A double blind comparison of fluoxetine and amitriptyline on cognitive function in elderly depressed patients. Human Psychophamacology 8: $41-47$

Fuirweather DB, Kerr JS, Hindmarch I (1993b) The effects of moclobemide on psychomotor performance and cognitive function. International clinical Pharnacology 8: 43-47

Farid NA, Bergström RF, Lemberger L, Ziege $\mathbb{E} A$, Tenbarge et al. (1986) Studies on the disposition of fluoxetine and radionctive isotopes. Poster presented at $15^{\text {th }}$ CINP congress, Puerto Rico

Fingl E, Woodbury DM (1964) General principles. In: Goodman LS, Gilman A (eds) The pharnuacologicall basis of therapeutics ( $3^{\text {rd }}$ edition), MacMillan, New York, pl,

Freeman HL, O'Hanlon $J^{*}$ (1995) Acute and subacute effects of antidepressants on performance. Journall of drug Development and Clinical Practice 7: 7-20

Frewer $L J$, Lader M (1993) The effects of nefazodone, imipramine and placebo and combined with alcohol, in normal subjects. International Clinicall Psychopharmacology 8: 13-20

Gilmore TM, Alexander BH, Mueller BA, Rivara FP (1996) Occupational injuries and medication use. American Joumal of Industrial Medicine 39: 234-239

Gleiter CH, Deckert J (1996) Adverse effects of beta-adrenoceptor blockers. Pharmacopsychiatry 29: $201-211,1996$ 
Gorenstein C, Bernik MA, Pompeia S (1994) Differential acute psychomotor and cognitive effects on diazepam on long-tem benzodiazepine users. Intemational Clinical Psychopharmacology 9 : $145-153$

Govararts JJGM, Nooren FPBM, Smeekens PFJ, wan Vhiet EWN (1989) Benzodiazepines en bedrijfsongevallen. Tijdschrift Sociale Gezondheidswetenschappen 67: 131-133

Granek E, Baker SP, Abbey H, Robinson E, Myers AH et al. (1987) Medications and diagnoses in relation to falls in a long-term care facility. Journal of American Geriatrics Society $35: 503$. 511

Grounds D, Stocky A, Evens P, Scott C et al. (1995) Antidepressants and side effects. Australian and New-Zealand Journal of Psychiatry 29: 156-157

Haenel T, Stockli HR, Truog P (1995) A case of rare side effects of certain antidepressant drugs. Nervenartz 66: 70-72

Hale AS, Pinninti NR (1995) Critical flicker fusion threshold and anticholinergic effects of chronic antidepressant treatment in remitted depressives. Joumal of Psychopharmacology 9:258-266

Heggmann K, Greenlee P, Johns RE (1991) Medication reporting in the workplace. Journal of Occupationall Medicine 33, 1131-1136

Herberg KW, Menke $\mathbb{H}$ (1981) Study of the effects of the antidepresant fluvoxamine on driving skills and its interaction with alcohol. TÜV Rheinland (Cologne) Technical Report

Hindmarch I, Harrison C (1988) The effects of paroxetine and other antidepressants in combination with alcohol in psychomotor activity related to car driving. Human Psychopharmacology 8: $417-422$

Hindmarch I, Shilingford J, Shillingford C (1990) The effects of sertraline on psychomotor performance in elderly volunteers. Journal of Clinical Psychiatry 12: $\$ 34-s 36$

Hindmarch I (1992) A review of the psychomotor effects of paroxetine. International Clinical Psychopharmacology 6: s65-s67

Hindmarch I, Kerr JS (1992) Behavioral toxicity of antidepressants with particular reference to moclobemide. Psychopharmacology 106: \$49-s55

Hindmarch I (1994) Instrumental assessment of psychomotor functions and the effects of psychotropic drugs. Acta Psychiatrica Scandinavia, 89, s49-s52

Hobi V, Gastpar $M_{*}$ Gatstpar $G$, Gilsdorf $U$, Kielholz P et al. (1982) Driving ability of" depressed patients under antidepressants. Journal of International Medical Research 10: 65-81

Hoehn-Saric R, Lipsey JR, McLeod DR (1990). Apathy and indifference in patients on fluwoxamine and fluoxetine. Journal of Clinical Psychopharmacology 10:343-345

Hommer D, Weingarter H, Breter A (1993) Dissociation of benzodiazepine-induced annesia from sedation by flumazenil pretreatment. Psychopharmacology 112:455-460

Jackson DM, Ryan C, Evenden J, Mohell N (1994) Preclinical findings with new antipsychotio agents: what makes them atypical? Acta Psychiatrica Scandinavia 89: $841 . \$ 48$

Jones BA (1997) Decreasing polypharmacy in clients most at risk. AACN Clinical Issues 8: 627-634

Kerr IS, Fairweather DB, Mahendran R, Hindmarch I (1992) The effects of paroxetine alone and in combination with alcohol on psychomotor performance and cognitive function in the elderly. International Clinical pharmacology $7: 101-108$

King DJ (1993) Measures of netroleptic effects on cognition and psychomotor performance in healthy volunteers. In: Hindmarch I, Stonier PD (eds). Human Psychopharmacology Vol 4 , JolnW Wiley \& Sonsi Ltdi, West Sussex, 195-209

King DJ (1994) Psychomotor disturbances induced by neuroleptics. Acta Psychiatrica Scandinavia 889: $553-559$ 
King DJ, Best $\mathbb{P}_{*}$ Lynch D, Manmon MF, Montgomery RC, Tiplady B, Yisak W (1995) The effects of remoxipride and chlorphemiramine on eye movements and psychomotor perfomance in healthy wolunteers. Journal of Psychopharmacology $9: 143-150$

King DJ (1997). BAP Consensus Statement. Guidelines for the use of antispychotic drug studies in healthy volunteers. Joumal of Psychopharnacology $11: 201-210$

Kinon DJ, Lieberman JA (1996) Mechanisms of action of atypical antipsychotics: a critical analysis. Psychopharmacology $124: 2-34$

Kirk T, Roache JD, Griffiths RR (1990) Dose response evaluations of the amnestic effects of triazolan and pentobarbital in normal subjects. Joumal of Clinical Psychopharmacology 10. $160-167$

Koelega HS. Benzodiazepines and wigilance performance: a review. Psychopharmacology 98: 145 156

Koepsell TD, Wolf ME, McClosky L, Buchmer DM, Louie D et al. (1994) Medical conditions and motor wehicle collision injuries in older adults. Joumal of American Geriatrics Society 42 : 695.700

Koryagin A (1981) Unwilling patients. The Lancet, april 11, 821-824

Kroboth PD, Folan MM., Lusch RM, Chaikin PC, Shukla UA et al (1995) Coadministration of nefazodone and benzodiazepines: I pharmacodynamic assessment. Journal of Clinical Pharmacology 15: 306-319, 1995

Lader M (1994) Historical introduction. Proceedings of the first international meeting on the neuroleptic induced deficit syndrome. Acta Psychiatrica Scandinavia 89: s6-s?

Lamy PP, Salzman C, Nevis-Olesen J (1992) Drug prescribing patterns, risks, and compliance guidelines. In : Salzman C,ed. Clinical Geriatric Psychopharmacology. 2nd ed. Baltimore, Williams \& Wilkins 15-37

Lader M, Melhuish A, Freka G, Fredricson Overo K, Christensen V (1986) The effects of citalopram in single and repeated doses and with alcohol on physiological and psychological measures in healthy subjects. European Journal of Clinical Pharmacology $31: 183-190$

Larson EB, Kukull WA, Buchner D, Reifler BV (1987) Adverse drug reactions associated with global cognitive impaiment in elderly persons. Annals of Internal Medicine 107: 169-173

Lasher TA, Fleishaker JC, Steenwyck RC, Antal EJ (1991) Pharmacokinetic, pharmacodynamic evaluation of the combined administration of alprozolam and fluoxetine. Psychopharmacology 104: 323,-327

Leonard B (1997) Fundamentals of psychophannacology. John Wiley \& Sons, 2nd ed, Chichester, MeW York Weinineim

Levander T (1994) Neuroleptics and the neuroleptic induced deficit syndrome. Acta Psychiatrica Scandinavia $89: 58-\mathrm{s} 13$

Leveille SG, Buchner DM, Koepsell TD, McClosky LW, Wolf ME et all. (1994) Psychoactive medications and injurious motor vehicle collisions involving older drivers. Epidemiology 5: $591+598$

Leysen JE, Gommeren W, Schotte A (1996) Serotonin receptor subtypes: possible roles and implications in antipsychotic drug action. In: Kane JM, Moller HJ, Wouters FA (eds), Serotonin in antipsychotic treatment, Marcel Dekker, New York, 51-75

Lichtenstein ML, Grifin MR, Comell JE, Malcolm E, Ray WA (1994). Risk factors for hip fractures occurring in the hospital. American Journal of epidemiology 140: 830-838

Liljequist R, Limoila M, Mattila MJ, Saario I, Seppala T (1975) Effects of two weeks' treatment with thioridazine, chlorpromazine, sulpiride, abd bromazepam, alone or in combination with alcohol, on leaming and memory in man. Psychopharmacologia 44: 205-208 
Limnoila M, Guthrie $\mathrm{S}_{2}$ Lister $\mathrm{R}$ (1986) Mechanisms of drug-induced impaiment of driving. In: O'Hanlon JF, De Gier H (eds) Drugs and driving. Tyylor and Francis, London, Philadelphia, pp $29-50$

Lord SR, Anstey KJ, Willams P, Ward IA (1995) Psychoactive medication use, sensori-motor function and falls in older women. British Joumal of Clinciol Pharmacology 39, 227-234

Malmivaara A, Helióvaara M, Knekt P. Reunanen A, Aromaa A (1993) Risk factors for injurious falls leading to hospitalization or death in a Cohort of 19500 adults. Annerican Joumal of Epidemiology 138: 384-394

Mandalos GE, Szarek BL (1990) Dose-related paranoid reaction associated with fuoxetine. Joumal of Nerwous and Mental Disorders 178: $57-58,1990$

Mander A, McCausland M, Workman B, Flaner H, Christophidis $\mathbb{N}$ (1994) Fluoxetine induced dyskinesia. Australian and New-Zealand Journal of Psychiatry 28: 328-330

Mattila MJ, Mattila ME, Konno K, Satrialho-Kere U (1988) Objective and subjective effects of remoxipride, alone and in combination with ethanol or diazepam, on performance in healthy subjects. Journal of Psychopharmacology 2: 138-149

Mattila MJ, Patat A, Seppälä T, Kalska H, Jalava ML, Vanakoski J, Lavanant C (1996) Single oral doses of amisulpride do not enhance the effects of alcohol on the performance and memory of healthy subjects. European Journal of Clinical Pharmacology 51: 161-166

Maxwell CJ, Neutel I, Hirdes JP (1997) A prospective study of falls after benzodiazepine use: a comparison of new and repeat use. Pharmacoepidemiology and drug safety 6:27-35

McClelland GR, Ciooper SM, Pilgrim AJ (1990) A comparison of the central nervous system effects of haloperidol, chlorpromazine and sulpiride in normal volunteers. British Journal of Clinical Pharmacology, 30: 795-803

Meghi C (1994) Acquired stuttering [letter]. Joumal of Family Practice 39: 325-326

Mirow S (1991) Cognitive dysfunction associated with fluoxtine [letter]. American Journal of Psychiatry 148: 948-949

Moon CAL, Davey A (1988) The efficay and residual effects of trazodone (150 mg nocte) and mianserin in the treatment of depressed general practice patients. Psychopharmacology 95: $57-813$

Moon CAL, Jesinger DK (1991)The effects of psychomotor performance of fluvoxamine versus mianserin in depressed patients in general practice. British Journall of Clinical Pharmacology 45: $259-262$

Neutel CI (1995) Risk of traffic accident injury after a prscription for a benzodiazepine. Annals of Epidemiology 5: 239-244

Neutel Cl, Downey W, Senft D (1995) Medical events after a prescription for a benzodiazepine. Pharmacoepidemiology and Drug Safety 4:63-73

Newhouse PA, Richter EM (1996) Comparison of sertraline and fluoxetine in depressed geriatric outpatients: plasma levels and efficacy. Poster presented at the $20^{\text {th }}$ CINP congress, Melbourne

O'Hanlon JF, Haak TW, Blaaww GJ, Riemersma JBJ (1982) Diazepam impairs lateral position control in highway driving. Science $217: 79-81$

O'Hanion JF (1984). Driving performance under the influence of drugs. Rationale for, and apllication of, a new test. British Journal of Clinical Pharmacology $18: 121 \mathrm{~s}-129 \mathrm{~s}$

O'Hanlon JF, Volkerts ER, Louwerens JW, Gloerich ABM, Brookhuis KA (1984) Zopiclone"s residual affects on actual driving performance wersus those of nitrazepam and flunitrazepam. Clinical Neuropharmacology 7: $620 \mathrm{~s}-621 \mathrm{~s}$

O'Hanlon JF, Volkerts ER (1986) Hypnotics and actual driving performance. Acta Psychiatrica Scandimavia $332: \$ 95-\$ 104$ 
O'Hanlon JF, Brookhuis KA, Lowwerens JW, Volkerts ER (1986) Performance testing as part of drug registration. In: JF $\mathrm{O}^{\prime H}$ Hanlon, JJ De Gier (eds). Drugs and Driving, Taylor and Francis, London

O'Hanlon JF (1991) Review of buspirone's effects on human performance and related wariables. European neuropsycholopharmacology $1: 489-501$

O"Hanlon Jf, Vemeeren A, Uiterwijk MMC, Veggel wan LMA, Swijgman HF (1995) Anxiolytics" effects on the actual driving performance of patients and healthy volunteers in a standardized test. Neuropsychobiology 31:811-88

O'Hanlon JF (1995) Zopiclone's residual effects on psychomotor and information processing skils involved in complex tasks such as car driving: a critical review, European Psychiatry $10: 137 \mathrm{~s}-144 \mathrm{~s}$

O'Hanlon JF, Ramaekers JG (1995) Antihistamine effects on actual driving performance in a standard test: a summary of Dutch experience, 1989-1994. Allergy 50: 234-242

O'Hanton JF (1996) Antidepressant therapy and behavioral competence. British Journal of Clinical Practice 50: 381-385)

O'Handon JF, Robbe HWJ, Vermeeren A, Van leeuwen C, Danjou P (1997) Venlafaxine's effects on healthy volunteers" driving, psychomotor and vigilance performance during 15-day fixed $(75 \mathrm{mg} / \mathrm{d})$ and incremental $(75-150 \mathrm{mg} / \mathrm{d})$ dosing regimens. Technical report, Institute for Human Psychopharmacology, Maastricht, The Netherlands 1997.

Oster G, Russel MW, Huse DM, Adams SF, Imbimbi J (1987) Accident- and injury-related health care utilization among benzodiazepine users and nonusers. Journal of Clinical Psychiatry 48(suppl): 17-21

Oster G, Huse DM, Adams SF, Imbimbo J, Russel MW (1990) Benzodiazepine tranquilizers and the risk of accidental injury. American Journal of Public Health 80: 1467-1470

Parrot AC (1987) Assessment of psychological performance in applied situations. In. T Hindmarch, $\mathrm{P}$ Stonier (eds), Human Psychopharmacology; measures and methods. Vol 1. John Wiley \& Sons, Chichester, New York, Brisbane, pp 93-111

Patat A, Perault MC, Vandel B, Danjou Ph, Brohier S et al. (1995a) Assessment of the interaction between a partial agonist and a full agonist of benzodiazepine receptors, based on psychomotor performance and memory, in healthy volunteers. Journal of Psychopharmacology 9: 91-1.01

Patal A, Gandon JM, Durrieu G, Le Coz F, Curet $O$ et al. (1995b) Effects of single and multiple doses of a new reversible $\mathrm{MAO}-\mathrm{A}$ inhibitor, befloxatone, on psychomotor performance and memory in healthy subjects. Human Psychopharmacology 19: 11 1-125

Patten SB, Love EJ (1994) Drug induced depression. Incidence, avoidance and management. Drugg Safety 10: 203-219, 1994

Peet M, Peters S (1995) Drug-induced mania. Drug Safety 12: 146-153

Perrault GH, Depoortere R, Morel E, Sanger DJ, Scaton B (1997). Amisulpride: an atypical antipsychotic with D2/D3 dopamine receptor antagonistic activity and limbic selectivity: III behavioral profile. Journal of Pharmacology and Experimental Therapeutics, 280: 73-82

Peselow ED, Corwin J, Fieve RR, Rotrosen I, Cooper TB (1991). Dissappearence of memory deficits in outpatient depressives responding to imipramine. Journal of affective disorders $21: 173$. 183

Peuskens I (1995). Risperidone in the treatment of patients with chronic schizophrenia: a multinational, multi-centre, double blind, parallel-group study versus haloperidol. Bristish Journal of Psychiatry, 166: 712-726

Polster MR, MoCarthy RA, O'Sullivan G, Gray PA, Park GR (1989). Midazolam induced amnesia: implications for the implicit/explicit memory distinction. Brain Cognition: 22, 244-265. 


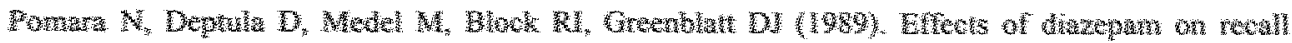

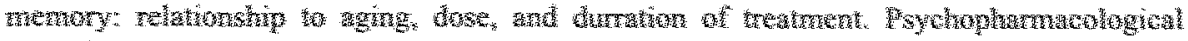

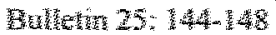

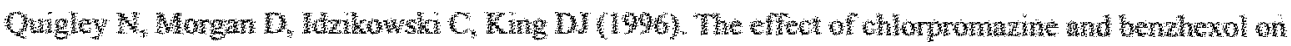

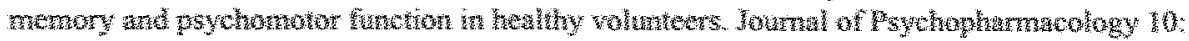
$46-152$

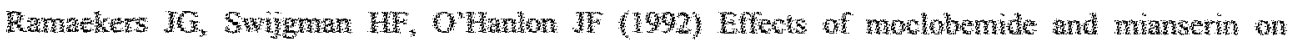

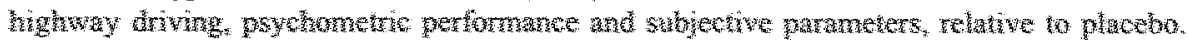

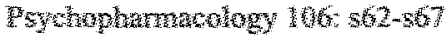

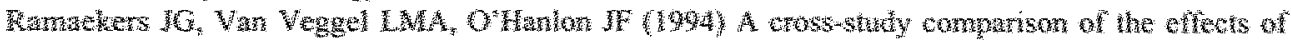

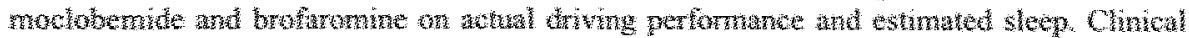

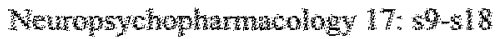

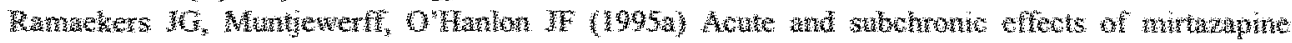

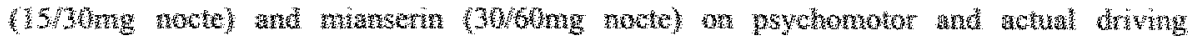

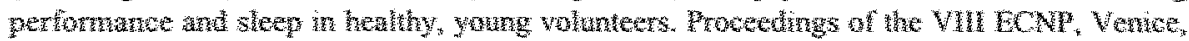

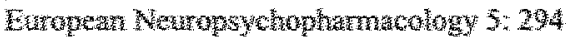

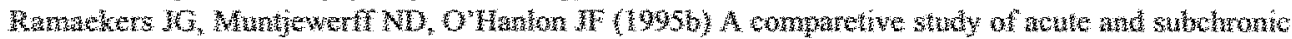

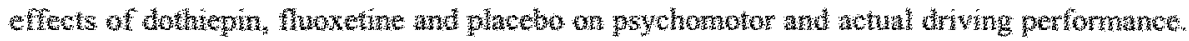

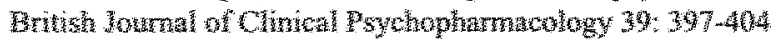

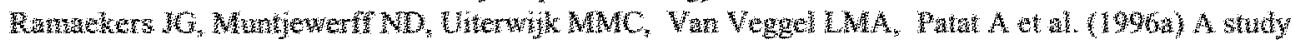

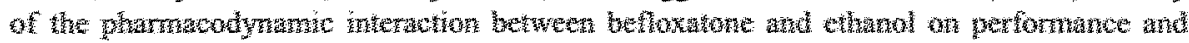

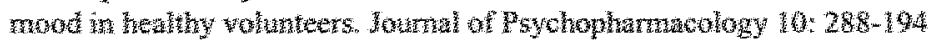

等

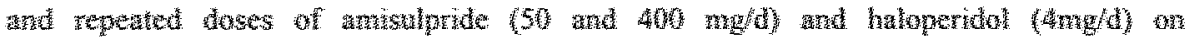

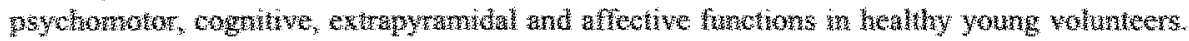

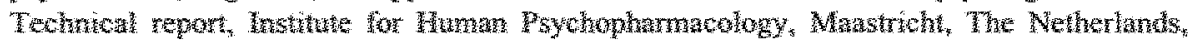
1996

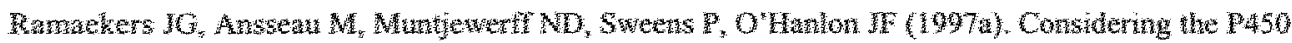

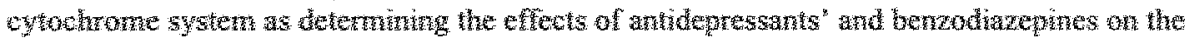

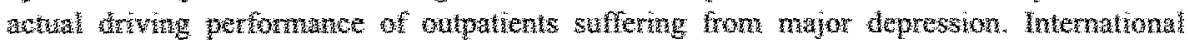

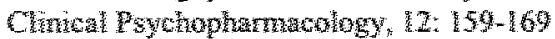

Ramaekers JG, Van Leeuwen C, O'Hanlon JF (1997b). A comparison of the effects of chlorpheniramine 8 and $12 \mathrm{mg}$, hs, when used with terfenadine $60 \mathrm{mg}, \mathrm{gmm}$, on volunteers' driving performance versus those of placebo, and flurazepam $30 \mathrm{mg}$, hs. Technical report, Institute for Human Psychopharmacology, Masstricht, The Netherlands

Rammsayer T, Gallhofer B (1995). Remoxepride versus haloperidol in helthy volunteers: psychometric performance and subjective tolerance profiles. International Clinical Psychopharmcology 10:31-37

Ray WA, Griffin MR, Sehaffner W, Baugh DK, Melton LF (1987). Psychoptropic drug use and the risk of hip fracture. New England Journal of Medicine 316:363-369

Ray WA, Griffin MR, Malcolm E (1991). Cyclic antidepressants and the risk of hip fracture. Archives of Internal Medicine 151: $754-756$

Ray WA, Fought RL, Decker MD (1992). Psychoactive drugs and the risk of injurious motor vehicle crashes in elderly drivers. American Journal of Epidemiology 136: 873-883

Richelson E (1996). Synaptic effects of antidepressants. Journal of Clinical Psychopharmacology 16 : $51-59$

Riedel WJ, Van Praag HM (1995). Avoiding and managing anticholinergic effects of antidepressants. CNS Drugs 3: 245-259 
Robbe HWJ, O'Hanlon JF (1995). Acute and subchronic effects of paroxetine 20 and $40 \mathrm{mg}$ on achal driving, psychonotor performance and subjective assessments in healthy volunteers. European Neuropsychopharmacology $5: 35-42$

Roenrs $T$, Claiburue $R$, Knox $M$, Toth T (1993). Effects of ethanol, diphenhydramine and triazolam after a nap. Neuropsychopharmacology $9: 239-245$

Roehrs I, Merloti L, Zorick $F$, Roth T (1994). Sedative, memory, and performance effects of hynotics. Psychopharmacology 116: 130-134

Rombaut NEI, Hindmarch 1 (1994) Psychometric aspects of antihistamines: a review. Human Psychopharmacology 9: 157-169

Ruthazer R, Lewis AL (1993) Antidepressants and falls among elderly people in long-term care. American Journal of Publiv Health 83: 746-749

Ruiz F (1994) Fluoxetine and the serotonin syndrome. Annals of Emergency Medicine 24: $983-985$

Ryynänen OP, Kiwela SL, Honkanen R, Laippala P, Saano V (1993) Medications and chronic diseases as risk factors for falling injuries in the elderly. Scandinavian Journal of Social Medicine 21: $264-271,1993$

Sakulsripong M, Curan HW, Lader M (1991) Does tolerance develop to the sedative and amnestic effects of antidepressants? European Journal of Clinical Pharmacology 40 : 43-48

Saletu B, Pekesch G (1987a) Recent adwances in clinical pharmacology of benzodiazepines Part $I$ : Pharmacodynamics. Human Psychopharmacology 2: 61-84

Saletu B, Grtinberger $J$, Linzmayer, Anderer $P$ (1987). Comparative placebo-controlled pharmacodynamic studies with zotepine and clozapine utilizing pharmaco-EEG and psychometry. Pharmacopsychiatry 20: 12-27

Schoemaker H, Claustre Y, Fage D, Rouquier L, Chergui K et al. (1997) Neurochemical characteristics of amisulpride, an atypical D2/D3 receptor antagonist with both presynaptic and limbic selectivity. Joumal of Pharmacology and Experimental Therapeutics 280: 83-97

Schwartz JC, Arrang JM, Garbarg M, Traiffort E (1994). Histamine. In: FE Bloom, DJ Kupfer (eds) Psychopharmacology: the fourth generation of progress. Raven Press, Ltd, New York, pp $397-405,1994$

Seppälia T, linnoila M, Elonen E, Mattila MJ, Maki M (1975) Effects of tryciclic antidepressants and alcohol on psychomotor skills related to driving. Clinical Pharmacology and Therapeutics 17: $515-221$

Sheahan SL, Coons SI, Robbins CA, Martin SS, Hendricks J et al.(1995) Psychoactive nedication, alcohol use, and falls among older adults, Journal of Behavioral Medicine 18:127-139

Shorr RI, Griffin MR, Daugherty JR, Ray WA (1991). Opioid analgesics and the risk of hip fracture in the clderly: codeine and propoxyphene. Journal of Gerontology $47: \mathrm{m} 111-115$

Siegfried K, O'Connoly M (1986). Cognitive and psychomotor effects of different antidepressants in the treatment of old age depression. International Clinical Psychopharmacology 1:231-243

Simons HER (1994). H, receptor antagonists. Comparative tolerability and safety. Drug Safety 10: $350-380$

Singh RK, Gupta AK, Singt B (1995). Acute organic brain syndrome after fluoxetine treatment. American Joumal of Psychiatry 152: 295-296

Spring B, Gelenberg AJ, Garvin R, Thompson S (1992). Amitriptyline, clovoxamine and cognitive function: a placebo controlled comparison in depressed out-patients. Psychopharmacology: $108,327-332$

Stanley N, Altort CA, Rombaut NEI, Hindmarch I (1996). Comparison of the effects of astemizole/pseudoephedrine and triprolidine/pseudoephedrine on CNS activity and psychomotor function. International Clinical Psychopharmacology 11:31-36 
Stan JM, Whalley LI (1994). Drug-induced dementia. Incidence, management and prevention. Drug Safety 11:310-317

Streufert S, Gengo FM (1993) Drugs and behavior: an introduction. In: S Streufert, FM Gengo (eds) Effects of drugs on human functioning. Karger, Basel, Freiburg, Paris, pp $1-12$

Stromberg C, Sepallä T, Mattila MJ (1988) Acute effects of maprotiline, doxepin and zimeldine with alcohol in healthy volunteers. Archives of Pharmacodynamics and Therapeutics 291: 217-228

Stille G, Herberg KW (1989). Traffic safety in treatment with dosulepin. Fortschritte der Medizin 107: 75078,1989

Stuck $A \mathbb{E}$, Beers $\mathrm{MH}_{3}$ Steiner A, Aronow HU, Rubenstein LZ, Beck JC (1994) mappropriate medication use in community residing older persons. Atchives of Internal Medicine 154: 2195-2200

Tinett ME, Speechley M, Ginter SF (1988). Risk factors for falls among elderly living in the community. New England Joumal of Medicine 319: 1701-1707

Tompson PJ (1991). Antidepressants and memory: a review. Human Pychopharmacology 6: 79-90

Van Boxtel MPJ. (1997) Physical health, vascular risk factors and age-related cognitive decline. Studies into physical determinants of normal cogmitive aging. Neuropsych Publishers, Maastricht

Van Laar MW, Volkerts ER, Van Willigenburg APP (1992). Therapentic effects and effects on actual driving performance of chronically administered buspirone and diazepam in anxious outpatients. Journal of Clinical Psychopharmacology 12:86-95

Van Laar MW, Van Willigenburg APP, Volkerts ER (1995) Acute and subchronic effects of nefazodone and imipramine on highway driving, cognitive functions, and daytime sleepiness in healthy adult and elderly subjects. Journal of Clinical Psychopharmacology 15:30-40

Vermeeren A, OHanlon JF, Declerck AC, Kho L (1995). Acute effects of zolpidem and flunitrazepam on sleep, memory and driving performance, compared to those of partial sleep deprivation and placebo. Acta Therapeutica 21: 47-64

Vermeeren A, O'Hanlon JF, Fidler C (1996). A single centre, double-blind, placebo-controlled, crossover study to compare the effects of four dosage regimens of fexofenadine hydrochloride on car driving and psychomotor performance. Technical report, Institute for Human Psychopharnacology, Maastricht, The Netherlands

Volkerts ER, O'Hanlon JF (1986) Hypnotics" residual effects on driving performance as determined by drug, dosage, thime after administration and nights of continual use. Ir: JF O Hanlon, JJ De Gier (eds). Drugs and Driving, Taylor and Francis, London

Volkerts ER, Abbink F, van Latar MW, Plomp TA, Maes RAA (1991) Comparison of the effects of ritanserin $5 \mathrm{mg}$ bid and lorazepam $1 \mathrm{mg}$ tid upon actual driving perfomance. Teelanical report, The Netherlands Institute for Drugs and Doping Research, Uniwersity of Utrecht

Volkerts ER, Van Laar MW, Van Willigenburg APP, Plomp PA, Maes RAA (1992) A comparative study of on the road and simulated driving performance after nocturnal treatment with lormetazepam Img and oxazepam 50mg. Human Psychopharmacology 7: 297.310

Vuuman EFPM, Van Veggel LMA, Sanders RL, Muntjewerff ND. O'Hanlon JF (1990). Effects of semprex-D and diphenhydramine on learning in young adults with seasonal allergic rhinitis. Allergy, Asthma and Immunology 76:247-252

Vuurman EFPM, Van Veggel LMA, Uiterwijk MMC, Leutner D, O'Hanlon JF (1993). Seasonal allergic rhinitis and anthistamine effects on childrens' learning. Annals of Allergy $71: 121-$ 126

Weingarter H.J, Hornmer D, Lister RQ, Thompson K, Wolkowitz (1992). Selective effects of triazolam or memory. Psychopharmacology 106:341-345 
Wesnes $K$, Simpson $P$, Christmas $L$ (1987) The assessment of human information-processing abilities in psychopharmacology. In: I Hindmarch, P Stonier (eds). Human Psychopharmacology; measures and methods. Vol 1. John Wiley \& Sons, Chichester, New York, Brisbane, pp 79-92

Weinstein $A$, Wilson $\mathrm{S}$, Bailley $\mathrm{S}$, Nutt $\mathrm{D}(1996)$. Sedative antidepressants impair wisual detection mechanisms in humans: Journal of Psychopharmacology 10: 141-145

Wilcox $\mathrm{SM}$, Himmelstein $\mathrm{DU}$, Woolhandler $\mathrm{S}$ (1994). Inappropriate drug prescribing for the community elderly. Joumal of the Anerican Medical Association 272: 292-296

Wittenborn JR (1987) Psychomotor tests in psychopharmacology. In: I Hindmarch, P Stonier (eds), Human Psychopharmacology; measures and methods. Vol 1. John Wiley \& Sons, Chichester, New York, Brisbane, pp 69.78

Woods JH, Katz JL, Winger G. Benzodiazepines: use, abuse, and consequences. Pharmacological Reviews 44: $151-347,1992$

Wylie KR, Thompson DJ, Wildgust HJ (1993). Effects of depot neuroleptics on driving performance in chronic schizophrenic patients. Joumal of Neurosurgery and Psychiatry 56:910-913 


\title{
CHAPTER 3
}

\section{The Effects of Moclobemide and Mianserin on Highway Driving, Psychometric Performance and Subjective Parameters, Relative to Placebo}

\begin{abstract}
The acute and subchronic effects of moclobemide and mianserin on driving and psychometric performance were compared to those of placebo in a double blind, crossover study involving 17 healthy volunteers. Mianserin (10 mg t.i.d), moclobemide (200 $\mathrm{mg}$ b.i.d) and placebo were administered according to a fixed schedule for eight consecutive days. Subjects" performance was measured on the $1^{\text {st }}$ and $8^{\text {th }}$ day of each treatment series. In addition, subjective sleep parameters, mood, and possible side effects were recorded each treatment day on questionnaires or visual analog scales. The results were highly consistent. Mianserin affected most of the performance measures while moclobemide affected none. Mianserin impaired driving and tracking performance and decreased CFF. Throughout its administration, subjects reported depressed levels of alertness, calmness and contentment. Sleep quality was unaffected, but sleep duration increased together with feelings of drowsiness and fatigue over the day. No statistical interactions between the factors Drugs and (Treatment) Days were found, indicating that little pharmacological tolerance developed over time during mianserin treatment. Mianserin's sedative properties are held responsible for all performance and subjective effects of the drug. Because moclobemide produced none of these effects it is concluded that this drug has no important sedative properties after twice daily administration of $200 \mathrm{mg}$.
\end{abstract}

JG Ramaekers, HF Swijgman, JF O'Hanlon. Psychopharmacology 106: s62-s67, 1992 


\section{INTRODUCTION}

After the introduction of irreversible monoamine oxidase inhibitors (MAOIs) for the treatment of depression in the late 1950s, the drug's popularity waxed and waned. One reason why psychiatrists were reluctant to prescribe MAOIs came from the recognition that they could potentiate the pressor effects of many exogenous amines, most notably tyramine. Without severe dietary restriction, patients treated with MAOIs could ingest tyramine-rich foods to provoke a hypertensive crisis. Still many psychiatrists, particularly in the UK, continued to prescribe MAOIs as first-line therapy for atypical depression (Paykel and White, 1989). While they did, the search continued for similarly acting drugs that could be used in greater safety. The breakthrough came when Johnson (1968) identified two MAO subtypes, now known as MAO-A and MAO-B, the former preferentially deaminates NA and 5-HT, and the latter, all nonpolar amines. Tyramine can be deaminated by either subtype so a drug which selectively inhibits MAO-A should be therapeutically effective without provoking a hypertensive crisis.

The first selective and reversible MAO-A inhibitor was moclobemide. As predicted, it is an efficacious antidepressant (Casacchia et al., 1985). Clinical trials have shown that it is also well tolerated causing few side-effects when given in doses up to about $600 \mathrm{mg} /$ day. Very importantly, moclobemide shows little tendency to potentiate the tyramine pressor reaction (Da Prada et al., 1988; Gieschke et al., 1988).

Initial indications from tolerability trials were that single doses below $200 \mathrm{mg}$ produce mild stimulation, and higher doses, sedation, which becomes marked above $900 \mathrm{mg}$ (Thieme, 1986; Breuel et al., 1988). Wesnes et al. (1989) summarized the results of two studies, respectively conducted with young and elderly healthy volunteers. In the first, a single dose of moclobemide $400 \mathrm{mg}$ reversed memory and cholce reaction time impairments occurring in a scopolamine $(0.7 \mathrm{mg} \mathrm{s.c}$.) challenge test. In the second study, moclobemide 100 and $300 \mathrm{mg}$ along with trazodone $100 \mathrm{mg}$ and placebo were separately given to two groups who were also respectively treated with ethanol $(0.5 \mathrm{~g} / \mathrm{kg})$ or a placebo drink. Trazodone consistently impaired performance in a number of psychomotor cognitive and postural steadiness tests for up to 6 hours after administration. Its effects were similar in both groups. In contrast, moclobemide had mixed effects which were neither large, nor dose-dependent, nor affected by the presence of ethanol. Both doses impaired vigilance but improved 
memory and choice reaction time performance relatwe to placebo. The possibility that noclobemide might affect performance after multiple dosing was investigated by Berin et al. (1990). They found wo differences between healthy volunteers" pertomance as measured in a battery of psychomotor tests taken after moclobemide $(200 \mathrm{mg}$ ti, $\mathrm{h}$ ) and placebo series lasting 5 days. When ethanol $(0.6 \mathrm{~g} / \mathrm{Kg}$ ) was given on the final freatment day, its adverse performance effects were slightly less following mochobemide than placebo.

These findings indicate that moclobenide, given in single or nultiple doses up to $600 \mathrm{mg} / \mathrm{day}$, has litte effect on perfomance. However there have been indications that the drug might possess both stimulating or sedating CNS activities which can occasionaly improve or degrade perfomance depending on the dose, duration of dosing or the experimental procedures exployed for measuring the effect. Primarily because wone of those testing procedures were conducted in a realunfe sething there remains some uncertainty whether practical behavioral abilites would be afected by the drug, and if $s o$, how.

A standara test of actual automoble dring perfomance has been developed to dispel uncertainties conceming the protical relevance of drug effects (OHanton et al. 1986). It was appled in the present study to meastare the acute and subchronic effects of moclobemide given according to a dosing regimen often used for initiating antidepressant therapy (i.e. $200 \mathrm{mg}$ b.i.d.). Manserin $30 \mathrm{mg}$ b.id. was selected as the active drug control for its known sedative and performance imparing properties (Mathla et al. 1978; Hindmarch and Subhan, 1986; Lowwerens et al., 1986). As such it fulfills the usual criteria for a verum to establish test sensitivity for sedating if not stimulating drug effects.

\section{MATERIAL AND METHODS}

Study design.

Drugs and placebo were administered in separate 8 day series according to a doubleblind, balanced, 3-way, cross-over design. A minimum of 13 days transpired between the end of one series and the beginning of the next. 


\section{Subjects and drug administration.}

Eighteen healthy volunteers, equally comprised of men and women between 26 and 5.4 years of age, were recruited as subjects. All were licenced drivers who owned and operated a vehicle for at least $8,000 \mathrm{~km} / \mathrm{yr}$ during the previous five years. All agreed to refrain from taking any form of medication, except oral contraceptives, during the period when they participated in the study. Exclusion criteria included the following: arterial hypertension, ECG abnormalities, body weight $15 \%$ outside of the population norms, history of alcohol or drug abuse, chronic or severe cardiovascular, respiratory, hepatatic, sleep, psychiatric or neurological disorders, excessive smoking and any known drug allergies.

Placebo and drugs were administered in identically appearing capsules. Dailly doses of moclobemide and mianserin were $200 \mathrm{mg}$ b.i.d and $10 \mathrm{mg}$ t.i.d., respectively. Subjects followed a fixed dosage regimen during eight consecutive days. The first dosing occurred at $07: 30 \mathrm{~h}, 08: 45 \mathrm{~h}$ or $10: 00 \mathrm{~h}$ for respective thirds of the group. Relative to the first doses, the second and third doses were taken $5 \mathrm{~h}$ and $10 \mathrm{~h}$ later. Moclobemide was given in the $1^{\text {st }}$ and $3^{\text {rd }}$ daily doses, and mianserin in all three.

\section{Testing procedures.}

Several procedures were used to assess drug and placebo effects. Laboratory psychometric testing, followed by a driving test, began $1 \mathrm{~h}$ and $2.5 \mathrm{~h}$ after the $3^{\text {rd }}$ dose on both the first and last days in each series. The separate testing phases lasted about one hour apiece. Furthermore, subjects kept a daily log of their sleep quality and its estimated duration in the mornings and side-effects and mood in the evenings by completing questionnaires every day in each series. Prior to the application of treatments, subjects were individually trained to a predefined level in each psychometric test. They also undertook a complete "dress rehearsal" of the standard driving test.

\section{Driving rest.}

The test has been fully described in prior publications (e.g. O'Hanlon et al., 1986). The subject's task is to operate a specially instrumented vehicle (Volvo station wagon) over a $100 \mathrm{~km}$ primary highway circuit while maintaining a constant speed $(95 \mathrm{~km} / \mathrm{h})$ and steady lateral position between the delineated boundaries of the right (slower) traffic lane. He or she is only allowed to deviate from this procedure in order to overtake a 
slower vehicle travelling in the same direction. Instrumentation aboard the velicle permits the continuous measurement of its steering wheel movement, heading angle, speed and lateral position relative to lane-line delineation. Two experimenters accompany the subject. One, a licenced driving instructor, is charged with responsibility for ensuring safety at all times. From his position in the front passenger seat he is able to observe the subject and his/her performance and to intervene, if necessary, using redundant vehicular controls. The other, seated in the right rear passenger's seat monitors the apparatus using a computer terminal. Analog voltage signals from the sensor systems are sampled at a rate of $4 \mathrm{~Hz}$ and stored on a computer (IBM AT) floppy disk file. Those computer recordings are later edited to remove data collected during overtaking maneuvers or disturbances caused by roadway or traffic situations.

The primary dependent variables are standard deviation of lateral position (SDLP) and time to line crossing (TLC). SDLP is an index of 'weaving' amplitude. It measures continuous road tracking error during uninterrupted high speed travel on a motorway. TLC continuously measures the time remaining before the vehicle would depart from the traffic lane along it's present tangent if the driver were to take no corrective action. The $15^{\text {th }}$ percentile TLC value $\left(\mathrm{TLC}_{15}\right)$, averaged over both left and right distributions, is taken as the performance measure. Both SDLP and TLC 15 are recorded over successive $10 \mathrm{~km}$ segments of the ride and over the entire test.

\section{Psychometric Tests}

Critical Fusion Frequency (CFF) is measured using a novel combination of the psychophysical Methods of Limits and Successive Approximations in a computercontrolled system. The subject is seated looking into a visual tunnel that displays a white light source in Maxwellian perspective. To begin, the computer alternatively increases and decreases the source flicker frequency (1:1 light/dark ratio) and the subject responds by pressing separate buttons whenever perception changes from one state to the other. After three complete cycles the approximate location of the subject's CFF is defined according to the Method of Limits. At that point the program identifies three frequencies in $1 \mathrm{~Hz}$ steps above, and three below the suspected threshold. Each of the six stimuli are shown five times im separate, randomized presentations lasting $3 \mathrm{sec}$ apiece. The subject is instructed to withhold responding during the presentation period and then give one of two responses indicating the perception of flicker or fusion. The proportion of each type of response are used to calculate intersecting linear functions 
in the frequency domain. The equal probability point where the functions intersect defines CFF with an accuracy of $0.2 \mathrm{~Hz}$.

The critical tracking test (CTT) was developed by Jex et al. (1966). It measures the subjects' ability to control a displayed error signal using a joystick in a $1^{\text {st }}$ order compensatory tracking task. Error is shown as the horizontal deviation of a cursor from the midpoint of a linear scale. As the task progresses the velocity of the cursor's deviations increase. The subject's compensatory responses increase in frequency with an increasing phase lag. Control is lost at the point where the compensatory response lags the cursor's last movement by $180^{\circ}$. The response frequency at this point is defined as the "critical frequency" or lambda-c.

In Moskowitz" (1973) divided attention task (DAT), the subject performs a combination of two tasks simultaneously for a period of 12 minutes. The primary task resembles the tracking task as described above, except that the difficulty level is adjusted to a level of $50 \%$ of the particular individual's maximum ability. Tracking error is measured as the difference in $\mathrm{mm}$ between the position of the cursor and the midpoint of the scale. The absolute mean tracking error over the entire test is taken as the final score in this subtask. The secondary task is to monitor each of the 24 peripheral LED displays showing the numerals $0-9$ and react to the appearance of the target, " 2 ", by removing the foot from a pedal. Numerals change asynchronously on all displays at intervals of 5 seconds. Inter-target times vary randomly between 5 and 25 seconds. Mean reaction time is recorded as a measure of performance on this subtask.

In Eriksen and Eriksen's (1974) response competition task (RCT), the subject is required to react by deflecting a joystick as quickly as possible after the appearance of any one of four possible target letters (e.g C, S, K, H) on a display. Two of them ( $\mathrm{H}$ and $\mathrm{K}$ ) require a leftward movement and the other two ( $\mathrm{S}$ and $\mathrm{C}$ ), the opposite. The target letter is either presented alone or flanked on each side by pairs of other letters on separate trials. Relative to the target, flanking letters can either be redundant, perceptually conflicting or creating a response conflict. Redundant flanking letters are the same as the stimulus letter (e.g. HHHHH) and often facilitate response speed. Perceptually conflicting flankers differ from the target in form but not with respect to eliciting an opposing response (e.g. SSCSS). The usual delay in responding is attributable to an additional requirement for perceiving the compatibility of adjacent letters. Finally, response conflict occurs when the flankers differ in form and also elicit an opposing response (e.g. SSHSS). The further delay in responding is attributable to 
he ine required for perceiving the incompatbiny of the abracent laters and inhibung the competing response. In total, 384 stmmus patems are presented, equaly comprised of all types, at a rate of 2 sec. These are partinoned in hve blocks with 30 sec rest pauses between them. Dependent waribo in this task are mean reachion thes to each stimutus ype.

The choice reaction time rask (CRT) is based on Stermberg"s (1969) memory search paradigm. The subject is intally shown a set of 1,2 of 4 leters on a display and told to memorize them. Series of 90 separde leters we presented after each memory set at intervals of $2 \mathrm{sec}$. Afer each presentation the subject decides whether or not the presented letter was contwined in the memory set, and responds as ancky and accurately as possible using comesponding push-buttons. The sequence of displayed letters contains equal numbers of members and non-members of the menory set, in random order. Dependent wartables were mean reaction times tor both "yes" and "no" responses and frequencies of incomect responses after each memory set.

\section{Subjecive assessments}

Subjects were required to complete a standard chmol sleep quality questionntre Mulder-Hajonides van der Meulen, 1981) and estimate its lotal duration every morning, immediately after aring from bed. At the end of the day they were required to indicate the occurrence and severty of possible side-effects - drowsiness, weakness, headache, fatgue, nervousness, nausea, dizziness and memory disturbances - on separate 10 on visual-analog scales. These were bounded by the descriptive tems, non-existent and intolerable. Mood was assessed using Bond and Lader's (1974) series of 16 visual analog mood scales. The authors' procedure was followed for deriving three statistically independent scores for measuring mood on respective alertness, calmness and contentment scalles.

\section{Statistical analysis}

With two exceptions, dependent variables were tested for the main effects and interactions of Drugs, Days and Gender using the same $3 \times 2$ (or 8 ) 2 mixed-model, multivariate analysis of variance (MANOVA, Norusis 1986). Exceptions occurred for variables measured in CRT and RCT where memory set size(x3) and response category $(x 4)$ constituted additional repeated-measures dimensions in respective MANOVA analyses. Detection of a significant $(\mathrm{p}<05)$ overall Drugs effect was 
followed by application of the Newman-Keuls à posteriori test for making separate drug-placebo mean comparisons.

\section{RESULTS}

One subject refused further participation in the study after experiencing unpleasant effects on her first day in the mianserin series. Her results were not included in the analysis. The Gender factor had no significant influence on any variable and for that reason is not mentioned again in this section.

\section{Driving perfornance}

Six rides were stopped prematurely by the driving instructor when he judged that the subjects were becoming too drowsy to safely continue. In five cases this occurred during mianserin treatment; four on Day $\mathbb{I}$ when the respective rides were $40,50,62$ and $50 \%$ complete and once on Day 8 when the ride was $35 \%$ complete. The other case occurred on Day 1 during placebo treatment when the ride was $85 \%$ complete.

Figures $1 \mathrm{a}$ and $\mathrm{lb}$ show mean SDLP as a function of distance driven in each condition on, respectively, the $1^{\text {st }}$ and $8^{\text {th }}$ treatment days. Higher values indicating poorer performance were always found in the mianserin condition. The mean differences were generally least at the beginning of the test but increased until the occurrence of the mid-ride turning maneuver. Thereupon performance improved somewhat in the mianserin condition but less in either of the others. The mean SDLP levels more or less stabilized for the remainder of the ride in moclobemide and placebo conditions but achieved new heights of impairment in the mianserin condition. One final aspect of these data is noteworthy. On Day 1 there was an indication that subjects actually drove better after moclobemide than placebo.

It is difficult and probably superfluous in this case to analyze changes in SDLP occurring over the course of the driving. The analysis of total test scores including all of the available data from every test provided a clear indication of differential treatment effects. There was a significant overall Drugs effect $\left(\mathbb{F}_{2.14}=17.78 ; p<.001\right)$. There was an overall effect of Days $\left(\mathrm{F}_{1,15}=6.18 ; \mathrm{p}<.025\right)$ but not of Drugs $x$ Days. Newman-Keuls tests show that the mean mianserin-placebo difference was significant $\left(q_{2,24}=8.25 ; p<.01\right)$ and that the moclobemide-placebo difference was not. 

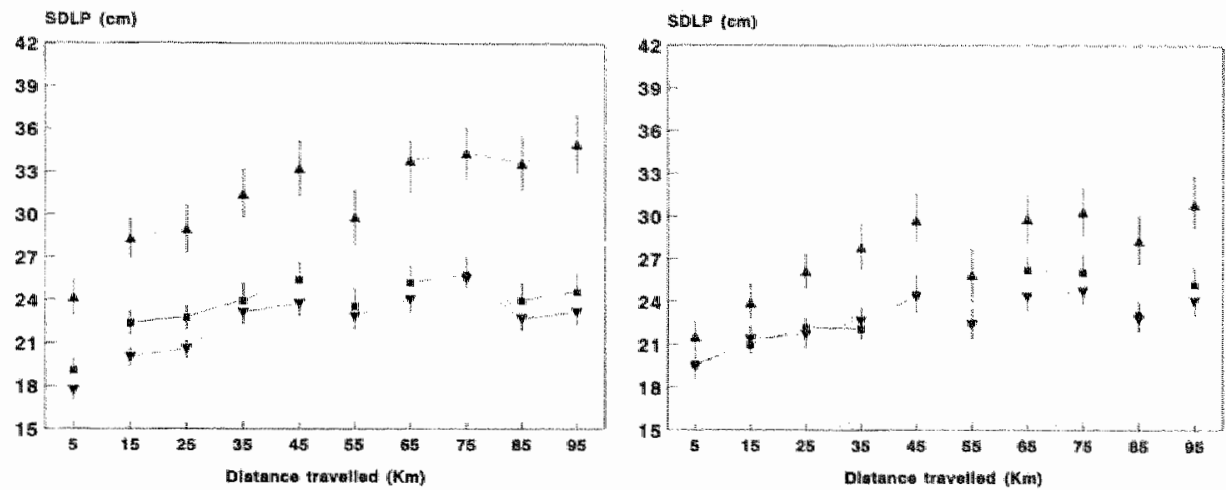

Figure 1 Mean SDLP ( $\pm S E$ ) as a function of distance travelled in each condition on the $f^{\text {st }}$ (left panel) and the $8^{\text {th }}$ (right panel) treatmentay. The functions are broken down at mid-test where the subjects recersed their direction of travel. Treatment are indicated as follows:

- placebo. Tmoclobemide, 4 mianserin.

$\mathrm{TLC}_{15}$, measured over the entire test, was not significantly affected by either factor or their interaction.

\section{Psychametric tests}

There were significant overall effects of Drugs on both $\mathrm{CFF}\left(\mathrm{F}_{2,14}=5.25 ; \mathrm{p}<.02\right)$ and $\mathrm{CTT}\left(\mathrm{F}_{2,14}=4.33 ; \mathrm{p}<034\right)$. No significant Days effect or Drugs $x$ Days interaction was found for lambda-c. CFF differed between days $\left(F_{1_{1} 15}=8.81 ; p<.01\right)$ but independently of Drugs. Separate drug-placebo comparisons revealed that mianserin affected CFF $\left.\left(q_{3,24}=5.28 ; \mathrm{p}<.01\right)\right)$ as well as lambda-c $\left(\mathrm{q}_{3,24}=4.40 ; \mathrm{p}<.05\right)$, while moclobemide affected neither. Figures 2 and 3 show mean CFF and lambda $\mathrm{c}$ values on both test days in every condition.

Tracking and reaction time scores from the DAT were similarly affected by treatments: both variables were significantly affected by Drugs $\left(\mathrm{F}_{2,14}=5.71\right.$ and 6.38 , respectively; $\mathrm{p}<.02)$, and Days $\left(F_{1.15}=10.60,16.91 ; \mathrm{p}<.005\right.$, respectively). Drugs $\mathrm{x}$ Days effects were not significant. Newman-Keuls tests revealed significant mianserinplacebo differences for both measures $\left(q_{3.24}=5.56,4.80\right.$, respectively; $\left.p<.01\right)$ but for neither in moclobemide-placebo comparisons.

Reaction times varied in the CRT and RCT in the expected manner, increasing in the former with memory set size, and in the latter with perceptual incompatibility and response conflict. Nonetheless Drugs failed to significantly affect reaction times 


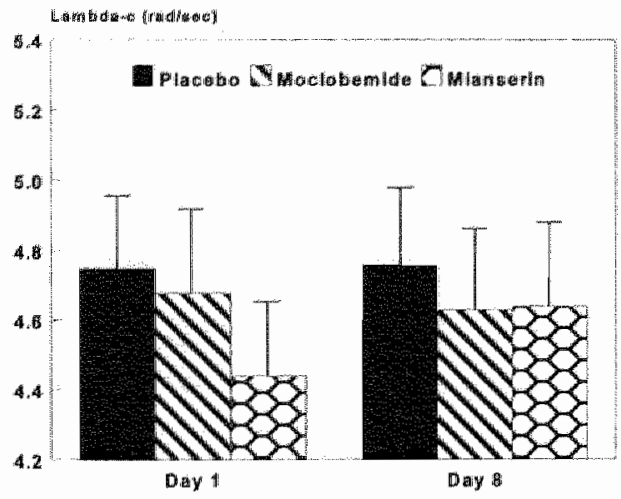

Figure 3. Mean ( 1 SE) Lambda-c in each treatment condition on treatment days 1 and 8 .

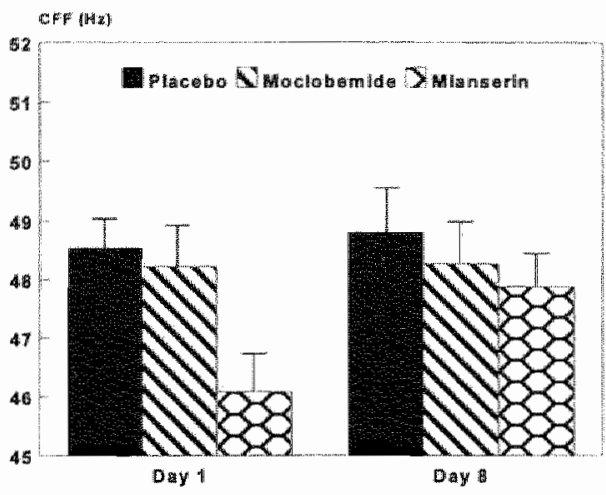

Figure 4. Mean (ISE) CFF in each treatment condition on treatment days 1 and 8.

differentially between stimulus categories or over all categories combined. The effect of Days was significant in both cases $\left(F_{1,15}=10.55,12.24\right.$, respectively; $\left.p<.005\right)$ but this factor failed to interact with Drugs in producing a significant interactive effect.

\section{Subjective assessments}

There was an overall effect of Drugs on estimated sleep duration $\left(\mathrm{F}_{2,14}=5.99 ; \mathrm{p}<.012\right)$. Yet sleep quality did not differ significantly among treatment conditions. There were no significant effects of Days or Drugs $x$ Days on either sleep measure. In general, the

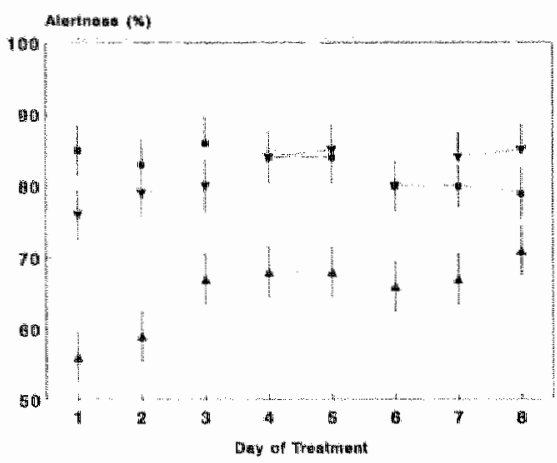

Figure 4. Mean ( $($ SE) alerthess score as a function of treatment days. For symbols see legend of Fig 1 . subjects reported sleeping an average of about $8.0 \mathrm{~h} /$ might throughout the week of mianserin treatment and about $7.5 \mathrm{~h}$ in each of the other conditions. The separately tested mianserin-placebo difference was significant $\left(\mathrm{q}_{2.24}=4.75 ; \mathrm{p}<.01\right)$.

The three derived scores from the Bond and Lader questionnaire, alertness, contentment and calmness were all significantly affected by Drugs $\left(\mathrm{F}_{2.14}=11.20\right.$, 8.18 and $6.80 ; p<.008)$. Again there was no significant Drugs $x$ Days interactive effect. 
A posteriori comparisons showed similar effects of mianserin relative to placebo. That drug caused the subjects to feel less alert $\left(\mathrm{q}_{3,24}=7.41 ; \mathrm{p}<.01\right)$, less content $\left(q_{3.24}=4.97 ; p<.01\right)$ and less calm $\left(q_{3.24}=4.31 ; p<.05\right)$. Maclobemide was uniformly without significant effect. Mean trends for alertness scores over days in each condition are shown in Figure 4. Those for the other scores were similar.

Drowsiness, fatigue and weakness were side-effects which discriminated significantly between conditions (Drugs: $F_{2,14}=9.24,9.90$ and $5.73 ; p<.014$ ). The subjects reported these as more prevalent/severe in the mianserin as compared to the placebo condition $\left(\mathrm{q}_{3.24}=6.72,6.24,9.05 ; \mathrm{p}<.01\right)$. There was no significant difference between reported side-effects in the moclobemide and placebo conditions.

\section{DISCUSSION}

The major purpose of this study was to determine whether moclobemide $200 \mathrm{mg}$ b.i.d. has any extra-therapeutic behavioral effects that might adversely affect the safety of skilled performance. The clearest evidence that the drug has none came from the driving test: the subjects' performance after moclobemide was not significantly different from that following placebo. Moreover, this result was supported by others obtained in the psychometric tests and from questionnaires concerning sleep, mood and side-effects. In general, moclobemide failed to significantly affect the subjects' performance or subjective assessments.

Two limitations of the study must be recognized before drawing the conclusion that moclobemide would always be free from untoward behavioral side-effects. First, the administered daily dose was only $2 / 3$ of the maximum recommended for treating depressed patients. The total absence of any moclobemide effect in the present study is therefore an encouraging indication, but no guarantee, that impairment would not emerge after higher doses within the drug"s therapeutic range. Secondly, the tests employed in this study, like all of those used in psychopharmacological research, are primarily sensitive to that constellation of reactions categorized as "sedative drug effects". As mentioned, there have been vague suggestions that moclobemide can be stimulating as well as sedative. There was no statistical evidence in the present study for a typical stimulant's effect on performance, mood or sleep. But if moclobemide possesses very mild stimulatory activity, it could have gone undetected. 
Mianserin consistently impaired the subjects' performance and altered their mood in ways anticipated from previous research. The CFF and CTT results provided confirmation of repeated observations that this drug generally impairs perceptual and motor functions, at least for the first few days of continual medication (Seppälä 1977; Curran and Lader, 1986). The drug's severely impairing influence on the subjects' $1^{\text {st }}$ day driving performance was also a close replication of healthy volunteers' reactions in the same test during a previous study (Louwerens et al., 1986). Mianserin's acute effects on SDLP were approximately the same as those of both doxepin and amitriptyline (divided $75 \mathrm{mg}$ daily doses) measured in similarly designed, subchronic studies (Schoenmakers et al., 1989; Robbe et al., 1989).

Yet the present study failed to confirm previous results indicating that mianserin's impairing effects gradually diminish to the point of complete tolerance after a week on medication (Curran and Lader op cit; Mattila et al., 1978). Tolerance was seen there in results obtained with the CFF and CTT but never enough to produce a significant Drugs $x$ Days interaction. Even less change in SDLP was found between driving tests conducted on the $1^{\text {st }}$ and $8^{\text {th }}$ days of mianserin medication. Lack of developing tolerance was also apparent from a more or less stable depression in the subjects' mood over the same period. The persistence of mianserin effects in this study was in sharp contrast to the diminution of tricyclic effects on SDLP and various unpleasant feelings that occurred over eight days in the studies cited above. There, nearly complete tolerance occurred within eight days, here it did not.

A final methodological point can be made in conjunction with the unusual persistence of mianserin's effect on SDLP. Sanders (1986) criticized the typical test battery approach for assessing drug effects because relatively brief tests preclude measuring drug by time-on-task interactions. One can easily imagine many practical activities where people perform the same activity for prolonged periods, sometimes with diminishing proficiency due to fatigue, boredom or wandering attention. It seems practically important to determine when a drug enhances a tendency toward poorer performance. Apparently mianserin did enhance this tendency in the present study. Though there was a difference between the subjects' mean SDLP in drug and placebo conditions from the beginning of the test, it increased as a function of time and more so on the $8^{\text {th }}$ treatment day than on the $1^{\text {st }}$. These results seem to justify Sanders" criticism and should be taken to indicate the wisdom of assessing drug effects in prolonged performance tests. 


\section{References}

Berlin 1, Coumot A, Zimmer R, Pedarmosse AM, Manfredi R, Molinier P, Pucch AJ (1990) Evaluation and comparison of the interaction between alcohol and noclobemide or clomipramine in healthy subjects. Psychopharmacology 100:40-45

Bond $\mathrm{A}$, Lader $\mathrm{M}$ (1974) The use of analogue scales in rating subjective feelings. Br. I Med Psychol $47: 211-218$

Breuel HP, Zimmer R (1988) Multiple dose tolerability and pharmacodynanics of moclobemide (Ro 11-1163) in healthy woltunteers. Roche Research Report No. B-116305

Casacchia M, Carolei A. Barba C, Frontini M, Rossi A, Meco G, Zylberman MR (1984) A placebo controlled study of the antidepressant activity of moclobemide; a new MAO-A inhibitor. Pharmacopsychiatry 17:122-125

Curran HV, Lader M (1986) The Psychopharmacological Effects of Repeated Doses of Fluvoxamine, Mianserin and Placebo in Healthy Human Subjects. Eur J Clin Phamacol 29:601-607

Da Prada $M$, Zürcher $G$, Wutrich I, Haefely WE (1988) On tyramine, food, beverages and the reversible monoamine oxidase inhibitor moclobemide. J Neural Transm 26:53 1-S56

Eriksen BA, Eriksen CW (1974) Effects of noise letters upon the identification of a target letter in a non-series task. Perception and Psychotropics 16:143-149

Gieschke R, Schmid-Burgk W, Amrein R (1988) Interaction of moclobemide, a new rewersible monoamine oxidase inhibitor with oral tyramime. J NeuralTransmis 26:S97-S104

Hindmarch 1 , Subhan $Z$ (1986) The effects of antidepressants taken with and without alcohol on information processing, psychometric performance and car handling. In: O'Hanlon $\mathrm{JF}$, De Gier JJ (eds) Drugs and Driving. Taylor and Francis, London

Jex HR, McDonnel JD, Phatak AV (1966) Critjcal tracking task for manual control research. IEEE Trans Hum Fac En 7:138-146

Johnson JP (1968) Some observations upon a new inhibitor of monoamine oxidase in brain tissues. Biol PharmacoL 17:1285-1289

Louwerens JW, Brookhuis KA, OHanlon JF (1986) Several antidepressants' acute effects upon actual driving performance and subjective mental activation. In: OHanlon $\mathrm{JF}^{\circ}$, De Gier JJ (eds) Drugs and Driving. Taylor and Francis, London

Mattilla MJ, Liljequist R, Seppälä T (1978) Effects of amitriptyline and mianserin on psychomotor skills and memory. Brit J Clin Pharmacol suppl 5:53-59

Moskowitz H (1973) Laboratory studies of the effects of alcohol on some variables related to driving. J Safety Research 5:185-192

Mulder-Hajonides van der Meulen WREH (1981) Measurements of subjective sleep quality. Proceedings of International European Sleep Congress, Elsevier, Amsterdam

Norusis MJ (1986) SPSS/PC + Advanced Statistics. MoGraw-Hill, New York

OHanlon JE, Brookhuis KA, Louwerens. JW, Volkerts ER (1986) Performance testing as part of drug registration. In: Offlanlon JF, De Gier JJ (eds) Drugs and Driving, Taylor and Francis, London

Paykel ES, White IL (1989) A curopean study of views on the use of monoamine oxidase inhibitors. Br J Psychiatry 155:9-17

Robbe HWJ, Schoenmakers EAJM, OHanlon JF (1989) Paroxetime and amitriptylineacute and subchronic effects on psychomotor and actual driving performance performance. Institute for Drugs, Safety and Behavior, Technical Report 89-04

Sanders AF (1986) Drugs, driving and the measurement of human performance. In: OHanlon JF, De Gier JJ (eds) Drugs and Driving, Taylor and Francis, London

Schoenmakers EAJM, Robbe HWJ, OHanion JF (1988) Acute and subchronic effects of the antidepressants levoprotiline and doxepin on the performance of healthy volunteers in 
psychometric and actual driving tests. Institute for Drugs, Safety and Behawior, Technical Report 88-03

Seppala $T$ (1977) Psychomotor skills during acute and two-week treatment with miasierin (Org GB 94) and amitriptyline, and their combined effects with alcohol. Annals Clin Research 9:66-72 Sternberg $\$$ (1969) Memory scaning: mental processes revealed by reaction time experiments. Am Scientist 57:421-457

Thieme (1986) Tolerability of moclobemide (Ro 114163 ) with ascending single oral doses in healthy male volunters. Roche Research Report No. B-113'883

Wesnes KA, Simpson PM, Christmas $L$, Anand $R$, McClelland GR (1989) The effects of moclobemide on cognition. I Neural Transm 28:91-102 


\title{
CHAPTER 4
}

\section{A Comparative study of acute and subchronic effects of dothiepin, fluoxetine and placebo on psychomotor and actual driving performance}

\begin{abstract}
The acute and subchronic effects of dothiepin $75 / 150 \mathrm{mg}$ and fluoxetine $20 \mathrm{mg}$ on critical fusion frequency (CFF), sustained attention and actual driving performance were compared to those of placebo in a double-blind, cross-over study involving 18 healthy volunteers. Drugs and placebo were administered for 22 days in evening doses. Fluoxetine doses were constant but dothiepin doses increased on the evening of day 8 . Performance was assessed on days 1, 8 and 22 of each treatment series. Subjective sleep parameters and possible side effects were reconded on visual analogue scales on alternate treatment days. Dothiepin reduced sustained attention on day 1 by $6.67 \%$ and CFF on day 22 by $1.13 \mathrm{~Hz}$. Fluoxetine reduced sustained attention days 1,8 and 22 of treatment by $7.41,6.67$ and $6.48 \%$ respectively. CFF decreased linearly over days during fluoxetine treatment and significantly differed from placebo on day 22 with $1.24 \mathrm{~Hz}$. Neither drug significantly affected driving perfomance. Whilst receiving dothiepin, subjects complained of drowsiness on days 1-3 of treatment and slept 43 min longer. After receiving fluoxetine, they reported dizziness, shakiness, nausea and concentration problems in the second or third week of treatment. Spontaneously reported adverse events resembled the side effects recorded on visual analogue scales but differed less between drug treatments. It is concluded that both drugs possess similar but apparently small potentials for impairing performance.
\end{abstract}

JG Ramaekers, ND Mantjewerf, JF O'Hanlon. Br. J Clin Phamac 39:397-404.1995 


\section{INTRODUCTION}

Dothiepin belongs to the group of tricyclic antidepressants (TCAs) that achieve their antidepressant efficacy through non-selective inhibition of monoamine uptake. TCAs are also antagonists of cholinergic, adrenergic and histaminergic receptors which may cause cognitive impaiment, postural hypotention and sedation. Fluoxetine belongs to a different class of antidepressant drugs, the selective serotonin reuptake inhibitors (SSRI). They increase the availability of serotonin in the synaptic cleft by inhibiting its neuronal reuptake. In clinical trials, SSRIs and TCAs have shown to possess similar antidepressant activities. SSRIs generally produce less side effects as compared to TCAs owing to a greater selectivity for serotonin. Consequently, SSRIs are generally regarded as behaviorally safe drugs, whereas TCAs are classified as impairing, particuJarly because of their sedative effects.

Though behavioral impairment depends primarily on the drug's intrinsic sedative activity, seen most clearly after initial doses, other factors such as phamacological tolerance and accumulation can influence its persistence with repeated dosing. Tolerance to antidepressants' sedative activity is generally recognized to diminish the acute impairing effects (Sepällä et al, 1975; Strömberg et al, 1988; Ramaekers et al, 1994). Accumulation occurs for most antidepressants when taken according to therapeutic dosing regimens. Dothiepin and its metabolite northiaden have elimination half lifes of 14-24 hand 34-45 h, respectively, and accumulate for two weeks before reaching steady state. Fluoxetine and its main metabolite norfluoxetine have elimination half lifes of $1-3$ and 7-15 days. With multiple doses the drug accumulates for 35 days (Farid et al, 1986). The possible influence of tolerance and accumulation on the immediate and late occurrence of side effects affecting performance should therefore not be ignored when comparing antidepressants' effects on performance.

Little information concerning the acute and long-term effects of dothiepin or fluoxetine was available prior to this study. Single doses of dothiepin $50 \mathrm{mg}$ impaired performance of healthy volunteers in several psychomotor and memory tests in one study (Allen et al, 1993) but not in another (Hindmarch, 1988). Several attempts have failed to show any impairing effects of fluoxetine 20 or $40 \mathrm{mg}$ on the performance of volunteers (Schaffler, 1989; Moskowitz et al, 1988). Multiple nightly doses of dothiepin, beginming at $75 \mathrm{mg}$ and increasing to $150 \mathrm{mg}$ after one week, generally had 
no effect on the performance of volunteers when measured on the $17^{\text {th }}$ day (Stille \& Herberg, 1989). They did however show a slight but significant impairment in a "concentration" test. Allen, Lader \& Curran (1988) administered a $40 \mathrm{mg}$ dose of fluoxetine to healthy volunteers each morning for one week. It had no effect in any of a battery of psychomotor and memory tests. Fairweather et al. (1993) reported that fluoxetine $20 \mathrm{mg}$ /day elevated elderly depressed patients' CFF, beginning after two weeks of therapy and continuing for the subsequent month. The comparative antidepressant amitriptyline $75 \mathrm{mg} /$ day, depressed CFF in a parallel group for two weeks, following which this measure returned to baseline. The difference in mean CFF between groups was always significant though their respective therapeutic responses were practically identical.

The current study was designed to measure and compare the acute and subchronic effects of dothiepin $75 / 150 \mathrm{mg}$ and fluoxetine $20 \mathrm{mg}$ on CFF, sustained attention and actual driving performance. Expectations based upon the studies mentioned above and similar studies with other TCAs and SSRIs (Seppällä et al, 1975; Ramaekers et al, 1994; Robbe et al, 1995; Kerr et al, 1991) were as follows. We hypothesized that dothiepin would cause mild impairment on day 1 , with attenuation of the effect on day 8 as a result of tolerance. The impairment on day 22 would be greater if drug accumulation was the determinating factor, and less if tolerance was the determining factor. We did not expect fluoxetine to cause impairment unless there was a hitherto unrecognized effect of accumulation of the parent drug or an active metabolite.

\section{MATERIAL AND METHODS}

\section{Subjects}

Eighteen healthy volunteers, 10 males and 8 females aged between $21-45$ years, were recruited by means of newspaper advertisements. Initial screening was accomplished on the basis of replies to a medical history/driving experience questionnaire. Qualified individuals were physically examined and blood samples and a standard 12-lead electrocardiogram were obtained from each one. Standard blood chemistry and haematology tests were conducted on these samples. All volunteers were licenced drivers who operated a vehicle for at least $5000 \mathrm{~km} / \mathrm{year}$ during the previous three 
years. Exclusion criteria included the following: history of psychotic illness or drug abuse including alcoholism, history of cardiovascular disease including recent myocardial infarction, heart block or other cardiac arrhytmias, history of allergy to tricyclics, renal, hepatic, sensory or neurological disease or a history of serious disorders of these types, woman of childbearing potential who were pregnant or lactating or failing to take medically acceptable contraceptive precautions, use of any psychoactive drug during the four weeks before entering the study, history of previous attempts at suicide.

The study was carried out in accordance with the World Medical Association's Declaration of Helsinki (Hong Kong Modification, 1989). It was approved by the standing Ethics Review Committee of the University of Limburg. Written informed consent was obtained from each subject prior to participation.

\section{Experimental design and drug administration}

Drugs and placebo were administered in separate 22-day series, according to a placebo controlled, 3-way, double-blind, cross-over design. Treatment orders were balanced and assigned to subjects by exhaustive random selection from six independent $3 \times 3$ Latin Squares. In the course of the three successive treatments, subjects' performance was tested after 1,8 and 22 days of treatment. A minimum of 35 days elapsed between the end of one treatment series and the beginning of the next.

Daily doses of dothiepin were $75 \mathrm{mg}$ during the first 8 treatment days and 150 $\mathrm{mg}$ from day $8 \mathrm{on}$. Fluoxetine was administed at a fixed daily dosage of $20 \mathrm{mg}$ during the 22 treatment days. Dosing started the evening before the first test day. Drugs and placebo were always ingested at $21: 30$ and 23:00 hours by respective halves of the subjects. Blood samples were collected on day 8,15 and 22 to determine mean plasma concentrations of both drugs by means of an HPCL method.

\section{Psychometric tests and driving}

Subjects were individually trained to perform both driving tests and two laboratory performance tests over the course of a single day before entering the study. At day 1, 8 and 22 of each treatment series, subjects undertook a sequence of performance tests scheduled at 12:00 $\mathrm{h}$ and $13: 30 \mathrm{~h}$ for respective halves of the group.

Critical Fusion Frequency (CFF) was measured in a computer-controlled system using a combination of the psychophysical Methods of Limits and Successive 
Approximations (Vuurman \& O'Hanlon, 1991). The subject was seated looking through an aperture of $2 \mathrm{~mm}$ (i.e "artificial pupil") into a visual tunnel that displayed a white light source in Maxwellian perspective. To begin, the computer alternatively increased and decreased the source flicker frequency (1:1 light/dark ratio) and the subject responded by pressing separate buttons whenever his perception changed from one state to the other. After three complete cycles, the approximate location of the subject's CFF was defined according to the Method of Limits. At that point, the programme identified two frequencies in $1 \mathrm{~Hz}$ steps above, two below and one at the suspected threshold. Each of the five stimuli were shown six times in separate, randomized presentations lasting $3 \mathrm{sec}$ each. The subject was instructed to withhold responding during the presentation period, and then give one of two responses indicating the perception of flicker or fusion. The proportions of each type of response were used to calculate intersecting linear functions in the frequency domain.

The Sustained Attention Test has been extensively used in studies on human vigilance performance (Mackworth, 1950). Subjects were seated in front of a computer screen displaying a circular arrangement of 60 dots simulating the second marks on a clock. Dots were briefly illuminated in clockwise rotation at a rate of one per second. Usually the rotation proceeded with a $6^{\circ}$ "jump". Subjects were instructed that at rare, irregullar intervals the target would proceed with a $12^{\circ}$ jump by skipping one of the dots in the normal sequence. This "double jump" was the signal to which subjects were required to respond by pressing a button. A response made within $4 \mathrm{sec}$ after the occurrence of a signal was registered as correct detection. A total of 30 signals were presented during the 45 minutes task. Ten signals occurred within each successive 15 minute period. The distribution of the intersignal intervals (ISI) was skewed. It contained more short intervals than long intervals, ranging from 8 sec to 7.20 minutes. Approximately 50 percent of the intervals fell in the range $8 \mathrm{sec}$ to $1 \mathrm{~min}, 25$ percent in the range 1 to $2 \mathrm{~min}, 15$ percent in the range 2-3 min and 10 percent in the range 3-7 min. The major dependent variables of the test were the number of Correct Detections (CD) and False Detections (FD). Because CD data were negatively and FD data positively skewed, they were subjected to conventional $\arcsin \left(\mathrm{X}^{\prime}=2 \arcsin \mathrm{X}^{0.5}\right)$ and logarithmic transformations, respectively, before entering statistical analyses.

The Highway Driving Test has been used for drug screening purposes in The Netherlands since 1981 (O'Hanlon et al, 1982). It was standardized the following year and has been applied in essentially the same manner ever since. The subject's task was 
relatively simple. He/she entered an 'actual' primary highway at the beginning of a 100 $\mathrm{km}$ circuit. He/she then proceeded to drive while attempting to maintain the vehicle at a constant speed $(95 \mathrm{~km})$ and steady lateral position between the delineated boundaries of the slower traffic lane. The subject was allowed to deviate from this procedure in order to pass slower vehicles traveling in the same lane. At an intersection halfway through the circuit, the subject drove off the highway and re-entered travelling in the opposite direction.

Lateral distance separating the vehicle and the left lane-line was continuously measured by an electro-optical device. Its signal was digitized at a rate of $4 \mathrm{~Hz}$ and stored on a computer disk for later editing and analysis. The off-line editing routine involved removal of all data segments that revealed signal loss, disturbance or the occurrence of passing manoeuvers. The primary measure is standard deviation of lateral position (SDLP). It measures continuous road tracking error during high speed travel on a highway.

The subject was accompanied by two investigators. A technician, whose task was to operate the equipment, was present in the rear passenger's seat. A licenced driving instructor was seated in the front passenger's seat with access to duplicate controls. His sole function was to ensure test safety. Subjects were informed that they would be asked to stop by the instructor if, in his opinion, their physical appearance or driving performance indicated the possibility of a control loss.

A preliminary version of the Car-Following Test was applied during a pilot study in 1985 (Brookhuis, 1985). The test begins with two vehicles traveling at 90 $\mathrm{km} / \mathrm{h}(56 \mathrm{mi} / \mathrm{h})$ in tandern separated by a distance of about $30 \mathrm{~m}$. The leading vehicle's speed was automatically controlled and the subject controlled the speed of the following vehicle. They were told to maintain an average headway of $30 \mathrm{~m}$ throughout the test. Furthermore they were informed to attend constantly to the leading vehicle since it might slow down then speed up at unpredictable times.

Headway was continuously measured by means of a DME 2000 optical distance sensor. The device was placed in the grill of the following vehicle and emitted laser signals in the direction of a reflection board that was mounted on the leading vehicle's towing bracket. Following emission, the laser signals were reflected from the board to the receiving end of the distance sensor. Distance was then deduced from the time lapse between transmission and receipt of the signal. 
Speed of the leading vehicle was automatically regulated by a modified "cruise control" system. It was activated by the investigator in the leading vehicle at the beginning of a test. In the initial phase and during intervals between manoeuvres the system maintained a constant speed of $90 \mathrm{~km} / \mathrm{h}$. To begin deceleration, the investigator activated a microprocessor that added to the speed signal which was interpreted by the cruise control as a deviation requiring a reduction in fuel flow. As the program continued, the microprocessor gradually ceased adding to the speed signal and began as gradually to subtract from it. When the vehicle's actual speed reached the desired minimum the process was reversed until the leading vehicle recovered its original speed whereupon the microprocessor again became quiescent. In this manner the vehicle's speed described a sine function over time within each manoeuvre, dropping from 90 to $70 \mathrm{~km} / \mathrm{h}$ and returning to $90 \mathrm{~km} / \mathrm{h}$ within $50 \mathrm{sec}$.

This manoeuvre was repeated five or six times. The entire test was conducted over a straight and levell $18 \mathrm{~km}$ section of a secondary highway. The velocity of the leading vehicle was transmitted via telemetry to the following vehicle and stored on a computer disk along with the following vehicle's own velocity and headway. Speed signals collected during manoeuvres entered a power spectral analysis for yielding phase-delay between the vehicle's velocities at the manoeuvre cycle frequency $(0.02$ $\mathrm{Hz}$ ). Phase-delay converted to a measure of the subject's average reaction time to the movements of the leading vehicle (RT), was then taken as the primary dependent variable from the car-following test. Headway $(\mathrm{H})$ and standard deviation of headway (SDH) during deceleration/acceleration maneuvers were taken as secondary dependent variables.

Subjective side effecis and sleep.

Side effects were measured on separate $100 \mathrm{~mm}$ visual analogue scales. The itenns included drowsiness, lack of concentration, memory disturbances, dizziness, nausea, weakness, headache, lack of coordination, nervousness and shakiness. Sleep was assessed using the Leeds Sleep Evaluation Questionnaire (Parrot \& Hindmarch, 1978). This questionnaire comprises a series of bipolar $100 \mathrm{~mm}$ visual analogue scale questions covering 4 aspects of sleep: ease of getting to sleep, quality of sleep, ease of awaking from sleep, and behavior following waking. Estimated sleep duration was recorded additionally. All questionnaires were completed following waking on alternate days of treatment. For analytical purposes they were later averaged over days 
1-3, 5-7,9-11, 13-15 and 17-21. All adverse events reported spontaneously by the subjects or in response to questioning were recorded in a CRF.

\section{Statistical methods}

All dependent variables of the CFF, sustained attention and both driving tests were tested for overall effects of Drugs and Days and Drugs $\times$ Days using repeated measures, multivariate analysis of variance (Norusis, 1986). Sustained attention was also tested for the effects of Time on task and Drugs $x$ Time on task. These were followed by uniwariate tests to compare treatment effects of dothiepin and fluoxetine with placebo.

Where the overall effect of Drugs or Drugs $x$ Days was significant ( $\leq \leq .05$ ), pairwise comparisons between drugs and placebo were performed using Fisher's protected LSD tests (one-tailed), to analyze differences on separate treatment days. In case of a significance, 1-tailed, 95\% confidence intervals (CI) of drug-placebo differences were calculated. If the overall Drugs $x$ Days interaction was significant, Roy-Bargman stepdown $\mathrm{F}$ tests were conducted to check for linear or quadratic trends over days.

Leeds Sleep Evaluation Questionnaire and subjective side effects were analyzed by means of the non-parametric Friedman test to detect an overall difference between treatments. These were followed by Wilcoxon's signed-rank test to compare the effects of drugs and placebo on separate treatment days. In contrast to Fisher"s LSD tests, the latter were performed independently of the significance level of the overall difference between treatments. We used these different methods because within treatment series, subjective assessments were made every other treatment day and laboratory and driving assessments only on treatment days 1,8 and 22. Because of the high number of observations, any overall test will accept $\mathrm{H}_{0}$ if most of these observation are equal, although real differences between a few pairs of treatments may exist. The hypothesized side effects of dothiepin and fluoxeine were expected either shortly after acute dosing or towards the end of the drugs" accumulation phase. If so, these could easily go undetected if the remaining observations caused the overall test to be nonsignificant. 


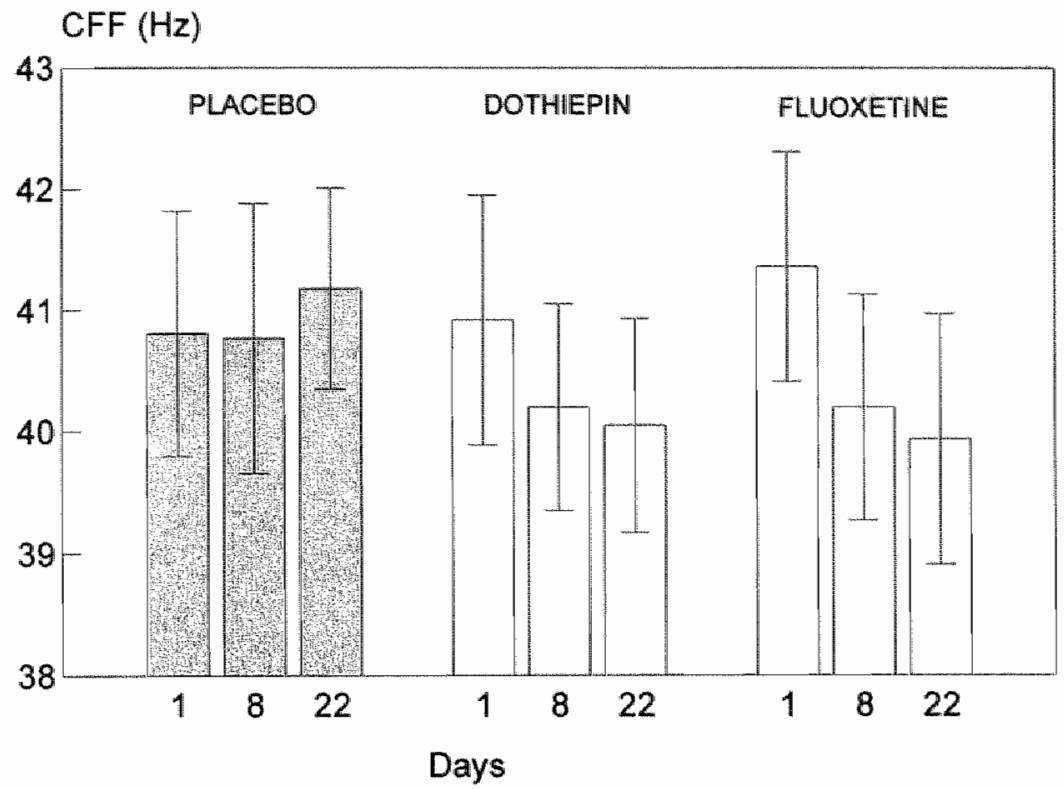

Figure 1 Mean (ESE) critical fusion frequency (CFF) in every treatmem condition on treatment days 1,8 and 22. On treatment days 8 and 22 mean (sd) plasma concentrations of dothiepin were 46.24 (52.48) and 71.70 (53.99) $\mu \mathrm{g}$ t respectively. Mean plasma (sd) concentrations of fuoxetine and norfluoxetine were respectively 34.47 (14.41) and 42.47 (17.47) $\mathrm{kg} \mathrm{l}^{\mathrm{t}}$ on day 8 and 57.83 (24.88) and 75.78 (28.29) $\mathrm{kg} \mathrm{l}^{\mathrm{l}}$ on day $22 \mathrm{of}$ reatment

\section{RESULTS}

$C F F$

Overall, mean CFF (Fig 1) values were not affected by the factors Drugs and Days. The interaction of Drugs $x$ Days was highly significant $\left(F_{4,9}=8.60, p=.004\right)$. Trend analysis showed a significant linear decrement of CEF during treatment with fluoxetine as compared to placebo $\left(F_{1,12}=5.02, p=.045\right)$. Separate comparisons between drug treatments and placebo showed no differences on day 1 and 8 . On day 22 both dothiepin and fluoxetine significantly decreased $\mathrm{CFF}$ by $1.13(\mathrm{CI}:-2.14$ to -.12$)$ and $1.24 \mathrm{~Hz}(\mathrm{Cl}:-2.25$ to -.23$)$ respectively $\left(t_{34}=1.83 \& 2.01 ; \mathrm{p}<.05\right)$. 


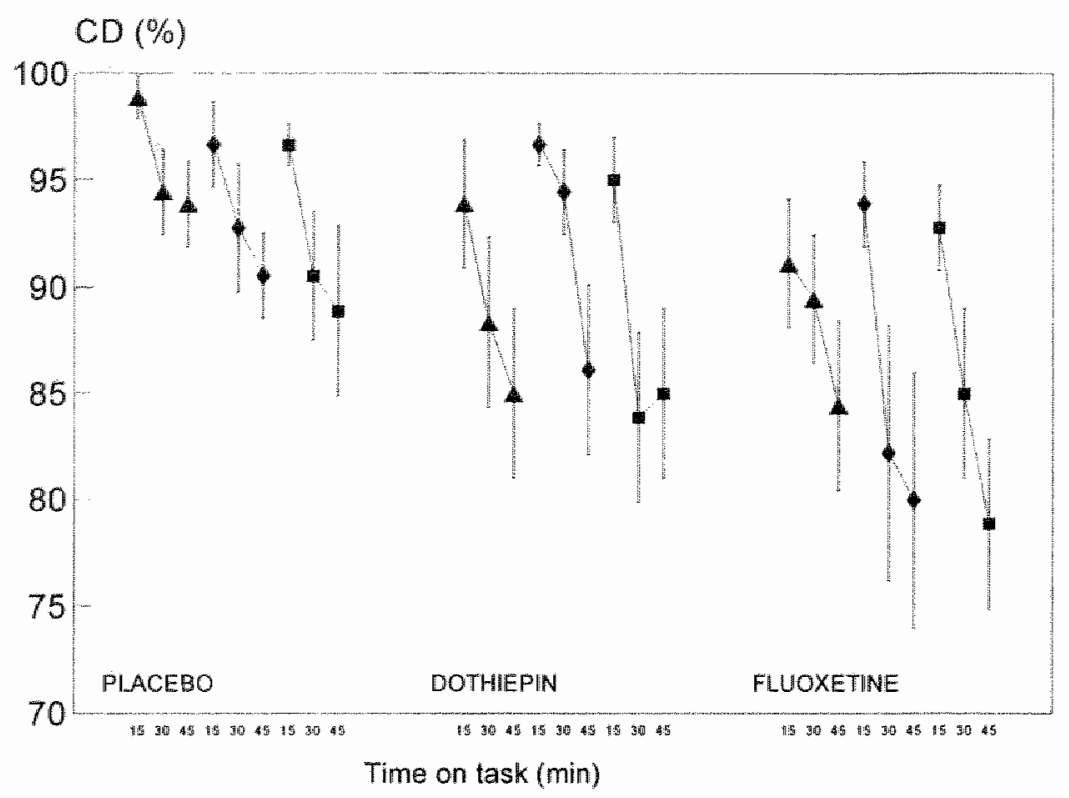

Figure 2 Mean ( $(S E)$ correct detections (CD) as a function of time on task on days 1 ( 4$), 8$ ( ) and $22(\boldsymbol{D})$ in every treatment condition. For mean plasma concentration see legend Fig 1

\section{Sustained Attention}

MANOVA showed that CD (Fig 2) was significantly affected by Drugs $\left(\mathrm{F}_{2,11}=4.22 ; \mathrm{p}\right.$ $=.044)$, Time on task $\left(F_{2,11}=p<.005\right)$ but not by Days and Drugs $x$ Days or Drugs $x$ Time on task. Univariate tests showed a significant main effect of fluoxetine on $C D$ $\left(\mathrm{F}_{1.12}=9.09 ; \mathrm{p}=.011\right)$ as compared to placebo. The effect of dothiepin approached significance $\left(F_{1,12}=3.51 ; p=.086\right)$. The effect of Time on task was significant during both treatments $\left(F_{2,11}=8.46 \& 11.05 ; p<.006\right)$. Since no effects of Drugs $x$ Time on task were found mean $\mathrm{CD}$ averaged over time were used for separate drug-placebo comparisons. They revealed that fluoxetine significantly decreased CD by 7.41 (CI: 11.33 to -3.56$), 6.67(\mathrm{Cl}:-14.27$ to -1.50$)$ and $6.48 \%(\mathrm{CI}:-9.45$ to -3.44$)$ on days 1,8

and 22 days of treatment respectively $\left(t_{34}=2.26 \& 3.11 \& 1.97\right.$, respectively; $\left.p<.05\right)$. Dothiepin significantly decreased CD after day $\mathbb{1}$ of treatment by $6.67 \%$ (CI: -11.96 to $-1.27, \mathrm{t}_{34}=2.54 ; \mathrm{p}<.05$ ). FD was not affected by any factor. 


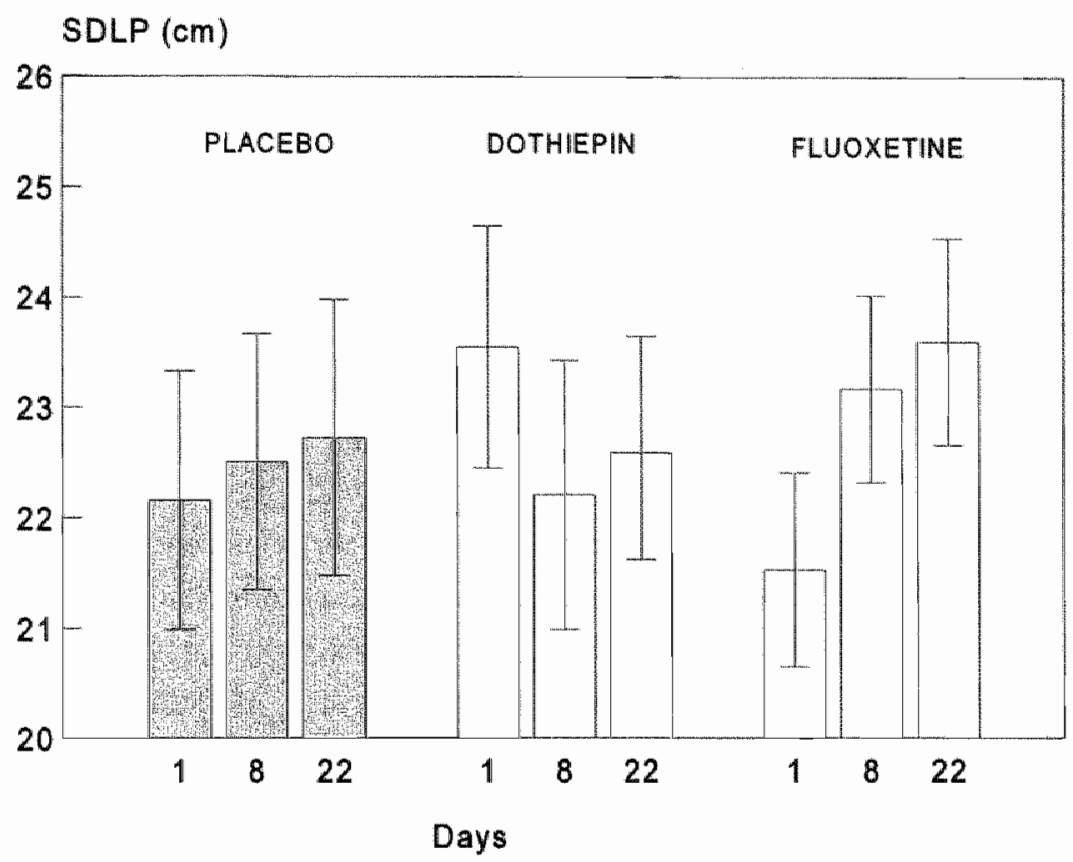

Figure 3 Mean ( $\pm S E$ ) standard deviation of lateral position (SDLP) on treatment days 1, 8 and 22 in every treatment condition.

\section{Driving Tests}

One subject was stopped by the driving instructor during the Highway Driving Test on day 8 of treatment with placebo after having completed $70 \%$ of the ride. No significant effects were found on any parameters in either the Highway Driving or the CarFollowing Test. Nonetheless, mean SDLP were in opposite directions during dothiepin and fluoxetine treatment conditions (Fig 3).

\section{Subjective sleep estimations}

No significant overall differences between conditions were found any sleep parameter. Differences in sleep duration approached significance $\left(\chi^{2}=22,68, \mathrm{~d} f=14, \mathrm{p}=.066\right)$. 
Separate drug-placebo comparison revealed increased difficulty awakening during days $1-3$ of dothiepin $(Z=-2.03 ; p=.043)$ and days $17-21$ of fluoxetine $(Z=-2.30 ; p=$ .02) treatment. However mean differences from placebo were very small $(-.7$ and $.5 \%$ ) and unlikely of practical relevance. Subjects estimated that duration of sleep on days 1.3 of dothiepin treatment was approximately 43 minutes (CI: 8.2 to 76.2 ) longer $(Z=-2.30 ; p=.02)$ than during placebo treatment. Getting to sleep, quality of sleep, and behavior following waking during treatment with fluoxetine or dothiepin did not differ from placebo.

\section{Subjective side effects and adverse events}

The major subjective side effects are summarized in Table 1. Overall, side effects did not significantly differ between treatments. Separate drug-placebo comparisons . Moreover the doses of dothiepin and fluoxetine were those normally used for treating depressed patients. Higher doses of both drugs are occasionally prescribed in clinical indicated that subjects felt more drowsy during days 1-3 of dothiepin treatment. Reported side effects increased throughout fluoxetine treatment. Relative to placebo, on days 9-11 subjects reported greater shakiness, and on days 13-15, more nausea. From day 17 on subjects reported more shakiness, nausea, concentration problems and dizziness after fluoxetine, than following placebo.

Table 1 Majon results from Wilcox signed ranks test of sublective side effects during treatment with dothiepin and thuoxetine. Mean differences (drug - placebo), standard error, mean rank of differences, $95 \%$ confidence intervats, frequencies of positive and negative differences or ties and $Z$ ratios are shown with the associated $P$ valiues.

\begin{tabular}{|c|c|c|c|c|c|c|c|c|c|c|}
\hline & $\begin{array}{l}\text { Days } \\
(\%)\end{array}$ & Whe alin & $\begin{array}{l}\text { SE } \\
\text { rank }\end{array}$ & Mran & $95 \% \mathrm{Cl}$ & $>0$ & $<0$ & Les & $z$ & $\mathrm{P}$ \\
\hline \multicolumn{11}{|l|}{ Doothopin } \\
\hline Drigwsiness & $1 \cdot 3$ & 5.08 & 2.10 & 5.64 & $2.04-9.19$ & 11 & 5 & 2 & -2.45 & 0.014 \\
\hline \multicolumn{11}{|l|}{ Furtwoxetine } \\
\hline \multirow[t]{2}{*}{ shatkiness } & $9-11$ & 7.03 & 3.39 & 1.89 & $0.46-3.32$ & 7 & 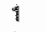 & 10 & -2.38 & 0.017 \\
\hline & $17-21$ & 7.26 & 4,00 & 4.47 & $1.45-6.88$ & 11 & 2 & 5 & -2.62 & 0.008 \\
\hline \multirow[t]{2}{*}{ Natusa } & $13-35$ & 2.09 & 1.58 & 3.50 & $0.13-6.87$ & 10 & 4 & 4 & -1.97 & 0.048 \\
\hline & $17-21$ & 2.59 & 1.19 & 4.16 & $0.93-7.39$ & 11 & 3 & 4 & -2.29 & 0.014 \\
\hline $\begin{array}{l}\text { concentraton } \\
\text { dificuly }\end{array}$ & $17-21$ & 13.35 & 471 & 244 & $0.42-4.85$ & 8 & 3 & 7 & -1.96 & 0.050 \\
\hline Dizzinass & $17-21$ & 16.91 & 3.91 & 2.83 & $0.13-5.54$ & 9 & 3 & 16 & -2.00 & 0.046 \\
\hline
\end{tabular}


In total, 119 complaints were spontaneously reported by subjects. In 23 cases it was judged that they were not treatment related. Among them, headache ( 7 gubjects) and symptoms of the common cold ( 5 subjects) were the most frequent. 1096 ases, complaints were judged to be treatment related. Treatment related adverse svents ars listed in Table 2. Adverse events were frequently reported by only one or two subjects per treatment. The type of adverse events differed among treatments. During huoxatine treatment, adverse events reported by more than two subjects were: nawsea $(6$

Table 2.Spontancously reported adverse events in every treatment condition and their ratie of occurrence.

Placebo Dothiepin Fluoxetine

\begin{tabular}{|c|c|c|c|}
\hline Pruritis & 1 & & \\
\hline Dry mouth & 2 & 6 & \\
\hline Dyspepsia & 1 & & 1 \\
\hline Borborygmi & 1 & & 1 \\
\hline Stinakiness & 2 & 4 & 2 \\
\hline Fatigue & 3 & 3 & 4 \\
\hline Headache & 6 & 5 & 5 \\
\hline Weakmess & & 1 & \\
\hline Nerwousness & 1 & 1 & 1 \\
\hline Concentration problems & & 3 & 4 \\
\hline Dizziness & 1 & 1 & $2^{\prime \prime}$ \\
\hline Nadsea & 2 & 1 & 6 \\
\hline Abdominal pains & & & 2 \\
\hline Memory lapse & & & 2 \\
\hline Dumingushed libido & & & 1 \\
\hline Parethesia & & & 1 \\
\hline Dianhoea & & 1 & \\
\hline Insomenta & & & 2 \\
\hline Muscle ternsion & & & 1 \\
\hline Diflicully waking up & 2 & 3 & \\
\hline Rasth on abotongen & $\|$ & & \\
\hline Palpitutions & & ! & \\
\hline Ponspiration & $\underline{1}$ & 1 & 1 \\
\hline Drowsiness & & 1 & 1 \\
\hline Depressed & & & 1 \\
\hline Coordination problems & & & 1 \\
\hline Difleculty falling asleep & 1 & & \\
\hline
\end{tabular}

Total complaints $\quad 25 \quad 32 \quad 39$

Totall subjects complaining

\begin{tabular}{llll} 
of any symptoms & 11 & 13 & 14 \\
\hline
\end{tabular}

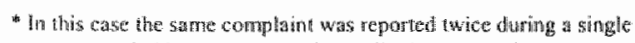
treament period by the samse subject. All other corniplaints were reported once per tret intent by different subjects. subjects), headache (5 subjects), fatigue and concentration problems (4 subjects).During dothiepin treatment they were: dry mouth (6 subjects), headache (5 subjects), shakiness (4 subjects), fatigue, concentration problems and difficulty waking up (3 subjects). During placebo treament there were fewer reports of adverse events. Headache (6 subjects) and fatigue (3 subjects) were most common.

\section{Blood assays}

Mean (sd) plasma concentrations of dothiepin on treatment days 8,15 and 22 as determined by an HPLC method were $46.24(52.48), 76.51(80.13)$ and $71.70(53.99) \mu \mathrm{g} / \mathrm{l}$ respectively. Mean plasma (sd) concentrations of fluoxetine and it"s metabolite norfluoxetine were respectively 34.47 $(14.41)$ and 42.4717 .47$) \mu g / 1$ on day 8 , $51.11(19.06)$ and $68.72(25.85) \mu \mathrm{g} / 1$ on day 15 and $57.83(24.88)$ and 75.78 $(28.29) \mu \mathrm{g} / \mathrm{l}$ on day 22 of treatment. 


\section{DISCUSSION}

The 3-week treatment periods in this study appear to be the longest ever undertaken by healthy volunteers for assessing antidepressant drug effects on performance practice but only to patients who fail to respond to those given in the present study. Thus these treatments closely approximated those of depressed patients up until the time when dothiepin and fluoxetine plasma concentrations closely approach steady-state. Performance changes measured in any of the test should therefore indicate drug properties of relevance to patients during their first three weeks of treatment. Drug effects on healthy volunteers ${ }^{t}$ performance would be only be difficult to generalize to patients if their exposure extended beyond the therapeutic latency period, since the drug"s net effects on them could then be predominantly determined by a therapeutic response.

The results did not entirely confirm expectations. Dothiepin's effects on performance were more or less as expected. The drug decreased sustained attention on day 1 and CFF on day 22. It had no significant effects on performance on day 8 . Fluoxetine's effects were more than expected and comparable in magnitude to those of dothiepin. A reduction in sustained attention was seen throughout treatment. CFF decreased linearly over days and differed significantly from placebo on day 22 . Side effects differed between drug treatment conditions, relative to placebo. Dothiepin increased the feeling of drowsiness and lenghtened sleep duration. Fluoxetine increased feelings of shakiness, nausea and dizziness and decreased concentration. Spontaneously reported adverse events followed the same pattern as recorded side effects but the former were less clearly divided between drug conditions. Together, these results indicate that dothiepin and fluoxetine possess about the same modest potential for impairing performance and produce about the same incidence of side effects when taken in these doses over a 3-week period.

Neither drug had any significant effect on driving performance. Mean SDLP suggested an initial dothiepin effect that diminished over the treatment period and the opposite for fluoxetine. The suggested effects were small in both cases. The failure to find any significant drug effects on driving performance indicates that the use of either dothiepin or fluoxetine would not be expected to seriously compromise patients' abilities to undertake such activities in real life. 
This is not to say that either drug would never affect any patient's performance in an untoward manner. Dothiepin was given to the subjects according to the manufacturer's recommendation in evening doses. The reason for that recommendation is that dothiepin possesses sedative properties. It would almost certainly cause sedation and performance impairment if taken over the day, at least before the occurrance of tolerance mitigates this effect. Tolerance was apparently sufficient in the present study to largely attenuate the drug's acute effects on sustained attention by the $8^{\text {th }}$ day of treatment. Escalating the dothiepin dose from 75 to $150 \mathrm{mg}$ nocte on the same night may have been followed by some residual sedation on day 9 and subsequently, but testing was not scheduled after the dose escalation. We cannot exclude the possibility that the subjects reacted to it adversely but no sign of this was observed in their reported side effects which did not differ between dothiepin and placebo conditions on days 9-11. Except for a significant difference in CFF between these conditions, no sign of a high dose effect was seen in tests given on day 22 . These results do not contradict the commonly held belief that dothiepin is a sedating antidepressant, nor that under some conditions it can impair performance. Rather they indicate that the drug's sedating activity can be controlled so as to minimize its effects on performance by gradually increasing therapeutic dosing regimen with nocturnal drug administration.

Fluoxetine was also given at night. Though not contrary to its manufacturer's recommendation, this procedure is contrary to the usual practice of administering the drug in the morning. This is normally done to avoid disturbing patients' sleep since insomnia is a relatively frequent fluoxetine side effect in clinical practice (Beasley et al. 1991; 1992). Nonetheless, the subjects' sleep did not seem unduly affected by nocturnal fluoxetine administration: on the average, their total estimated sleep duration was about the same as after placebo and only two individuals reported insomnia on one occasion apiece as an adverse event. It seems unlikely therefore that sleep disturbance was the factor responsible for the significant fluoxetine effects on performance in this experiment. Rather, those effects occurred in spite of the fact that they were measured at times other than when the drug's plasma concentrations were highest after repeated doses. If fluoxetine had been given in morning doses, one might expect to measure more rather than less impairment.

A methodological point should be made concerning the demonstration of a drop in mean CFF that occurred during fluoxetine treatment. Several investigators have reported the opposite, a rise in CFF, after single and multiple doses of fluoxetine and 
other SSRIs (Fairweather et al, 1993; Kerr et al, 1991; Hindmarch \& Bhatti, 1988). The apparent contradiction may be resolwed by noting that whereas subjects vieuwed the flickering light through an artificial pupil $(2 \mathrm{~mm})$ in the present study, no such device was employed to control the luminance falling on the retina in previous studies showing SSRI effects on CFF. The reason why this is important is that drugs that affect serotonergic neurotransmission can cause either pupillary miosis or mydriasis which can, respectively, lower or raise CFF according to the Ferry-Porter Law (Davson, 1976).

The influence of serotoninergic drugs on pupillary diameter was first noted by Millson et al. (1988) and confirmed by Danjou et al. (1992) who respectively gave subjects single doses of $5 \mathrm{HT}_{2}$ receptor agonists; ICI 139369 and ritanserin, respectively. The former investigators directly measured subjects" miosis after the drug while the latter inferred it from a large drop in subjects' CFF unaccompanied by any changes in their performance in a battery of highly sensitive psychomotor tests. Theoretically, SSRIs should have the opposite effect on pupillary diameter by increasing serotonin concentrations at post-synaptic receptors known to exist in the cilliary muscles (Moro et al, 1981). This was confirmed in subjects treated for seven days with paroxetine 20 $\mathrm{mg}$ qd (Deijen et al, 1989). Mydriasis occurred both after the first dose and at the end of the series as the subjects were tested while viewing a traffic film. The average degree of mydriasis they experienced on both occasions was $2 \mathrm{~mm}$ or about $50 \%$ of the total range of pupillary diameters. Had these subjects CFFs been measured, the same change in pupill diameter would almost certainly have led to elevated values. This finding underscores the need for controlling pupillary diameter when measuring serotonergic drug effects on CFF. When this is done, as in the present experiment, CFF changes can be taken as an index of the drug's central activity. Without this control, CFF changes undler the influtence of serotonergic drugs might not be a valid index of their central effects.

HPLC analyses showed that mean plasma concentrations of both drugs rose throughout treatment. On day 22, some drug effects on performance could still be found and some side effects persisted. It seems appropriate for future research on antidepressants to concentrate more on persistent or late-developing effects that influence performance and their correspondence with drug accumulation. 


\section{References}

Allen D A, Curran H V, Lader M (1993) Effects of lofepramine and dothiepin on menory and psychomotor function in healthy wolunteers. Journal of Psychopharmacology 7: $33-38$

Beasley C M, Sayler M E. Bosomworth J C, Wernicke I F (1991). Efficacy and activating-sedating effects in agitated and retarded depression. J Clin Psychopharmacol 11: 166-174.

Beasley C M. Sayler M E, Weiss A M, Potvin J H (1992)Fluoxetine, activating and sedating effects at multiple fixed doses. J Clin Psychopharmacol 12: 328-333

Brookhuis K A. Volkerts E R, O'Hamion J F (1986) The effects of some anxiolytics on car-following performance in real traffic. In: Alcohol, Dnugs and Traffic Safetym T86, eds Noordzij P C, Roszbach R, Amsterdam: Elsevier, 223-226.

Davson $\mathbb{H}$ (1976) The eye. Visual function in man. Vol 2a, N Y, London, San Fancisco, Academic Press.

Danjou P, Warot D, Hergueta T, Lacomblez L, Bouhours P, Peuch A J (1992). Comparative study of the psychomotor and antistress effects of ritanserin, alprazolam and diazepam in healthy subjects: some trait anxiety-independent responses. Int Clin Psychopharmacol 7: 73-80.

Deijen J B, Loriaux S M, Orlebeke J F, Vries de J (1989). Effects of paroxetine and maprotiline on mood, perceptual-motor skills and eye movements in healthy volunteers. Psychopharmacology $3: 149-155$

Farid NA, Bergström RF, Lemberger L, Ziege EA, Tenbarge J, Wolen RL, Dhahir PH (1986) Studies on the disposition of fluoxetine and radioactive isotopes. $15^{\text {bl }} \mathrm{CINP}$ congress, Puerto Rico, Collegium Internationale Neuropsychopharmacologium.

Fairweather D B, Kerr J S, Harrison D A, Moon C A. Hindmarch I (1993) A double blind comparison of fluoxetine and amitriptyline on cognitive function in elderly depressed patients. Human Psychopharmacology 8: 41-47

Hindmarch $\mathrm{I}$, Bhatti $\mathrm{J} \mathrm{Z}$ (1988) Psychopharmacological effects of sertraline in normal healthy subjects. Eur J Clin Pharmacol 35: 221-223

Hindmarch I (1988) Three antidepressants (amitriptyline, dothiepin, fluoxetine) with and without alcohol, compared with placebo on tests of psychonotor ability related to car driving. Human Psychopharmacology 2: 177-183.

Kerr J S, Sherwood N, Hindmarch I (1991). The comparative psychopharmacology of 5HT reuptake inhibitors. Hunan Psychopharmacology 6: 313-317.

Mackworth N H (1950) Researches on the measurement of human performance. Medical research counsil special report 1950; No 268, H.M. Stationary Office. London. Also in: Selected papers on human factors in the dexign and ase of control systems, ce sinaiko H.W. NewYork: Dover, 1961, 1.74-331.24

Millson D S, Harry J D, Haworth S J, Willikson D (1988) Effects of a 5-HI antagonist (ICI 169369 ) on pupillary response. In procedings of the B.P.S, abstract C40 1988 .

Moro $F$, Scapagnini U, Scaletta $S_{1}$ Drago F (1981) erotonin nerve endings and regulation of pupillary dianeters. Annals of Opthalmology $13: 487,490$.

Moskowitz H, Burns M (1988) The effects on performance of two anti-depressants alone and in combination with diazepam. Prog in Neuro-Psychopharmacol \& Biol Psychiat 12: 783-792

Norusis M J. SPSS/PC + Advanced Stanstics, New-York, McGraw-Hill 1986.

O'Hanion J F. Haak $T$ W, Blaaw $G$ J, Riemersma J B J (1982) Diazepam impairs laterall position control in highway driving. Science $217: 79-81$

Parrot A C, Hindmarch I (1978) A factor analysis of sleep evaluation questionnaire. Psychological Medicine 8: 325-329 
Ramackers J $G_{2}$ Veggel van L M A, O'Hanlon J F (1994). A cross-study comparison of moclobemide and brofaromine on actual driving performance and estimated sleep. Clin Neuropharmacol $17 . \$ 9-\$ 18$.

Robbe HWJ, OHanilon J F (1995) Acute and subchronic effects of paroxetine 20 and $40 \mathrm{mg}$ on actual driving performance and subjective assessments in healthy volunteers. Eur Neuropsychopharmacol $5: 35-42$

Seppälla $T$, Linnoila M, Elonen E, Mattila M J, Maki M (1975) Effects of tricychic antidepressants and alcohol on psychomotor skills related to driving. Clin Pharmacol and Therapeutics 17: $515-522$

Schaffer K (1989) Study on performance and alcohol interaction with the antidepressant fuoxetine. Int Clin Psychopharmacol 4(Suppl): 15-20.

Stille G, Herberg K W (1989). Verkelurssicherheit unter dosulepin-behandlung. Fortschritte der Medizin: Psychiatrie 2: 75-78

Strömberg C, Suokas A, Seppalla T (1988) Interaction of alcohol with maprotiline or nomifense: echocardiographic and psychomotor effects. Eur J of Clin Pharmacol 35: 593-599.

Vuuman FPM, O'Hanlon JF (1991) An improved method for measuring drug effects on the critical fusion frequency (abstract). European Neuropharmacology 1: 467 . 


\title{
CHAPTER 5
}

\section{A study of the pharmacodynamic interaction between befloxatone and ethanol on performance and mood in healthy volunteers.}

\begin{abstract}
The effects of befloxatone ( $20 \mathrm{mg}$ od for 10 days) alone and in combination with ethanol on psychomotor performance, memory and mood were assessed in a randomized, double-blind, placebo controlled study. On treatment days 6,8 and 10, subjects received $0.5,0.8 \mathrm{~g} / \mathrm{kg}$ ethanol and ethanol placebo in randomly assigned, balanced orders, $2 \mathrm{~h}$ post drug. Critical fusion frequency (CFF), choice reaction time (CRT), postural instability, critical tracking (CTT) and mood were measured $1 \mathrm{~h}$ before ethanol and 1, 3 and $5 \mathrm{~h}$ afterwards. Divided attention (DAT), sustained attention and memory (immediate and delayed recall) were also measured in single tests, $2-5.5 \mathrm{~h}$ post ethanol. Ethanol's effects were generally significant when blood alcohol concentrations (BAC) after both doses were the highest; i.e. 0.48-0.67 and 0.96-1.10 $\mathrm{mg} / \mathrm{ml}$. Those effects were virtually gone after the subjects mean BACs fell below 0.40 $\mathrm{mg} / \mathrm{ml}$. Befloxatone alone had no significant impairing effect in any test. Neither did it significantly interact with ethanol to cause any greater impairment than the latter alone. It was concluded that befloxatone does not potentiate the sedating and impairing effects of ethanol.
\end{abstract}

JG Ramaekers, ND Muntjewerff, MMC Uiterwijk, LMA wan Veggel, A Patat, G Durrieu, JF O'Hanlon. J Psychopharmacol 10: 288-294, 1996 


\section{INTRODUCTION}

Befloxatone is a monoamine oxidase-A inhibitor of the oxazolidinone family. In vitro biochemical studies have shown that befloxatone causes reversible, selective, and competitive inhibition of monoamine oxidase- $\mathrm{A}$ in brain, heart, liver, and gut specimens from rats and humans (Curet al, 1994; Rovei et al, 1994). After oral administration in humans, the maximal concentration is reached in approximately 1.5 to $3 \mathrm{~h}\left(\mathrm{~T}_{\max }\right)$, and the apparent elimination half-life is about $11 \mathrm{~h}$. Steady state is reached within 3 days. Initial tolerability studies involving healthy volunteers treated with single doses up to $160 \mathrm{mg}$ and with repeated doses up to $40 \mathrm{mg}$ bid for 7 days showed that the drug is well tolerated. Subjective side effects, spontaneously reported adverse events and psychomotor performance (reaction time and recognition memory) were comparable to those recorded during placebo treatment (Ansseau et al, 1992). In addition, pharmacodynamic studies in healthy volunteers showed that single doses of 5,10 and $20 \mathrm{mg}$ befloxatone and repeated doses of $5 \mathrm{mg}$ bid and $10 \mathrm{mg}$ od for 6 days have no impairing effects on vigilance, information processing or memory (Patat et al. 1995a, 1995b).

The main purpose of this study was to determine whether befloxatone potentiates ethanol's impairing effects on performance and mood. Tricyclic antidepressants do so when given in doses too low to affect performance by themselves (Hindmarch, 1988) and also after their initial effects have been attenuated by tolerance occuring with repeated daily dosing (Seppällä et al, 1975; Lader et al, 1986; Allen et al., 1988). Even fluvoxamine, a selective serotonin reuptake inhibitor not known to possess intrinsic impairing properties, was shown in one study to potentiate ethanol's effects on performance (Herberg and Menke, 1981). In contrast, other selective and reversible MAO-A inhibitors (moclobemide and brofaromine) not only failed to potentiate ethanol's effects, they slightly antagonized them in certain performance tests (Berlin et al, 1990; Kerr et al, 1993).

The present study was designed to show a possible drug (befloxatone and placebo) $x$ ethanol $(0,0.5$ and $0.8 \mathrm{~g} / \mathrm{kg})$ interaction in a $2 \times 3$ factorial design. Volunteers' performance and mood were assessed after repeated doses of befloxatone $20 \mathrm{mg}$ od, the highest dose intended for routine antidepressant therapy. 


\section{MATERIAL AND METHODS}

\section{Subjects}

Eighteen healthy young male volunteers aged between 18 and 35 years were recruited by a newspaper advertisement. Their medical examination included a physical examination with measurements of supine and standing blood pressure, laboratory tests (hematology, blood chemistry, serologic test and urinalysis) and a 12-lead electrocardiogram (ECG). Exclusion criteria were as follows: excessive smoking (i.e more than 10 cigarettes per day); positive urine drugs screen and binocular visual acuity, corrected or uncorrected, that deviated by more than 0.65 diopters from normal. The study was carried out in accordance with the World Medical Association's Declaration of Helsinki (Hong Kong Modification, 1989). It was approved by the standing Ethics Review Committee of the University of Limburg. Written informed consent was obtained from each subject prior to participation.

\section{Study design and drug/ethanol administration}

Befloxatone $20 \mathrm{mg}$ od and placebo were administered in identically appearing capsules during separate 10-day series according to a 2-way, double blind, cross-over design. Three test sessions occurred on treatment days 6,8 and 10 . Subjects received $0.5 \mathrm{~g} / \mathrm{kg}$ or $0.8 \mathrm{~g} / \mathrm{kg}$ ethanol, and ethanol placebo, single blind, during the respective test sessions. The orders of the two drug periods by 3 ethanol treatments were completely balanced between three blocks of six subjects apiece, with the constraint that no treatment could occur at the same ordinal position in both periods for the same individual. Orders were assigned to subjects by exhaustive random selection. There was a washout period of at least one week between treatment periods.

On days without testing, subjects ingested drug or placebo after breakfast between 08:00 and 09:30 h. On test days they did so after a standard meal in the presence of a Medical Supervisor at either 9:00 or 9:30 h. They received ethanol and ethanol placebo $2 \mathrm{~h}$ later so that plasma drug and ethanol concentrations would arrive simultaneously at their respective maxima during the next $1-2 \mathrm{~h}$. Ethanol $(99.8 \%)$ was mixed with orange juice to a volume of $300 \mathrm{ml}$. Ethanol-placebo consisted of $2.5 \mathrm{~g}$ of ethanol floated on $300 \mathrm{ml}$ of orange juice. Ethanol and orange juice were consumed within a period of 15 minutes. 


\section{Performance assessments}

Two training sessions were held in order to familiarize the subjects with the performance tests and to minimize learning effects. CFF, CTT, CRT, postural instability and mood questionnaires were given within 20-min periods beginning at $1 \mathrm{~h}$ before and 1,3 and $5 \mathrm{~h}$ post ethanol (i.e. 1, 3, 5 and $7 \mathrm{~h}$ post drug). DAT and the sustained attention test were given once at times beginning 2 and $4 \mathrm{~h}$ post ethanol. The memory test was given in three sections. Immediate recall was measured at $1 / 3 \mathrm{~h}$, and delayed recall at $3^{1 / 3}$ and $5^{1 / 3}$ post ethanol.

$\mathrm{CFF}$ ( $\mathrm{Hz}$ ) is the visual system's threshold for repeatedly responding to and recovering from discontinuous (on-off) light stimulation. Trains of stimuli arriving at the retina at frequencies below the CFF threshold are perceived as flicker, those above, as constant light (Vuurman et al., 1994).

CTT (rad/s) measures the ability to control an inherently unstable error signal in a $1^{\text {st}}$-order compensatory tracking task. The subject uses a joy-stick to control the direction and velocity of a cursor, which tends to diverge horizontally from the center of a display with progressively increasing velocity. The compensatory response of the subject increasingly lags the error signal until the point comes were the two frequencies are $180^{\circ}$ out of phase. At that point the subject's response adds to, rather than subtracts from, the error and control is lost. The frequency at which control loss will occur is commonly defined as the "critical frequency" or "Lambda ${ }_{c}$ ". Theoretically, the reciprocal of lambda $a_{c}$ is a direct measure of the subject's minimum perceptual-motor delay lag during a closed-loop operation. (Jex et al. 1966).

CRT (msec) measures the subject's average reaction time to the words "left" and "right" using corresponding push-buttons. Half of each type are displayed at compatible and incompatible (i.e left or right) positions (Vuurman et al., 1994).

The Postural Instability Test (Kapteyn et al. 1983), or Body Sway Test, begins with the subject standing on the centre of a force-platform with his feet making an angle of $30^{\circ}$. Two, 60-second recording epochs follow, the first with the subject's eyes open, the second, closed. The final scores is the logarithm of the area (curve surface, log) circumscribed by the postural oscillations within the recording epochs.

The Sustained Attention Test is a variant of the classic Mackworth (1950) "Clock Test". Subjects are seated in front of a computer screen displaying a circular arrangement of 60 grey dots simulating the second mark on a clock. Dots are briefly illuminated in clockwise rotation at a rate of one per second. Occasionally the rotation 
proceeds with a "double jump" by skipping one of the dots in the normal sequence. The dependent variables of the test is the number of correct detections. The entire test lasts 45 minutes.

DAT requires subjects to perform two tasks simultaneously. The primary task is the same as in CTT above, except that the error deviation frequency remains constant at $50 \%$ of the particular individual's lambda-c. Performance in this subtask is measured as the average tracking error in $\mathrm{mm}$. The secondary task is to monitor each of the 24 numerals $(0-9)$ in the peripheral corners of the display, which asynchronously change at intervals of 5-10 sec; and, to detect the occurrence of one in particular (i.e. "2"). Average reaction time is recorded in this subtask.

The Memory Test begins with memorizing a list of 15 monosyllabic words. Each word is shown on the computer display for 2 seconds and the subject reads it aloud. When the series ends the subject recalls as many words as possible. Thereupon the same list is presented in the same manner on four successive occasions. The number of words correctly recalled in all trials are summed to yield the total immediate free recall score. After 2 and 4 hour delays, the subject is asked to recall as many words. The numbers of words correctly recalled are taken as the respective delayed recall scores.

\section{Mood}

A series of $16100-\mathrm{mm}$ horizontal visual analog scales are used to subjectively evaluate changes in mood experienced by the subject. Separate scales bear opposing descriptive terms at each terminal (e.g. calm - excited) and the neutral state is supposed to lic in the middle. Scores are measured in $\mathrm{mm}$ from the end of the scale. The weighted sums of three exclusive sets of scale items are calculated to yield scores for Alertness, Contentedness, and Calmness (Bond et Lader, 1974).

\section{Sleep Questionnaire}

Subjects were required to complete a standard clinical sleep quality questionnaire (Mulder-Hajonides van der Meulen, 1981) describing the quality of their sleep and estimating its total duration on treatment days 2 to 10 , after awakening. 


\section{Pharmacokinetics}

Blood Alcohol Concentration (BAC) was estimated from expired alveolar air using the Lion SD3 breathanalyzer th prior to ethanol and $1,1 \frac{1}{3}, 2,3,4,5 \mathrm{~h}$ afterwards. The discrimination limit was $0.05 \mathrm{mg} / \mathrm{ml}$. Blood samples were collected immediately before and $23 / 4 \mathrm{~h}$ post drug on all test days. Befloxatone and its $\mathrm{O}$-demethylated metabolite were assayed using HPLC with fluometric detection. The quantification limit was $0.5 \mathrm{ng} / \mathrm{ml}$.

\section{Statistical analysis}

Each dependent variable was analysed at every time point using a 2 factor, repeated measurements analysis of variance (ANOVA). The main effect of Drug (befloxatone versus placebo) was tested in the conventional manner. That of Ethanol was partitioned into linear and quadratic components for measuring the significance of trends over the administered doses; $0,0.5$ and $0.8 \mathrm{~g} / \mathrm{kg}$. Partitioning was accomplished by multiplying the raw scores by orthogonal polynomial coefficients. The interaction, Drugs $x$ Ethanol, was similarly partitioned for testing the differences in trends occurring after befloxatone and placebo over the three ethanol doses. The pooled within subject residual variance was used as the error term for conducting all tests within a particular set.

\section{RESULTS}

\section{Missing Data}

Complete data were obtained from all subjects in every test but one. One subject was unable to fixate on the stimulus in the CFF test after receiving ethanol in either dose. His data were excluded from the analysis.

\section{Ethanol}

Pharmacokinetics. Figure 1 shows mean ( \pm sd) blood alcohol concentrations as a function of time after drinking after both befloxatone and placebo with the high and low ethanol doses. Peak concentrations were apparently achieved after about $1 \mathrm{~h}$. The elimination phase proceeded by zero-order kinetics from a point in time about $30 \mathrm{~min}$ later. Average maxima were close to $1.1 \mathrm{mg} / \mathrm{ml}$ after the high dose and about 0.7 


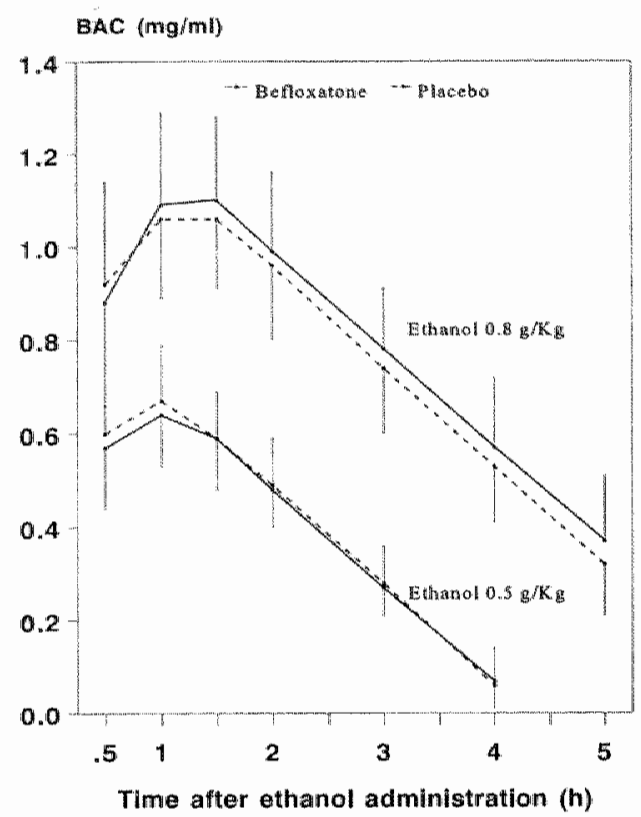

Figure 1 Mean (SD) blood alcohol concentrations $(B A C \mathrm{~S})$ as a function of time after administration of $0.5 \mathrm{~g} / \mathrm{kg}$ and 0.8 $\mathrm{g} / \mathrm{kg}$ in every treatment condition. $\mathrm{mg} / \mathrm{ml}$ after the low dose. The rate of ellimination was constant at about 0.2 $\mathrm{mg} / \mathrm{ml} / \mathrm{h}$. There were no significant differences in either maxima nor rates of elimination due to pretreatment.

Pharmacodynamics. Descriptive statistics (means, se) of CFF, CTT, CRT, DAT, sustained attention and mood variables as recorded at various times after all treatment combinations and a summary of significant results are provided in Table 1. Significant, linear dose-related performance impairment was generally found in every test when ethanol concentrations were near maximum (i.e., $\mathbb{1}-2 \mathrm{~h}$ post ethanol). The only exception occurred in the CFF test where a similar trend just failed to reach significance

$(\mathrm{p}=.08)$. Word learning, as measured by the total number of items immediately recalled during their sequential presentations, was also impaired (Figure 2). Subjective alertness and calmness likewise declined as a linear function of the ethanol dose during this period.

At times 2-4 h after drinking, ethanol significantly impaired DAT and CTT performance while it increased body sway with eyes opened and closed (Fig 3). Mood parameters were significantly altered during this period: subjects felt less alert and content in relation to the dose. The memory test showed two significant effects: doserelated declines in both the absolute frequencies of words correctly recalled after a 2 hour delay and those frequencies relative to the maximum numbers of words recalled in any of the immediate recall series.

Few effects were still significant in tests conducted $4-51 / 2 \mathrm{~h}$ after drinking. Subjective alertness still showed significant dose-related effects but the only objective 


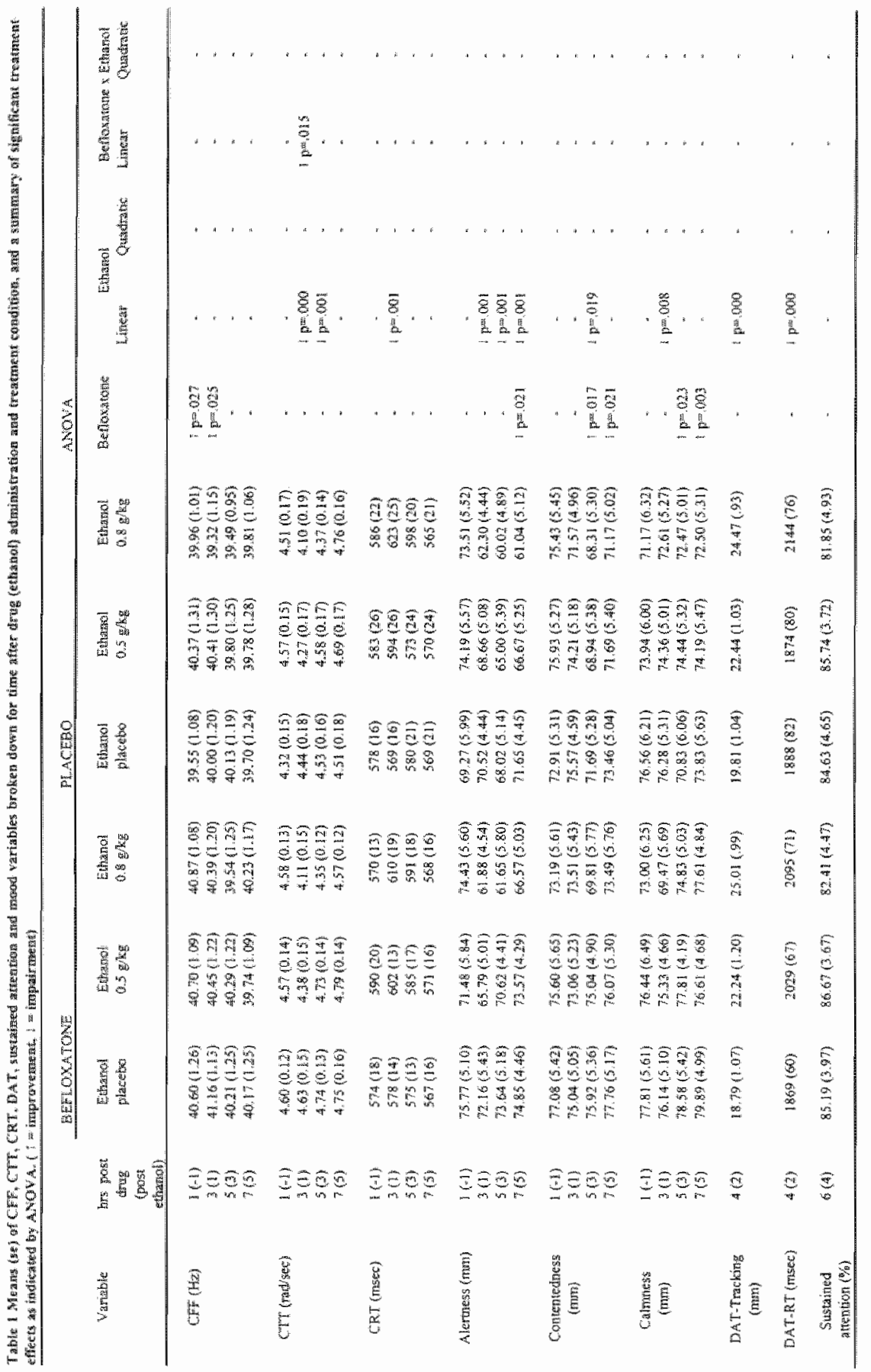


sign of impaiment was found in the eyes-open body sway test. Delayed recall scores from the last test still showed a significant ethanol effect.

\section{Befloxatone}

Pharmacokinetics. Neither the mean plasma concentration of befloxatone, nor that of its metabolite, changed significantly in pre-dosing samples over days 6,8 and 10 . Concentrations measured $2 \%$ h later ( $\% \mathrm{~h}$ post ethanol) likewise failed to to differ significantly over days. However mean concentrations of befloxatone were ligher when co-administered with ethanol (Table 2). A posteriori testing showed that the mean befloxatone concentration rose with the ethanol dose $\left(\mathrm{F}_{1.34}=21.05 ; \mathrm{p}=.000\right)$ and its metabolite fell $\left(\mathrm{F}_{1,34}=6.76 ; \mathrm{p}=.014\right)$. The significance of this relation further increased after covariate adjustment for pre-dosing levels that existed on the same days $\left(F_{1,33}=10.24 ; p^{=0.003)}\right.$.

Table 2 Mean (se) plasma concentrations of befloxatone and its $\mathrm{O}$-demethyl metabolite (ODB) before $\left(\mathrm{C}_{\text {man }}\right)$ and $2 \% \mathrm{~h}\left(\mathrm{C}_{2.45 \mathrm{~s}}\right)$ after drug administration ( $\%$ h post ethanol).

\begin{tabular}{|c|c|c|c|}
\hline & $\begin{array}{l}\text { Ethanol } \\
\text { placebo }\end{array}$ & $\begin{array}{l}\text { Ethanol } \\
0.5 \mathrm{~g} / \mathrm{kg} .\end{array}$ & $\begin{array}{l}\text { Ethanol } \\
0.8 \mathrm{~g} / \mathrm{kg}\end{array}$ \\
\hline Beflowatone $\mathrm{C}_{\text {min }}$ & $2.0(0.2)$ & $2.7(0.5)$ & $2.5(0.3)$ \\
\hline $\mathrm{ODB} \mathrm{C}_{\text {rmin }}$ & $20.9(1.8)$ & $24.0(2.0)$ & $23) 1(1.4)$ \\
\hline Befloxatone $C_{2.45 / 7}$ & $54.4(3.2)$ & $66.6(4.0)$ & $78.3(5.0)$ \\
\hline $\mathrm{ODE} C_{2.45 \mathrm{~b}}$ & $83.3(6.1)$ & $72.6(4.2)$ & $68.8(4.4)$ \\
\hline
\end{tabular}

Pharmacodynamics. The drug had very few significant effects relative to placebo. Those observed made it appear as if befloxatone slightly improved performance and

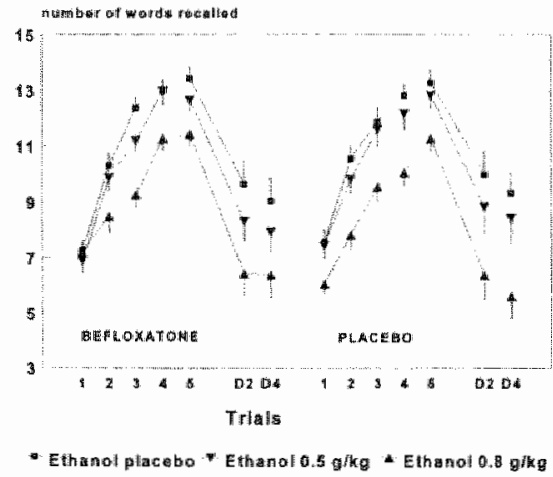

Figure 2. Mean (SE) immediate recall scores in every treament condition. Immediate racall scares (swmmed over 5 leaming trials) were assessed at $2(D 2)$ and 4 h (D4) affer the leaming session. Ethanol doses progressively impaired immediate recall and delayed recall $(p=000)$ 
subjective feelings. The drug significantly elevated mean CFF before and 1 h post ethanol and diminished body sway with eyes open in tests given th before ethanol. It generally improved the subjects" mood close to the ends of test sessions: they rated themselves as more contented and calm at both 3 and 5 h, and as more allert at the latter time after ethanol. No effects of befloxatone on sleep quality or duration were found as compared to placebo.

\section{Interactions between befloxalone and ethanol}

There was little indication that the subjects' reaction to ethanol was differentially affected by pretreatments with befloxatone and placebo. A significant linear interaction was recorded for the CTT conducted 5 h post ethanol. At that time performance during befloxatone and placebo treatment were comparable after administration of ethanol, but performance after placebo ethanol was inexplicitly poor during placebo treatment. A significant quadratic interaction was for body sway (eyes closed) at 3 th after crinking. At that time body sway was more affected by befloxatone/ethanol than placebo/ethanol.
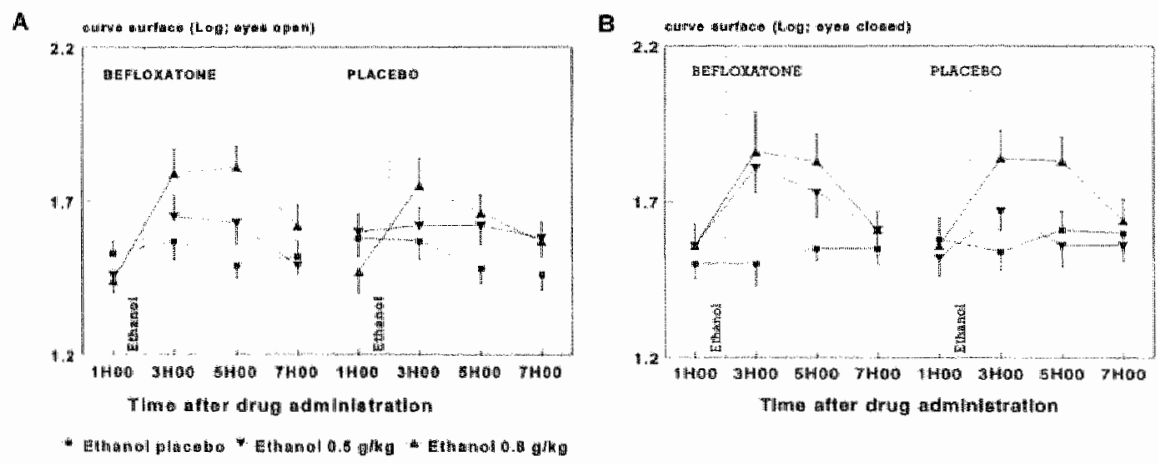

Figmre 3 Mean (SE) curve surface in respecively the eyes open (A) and eyes closed (B) condition as a function of time after drug and ethanol administration in every treatment condition. Befloxatone decreased curve surface at i h post-drug $(p=047)$ in the eyes open condition. Ethanol significamly increased curve surface at $l \mathrm{l}$ and $3 \mathrm{~h}$ affer drinking in the eyes closed condition ( $p=000$ ) and at 1,3 , and $5 \mathrm{~h}$ in the eyes open condition $(p<$, 03). Befloxatone potentiated the effect of ethanol 3 h after drinking in the eyes closed condition $(p=.023)$ 


\section{Adverse Events}

No serious adverse events were recorded during the study. Prior to the administration of ethanol, no adverse event was recorded more than once from any subject receiving befloxatone. Three subjects reported mild dizziness while taking placebo. After the low ethanol dose, 13 and 16 subjects reported dizziness and 4 and 2 subjects "felt drunk" when their pretreatments were placebo and befloxatone, respectively. The same frequencies after the high ethanol dose were 1 and 2 and 17 and 18 , respectively. Though not tested statistically, it would appear that adverse events were mainly attributed to ethanol and hardly different after befloxatone and placebo pretreatments.

\section{DISCUSSION}

The objectives of the present study were to determine the effects of befloxatone, at steady state, alone and in combination with ethanol, on performance and mood in young healthy volunteers. The ethanol doses, 0.5 and $0.8 \mathrm{~g} / \mathrm{kg}$, were chosen because they are respectively known to be marginally and substantially impairing. Within $1-2 \mathrm{~h}$ they produced maximal mean blood alcohol concentrations of .67 and $1.10 \mathrm{mg} / \mathrm{ml}$, respectively. At that time, ethanol affected subjective alertness and practically every performance variable in a significant, linearly dose-related manner. Performance in most tests remained significantly impaired for $2-4 \mathrm{~h}$ post ethanol while these concentrations declined over the ranges $.49-.07$ and $1.0-.57 \mathrm{mg} / \mathrm{ml}$. Ethanol's effects were virtually gone after $4 \mathrm{~h}$ when its concentration was below $.37 \mathrm{mg} / \mathrm{ml}$ in the high dose conditions.

Ethanol's dose-related effects on memory were particularly noteworthy. At 11/3 $h$ after drinking, ethanol retarded word learning as evinced by the significant decline in total immediate recalli scores over ethanol doses. Consolidation of the newly acquired information in long term memory was also affected by ethanol. When asked to recall the word list $2 \mathrm{~h}$ later, the subjects' delayed recall scores reflected the effect of ethanol given earlier. Their delayed recall scores also declined as a significant linear function of the dose, both in absolute terms and relative to the highest immediate recall scores achieved earlier. At $4 \mathrm{~h}$ after drinking absolute and relative scores were the same of less than before, although blood alcohol concentrations were by then very low. If the previous results were solely due to faulty retrieval, one would expect to see a partial 
recovery of delayed recall scores. The lack of recovery thus suggests that consolidation failed to occur in a normal manner.

The CFF test failed to show the expected ethanol effect. CFF measurement became increasingly difficult after administration of ethanol doses. Several subjects could not rellably fixate upon the stimulus for discriminating flicker from fusion. Consequently their CFF threshold levels dropped or rose in an erratic manner. The sustained attention test also failed to show a significant ethanol effect. However, at the time it was given, $4-4 \frac{3}{4} \mathrm{~h}$ after drinking, blood ethanol concentrations had declined below $.5 \mathrm{mg} / \mathrm{ml}$ after the high dose and almost to the vanishing point after the low dose. The main reason the test was inserted in the schedule at this time was to measure a possible difference between befloxatone and placebo effects on vigilance. As it happened, there was none. This, rather than the absence of an ethanol effect, is the meaningful result. It confirms an earlier failure to measure any befloxatone effect on volunteers' performance in a vigilance test after single and repeated 5 and $10 \mathrm{mg}$ doses (see Introduction).

The overall effects of befloxatone on performance significantly differed from placebo"s in only three cases; in the eyes open body sway test one hour before drinking and in the CFF tests given both one hour before and one hour after drinking. All three mean differences were small in magnitude and all were of the direction of performance improvement after befloxatone. However, results from the CFF, at least when measured after ethanol administration, may be misleading for the reason given above. The general failure for befloxatone and other reversible MAO-A inhibitors to influence psychomotor performance, with exceptions mainly in the direction of performance improvement, was noted in a review by Patat et al. (1995). After befloxatone pretreatment, regardless of the ethanol dose, subjects rated themselves as being more alert, content and calm at the end of test days than at the beginning. Volunteers can not be expected to show antidepressant drug effects that enhance patients' mood under ordinary circumstances. Yet this study shows that befloxatone enhances volunteers mood under extraordinary circumstances; i.e. after fatiguing testing, sometimes coupled with the unpleasant after-effects of mild-moderate ethanol intoxication.

Two statistically significant pharmacodynamic interactions seemed to show differential pretreatment effects on the subjects responses to ethanol. That involving CTT was probably spurious because it did was not reflect differential effects of ethanol but ethanol placebo. Performance was unexpectedly poor after the latter when subjects 
where pretreated with placebo. The other involved body sway. With eyes open body sway was in one test more affected by befloxatone than placebo. However the isolation of this event and its late time of occurrence (i.e. $3 \mathrm{~h}$ after drinking) probably means that it was a chance result.

Pharmacokinetic data showed that befloxatone had no effects on ethanol metabolism. Surprisingly, the opposite (i.e an effect of ethanol and befloxatone) seemed to occur 45 minutes after drinking ethanol, when much of the absorption and distribution of befloxatone had already been completed. Mean befloxatone concentration rose in direct relationship with ethanol dose and in addition mean concentration of the demethyl metabolite fell proportionally. This suggests that ethanol inhibited the O-demethylation of befloxatone in the same manner as it interferes with the oxidative metabolism of many drugs, including tricyclic antidepressants, by inhibiting certain isozymes comprising the cytochrome P450 system (Rudorfer and Potter, 1987). However this explanation was not supported by inspection of the individual data: only about a third of the subjects' befloxatone concentrations rose as its metabolite's fell with increasing ethanol doses. Thus the final explanation must await a complete pharmacokinetic assessment of the interaction between ethanol and befloxatone. It is only important to note in the present context that the interaction, if it occurred, did not result in any potentiation of ethanol's effects on performance. It is therefore concluded that befloxatone given in $20 \mathrm{mg}$ doses for 6-10 days does not impair performance and does not potentiate the impairing effects of ethanol in blood concentrations below $1.1 \mathrm{mg} / \mathrm{ml}$.

\section{References}

Allen D, Lader M, Curran HV (1988). A comparative study of the interactions of alcohol with amitriptyline, fuoxetine and placebo in normal subjects. Prog Neuro-Psychopharmacol Biol Psychiatry. 12:63-80.

Ansseau M, Caille P, Derks C, Cieren-Poiseux I, Wauthy J, Ego $D_{*}$ Curet $O$, Thiola $A$, Rovei $V$, Jarreau FX (1992) Phase I study of single ascending doses of befloxatone, a new reversible MAO-A inhibitor antidepressant. Clinical Neurophatmacology, 15(S1), $328 \mathrm{~B}$.

Berlin 1, Cournot A, Zimmer R, Pedarriosse AM, Puech A (1989). Evaluation and comparison the interaction between alcohol and moclobemide or clomipramine in healthy subjects. psychopharmacology 100: $40-45$.

Bond $\mathrm{A}$, Lader $\mathrm{M}$ (1974). The use of analogue scales in rating subjective feelings. Br J Med Psychol $47: 211-218$

Curet O, Damoiseau G, Labaune JP. Rovei V, Jarreau FX (1994) Effects of befloxatone, an new potent MAO-A inhibitor, on cortex and stratium monoumines in freely moving rats. J. Neurat. Transm. $41(\mathrm{~S}): 349-355$. 
Herberg $K W_{\text {, Menke }} \mathrm{H}$. (1981) Study of the effects of whe antidepressant fluvoxamine on driving skills and its interaction with alcohol. TUV Remland (Cologne) Technical report, 1981.

Hindmarch I (1988). Three antidepressants (amimiptyline, dothiepin, fluoxetine) with and without alcohol, compared with placebo on lests of psychomotor ability related to car driving. Human Psychopharmacol 2:177-183.

Jex HR, Mc Donell JD (1966). Critical tracking task for marual control research. IEEE Trans. Hum. Fac. Electron, HEE-7, 138-145.

Kapteyn TS, Bles W, Njiokiktjein ChJ, Kadde L, Massen CH, Mol JMF (1983). Standardization in. platform stabilometry being part of posturography. Agressology 24: 321-326.

Kerr JS, Fairweather, Hindnarch I (1993) The effects of brofaromine alone and in conjunction with alcohol on cognitive function, psychomotor performance, mood and sleep in healthy volunteers. Human psychophamacology 8: 107-116.

Lader M, Melhuish A, Freka G, Fredricson Overo K, Cristensen V (1986). The effects of citalopram. in single and reperted doses and with alcohol on physiological abd psychological measures in healthy subjects. Eur J Clin Pharmacol. 31:183-190.

Mackworth WH (1950) Researches on the measurement of human performance. Medical research. council special report No. 268, London, HMSO.

Mulder-Hajonides van der Meulen WREH (1981). Measurements of subjective sleep quality. Proceedings of International European Sleep Congress. Elsevier "Amsterdam.

Patal A, Gandon JM, Durrieu G, Le Coz F, Curet O, Cimarosti I, Allain H (1995a) Effects of single and multiple doses of a new reversible $\mathrm{MAO}-\mathrm{A}$ inhibitor, befloxatone, on psychomotor performance and memory in healthy subjects. Human Psychopharmacol. 10:111 125.

Patat A, Warot D, Berlin I, Durrieu G, Zieleniuk I, Puech A (1995b) Effects of befloxatone on psychomotor performance and memory. Br J Clin Pharmacol (in press).

Ray WA, Fought RL, Decker MD (1992) Psychoactive drugs and the risk on injurious motor wehicle crashes in elderly drivers. Am J Epidemiol. 136: 873-883.

Rovei V, Caille D, Curet O, Ego D, Jarreau FX (1994) Biochemical pharmacology of befloxatone (MD370503), a new potent reversible MAO-A inhibitor. J. Neural. Transm. 41(S): 339-347.

Rudorfer MV, Potter WZ (1987) Pharmacokinetics of antidepressants. In Meltzer HY (ed), Psychopharmacology: The Third Generation in Progress. Raven Press, New York, pp 1353 1363.

Seppälla T, Linnoila M, Elonen E, Matila MJ, Maki M (1975). Effects of tricyclic antidepressants and alcohol on psychomotor skills related to driving. Clin Pharmac Ther. 17:515-522.

Vuuman E, Uiterwijk MMC, Rosenzweig P, OHanlon JF (1994) Effects of mizolastine and clenestine on actual driving performance and psychomotor performance in healthy volunteers volunteers. $47: 253-259$. 


\section{CHAPTER 6}

\section{Considering the cytochrome $\mathrm{P} 450$ system as determining the combined effects of antidepressants and benzodiazepines on actual driving performance of depressed outpatients}

\section{ABSTRACT}

Parallel groups of depressed (DSM III-R) outpatients received moclobemide (22) and fluoxetine (19), double blind, for 6 weeks. Respective starting doses were $150 \mathrm{mg}$ bid and $20 \mathrm{mg}$ qam. These could be doubled after 3 weeks for greater efficacy. Chronic users of benzodiazepine (BZD) anxiolytics continued taking them as comedication. Therapeutic and side effects were assessed using conventional rating scales. Actual driving performance was assessed during the week prior to therapy and at 1,3 and 6 weeks thereafter using a standardized test that measures standard deviation of lateral position (SDLP). Similar remissions in depressive symptoms and side effects occurred in both groups. Patients drove with normal and reliable $(r=87)$ SDLPs before treatments. Most continued to do so but a few drove with progressively rising SDLPS and the overall trends were significant in both groups $(\mathrm{p}<.03)$. A post hoc multiple regression analysis was applied for identifying factors that correlated with SDL.P in separate tests after the beginning of therapy. At 3 and 6 weeks there were significant $(p<03)$ relationships involving the same factor: Patients who drove with progressively higher SDLPS appeared to be those using BZDs that are metabolized by a P450 isozyme subject to inhibition by their particular antidepressant.

JG Ramaekers, $M$ Ansseau, ND Muntjewerf. JP Sweens, JF OHanlon. In Clin Psychopharmacol 12:159-169, 1997 


\section{INTRODUCTION}

Information pertaining to driving performance of depressed outpatients prior to or during antidepressant drug therapy is relatively sparse. Pharmacoepidemiological surveys indicate that unmedicated depressed patients drive with a higher than normal risk of becoming involved in injurious traffic accidents (Nelson, 1986); and that elderly patients treated with higher doses of sedative tricyclic antidepressants become involved in accidents more frequently than age- and sex-matched normal controls (Ray et al, 1992; Leveille et al, 1994). However there are as yet no epidemiological data concerning the effects on accident risk of modern antidepressants, such as the sellective serotonin reuptake inhibitors (SSRIs) or selective and reversible inhibitors of monoamine oxidase-A. (RIMAs).

The present attempt to measure to effects of moclobemide and fluoxetine on actual driving performance proceeded from similar research in healthy volunteers (Ramaekers et al, 1992, 1995). In separate, studies individuals were treated with either moclobemide $200 \mathrm{mg}$ twice a day or fluoxetine $20 \mathrm{mh}$ hs and with another antidepressant and placebo, for periods of 8 and 21 days, respectively. Driving performance was assessed on treatment days 1 and 8 in both studies and on treatment day 21 in the longer series. Neither moclobemide nor fluoxetine significantly affected the respective groups ${ }^{*}$ driving performance. From these results one would not expect either drug to impair the present patients' driving performance, at least not over comparable treatment periods. However the the patients' treatments were scheduled to last longer than the volunteers', so the possibility of belated driving impairment could not be excluded. The contrary could also be expected if the therapeutic effect of antidepressant treatment were to determine the patient's driving performance. The remission of the patients'symptoms during moclobemide or fluoxetine therapy might lead to driving improvement if their driving performance was generally deficient to begin with. There were still other reasons to suppose that the results of the previous studies might differ from those of the present study. It is far more difficult to control the influence of factors that can interact with antidepressants to affect performance in trials involving patients. One factor prominent in the area where this study was conducted (Liège, Belgium), is the high prevalence of benzodiazepine (BZD) use (Ansscau, 1988; Petit et al, 1994). In Belgium, most patients suffering from depression are treated with an antidepressant and a BZD concurrently, particularly when the former has insomnia, anxiety or agitation as possible side effects. The protocol of the 
present study allowed patients entering the study to continue their longstanding use of BZD as comedication.

This offered the opportunity of applying a post-hoc analysis to determine whether certain pharmacokinetic antidepressant-BZD interactions affect patients" driwing performance. Moclobemide and fluoxetine are known primarily to inhibit different cytochrome P450 isozymes that are responsible for the oxidative metabolism of many BZDs. The greatest inhibitory activity of moclobemide is at CYP2C19 and to a lesser extent also at CYP1A2 and CYP2D6 (Gram et al, 1995). Inhibition of the latter produces no meaningful change in the pharmacokinetics of moclobemide (Guentert et al, 1995). Fluoxetine is a potent inhibitor of CYP2D6 as well as CYP3A3/4 (Lane et al, 1995). Some BZDs are substrates of CYP2C19, some are substrates of CYP3A3/4, and others are substrates of none of the isozymes inhibited by the antidepressants. The BZD comedication used by patients in the present study could either be metabolically competitive or noncompetitive with their particular antidepressant. The former might accumulate over time and cause the patient to drive progressively worse. That certain combinations of antidepressants and BZDs result in the accumulation in plasma accompanied by progressive performance impaiment has already been demonstrated in healthy volunteers treated with either fluoxetine or nefazadone together with alprazolam (Lasher et al ,1991; Kroboth et al, 1995).

\section{MATERIAL AND METHODS}

\section{Subjects}

Intake interviews were conducted by five psychiatrists under the supervision of the Professor of Psychiatry, University of Liege. Outpatients were included if satisfying the following criteria: age, 18-65 y; diagnosis of Major Depression according to DSM UIR criteria; symptom severity associated with a score 217 on the 17 -item Hamilton Depression Rating Scale (HDRS); possession of a valid driver's licence; and, written informed consent after reading "Information for Volunteers". Patients were excluded on the basis of the following: alcohol and/or drug abuse; acute confusional state, delusions or hallucinations; hypersensitivity to the investigational drugs; serious concomitant illness or intercurrent disease; presumption of a need for hospitalization due to suicide or other factors; engagement in structured analytical or behavioral psychotherapy which might influence the course of the depressive illness during the 
trial, excluding psychotherapeutic support; renal or liver failure or previous viral or drug hepatitis; treatment with cimetidine; personality disorders presenting an important risk of non-compliance; occurrence of cerebrovascular accidents in the year prior to study entrance; duration of the present depressive episode of lless than two weeks; use

Table 1 Patient demofmaphic data and characteristics of thein depressive episode

\begin{tabular}{|c|c|c|c|}
\hline & $\begin{array}{c}\text { Moclobemide } \\
(\mathrm{N}=22)\end{array}$ & $\begin{array}{c}\text { Fluoxerine } \\
(N=19)\end{array}$ & $\begin{array}{c}\text { All patients } \\
(\mathrm{N}=41)\end{array}$ \\
\hline \multicolumn{4}{|l|}{$5 e x$} \\
\hline Male & $13(59 \%)$ & $12(63 \%)$ & $25(61 \%)$ \\
\hline Femper & $9(41 \%)$ & $7(37 \%)$ & $16(39 \%)$ \\
\hline \multicolumn{4}{|l|}{ Age $(y n)$} \\
\hline Mean & 42.3 & 42.4 & 42.3 \\
\hline Minimtam: & 27.0 & 28.2 & 27 \\
\hline Maximuny & 55.4 & 54.2 & 55.4 \\
\hline \multicolumn{4}{|l|}{ HDRS (Mnclusion) } \\
\hline Mean & 21.7 & 224 & 22.0 \\
\hline minimum & 17 & 18 & 17 \\
\hline maxinum & 27 & 32 & 32 \\
\hline \multicolumn{4}{|l|}{ Precipitating factor } \\
\hline None & $1(5 \%)$ & $2(11 \%)$ & $3(7 \%)$ \\
\hline Somatic illness & $1(5 \%)$ & $0(0 \%)$ & $1(2 \%)$ \\
\hline Psycho-social stressoris & $15(73 \%)$ & $15(79 \%)$ & $31(76 \%)$ \\
\hline Somatic illness and psycho-social stressors & $3(14 \%)$ & $2(11 \%)$ & $5(12 \%)$ \\
\hline Uncentain & $1(5 \%)$ & $0(0 \%)$ & $1(2 \%)$ \\
\hline \multicolumn{4}{|l|}{ Tine between last andcurrent eplsode (mo) } \\
\hline Mexh & 20.3 & 126 & 16.8 \\
\hline Minimum & 1.4 & 0.5 & 0.5 \\
\hline Maximum & 157.7 & 73.8 & 157.5 \\
\hline \multicolumn{4}{|l|}{ Chamacterization } \\
\hline Depression with atoxicty & $9(41 \%)$ & $10(53 \%)$ & $19(46 \%)$ \\
\hline Depression with minly somatic symptorys & $2(9 \%)$ & $3(16 \%)$ & $5(12 \%)$ \\
\hline Agitatied depression & $5(23 \%)$ & $3(16 \%)$ & $8(20 \%)$ \\
\hline Retarded depression & $3(14 \%)$ & $1(5 \%)$ & $4(10 \%)$ \\
\hline Neurotic depression & $3(14 \%)$ & $1(5 \%)$ & $4(10 \%)$ \\
\hline Neurotic depression with anxiey & $0(0 \%)$ & $1(5 \%)$ & $1(2 \%)$ \\
\hline
\end{tabular}

of fluoxetine within 5 weeks prior to study entrance; use of other marketed antidepressants or investigational drugs within 7 days or ECT within 4 weeks prior to study entrance; and for females, pregnancy, lactation or the failure to use reliable contraceptives for less than 3 months. 
A total of 41 patients ( 25 males and 16 femalles) were included. Their demographics and diagnostic categorization are summarized in Table 1. The study was carried out in accordance with the Declaration of Helsinki (Hong Kong Modification, 1989). The study protocol and information for volunteers were reviewed and approved by the standing Medical Ethics Committees of the Universities of Liege and Maastricht.

\section{Design}

The study was conducted according to a 2 -leg, double-blind, parallel-group design. A period of 3-7 days elapsed between patient enrollment and the beginning of trial medication. Thereupon, patients were randomly assigned to receive moclobemide 150 $\mathrm{mg}$ bid or fluoxetine $20 \mathrm{mg}$ qam for 6 weeks (43 days). At the discretion of the attending psychiatrist this dosage could be doubled from day 22 on in case of insufficient efficacy. Moclobemide and fluoxetine were administered in identical appearing capsules containing $150 \mathrm{mg}$ and $20 \mathrm{mg}$ respectively. One or two moclobemide capsules were taken in the morning and evening of every treatment day. One or two fluoxetine capsules were taken in the morning, and matching placebo capsules, in the evening. Patients were instructed to take their medication after a meal. In order to ensure patient compliance with the medication regime, the returned medication was checked and counted at each visit.

Concomitant BZD medication was allowed for patients who had already been prescribed a single drug for more than 3 months prior to study entrance. In these cases, prescription of the same BZD continued throughout the study. If needed, patients who had not used a BZD prior to study entrance were allowed to receive one or two doses of oxazepam, $10 \mathrm{mg}$ over the day or $30 \mathrm{mg}$ hs. Type and dose of BZD comedication were filed in prescription records. Compliance with BZD prescription was not checked. Other psychoactive drugs or ECT were prohibited during the trial.

\section{Clinical assessments}

Clinical assessments were conducted by the attending psychiatrists at day 1, 8, 15,22 and 43. Besides the HDRS, the Montgomery Asberg Depression Rating Scale (MADRS), Beck"s Depression Inventory (BDI), and a Clinical Global Impression (CGI) scale were used. In addition the occurrence of side-effects were checked using a standardized adverse events questionnaire. 


\section{Driwing assessments}

Patients undertook a driving test on 6 occasions. A training session and two baseline tests occurred during the week preceding the onset of treatment. Thereafter, driving performance was tested in the morning of day 8,22 and 43 of treatment. Patients were met at home by an investigator and transported to the driving site. He/she then entered a primary highway (4 lane, divided) at the beginning of a $100 \mathrm{~km}$ circuit between the Belgian cities Tongeren and Haelen. He/she proceeded to drive while attempting to maintain the vehicle at a constant speed $(95 \mathrm{~km} / \mathrm{h})$ and steady lateral position between the delineated boundaries of the slower traffic lane. The patient was allowed to deviate from this procedure in order to pass slower vehicles traveling in the same lane. At an intersection halfway through the circuit, the patient drove off the highway and reentered traveling in the opposite direction. At the end of the driving test, the patient was driven home by the investigator.

The patient was accompanied by a technician, whose task was to operate the equipment, and a licensed driving instructor seated in the front passenger's seat with access to dual controls. His sole function was to ensure test safety. Patients were instructed to operate safely at all times and that the treatments might affect their ability to do so. They were informed of their legal responsibility to stop a test in progress if feeling for any reason that to continue would be unsafe. They were further informed that they would be asked to stop by the instructor if, in his opinion, their physical appearance or driving performance indicated the possibility of a control loss. An electro-optical device mounted at the rear back of the instrumented vehicle continuously measured the lateral distance separating the vehicle and the left lane-line. This signal was digitized at a rate of $4 \mathrm{~Hz}$ and stored on an onboard computer disk file for later editing and analysis. The off-line editing routine involved removal of all data segments that revealed signal loss, disturbance or occurrence of passing maneuvers. The remaining clean data were then used to calculate means and variances for lateral position. The square root of the variance, or standard deviation of lateral position (SDLP) was then taken as the primary measure of driving performance.

\section{Statistics: a priori comparisons}

Efficacy and driving variables were evaluated in two ways: between patients' baseline and the last visit for the intention to treat population and over all visits for those completing the study. A repeated measures analysis of variance (ANOVA) was used to test for the effects of the factor Drugs, Time and their interaction on HDRS, MADRS 
and BDI scores. Ordinal CGI scores were compared between Drugs for every visit separately by means of a non-parametric Mann-Whitney test. Side effects were evaluated using the Chi-square test or in the case of too small expected frequencies, the Fisher-Exact test.

The coefficient of correlation between all patients' two baseline SDLP scores was calculated before averaging them, per patient, to a single pretreatment score. SDLP scores at baseline and during treatment then entered a repeated measures, multivariate analysis of variance (MANOVA) to evaluate the effects of Drugs, Time and their interaction. Orthogonal polynomial contrast were used to measure linear, quadratic and cubic trends over Time.

\section{Statistics: a posteriori comparisons}

A post-hoc multiple linear regression analysis was applied to determine whether other factors independently correlated with driving performance. Selected factors were either continuous variables or dichotomous indicator ( 0 or 1$)$ variables. Factors belonging to the former category were: Pretreatment SDLP (average of two baseline scores) and Depression Severity (MADRS). Those belonging to the latter were: Antidepressant (moclobemide or fluoxetine); Double Dose (1x or $2 \mathrm{x}$ the starting antidepressant dose after the $3^{\text {rd }}$ treatment week); Sleep Disturbance, Nervousness, Nausea (presence or absence); BZD Comedication (presence or absence), High Dose BZD comedication (presence or absence of doses exceeding Petit et al's (1994) local definition of 'defined daily doses (DDD)') and Competitive BZD comedication (presence or absence).

The rationale for identifying certain BZDs taken by these patients as competitive with moclobemide, and others with fluoxetine, is lengthy and for that reason reserved for Discussion. For now the former are simply listed as clorazepate, prazepam, diazepam, cloxazolam and clotiazepam; and the latter as bromazepam and alprazolam.

Stepwise construction of multiple linear regression equation began with the calculation of product moment or biserial coefficients of correlations between each of the independent variables and the dependent variable, SDLP. The first independent variable considered for entry into an regression equation was the one with the largest positive or negative correlation with the dependent variable. The proportion of variance "explained" by the equation (i.e $\mathrm{R}^{2}$ or Goodness of Fit) was then evaluated relative to the residual variance by F-test. The variable entered the regression equation if $\mathrm{R}^{2}$ was significant. Once a variable was selected, the partial correlations between 
SDLP and each of the other independent variables not in the equation, adjusted for the independent variable in the equation, were used to select the next one. The independent variable with the largest partial correlation was the next candidate for inclusion in the equation. It was entered if associated with a significant change in $\mathrm{R}^{2}$ as indicated by the T-test. Subsequently, a new set of partial correlations was calculated, again adjusted for independent variable(s) in the equation. Variable selection terminated when no more variables significantly increased $\mathrm{R}^{2}$. This analysis was separately applied on data collected after 1,3 and 6 weeks of treatment.

\section{RESULTS}

Intent to treat population and completers.

The intent to treat population comprised 41 patients of whom 22 and 19 were assigned to moclobemide and fluoxetine groups. Two patients withdrew after 2 and 3 weeks of moclobemide treatment; one for reasons unrelated to treatment and the other because of side effects (nervousness, agitation, sleep disturbances). Another patient's moclobemide treatment was stopped after 5 weeks due to the psychiatrist suspicion that he might develop mania. This patient completed the final driving test, albeit one week earlier than the others. One patient withdrew during the first week of fluoxetine treatment because of nervousness, agitation and sleep disturbance. Another member of the fluoxetine group provided all clinical data but did not perform his last driving test because he immediately departed on a vacation. In summary, complete clinical data were collected for 18 and 19 patients, and complete driving data, for 20 and 17 patients in the moclobemide and fluoxetine groups, respectively.

\section{Efficacy}

Descriptive statistics and results of statistical analyses of HDRS, MADRS and BDI scores are given in Table 2. ANOVA and Mann-Whitney tests provided comparable results for the intent to treat population and completers. Moclobemide and fluoxetine produced similar, significant reductions in mean depression ratings on all scales during 6 weeks of treatment. The drugs' comparable effects on depressive symptoms were further demonstrated by HDRS scores at the final assessment. In the moclobemide group, $55 \%$ of the intent to treat population and $58 \%$ of the completers showed HDRS scores less than 10 or a decrease from baseline of more than $50 \%$. In the fluoxetine 
group, respectively $53 \%$ and $61 \%$ showed these positive responses. Cal ratings at baseline and during therapy did not differ between treatment groups.

Table 2 Mean (sd) HDRS, MADRS and BDI scores by groups and times of assessments: and, $p$-values associated with effects of Drugs, Time and their interaction for intent to treat patients and completers (moc moclobemide; flu=fluoretime).

\begin{tabular}{|c|c|c|c|c|c|c|}
\hline \multirow{2}{*}{ Thine of Assessmentis } & \multicolumn{2}{|c|}{ HDRS } & \multicolumn{2}{|c|}{ MADRS } & \multicolumn{2}{|c|}{$B D Y$} \\
\hline & $F L U$ & $M O C$ & FLL & $M O C$ & Fu & MOC \\
\hline Baseline & $\begin{array}{l}22.7 \\
14.0\end{array}$ & $\begin{array}{l}20.8 \\
(3.1)\end{array}$ & 28.1 & $\begin{array}{l}26.5 \\
10.2)\end{array}$ & $\begin{array}{l}16.1 \\
(7.4)\end{array}$ & $\begin{array}{l}15.6 \\
(5.5)\end{array}$ \\
\hline Werk 1 & $\begin{array}{l}17.5 \\
(4.8)\end{array}$ & $\begin{array}{l}18.6 \\
(3.6)\end{array}$ & 21.2 & $\begin{array}{l}22.5 \\
(6.4)\end{array}$ & $\begin{array}{l}12.6 \\
(4.7)\end{array}$ & $\begin{array}{l}13.2 \\
(5.4)\end{array}$ \\
\hline Werek 2 & $\begin{array}{l}14.6 \\
(4.8)\end{array}$ & $\begin{array}{l}15.9 \\
(6.7)\end{array}$ & $\begin{array}{l}18.5 \\
(7.4)\end{array}$ & $\begin{array}{l}19.6 \\
(9.6)\end{array}$ & $\begin{array}{c}9.7 \\
(5.8)\end{array}$ & $\begin{array}{l}13.7 \\
(8.7)\end{array}$ \\
\hline Week 3 & $\begin{array}{l}13.5 \\
(5.2)\end{array}$ & $\begin{array}{l}14.1 \\
(5.9)\end{array}$ & $\begin{array}{l}16.8 \\
(7.7)\end{array}$ & $\begin{array}{l}18.7 \\
(9.6)\end{array}$ & $\begin{array}{l}11 . .1 \\
(7.2)\end{array}$ & $\begin{array}{l}130 \\
0.07\end{array}$ \\
\hline Week 6 & $\begin{array}{l}11.1 \\
(6.1)\end{array}$ & $\begin{array}{l}12.2 \\
(5.8)\end{array}$ & $\begin{array}{l}13.7 \\
(8.8)\end{array}$ & $\begin{array}{l}14.3 \\
(8.5)\end{array}$ & $\begin{array}{c}9.2 \\
(8.5)\end{array}$ & $\begin{array}{l}10.8 \\
(6.7)\end{array}$ \\
\hline Last visit & $\begin{array}{l}11.7 \\
(6,6)\end{array}$ & $\begin{array}{r}12.1 \\
(5.4)\end{array}$ & $\begin{array}{l}14.5 \\
(9.2)\end{array}$ & $\begin{array}{r}142 \\
(7.9) \\
\end{array}$ & $\begin{array}{r}9.5 \\
(8.3)\end{array}$ & $\begin{array}{l}10.3 \\
(6.4)\end{array}$ \\
\hline ANOYA & $\begin{array}{c}\text { Completers } \\
(N=37)\end{array}$ & $\begin{array}{c}\text { Intent no } \\
\text { trear }(N=41) \\
\end{array}$ & $\begin{array}{c}\text { Complerers } \\
\left(N^{4}=37\right)\end{array}$ & $\begin{array}{c}\text { Intexur to } \\
\text { treat }(N=4)\end{array}$ & $\begin{array}{c}\text { Complesers } \\
(N=37)\end{array}$ & $\begin{array}{l}\text { Inean ro } \\
\text { treat }(N=4)\end{array}$ \\
\hline Diruggs & $p=528$ & $p=.381$ & $p=650$ & $\eta=667$ & $p=1.8$ & $p=603$ \\
\hline Time & $\mathrm{p}<0.000$ & $p<, 001$ & $p<001$ & $p<00$ & $p<0001$ & $p \times 00 !$ \\
\hline Drugs by Time & $\mathrm{p}=727$ & $p=654$ & $p=761$ & $p=650$ & $p=304$ & $p=877$ \\
\hline
\end{tabular}

\section{Adverse events}

Nausea, nervousness/agitation, sleep disturbances and dizziness were reported by 6,5 , 3 and 2 patients in the fluoxetine group and by $5,6,11$ and 1 patients in the moclobemide group. None of these frequencies differed significantly between groups. In addition 5 patients meported dry mouth during fluoxetine treatment.

\section{Dose doubling and BZD comedication}

After 3 weeks of treatment, daily dose was doubled for $14(67 \%)$ patients in the moclobemide group and for $6(33 \%)$ patients in the fluoxetine group $(p=.08), B Z D$ anxiolytics were being taken by 30 patients at study entrance and their use continued during treatment. One patient started taking BZD comedication during the study. In total, $16(73 \%)$ and $15(79 \%)$ patients in the moclobemide and fluoxetine group, respectively, used $B Z D$ during treatment. The types of comedication taken by patients 
in both groups, the numbers using each one and the numbers taking them in higher than the respective DDDs are given in Table 3.

Table 3 Number of patients receiving HZD comedication, and doses higher than DDD.

\begin{tabular}{|c|c|c|c|c|}
\hline \multirow[b]{2}{*}{$B Z D(D D D)$} & \multicolumn{2}{|c|}{ Fluoretine $(N=19)$} & \multicolumn{2}{|c|}{ Moclobemide $(N=22)$} \\
\hline & Hpatients & $\begin{array}{c}\text { Doses }> \\
D D D\end{array}$ & H patients & $\begin{array}{c}\text { Doses }> \\
D D D\end{array}$ \\
\hline Clorazepate (20mg) & - & - & 3 & 2 \\
\hline Prazepsm (30mg) & 1 & - & 2 & 1 \\
\hline Dinzepum (10mg) & 1 & - & $\mathbb{1}$ & 1 \\
\hline Clowarolam (2mg) & . & - & $\mathbb{1}$ & 1 \\
\hline Clotiazepam (5mg) & - & - & 1 & $i$ \\
\hline Bromazepam (10mg) & $4^{\prime \prime}$ & $2^{*}$ & 1 & 1 \\
\hline Alprazolam (1 mg) & 3 & 2 & 1 & - \\
\hline Oxazepam (50mg) & 3 & . & 5 & . \\
\hline Lorazepam (2.5mg) & 3 & 3 & $\mathbb{1}$ & $\mathbb{1}$ \\
\hline "rotal cases & 15 & 7 & 16 & 8 \\
\hline
\end{tabular}

"One pationt only conjpleatat driving tests at baselancs.

Driving performance: A priori analyses

Figure 1 shows the relationship between the patients' two SDLP scores from consecutive baseline tests. They drove with similar SDLP mean \pm SE values on both occasions $(24.2 \pm 0.95$ versus $24.1 \pm 0.81 \mathrm{~cm})$ and the individual values were highly reliable ( $r=87$ ). There was no difference between SDLP scores of patients who were taking BZDs and those who were not, neither for each test separately nor for both combined (combined mean $\pm \mathrm{SE}, 24.1 \pm 0.91$ versus $24.2 \pm 1.59 \mathrm{~cm}: \mathrm{F}_{1,39}=004$; $\mathrm{p}=.95$ ).

Figure 2 shows each group"s mean SDLP (SE) in baseline tests and in those given after 1, 3 and 6 weeks of treatment. MANOVA revealed no significant overall mean differences in SDLP between the fluoxetine and moclobemide groups for either the intent to treat population or the completers. Within subjects the overall linear increase in SDLP over time was significant for the intent to treat population and the completers $\left(F_{1,34}=5.35, p=.026 \& F_{1,35}=5.44, p=.026\right)$. The interaction between Drug and Time was not significant. 


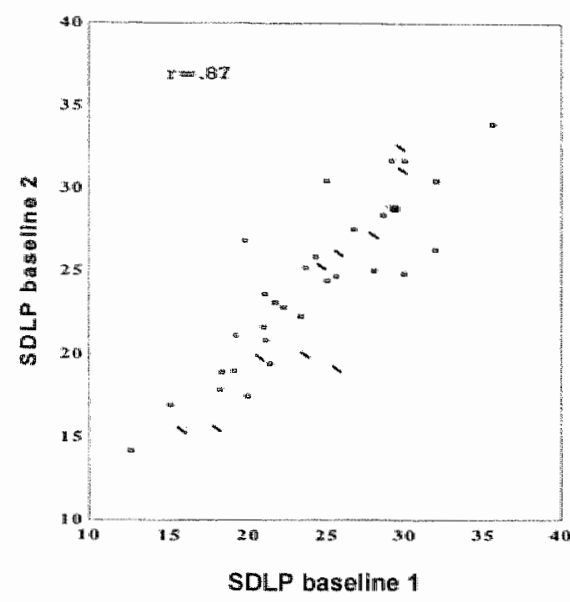

Figure 1 Individual driving performance. of 1 depressed outpatients at the first and the second baseline test. Thirty patients were $B Z D$ users (a), others were non-users (x)

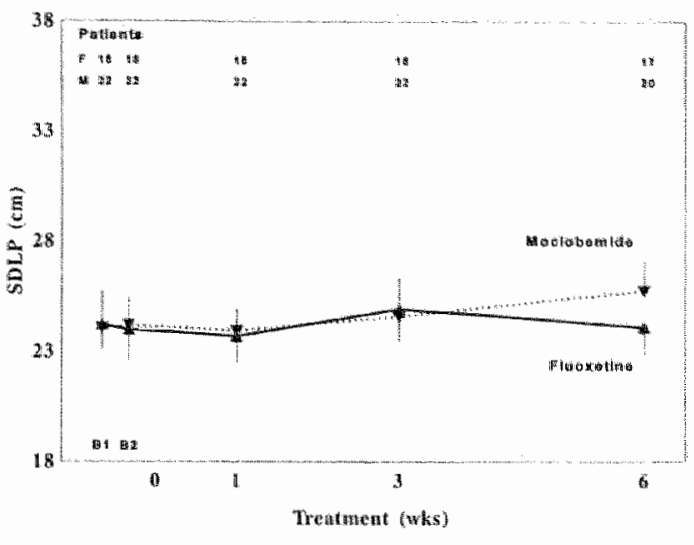

Figure 2 Mean (tE) SDLP during baseline tests and those given after 1,3 and 6 weeks of therapy with fluovetine and noclobemide. Number of patients participating are noted separately for groups receiving fluoxetine (F) and mociobemide $(M)$

\section{Driving performance: A posteriori analyses}

Results from the multiple linear regression analysis are given in Table 4 . These show that Pretreatment SDLP correlated strongly with scores measured on subsequent occasions. The proportions of SDLP variance 'explained' by pretreatment scores were $.81, .78$ and .64 after 1,3 and 6 weeks of therapy. That this proportion dropped between weeks 3 and 6 implies the growing influence of other factors on the patients' driving performance. There may have been several but the only one that to emerge as a significant determinant of SDLP variation was competitive BZD comedication. Inclusion of this dichotomous variable in the equation increased the proportion of "explained" SDLP variance by 0.02 after week 3 and by 0.05 after week 6.

Fig 3 illustrates the effects on mean (SE) SDLP of both antidepressants, separately and together, in the presence or absence of competitive BZD comedication. Although data from subgroups using noncompetitive and no $\mathrm{BZD}$ comedication were combined in the regression analysis, their separate mean SDLP values are shown separately in the figure. It is clear that none of these subgroups" performances changed substantially from baseline levels over the course of treatment. In contrast, mean SDLP rose progressively from baseline for the subgroup taking moclobemide in combination with competitive BZD comedication. The subgroup taking fluoxetine in combination with 
Table 4. Variables enfering the multiple linear regression analysis and their associated p-values as indicated by $\mathrm{F}$ and $\mathrm{T}$ tests (Slope and intercept values are shown in the column labelled $B$ )

\begin{tabular}{|c|c|c|c|c|c|c|c|c|c|}
\hline \multirow[b]{2}{*}{$\begin{array}{l}\text { Wariables in the } \\
\text { equation }\end{array}$} & \multicolumn{3}{|c|}{ Week 1} & \multicolumn{3}{|c|}{ Week 3} & \multicolumn{3}{|c|}{ Week 6} \\
\hline & $B$ & $T$ & $\mathrm{p}$ & $\mathrm{B}$ & $\mathrm{T}$ & $\mathrm{p}$ & B & $\mathrm{T}$ & $p$ \\
\hline (Constanit) & 3.88 & 2.45 & .018 & 1.67 & .83 & .394 & 3.52 & 1.31 & .198 \\
\hline Pretreatrnent SDLP & .82 & 12.88 & .000 & .92 & 11.53 & .000 & .86 & 7.77 & .000 \\
\hline Competitive $B Z D$ & & & & 2.04 & 2.46 & .019 & 2.81 & 2.39 & .023 \\
\hline Multipile $\mathbb{R}$ & \multicolumn{3}{|c|}{.902} & \multicolumn{3}{|c|}{.901} & \multicolumn{3}{|c|}{.830} \\
\hline R Square I variable & \multirow{2}{*}{\multicolumn{3}{|c|}{.813}} & \multicolumn{3}{|c|}{.779} & \multicolumn{3}{|c|}{.635} \\
\hline R Square $2^{\text {nu }}$ ariable & & & & \multicolumn{3}{|c|}{.811} & \multicolumn{3}{|c|}{.689} \\
\hline Analysis of variance & \multicolumn{3}{|c|}{$F_{1: 18}=165.89 ; p<<.001$} & \multicolumn{3}{|c|}{$F_{7.36}=77.41 ; p<.001$} & \multicolumn{3}{|c|}{$F_{2,3}=36.61 ; p<001$} \\
\hline $\begin{array}{l}\text { Variables not } \\
\text { in the equation }\end{array}$ & \multicolumn{3}{|c|}{$\mathrm{p}$} & \multicolumn{3}{|c|}{$\mathrm{p}$} & \multicolumn{3}{|c|}{$\mathrm{p}$} \\
\hline Antidepressants & \multicolumn{3}{|c|}{.707} & \multicolumn{3}{|c|}{.612} & \multicolumn{3}{|c|}{.236} \\
\hline Double Dose & \multicolumn{3}{|c|}{ not applicable } & \multicolumn{3}{|c|}{ not applicable } & \multicolumn{3}{|c|}{.842} \\
\hline Depression Sewerity & \multicolumn{3}{|c|}{.336} & \multicolumn{3}{|c|}{.884} & \multicolumn{3}{|c|}{.421} \\
\hline BZD Comedication & \multicolumn{3}{|c|}{.210} & \multicolumn{3}{|c|}{201} & \multicolumn{3}{|c|}{.340} \\
\hline High doses BZD & \multicolumn{3}{|c|}{.801} & \multicolumn{3}{|c|}{.419} & \multicolumn{3}{|c|}{.790} \\
\hline Competitive $\mathrm{BZD}$ & \multicolumn{3}{|c|}{.832} & & & & & & \\
\hline Sleep Disturbances & & .062 & & \multicolumn{3}{|c|}{.905} & & .953 & \\
\hline Nervousness & & .468 & & & .213 & & & .220 & \\
\hline Nausea & & .463 & & & .491 & & & .196 & \\
\hline
\end{tabular}

competive BZD comedication showed a similar rise in mean SDLP after 3 weeks but then a recovery to baseline levels after week 6 .

\section{DISCUSSION}

This was the first study to assess objectively the driving performance of depressed outpatients before and during antidepressant therapy. The purpose was to determine whether the drugs' therapeutic or side effects influence the patients' driving performance. Moclobemide and fluoxetine produced similar remissions in the respective groups' depressive symptoms over the course of parallel 6-week treatment periods. It should be noted, however, that a higher proportion of the moclobemide group required dose-doubling to achieve this improvement (i.e 67 versus $33 \%, p=.08$ ). 


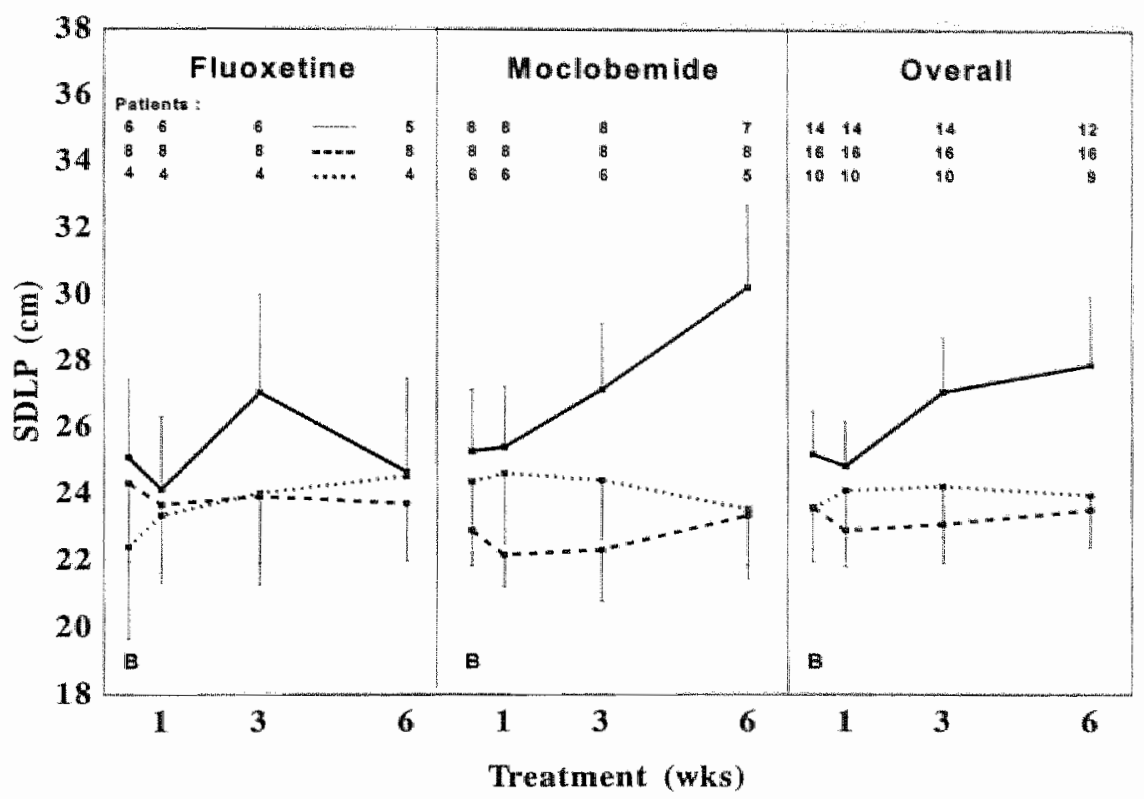

Figure 3 Mean ( 1 SE) SDLP as a function of rime for subgroups of patients receiving (-) competitive comedication, (--.) noncompetitive comedication or" ("..) none at all during treatment with fuoxetine and moclobemide

The drugs' side effects (nervousness, irritability and sleep disturbances) were likewise similar in frequency and severity.

The patients' baseline driving performance were reliable, as indicated by a testretest correlation of 0.87 . They drove with a mean SDLP of approximately $24 \mathrm{~cm}$ during both tests. This only slightly higher than mean values recorded for healthy volunteers or anxious patients in similar studies (i.e 19-23 cm, Van Laar et al, 1992; O'Hanlon et al, 1995; Ramaekers et al, 1995). All but one of the present patients drove at baseline with SDLPs that were well below the established normal limit of $35 \mathrm{~cm}$. Most of them were BZD users. Yet the users' mean SDLP was little different from that of the minority who were not using BZDs. This finding confirms results from previous studies experimental and epidemiological research. Van Laar et al (1992) treated. anxious patients for 4 weeks with diazepam $5 \mathrm{mg}$ tid. Their driving impairment was substantial after the first week but gradually diminished over time. After 4 weeks, their driving performance no longer significantly differed from baseline. Neutel (1995) calculated the risk of becoming involved in an injurious traffic accident for 148,000 patients as a function of time after receiving a prescription for BZD anxiolytics relative 
to that of 98,000 controls. Patients drove with a risk that was 13.5 times higher than the controls during the first week after their prescription were filled, but after 4 weeks the relative risk had decreased to a value of 2.6 with no measurable effect after that. Together these results indicate that depression itself, but not long-term use of BZDs was responsible for the patients' slightly deficient driving performance at the time of study entry.

The progressive remission in both groups' depressive symptoms was not accompanied by an improvement in driving performance. In fact the opposite occurred: mean SDLP for all patients combined rose throughout the 6-week treatment period. The rising trend was very gradual but statistically significant. Though there was no significant difference in trends between both groups, that for the moclobemide group was most pronounced. This was surprising since moclobemide does not accumulate with repeated dosing, whereas fluoxetine and its active metabolite do so to marked degrees. Thus we suspected that some factor besides or in addition to the antidepressants was responsible for at least some patients' progressive deterioration in driving ability. Several were conceivable and the post hoc analysis was applied in the hope of identifying the factor or factors responsible for the change.

One was suggested by concern about antidepressant-BZD interactions involving the cytochrome P450 enzyme system (Bresen, 1993; Von Moltke et al, 1995) Among all of the P450 isozymes so far identified in humans only CYP2C19, and two almost identical isozymes of the CYP3A subfamily, respectively -3 and -4 (CYP3A3/4), are able to catalyze oxidative reactions involving BZDs (Ketter et al, 1995). Moclobemide is a substrate for and a relatively potent inhibitor of CYP2C19 (Gram et al, 1995). Fluoxetine's metabolite, norfluoxetine, is a potent inhibitor of CYP3A3/4 (Von Moltke et al, 1994). CYP3A3/4 inhibitors retard the first steps in the metabolism of bromazepam (3-hydroxylation: Van Harten et al, 1992) and alprazolam, triazolam and midazolam (a-hydroxylation: Lasher et al, 1991; Kroboth et al, 1995). Andersson et al. (1994) found that the inhibition of both CYP3A3/4 and CYP2C19 retarded the Ndemethylation of diazepam to form nordiazepam, but that only the former prevented the 3-hydroxylation of diazepam to form temazepam in vitro. Bertilsson et al (1989) provided the first indication that nordiazepam's metabolism proceeds through the polymorphic isozyme responsible for hydroxylation of S-mephenytoin, later identified as CYP2C19 (Wrighton et al, 1.993; Goldstein et al, 1994). They showed that clearance and elimination of diazepam and nordiazepam in extensive hydroxylators of $\mathrm{S}$ mephenytoin proceeded at twice the rates found in poor metabolizers. In addition, 
Caraco at al (1995) showed that concomitant administration of diazepam and ameprazole, a CYP2C19 inhibitor, reduced diazepam' clearance and increased nordiazepams' AUC in extensive metabolizers. Fluoxetine also reduced diazepam's clearance, but at the same time lowered nordiazepam"s AUC by presumably inhibiting CYP3A3/4 (Lemberger et al, 1988). Thus the evidence so far indicates that while diazepam is N-demethylated at both CYP3A3/4 and CYP2C19, nordiazepam's 3hydroxylation mainly, if not entirely, occurs at CYP2C19.

Moclobemide's effects on BZDs' metabolism are still unknown but for purposes of analysis they were assumed to be those of a CYP2C 19 inhibitor. Thus we dichotomized between those patients taking moclobemide with any $\mathrm{BZD}$ that possesses nordiazepam among its metabolites, and those taking another BZD or none. We further assumed that fluoxetine primarily inhibits CYP3A3/4. Again we dichotomized between those patients taking $B Z D$ that are known substrates of that isozyme, except diazepam, and those taking another BZD or none. The former patients in both grotups were defined as taking competitive comedication, and the latter as taking noncompetitive medication or none. A question arose in the case of one patient taking the combination of noclobemide and the little known BZD, clotiazepam. The combination was defined as competitive, mainly because clotiazepam's metabolism proceeds by $\mathrm{N}$-demethylation and 3-hydroxylation, like diazepam's, though more rapidly (Ochs et a1, 1984). We admit that this assignment was more arbitrary than the others.

The dichotomization yielded interesting results in the multiple regression analysis. Its application with the data from the driving test after 1 week of antidepressant therapy showed no significant partial correlation between patients use of competitive BZDs and SDLP. At that time, their performance was simply related to pre-existing individual differences in SDLP, showing again the stability of the measure in the absence of any new factor. Subsequent applications with data from tests given after both the $3^{\text {rd }}$ and $6^{\text {th }}$ week indicated the emergence of a new factor. At these times, the dichotomous variable identifying users and non-users of competitive BZDS correlated significantly with SDLP. In general. patients taking competitive BZDs drove progressively worse, whereas the others continued to drive in about the same manner as before. We assume that a rising brain concentration of the comedication, or its active metabolite, due to the particular antidepressants inhibition of the inactivating isozyme was the root cause for the former patients" deterioration. 
There was an apparent difference between the persistence of driving impairment in patients taking competitive BZD comedication with moclobemide and fluoxetine. For the moclobemide subgroup, mean SDLP rose throughout the 6-week treatment period, but for the fluoxetine subgroup, only until the $3^{\text {rd }}$ week. Maximal elevations in mean SDLP in the fluoxetine and moclobemide subgroup were around 2 and $5 \mathrm{~cm}$ respectively, which were close to elevations previously shown in social drinkers while operating with blood alcohol concentrations of 0.50 and $0.80 \mathrm{mg} / \mathrm{ml}$ respectively (Louwerens et al, 1987). Possibly this difference is related to the respective sites of the pharmacokinetic interaction. The only known BZD substrates of CYP2C19, diazepam and nordiazepam, are slowly metabolized under normal circumstances. Except for diazepam, those of CYP3A3/4 are all more rapidly metabolized. Supposing moclobemide and fluoxetine/norfluoxetine selectively inhibit. these respective isozymes to similar degrees, it would take longer for substrates of CYP2C19 to reach a new steady state than substrates of CYP3A3/4. This does not imply that moclobemide's interaction with competitive BZDs is any more consequential for patient safety than fluoxetine's. It might have appeared that way if all of the patients had been taking nordiazepam during the study. But exactly the opposite impression might have been given if they had been taking alprazolam.

The dual purpose of every post hoc analysis is to simultaneously explain an unforseen result and provide hypotheses for further research. Some explanations for the unforseen deterioration in some patients' driving performance at a relatively late stage during their treatment with study medication seemed necessary in view of the likelihood that the same could occur in real-life. Our explanation is for the moment tentative and mainly of heuristic value. Well controlled studies should now be undertaken to determine which antidepressant-BZD combinations are and are not compatible with patient safety as they engage in potentially dangerous activities, like driving.

\section{References}

Andersson T, Miners JO, Veronese ME, Birkett DJ (1988). Diazepan metabolism by human liver microsomes is mediated by both $S$-mephenytoin hydroxylase aand CYP3A isoforms. IClin Psychopharmacol 15: 131-137.

Ansseau M (1988). The pharmacological treatment of anxiety. Rev Med Liege 43: 80-91.

Bertilsson L, Herthorn TK, Sanz E, Tybring G, Sawe J, Villén T (1989) Importance of genetic factors in the regulation of diazepam metabolism: relationship to S-mephenytoin, but not to debrisoquin, hydroxolation phenotype. Clin Pharnacol Ther 45:348-355. 
Brosen $\mathbb{K}$ (1993) Isozyme specific drug oxidation: genetic polymorphism and drug-adrug interactions. Nord J Psychiatry 47 (suppl):21-26.

Caraco $Y$, Tateishi $T$, Wood AJI (1995) Interethnic differences in omeprazole's inhibition of diazepam metabolism. Chin Pharnacol Ther 1:62-72.

Flockhart DA (1995) Drug interactions and the cytochrome P450 system. Chin Pharmacokinet 29 (suppl): $45-52$.

Goldstein JA, Faletto MB, Romkes-Sparks M (1994) Evidence that CYP2C19 is the major (S)mephenytoin 4'-hydroxylase in humans. Biochemistry $33: 1743-1752$.

Gram LF, Guentert TW, Grange S, Vistisen K, Brosen K (1995) Moclobemide, a substrate of CYP2C19 and an inhibitor of CYP2C19, CYP2D6 and CYP 1A2: a panel study. Clin Pharm Ther $57: 670-677$,

Guentert TW, Grange S, Bock J, Waldburger R, Birnboeck H (1995) Lack of an important influence of CYP2D6 oxidation status on the pharmacokinetics of moclobemide. Clin Pharm \& Therapeutics 57(2): 151 .

Ketter TA, Flockhard DA, Post RM, Denicoff K, Pazzaglia PJ, Marangell LB, George MS, Callahan AM (1995) The emerging rolle of cytochrome $P 4503 \mathrm{~A}$ in psychopharmacology. If Clin Pharmacol 15:387-398.

Kroboth PD, Folan MM, Lusch RM, Chaikin PC, Shukla UA, Barbaiya R, Salazar DE (1995) Coadministration of nefazodone and benzodiazepines: I pharmacodynamic assessment. I of Clin Pharmacol 15: 306-319.

Lane $\mathbb{R}$, Baldwin D, Preskorn S (1995) The SSRI's: advantages, disadvantages and differences. J of Psychopharmacol 9 (suppl): 163-178.

Lasher TA, Fleishaker JC, Steenwyck RC, Antal EJ (1991) Pharmacokinetic, phamacodynamic evaluation of the combined administration of alprazolan and fluoxetine. Psychopharmacology 104: 323-327.

Lemberger L, Rowe H, Bosonworth JC, Tenbarge JB, Bergstron RF (1988) The effect of fluoxetine on the pharmacokinetics and psychomotor responses of diazepam. Clin Pharmacol Ther $43: 412-419$.

Leveille SG, Buchner DM, Koepsell TD, McClosky LW, Wolf ME, Wagner EH (1994) Psychoactive medications and injurious motor vehicle collsions involving older drivers. Epidemiology 5: $591-598$.

Nelson RC (1986) Psychotherapeutic drugs, mental disorders and automobile crashes: a case-control study of 1308 females. [Dissertation]. Minneapolis, Mimnisota: University of Mirnisota.

Neutel CII (1995) Risk of traffic accident injury after a prescription for a benzodiazepine. Pharmacoepidemiology 5: 239-244.

Ochs HR, Greenblatt DJ, Verbyrg-Ochs B, Harmatz JS, Grehl HI (1984) Disposition of clothiazepam: influence of age, sex, oral contraceptives, cimetidine, isoniazid and ethanol. Eur $\mathrm{J}$ Clin Pharmacol 26:55-59.

O'Hanlon JF, Vermeeren A, Uiterwijk MMC, Veggel van LMA, Swijgman HF (1995) Anxiolylics' effects on the actual driving performance of patients and healthy volunters in as standardized test. Neuropsychobiology 31:81-88.

Petit N, Delporte JP, Ansseau M, Albert A, Jeusette F (1994) Drug utilization review of oral forms of benzodiazepines in a Beigian 635-bed teaching hospital Pharm World Sci 16: 181-186.

Ray WA, Fought RL, Decker MD (1992). Psychoactive dngs and the risk of injurious motor vehicle crashes in elderly. Am J Epidemiology 136:873-883.

Ramaekers JG, Swigman $\mathrm{HF}$, OHanlon JF (1992) Effects of moclobemide and mianserin on highway driving, psychometric performance and subjective parameters, relative to placebo. Psychophamacology 106 (suppl): 62-67. 
Ramackers JG, Muntjewerf ND, OHanlon Jf (1995) A comparative study of the acute and subchronic effects of dothiepin, fluoxetine and placebo on psychomotor and actual driving performance. Br J Clin Pharmac 39:397-404.

Van Harten $J$, Holland RL, Wesnes $K$ (1992) Infuence of multiple dose administration of fluvoxamine on the pharmacokinetivs of the benzodiazepines bromazepam and lorazepan: a tandomized, cross-over study. Eur Neuropharmacol 2: 281.

Van Laal" M, Volkerts ER, Willigenturg van APP (1992) Therapeutic effects and effects on actual driving performance of chronically administered buspirone and diazepam in anxious outpatients. J Clin Psychopharmacol 12(2): 86-95.

Von Moltke LL, Greenblatt DJ, Harmatz JS, Shader RI (1994) Editorial. Cytochromes in psychopharnacology. J Clin Psychopharmacol 14: 1-4.

Wrighton SA, Stevens JC, Becker GW, Vandenbranden M (1993) Isolation and characterization of human liver cytochrome P450 2C19: correlation between $2 \mathrm{C} 19$ and S-mephenytoin 4:lyydroxilation. Arch Biochem Biophys 306:240-245. 


\title{
CHAPTER 7
}

\section{Psychomotor, cognitive, extrapyramidal and affective functions of healthy volunteers during subchronic treatment with an atypical (amisulpride) and a classic (haloperidol) antipsychotic.}

\begin{abstract}
Twenty-one subjects participated in the 4-way, randomized, double-blind, cross-over study with repeated daily doses of amisulpride $50 \mathrm{mg}$, anisulpride $400 \mathrm{mg}$, haloperidol $4 \mathrm{mg}$ and placebo. Subjects were institutionalized during treatment periods under $24 \mathrm{~h}$ medical supervision. They performed a series of psychomotor and cognitive tests 1 h before and 3 and 6 h after dosing on Days 1 and 5. Their extrapyramidal disturbances and drug related feelings were assessed at the end of each replication. Psychiatric interviews and ratings of depression, subjective well-being and negative symptoms occurred on Day 4. Amisulpride $50 \mathrm{mg}$ had no significant effect on any parameter. Amisulpride $400 \mathrm{mg}$ had several adverse effects on psychomotor and, though less, cognitive performance on the $5^{\text {th }}$ day only. Amisulpride 400 produced no significant extrapyramidal disturbances in the group as a whole, though it may have in some individuals. Also, it produced no signs of mental disturbances on clinical rating scales or during a structured psychiatric interview. Haloperidol ubiquitously impaired psychomotor and cognitive performance, similarly after the first and the final doses. It produced extrapyramidal disturbances in almost every subject, the most common being akathisia and the most severe, in the case of one indiwidual, acute dystonia. Unlike amisulpride, haloperidol produced a number of mental disturbances, the most noteworthy being negative symptoms. Amisulpride appears to be a well tolerated drug. Its side effects should be much less troublesome to patients using the drug chronically than those of classic antipsychotics, like haloperidol.
\end{abstract}

JG Rawaekers, JW Lowwerens, ND Muntjewerff, H Milius, A de Bie, P Rosenzweig. A Patat, JF O'Hanlon. IClin Psychophamacol, in press 


\section{INTRODUCTION}

Bvery currently available antipsychotic drug is a $D_{2}$ receptor antagonist. The first effective antipsychotics, the phenothiazines, also possessed affinities for $5 \mathrm{HT}_{2}, \mathrm{H}_{1}, a_{1}$ and AcM receptors which were thought to be irrelevant for efficacy and responsible for unwanted side effects, such as hypotension and sedation. Efforts to develop new antipsychotics focussed upon compounds possessing greater $\mathrm{D}_{2}$ receptor selectivity and binding affinity. Drugs like haloperidol were the consequence. Unfortunately, these retained the worst side effects of the earlier compounds, the most obvious being sedation and a variety of extrapyramidal disturbances (Casey, 1995; King, 1993). Less obvious but almost as troublesome for patients were a number of mental disturbances, collectively known as the Neuroleptic Induced Deficit Syndrome (NIDS); i.e psychic indifference, concentration difficulties, diminished conation, affect and motivation (Levander, 1994; Lader, 1993; King, 1994). The strategy for developing antipsychotics underwent a revolution after the belated recognition that clozapine fails to produce extrapyramidal motor symptoms and that it seems to be the most efficacious antipsychotic for treating 'neuroleptic-resistant' schizophrenics (Baldessarini \& Frankenburg, 1991; Meltzer, 1994). Its success has encouraged the development of new 'clozapine-like' antipsychotics sharing a low $5 \mathrm{HT}_{2 \mathrm{~A}} / \mathrm{D}_{2}$ binding ratio, and a high affinity for $H_{1}$ and $\alpha_{1}$ and, sometimes, AcM receptors as well (Leysen et al, 1996) Thus, antipsychotic drug development has returned full circle.

Yet not all atypical antipsychotics possess multireceptor binding profiles. Those belonging to the substituted benzamide family have emerged from a parallel line of development as very strong therapeutic alternatives (Freeman, 1997; Rein \& Turjanski, 1997; Kahn et al, 1994). Sulpride, the prototype, was introduced about the same time as clozapine in the late $1960 \mathrm{~s}$, followed later by its structural analogs, remoxipride and amisulpride. Though very selective $D_{2}$ and $D_{3}$ receptor antagonists, substituted benzamides also possess a low tendency to cause extrapyramidal symptoms (EPS). Moreover they are far less sedating than most other antipsychotics. Sulpride and remoxepride produced relatively mild psychomotor and cognitive impairment that was less or comparable to what was seen after subtherapeutic doses of classic antipsychotics (Liljequist et al, 1975; Barfai \& Wiesel, 1986; Fagan et al, 1991; Mattila et al, 1988; MoClelland et al, 1990; King et al, 1995). Single doses of amisulpride also had minimal effects on psychomotor performance, attention and memory (Mattila et al, 1997) 
Amisulpride's efficacy and benign side-effect profile have been recently explained on the basis of preclinical receptor binding, neurochemical and animal model studies (Schoemaker et al, 1997; Perrault et al, 1997; Scatton et al, 1997) Amisulpride possessed high in vitro binding affinity for human $\mathrm{D}_{2}$ and $\mathrm{D}_{3}$ receptors and preferentially recognized the latter in vivo. It showed little or no binding affinity for any other monoamine receptor and none for sigma or muscarinic-acetylcholinergic receptors in rats. Various tests showed that amisulpride attaches at presynaptic before postsynaptic dopamine receptors as its concentration rises. In rats, this change in the location of the drug's activity with a rising concentration first potentiated then blocked hyperactivity and stereotypies caused by the simultaneous presence of a dopamine receptor agonist. Amisulpride also displayed a regional difference in $\mathrm{D}_{2} / \mathrm{D}_{3}$ binding affinity. As judged from in wivo radioligand displacement, amisulpride's affinity for limbic $D_{2}$ and $D_{3}$ receptors in rats was about 2-3 times higher than those in the striatum. In vitro tests of the drug's regional effect on dopamine biosynthesis (i.e. tyrosine hydroxylase activity) and extracellular metabolism (DOPAC levels) in rats confirmed that amisulpride increases dopaminergic neuronal activity more in limbic than striatal structures.

The current study sought to confirm the suspected advantages of amisulpride's limited, dose related activity within dopamine systems and its general lack of interference with any other neurotransmitter system that sustains arousal. Patients whose symptoms are controlled. with high therapeutic doses should experience less psychomotor, cognitive and mental disturbances relative to a classic antipsychotic. Moreover, the preferential blockade of the $\mathrm{D}_{3}$ receptor in vivo and the limbic selectivity of amisulpride should preclude severe extrapyramidal disturbances seen with classic antipsychotics. Stimulation of dopamine transmission with lower therapeutic doses should increase alertness, mood and behavioral competence in patients. All of this would be difficult to establish in a comparative clinical trials involving schizophrenic patients. Confounding factors in patient samples (i.e heterogeneity with respect to primary pathologies, comorbidities, symptom severities or comedication) would tend to obscure differences in drug effects; and, any that did emerge would be difficult to interpret without reference to placebo control data. The alternative is treating healthy volunteers with repeated therapeutic doses of different antipsychotics and placebo, and measuring differential treatment effects using objective and subjective tests of affective, cognitive, extrapyramidal and psychomotor functions. The premise for such studies is that psychotic patients and healthy volunteers react in similar ways to all 
drug activities that are pharmacologically irrelevant to the antipsychotic effect. Evidence supporting this premise was recently reviewed at a consensus conference convened by the British Association for Psychopharmacology (King, 1997). The conclusion was that properly designed and conducted healthy volunteer studies are valid for discriminating between the side-effects of antipsychotic drugs.

\section{MATERIAL AND METHODS}

\section{Subjects}

Volunteers were recruited by a newspaper advertisement briefly specifying the nature of the study and the inclusion criteria; i.e. males or females, ages 18-35 years and willingness to give Informed Consent. Volunteers were screened in four stages: medical history, physical examination, psychiatric interview and tolerability check. Initial screening occurred on the basis of response to a medical history questionnaire and a physical examination including measurement of vital signs and reflexes, blood pressure, a 12-lead electrocardiogram, and routine laboratory determination of hematological and blood chemistry parameters. Exclusion criteria were clinically relevant abnormalities at physical examination, ECG or laboratory tests, binocular visual acuity (corrected or uncorrected) that deviated from normal by more than 0.65 diopters, history of drug hypersensitivity, drug use/abuse or alcoholism, gastrointestinal, hepatic, renal, cardiovascular or neurological disorders, pregnancy characterized by a positive pregnancy test (urine $\beta \mathrm{HCG}$ measured before each treatment period).

The psychiatric interview determined that the individual mental status was essentially normal. The psychiatrist also explained the nature of the study and expected drug effects. Within a week after this interview, subjects indicated their Informed Consent to participate in the tolerability check and, conditional willingness to continue into the study proper. To check tolerability, subjects received a single dose of haloperidol $4 \mathrm{mg}$ in the morning. They were closely supervised for at least the subsequent eight hours. Out of 28 volunteers who undertook the tolerability check, two declined to enter the main study after experiencing mild akathisia. The other five declined for reasons unrelated to treatment. A total of 21 healthy young male (16) and female (5) volunteers entered the study proper. The study was carried out in accordance with the Declaration of Helsinki (Hong Kong Modification, 1989). Its 
protocol was reviewed and approved by the standing Medical Ethics Committee of Maastricht University.

\section{Study design and treatments}

Subjects received multiple-dose treatments on separate occasions according to a 4 period, double-blind, cross-over design. Washout periods of at least 10 days separated successive treatment periods. Each treatment lasted five days. During treatment subjects resided in a secure housing facility, under continuous medical supervision.

On Day 1 and 5 of each treatment period, subjects ingested 2 capsules in the morning at least $1.5 \mathrm{~h}$ after a standardized breakfast (placebo + placebo or amisulpride $50 \mathrm{mg}+$ placebo or amisulpride $200 \mathrm{mg}+$ amisulpride $200 \mathrm{mg}$ or haloperidol $2 \mathrm{mg}+$ haloperidol $2 \mathrm{mg}$ ). On Day 2, 3 and 4 of each treatment period, each subject received treatments at the same hour in the moming (1 capsule of amisulpride $50 \mathrm{mg}$ or haloperidol $2 \mathrm{mg}$ or amisulpride $200 \mathrm{mg}$ or placebo, respectively) and also in the evening ( 1 capsule of placebo or haloperidol $2 \mathrm{mg}$ or amisulpride $200 \mathrm{mg}$ or placebo, respectively). These were given by the Medical Supervisor with $150 \mathrm{ml}$ of water after a standardized breakfast and dinner. Treatment orders were randomly assigned to the subjects in a Williams Balanced Block design; i.e. one orthogonal balanced Latin square obtained by the Sheehe-Bross algorithm. No concomitant treatments were scheduled. However it was recognized in the study protocol that anticholinergic drugs might be necessary for treating side effects of the study medication in certain subjects.

\section{Training procedures and time of testing}

Training occurred in two sessions scheduled during the two weeks that preceded the first treatment period. Training in critical tracking (CTT), divided attention (DAT) and choice reaction time (CRT) continued until the subject had performed each one with less than $\pm 5 \%$ variance from the average measured over the final three trials. Performance on syntactic reasoning (SR), digit symbol substitution (DSST) and sustained attention (VIG), show little practice effect, so for these, training simply involved the administration of one (VIG) or two (others) trials.

Tests of psychomotor, cognitive and extrapyramidal function were conducted at baseline ( $-1 \mathrm{~h}$ pre dose), and between $3-4 \mathrm{~h}$ and $6-7 \mathrm{~h}$ post dose on Day 1 and 5 , with exception of VIG which was administered twice; i.e between $4-5$ and $7-8$ h post dose on Day 1 and 5. Ratings of affective functions were conducted on Day 4, except for the 
Addiction Reseach Center Inventory (ARCl) which was administered along with tests of psychomotor, cognitive and extrapyramidal function.

\section{Assessments of psychomotor functions}

CTT (Jex et al, 1966) measures the subject's ability to control a displayed error signal in a 1 st-order compensatory tracking task. Error appears as horizontal deviation of a cursor from midpoint on a horizontal, linear scale. Compensatory joy-stick movements null the error by returning the cursor to the midpoint. The frequency of cursor deviations, and therefore its velocity, increases as a stochastic, linear function of time. The subject is required to make compensatory movements with a progressively higher frequency. Eventually his response frequency lags the error signal by $180^{\circ}$. At that point, the subject's response adds to, rather than subtracts from, the error and control is lost. The frequency at which control loss occurs is commonly called "lambda-c" (the "critical frequency"). The reciprocal of this frequency is theoretically the perceptual/motor delay lag for humans operating in closed-loop system. The subject performs this test in five trials on each occasion and the median lambda-c is recorded as the final score.

DAT (Moskowitz, 1973) measures the ability to divide attention between tracking and monitoring subtasks performed simultaneously. The former subtask requires the use of a joystick to continuously null the horizontal movement of a cursor from the center of a display. The cursor travels in both directions with irregular velocity, on the average, $50 \%$ of that which is just controllable by the particular subject. Tracking error (DAT $T_{T R}$ ) is measured by the absolute distance $(\mathrm{mm})$ between the cursor's position and the center. The latter subtask involves monitoring 24 singledigit numbers $(0-9)$ that are arranged around the display's periphery. The numbers change asynchronously every 5 seconds. The requirement is to react as rapidly as possible by lifting the foot from a pedal any time a target, the numeral " 2 ", appears. Average reaction time (DAT $\mathrm{RT}_{\mathrm{RT}}$ ) to targets is recorded as the second response measure.

CRT measures the subjects" average reaction time to the words 'left' and 'right" using corresponding push-buttons. Half of each type are displayed at compatible and incompatible (i.e left or right) positions. Subjects are urged to respond as quickly as possible. Average reaction time and total errors were scored over 48 trials.

VIG (Mackworth, 1950) has been extensively used in studies on human vigilance performance. Subjects are seated in front of a computer screen displaying a circular arrangement of 60 grey dots simulating the second mark on a clock. Dots are 
briefly illuminated in clockwise rotation at a rate of $1 / 0.5 \mathrm{sec}$. Occasionally, the rotation proceeds with a 'double jump' by skipping one of the dots in the normal sequence. The dependent variable of the test is the number of correct detections. The test lasts 45 minutes.

\section{Assessments of cognitive functions}

SR (Baddeley, 1968) consists of a series of sixteen short sentences. Eacl describes the order of two letters; e.g. "B follows A". Each sentence is followed immediately by the same letters. Half of the time the order is the same as in the sentence, and half, the opposite. Sentence difficulty varies within the series, from simple active sentences, as given above, to more complicated sentences involving passives, negatives or both; e.g. "B is not followed by A". The required response is to indicate as rapidly as possible using appropriate push buttons whether or not the letter pair are in the same order as given by the preceding sentence. Number of correct responses is the dependant variable.

DSST is a computerized version of the original paper and pencil test taken from the Wechsler Adult Intelligence Scale (Wechsler, 1981). The subject is briefly shown an encoding scheme consisting of a row of squares at the top of the screen, wherein nine digits are randomly associated with particular symbolls (i.e $\cup, \wedge, \perp, 0, \sqsupset,=,-$, $\mathrm{X}, \mathrm{L}$ ). The same symbols are presented in a fixed sequence at the bottom of the screen as a row of separate response buttons. The randomization procedure is chosen such that symbols never appear at the same ordinal position within both rows. The encoding scheme and the response buttons remain visible while the subject is shown successive presentations of a single digit at the centre of the screen. The task is to match each digit with a symbol from the encoding list and click the corresponding response button. The number of digits correctly encoded within 3 minutes is the performance measure.

\section{Assessments of extrapyramidal motor functions}

Subjective ratings of extrapyramidal symptoms were measured by the Simpson-Angus Extrapyramidal Side Effect Scale (Simpson, 1970) and the Barnes Akathisia Scale (1989). 
Assessments of affective functions

ARCl (Haertzen, 1966) aims to determine an effect profile of drugs through drugspecific "state" questions pertaining to attitude, feelings and mood. The scale has been validated and proven reliable for detecting drug related feelings common to each of the following groups of drugs: morphine benzedrine group (MBG) for measuring euphoria, lysergic acid diethylamide (LSD) for measuring dysphoric feelings and depersonalization, pentobarbitatal chlorpromazine alcohol group (PCAG) for measuring sedation, benzedrine group ( $B G$ ) for measuring competence and alertness, and amphetamines $(\mathrm{A})$ for measuring mental activation and motivation.

During a psychiatric interview the following rating scales were administered: Negative Symptoms Subscale from the Positive and Negative Symptoms Scale (PANSS; Kay, 1991.), Hamilton Depression Scale (HAMD 17-item; Hamilton, 1976), the Subjective Well-Being Under Neuroleptics Scale (SWN; Naber, 1994), and the Present State Examination (PSE; Wing \& Sturp, 1978). The latter was administered according to the World Health Organization's SCAN procedure (Wing et al, 1974). Relevant sections of the PSE were covered by the psychiatrists' questions during the greater part of the interview. The psychiatrists' ratings were condensed by semiquantitative coding of all complaints to the following items; global clinical impression, interference with daily activity, drowsiness, sleep disturbances, loss of energy, akathisia (mental and motoric), tremor, stiffness, dry mouth, inability to concentrate, irritability, social withdrawal and blurred vision.

\section{Pharmacokinetics and prolactin}

Blood samples taken prior to dosing and 5 h post-dose on Day 1 and 5 were used for establishing drug plasma and prolactin concentrations. Amisulpride and haloperidol were assayed in plasma by HPLC with fluorescence and UV detection respectively. Limits of quantification were $0.5 \mathrm{ng} \cdot \mathrm{ml}^{-1}$ and $2.5 \mathrm{ng} \cdot \mathrm{ml}^{-1}$ respectively. Prolactin was assayed using an immunoenzymatic method (SRI - Biochem Immuno Systems $Q$ ).

\section{Statistical analysis}

All analyses were conducted using the SPSS PC+ statistical program series. Each objective performance variable was analysed at every time of measurement using a 2factor ANOVA (Subject x. Treatment). These were followed by planned LSD tests for comparing all drug-placebo differences and also that between the haloperidol and amisulpride $400 \mathrm{mg}$ conditions. Subjective ratings were analysed at every time point by 


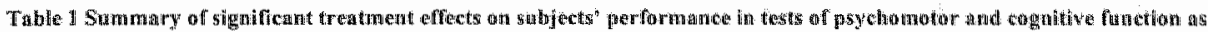

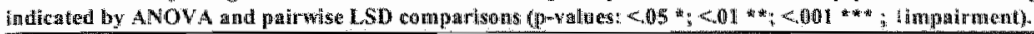

\begin{tabular}{|c|c|c|c|c|c|c|c|c|}
\hline \multirow[t]{3}{*}{ Tests } & \multirow[t]{3}{*}{ Day } & \multirow{3}{*}{$\begin{array}{c}\text { Time } \\
\text { (H) }\end{array}$} & \multicolumn{2}{|c|}{ ANONA } & \multicolumn{4}{|c|}{ LSO } \\
\hline & & & \multirow[b]{2}{*}{ dr } & rall & \multirow{2}{*}{$\begin{array}{c}\text { AMS } 50 \text { ws } \\
\text { PU.A } \\
t\end{array}$} & \multirow{2}{*}{$\begin{array}{c}\text { AMS } 400 \\
V \\
\text { PP } \\
r\end{array}$} & \multirow{2}{*}{$\begin{array}{c}\text { MAL } \mathrm{Ls} \\
\text { MLA } \\
i\end{array}$} & \multirow{2}{*}{$\begin{array}{c}\text { MAL } \\
\text { AMS } 400 \\
\text { \# }\end{array}$} \\
\hline & & & & $\mathbf{F}$ & & & & \\
\hline \multicolumn{9}{|c|}{ Psychomotor Fancitons } \\
\hline \multirow[t]{6}{*}{ CTT } & 1 & -1 & m: & - & - &. & - & - \\
\hline & & 3 & 3,48 & $22.79 *$ & - & $\propto$ & $38.00 * *$ & $153.42 * *$ \\
\hline & & 6 & 3,48 & $23.26 * *$ & - & $\therefore$ & 50,67 & 42.64 *ath \\
\hline & 5 & -1 & 3,48 & $6.7 .4 \%$ & 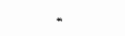 & $14.02 *$ & $1390 * *$ & * \\
\hline & & 3 & 3,48 & $9.11 * *$ & - & 680 & $115.26 \%$ & $=$ \\
\hline & & 6 & 3,48 & $1930 *$ & 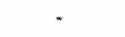 & $118.56 \%$ & $134,34 * * *$ & - \\
\hline \multirow[t]{5}{*}{ CRT } & 1 & 3 & 3,48 & $4.01 \%$ & . & 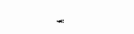 & 15.07 * & $111.15 *$ \\
\hline & & 6 & 3,48 & $7.79 *$ & - & - & 116.97 & $\left.111.61\right|^{\text {wink }}$ \\
\hline & 5 & -1 & . & $\therefore$ & - & - & - & $15.46 *$ \\
\hline & & 3 & 3,48 & $2.86 \%$ & * & - & 5.84 & 6.43 \\
\hline & & 6 & 3,46 & $3.97 *$ & 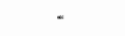 & - & 19.05 & 16.44 \\
\hline \multirow[t]{6}{*}{$\mathrm{DAT}_{\mathrm{TRR}}$} & 1 & -1 & - & - & - &. & - & 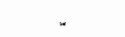 \\
\hline & & 3 & 3,48 & $6.60 * *$ & $*$ & * & $11550 \%$ & 9.40 \\
\hline & & 6 & 3,48 & $14.93^{* 1 * *}$ & - & * & $131.08 *$ & $27.29 * * *$ \\
\hline & 5 & -1 & 3,48 & $6.70 * *$ & . & 1560 & $116.36^{*} *$ & 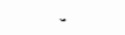 \\
\hline & & 3 & 3,48 & $20.87 * *$ & - & 18.87 & 47.69 & 15.42 * \\
\hline & & 6 & 3,48 & $15.81 *$ & . & $112.28 * 4$ & $134.69 * *$ & 15.14 . \\
\hline \multirow[t]{6}{*}{$D A T_{k T}$, } & 1 & -1 & $\ldots$ & - & - & - & - & . \\
\hline & & 3 & - & - & - & • & - & - \\
\hline & & 6 & 3,48 & $2.82 *$ & - & - & $15.03 *$ & $16.57 *$ \\
\hline & 5 & -1 & - & - & - & 14.72 & 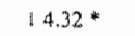 & $\approx$ \\
\hline & & 3 & 3,48 & $3.21 *$ & . & . & $18.07 *$ & - \\
\hline & & 6 & 3.47 & $6.17 \%$ & - & $18.20 *$ & 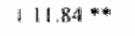 & - \\
\hline \multirow[t]{4}{*}{ vio } & 1 & 4 & 3.48 & 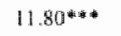 & . & . & $122.45 *$ & $112.25 \%$ \\
\hline & & 7 & 3,48 & $15.37 * * *$ & - & - & $12600 *$ & 12894 的出 \\
\hline & 5 & 4 & 3,48 & $13.43 *$ & - & $199.44 *$ & $28,27 *$ & - \\
\hline & & 7 & 3,46 & $1381 * * *$ & - & $110.72 *$ & $22.74 * * 16$ & - \\
\hline
\end{tabular}

Cognitrue Functions

SR

\begin{tabular}{|c|c|c|c|}
\hline \multirow[t]{3}{*}{1} & -1 & - & . \\
\hline & 3 & - & - \\
\hline & 6 & 3.48 & $4.54 *$ \\
\hline \multirow[t]{3}{*}{5} & - 目 & 3.48 & $378 *$ \\
\hline & 3 & 3,48 & $12.49^{\text {nd }}$ as \\
\hline & 6 & 3.48 & 7.86 *.4* \\
\hline
\end{tabular}

DSST

\begin{tabular}{|c|c|c|c|}
\hline ! & -1 & - & . \\
\hline & 3 & 3,48 & $4.51 * *$ \\
\hline & 6 & 3,48 & $7.45 *$ \\
\hline 5 & -1 & - & - \\
\hline & 3 & 3,48 & 16.59 \\
\hline & 6 & 3,47 & $1747 \%$ \\
\hline
\end{tabular}

$\left|5.3 n^{*} \quad\right| 11.87 * 6$

$+12.75 * 15.40 * \%$

$14.74 *$ 
means of the non-parametric Friedman tests to detect an overall effect of Treatments. These were followed by Wilcoxon"s Signed Rank Test to compare the effects of drug treatments and placebo, and, of haloperidol and amisulpride $400 \mathrm{mg}$. Analyses were conducted on absolute scores unless significant differences were measured between treatments at baseline. In such cases further analyses were conducted on changes from baseline. The alpha llevel was set at $5 \%$, two-tailed for the pair comparisons.

\section{RESULTS}

\section{Dropouts and missing data}

Twenty-one subjects entered the study. Two dropped out for reasons unrelated to treatment and another two because of adverse events which occurred during haloperidol treatment. One of the latter did so after the first dose for reasons of akathisia, malaise and vomiting; the other, after experiencing acute dystonia (spasm of the masseters and torticollis) on Day 2. A summary of all adverse events is provided below. Two subjects were unable to perform tests at the times scheduled for final performance assessments in the haloperidol and amisulpride $400 \mathrm{mg}$ conditions, respectively. The first subject declined to take the tests because of adverse events he was experiencing at the time. The second departed early to deal with an urgent family problem. Thus their data were missing from the $6 \mathrm{~h}$ sets for these conditions. Otherwise the data were complete.

\section{Psychomotor functions}

The three tests measuring the ability to respond rapidly and accurately to a variable sensory input were CTT, CRT and DAT. Mean ( \pm SEM) performance scores from the tests are shown as functions of time with respect to dosing on Days 1 and 5 in Figures 1 and 2. The results of corresponding statistical analyses are summarized in Table 1. CTT measured significant overall treatment effects at all times after initial dosing. Mean $\lambda_{v}$ was significantly lower after haloperidol than placebo at all times, including that before final dosing on Day 5. The mean effects of amisulpride $400 \mathrm{mg}$ were markedly less than haloperidol's but also differed significantly from placebo's at both times after dosing on Day 5. Amisulpride $50 \mathrm{mg}$ failed to affect performance significantly at any time in this or any other test. Mean reaction times in CRT differed significantly between conditions at baseline. Consequently changes from baseline in 
reaction time $(\triangle \mathrm{RT})$ were analysed. Overall treatment effects were generally significant due almost exclusively to haloperidol. After the first dose, mean $\Delta R T$ ascended to significant heights above corresponding placebo levels. The difference remained significant before dosing on Day 5, and after that, increased to even greater heights. Interestingly, haloperidol failed to significantly affect the accuracy of responding, relative to placebo. It would seem that haloperidol did not make the subjects more succeptable to distraction despite retarding their responses. Amisulpride

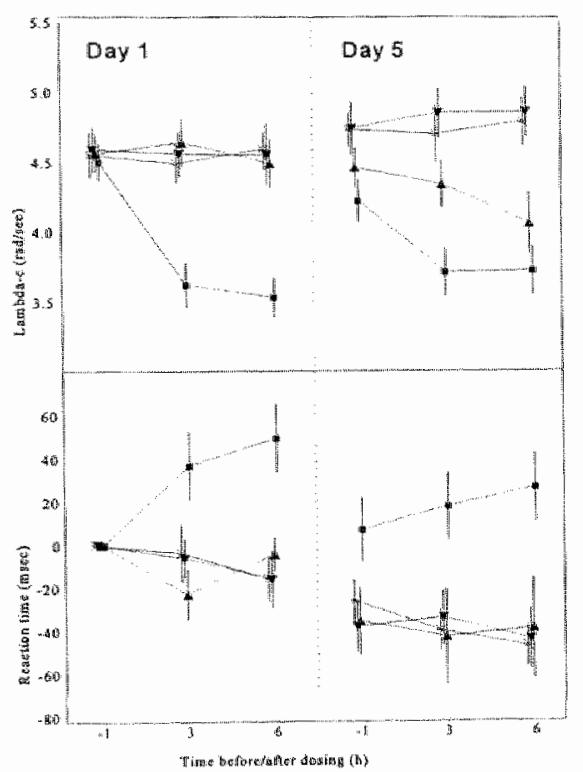

Figure 1 Mean ( \pm SE) lambda-c in the CTT (upper panel) and change of reaction time from baseline (lower panel) as functions of iime affer dosing on Days 1 and 5. Symbols indicate the following treatments : placebo *: amisulpride 50mg, amisulpride $400 \mathrm{mg}$, A haloperidol $4 \mathrm{mg}$,

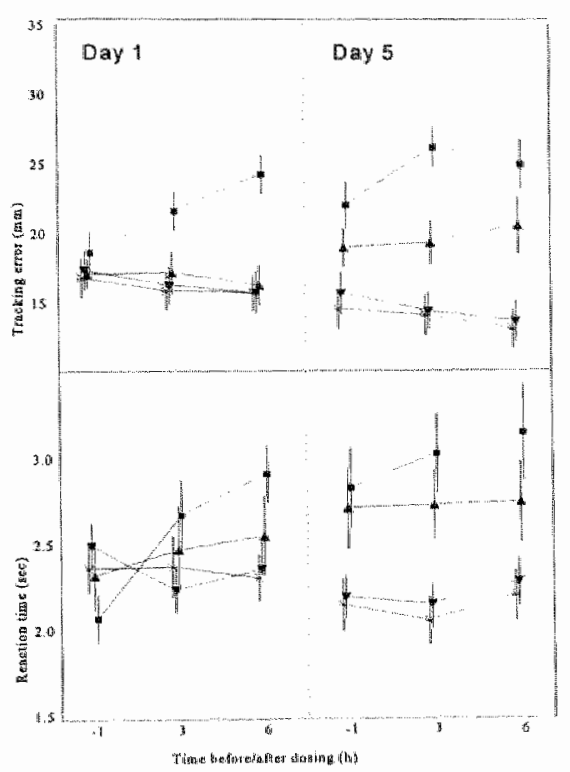

Figure 2 Mean ( $($ SE) tracking error (upper paneljand reaction times to peripheral signals (lower panel) in the DAT (upper panel) as functions of time after dosing on Days 1 and 5 . Symbols indicate the following treatments : placebo, , **amisulpride $50 \mathrm{mg}, \mathbf{\nabla}$; amisulpride $400 \mathrm{mg}, 4$; haloperidol $4 m g$,

$400 \mathrm{mg}$ never affected either aspect of performance in CRT. Overall treatment effects on tracking error in the DAT were always significant after initial dosing. Overall effects on reaction times to peripheral signals in this test were also significant, or nearly so in all repetitions after $3 \mathrm{~h}$ on Day 1. Haloperidol's effects on both measures 
were generally the strongest but amisulpride $400 \mathrm{mg}$ 's were also significant before and after dosing on Day 5. Both measures changed in parallel after final dosing, indicating general inattention to the dual task rather than a concentration on one aspect to the detriment of the other.

Sustained attention, as measured by the percentage of signals detected in VIG, varied significantly between treatment conditions when measured 4 and $7 \mathrm{~h}$ post dosing on both Days. Haloperidol reduced the mean detection rate to between 31 and $41 \%$, whereas mean rates after placebo were between 61 and $72 \%$ in different tests.

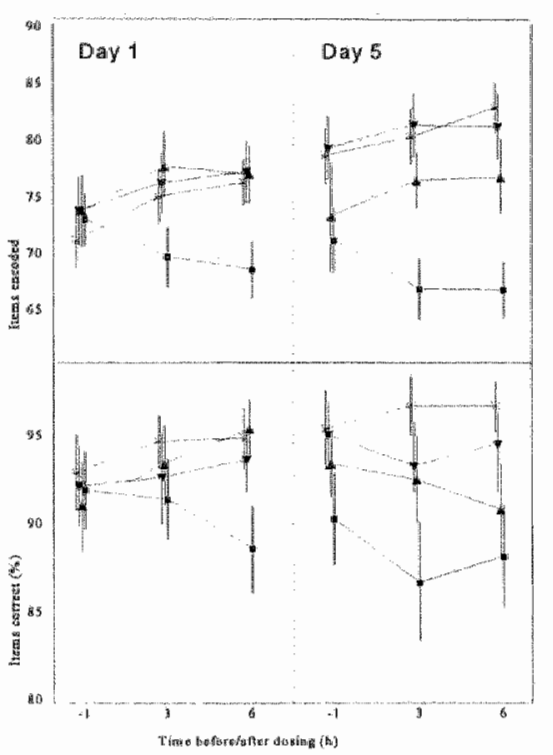

Figure 3 Mean ( \pm SE) number of items correctly encoded in the DSST (upper panel) and percentage of items correct in the SR (lower panel) as functions of time after dosing on Days 1 and 5. Symbols indicate the following treatments: placebo *; amisulpride 50mg, amisulpride 400mg. haloperidol $4 \mathrm{mg}$ Amisulpride $400 \mathrm{mg}$ 's effects did not differ significantly from placebo's on Day 1 and were likewise significantly less than haloperidol's. However on Day 5, amisulpride $400 \mathrm{mg}$ 's effects at 4 and $7 \mathrm{~h}$, producing mean rates of 45 and $54 \%$, did not differ significantly from haloperidol's, and like them were significantly greater than placebo's.

\section{Cognitive functions}

Figure 3 shows treatment effects in DSST and SR; i.e., those tests that placed the heaviest load on working memory. Amisulpride $400 \mathrm{mg}$ had no effects on Day 1 in either test whereas haloperidol significantly impaired performance in both, beginning at $3 \mathrm{~h}$ in DSST and $6 \mathrm{~h}$ in SR when overall treatment effects were also significant. Haloperidol's separate effects prior to dosing on Day 5 were also significant as was the overall effect in SR (The overall effect in DSST just missed being significant; $p=055$ ). Haloperidol's mean impairing effects increased in magnitude and significance after the final dose. Amisulpride $400 \mathrm{mg}$ 's effects, though significantly less than haloperidol's, were also significantly greater than placebo's at 3 and 6 h in SR and the latter alone in DSST. 


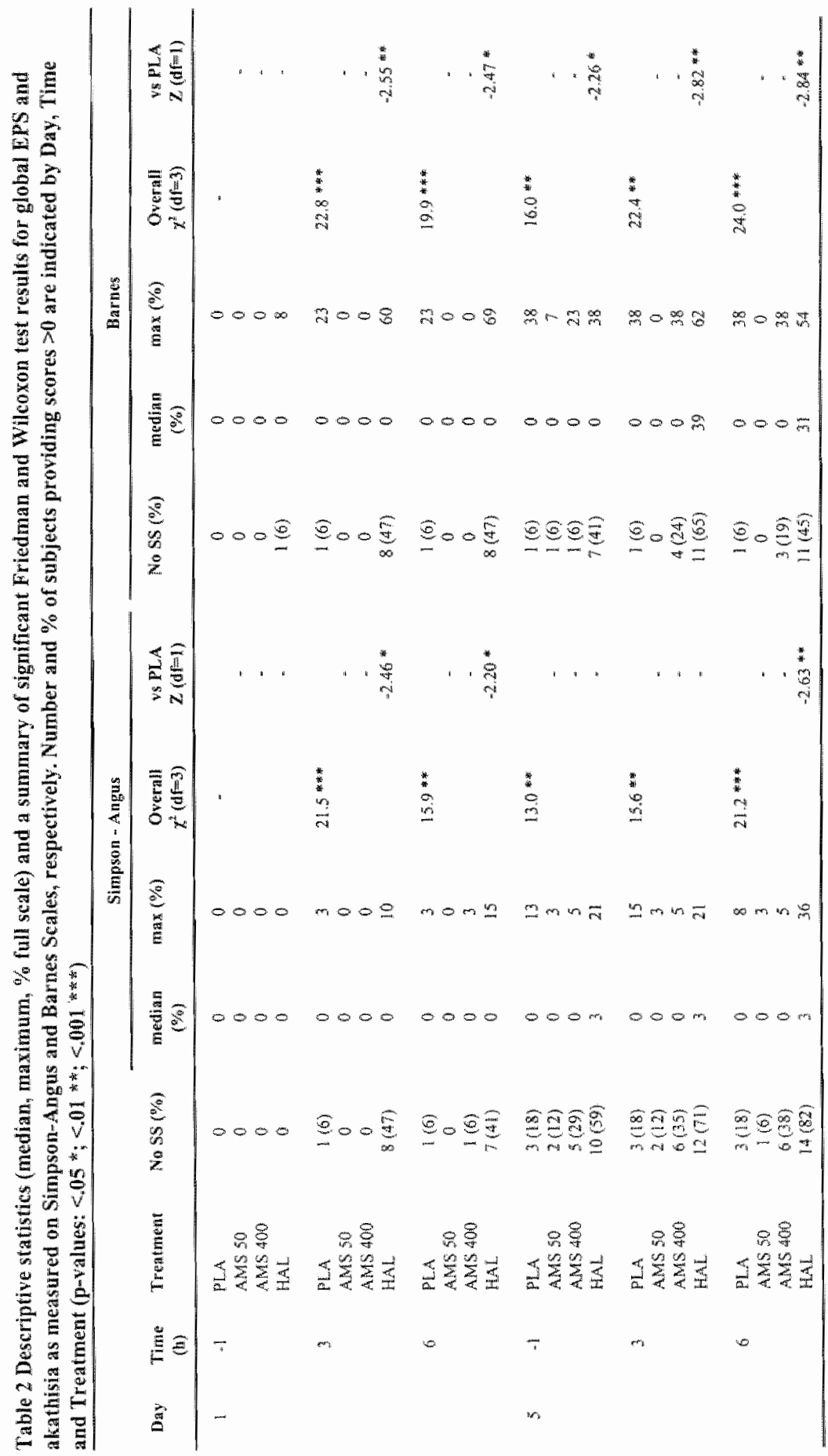


Extrapyramidal motor functions and comedication

Table 2 gives median and maximum ratings as percentages of full scale and summarizes statistical test results for global EPS and akathisia ratings on the SimpsonAngus and Barnes scales, respectively. It is evident from these data that only haloperidol caused the subjects ${ }^{7}$ EPS to rise significantly on Day 1 . Akathisia was the prominant symptom, afflicting just under half of the subjects. The same symptom was present in about as many subjects before dosing on Day 5 and afterward, both the number of subjects suffering akathisia and its severity increased. No such symptoms afflicted subjects during their first days of amisulpride treatment with either dose and none occured thereafter on the lower dose. Amisulpride $400 \mathrm{mg}$ caused some akathisia in four subjects and tremor without akathisia in two more after the final dose. However, global EPS and akathisia was on that day always significantly lower after amisulpride $400 \mathrm{mg}$ than haloperidol (Simpson-Angus: $\mathrm{z} \geq-2.64 ; \mathrm{p} \leq .01$; Barnes: $\mathrm{z} \geq-$ $2.34 ; \mathrm{p} \leq .02)$.

These differences in EPS occurred despite the fact that the subjects sought anticholinergic medication far more often after haloperidol than amisulpride. Eleven (65\%) of the completers required biperiden $2 \mathrm{mg}$ p.o., 1-3 times per day for 1-5 days, nine after haloperidol allone and two after both haloperidol and amisulpride $400 \mathrm{mg}$. First biperiden doses were given to five subjects in the haloperidol condition shortly before the $3^{\text {rd }}$ test battery repetition on Day 1 . The two subjects who also required comedication during treatment with amisulpride $400 \mathrm{mg}$ began dosing on Days 2 and 3 , respectively.

\section{Affective functions: $A R C I$}

Significant overall treatment effects and a significant difference between haloperidol and placebo effects on the subjects" feelings were found together on every ARCI scale. Neither amisulpride dose significantly affected feelings. At successive times of measurement on Day 1, haloperidol produced dysphoric feelings and depersonalization (LSD: $z=-3.17 \&-2.81 ; \mathrm{p}<.01$ ), lethargy and mental dullness (PCAG: $z=-2.02 \&-$ $2.76 ; p<.05)$; and , at the final time, reduced competence and alertness $(B G: z=-3.13$; $p<.01$ ), and mental activation and motivation ( $A: z=-2.22 ; p<05)$. LSD scores no longer differed significantly between haloperidol and placebo conditions on Day 5 . However, all of the other mean differences increased in magnitude and significance, both before and after final dosing. Dysphoric feelings, as indicated by a reduction in MBG scores, were present over the entire day $(z=-2.01,-2.45 \&-2.81 ; p<.05)$. 


\section{Affective functions: psychiatric interview}

The major results of the structured psychiatric interview on Day 4 are summarized as follows. Neither dose of amisulpride significantly affected any parameter on the HAMD, SWN or PANSS, relative to placebo. Yet the overall treatment effects were significant in all cases $(\mathrm{p}<.01)$ due to separately significant haloperidol- placebo differences. Haloperidol produced higher ratings of depression on HAMD (mean \pm SEM, $3.65 \pm .95$ vs $0.82 \pm .35: z=1.94 ; p=.051$ ), lower feelings of well-being on the SWN ( $183 \pm 4$ vs $193 \pm 15: z=-2.19 ; p=.028)$ and more negative symptoms on the PANSS ( $9.76 \pm .55$ vS $7.41 \pm .26: z=-2.31 ; p=.021$ ). Amisulpride $400 \mathrm{mg}$ 's effects were significantly less than haloperidol's in all cases $(z \geq-2.14 ; p \leq .032)$. The results of the PSE were similar. Of the 13 feelings scored by the psychiatrists, five were adversely affected by haloperidol relative to placebo: interference with normal activities, drowsiness, akathisia-mental, akathisia-motoric, weak concentration $(z \geq-$ $2.52 ; \mathrm{p} \leq .012$ ). And, the global clinical impression of the subjects' condition was also significantly worse after haloperidol than placebo $(z=-3,45 ; p=.001)$. Only drowsiness was rated as significantly greater after amisulpride $400 \mathrm{mg}$ than placebo (z $=-2.58 ; p=.01)$. The global clinical impression of that drug's effects was also significant $(z=-2.50 ; p=.012)$. The psychiatrists were nonetheless easily able to discriminate between haloperidol's and amisulpride's effects. Except for drowsiness, which they rated as equivalent after both drugs, all of the aforementioned impressions of the subjects' condition were significantly worse after haloperidol than amisulpride $(z \geq-2.60 ; \mathrm{p} \leq .01)$.

\section{Drug and prolactin concentrations.}

Plasma haloperidol concentrations were generally below the nominal $2.5 \mathrm{ng} / \mathrm{ml}$ detection limit for the assay, except $5 \mathrm{~h}$ after the final dose. Then, concentrations between 1.0 and $4.5 \mathrm{ng} / \mathrm{ml}$ were measured in 11 of 17 subjects (mean \pm SD $1.9 \pm 1.5$ $\mathrm{ng} / \mathrm{ml}$ ). Amisulpride concentrations just before and $5 \mathrm{~h}$ after final $50 \mathrm{mg}$ were within the ranges $0.7-17.1$ and $9.7-37.5 \mathrm{ng} / \mathrm{ml}(8.5 \pm 4.6$ and $25.8 \pm 14.4 \mathrm{ng} / \mathrm{ml})$. For the final $400 \mathrm{mg}$ dose, the respective values were $35.6-218$ and $135-744 \mathrm{ng} / \mathrm{ml}(132 \pm 54.4$ and $389 \pm 202 \mathrm{ng} / \mathrm{ml}$ ). Plasma prolactin concentrations are given in Table 3

\section{Spontaneously reported adverse events}

As mentioned, one subject experienced acute dystonia. The event occurred approximately $10 \mathrm{~h}$ after he received a $2 \mathrm{mg}$ dose of haloperidol on Day 2. Treatment 
Table 3 Mean (SE) protactin concentrations in plasma obtaingel prior to dosing (Oh) and sh post dosing un Drys 1 and 5 in every condition.

\begin{tabular}{|c|c|c|c|c|}
\hline & \multicolumn{4}{|c|}{ Prolactin concentration $\left(\mathrm{ng} \cdot \mathrm{m}^{-1}\right)$} \\
\hline & \multicolumn{2}{|l|}{ Day 1} & \multicolumn{2}{|l|}{ Day 5} \\
\hline & $0 \mathrm{~h}$ & $5 \mathrm{~h}$ & $0 \mathrm{~h}$ & $5 \mathrm{~h}$ \\
\hline Placebo & $7.38(0.56)$ & $6.22(0.42)$ & $7.43(0.61)$ & $7.74(0.74)$ \\
\hline Amisulpride 50 & $7.89(0.64)$ & $36.96(6.05)$ & $41.77(4,95)$ & $47.23(5.25)$ \\
\hline Amisulpride 400 & $7.91(0.77)$ & $38.31(7.41)$ & $45.09(5.23)$ & $51.05(7.88)$ \\
\hline Haloperidol & $7.08(0.51)$ & $46.40(6.57)$ & $19.04(2.21)$ & $36.76(4.54)$ \\
\hline
\end{tabular}

consisted of biperiden $7.5 \mathrm{mg}$ i.m. followed by $2 \mathrm{mg}$ p.o. The subject recovered completely within $45 \mathrm{~min}$. Less disturbing adverse events were reported frequently by all 20 subjects who took haloperidol: akathisia (13), fatigue (10), apathy (6), hypertonia (6), tremor (5), drowsiness (4), nervousness (4), abnormal vision (3), malaise (2), hypersaliwation (2) and others reported by a single individual. In total, 68 adverse events were reported in the haloperidol condition. Amisulpride $400 \mathrm{mg}$ was taken by 19 subjects. Their most frequent compliant was fatigue (7), followed by apathy (5), drowsiness (4), tremor (4), akathisia (3) hypertonia (2) and nervousness (2). Along with adverse events reported by a single individual, the total number was 38 . Adverse event profiles for 19 subjects who took amisulpride $50 \mathrm{mg}$ and placebo were similar, as were the total numbers of events; i.e., 19 and 22, respectively. Their most frequent complaints were apathy $(4 \mathrm{x})$ and headache $(5 \mathrm{x})$, respectively. All subjects recovered completely within $48 \mathrm{~h}$ following cessation of medication in every condition.

\section{DISCUSSION}

\section{Effects of haloperidol}

Haloperidol produced effects that were profoundly-impairing and distressing in practically every subject. Virtually the same pattern of impairments were measured in repetitions of psychomotor and cognitive tests after the subjects ingested a $4 \mathrm{mg}$ dose on Days 1 and 5. Every performance parameter was significantly affected by 
haloperidol relative to placebo, usually at both times of testing on Days 1 and 5 . There was no sign that the subjects developed tolerance for haloperidol's impairing effects. In fact, the opposite occurred. The drugs' accumulation over four days of dosing was apparently responsible for significantly impairing the subjects' performance in most tests given during the hour before the final dose on Day 5 . Haloperidol also produced significant rises in both EPS and akathisia ratings on Day 1 and 5. The subjects were understandably disturbed by akathisia and $11(65 \%)$ of the 19 subjects who completed the haloperidol condition requested medical intervention. They began biperiden comedication, 2-6 mg/d on Days 1-3 and generally contimued through Day 5.

Results obtained from the subjects during the psychiatric interviews were among the most important of the study. They indicated that haloperidol significantly interfered with the subjects' daily activities, made them drowsy, caused both mental and motoric akathisia, and disturbed their ability to concentrate. The subjects' mean responses on all clinical rating scales differed significantly between haloperidol and placebo treatment conditions. They were more depressed (HAMD) and had lower feelings of well being (ARCI and SWN). Their scores on the PANSS subscale for negative symptoms were also significantly elevated. The implication is that classic antipsychotics, like haloperidol, either cause negative symptoms or cause side-effects that inflate negative symptom scores. Either interpretation should have a profound bearing on how one views the results from clinical trials comparing atypical and classic antipsychotics. If the newer drugs emerge as more efficacious for reducing negative symptoms, it may only be in comparison to older drugs that exacerbate them or inflict similarly appearing side-effects.

\section{Effects of amisulpride $50 \mathrm{mg}$}

The purpose of treating subjects with the low dose was to test the hypothesis that amisulpride's preferential binding at $\mathrm{D}_{2} / \mathrm{D}_{3}$ autoreceptors results in psychoactivation. As it happened, amisulpride $50 \mathrm{mg}$ had no effects on any objective or subjective parameter at any time during the study. The failure to find activating effects of amisulpride $50 \mathrm{mg}$ confirms the results of a previous study (Peretti et al, 1997), and contradicts those of another (Grünberger et al, 1985). The latter study involved 10 volunteers who were treated with single doses of amisulpride $12.5,25,50$ and $100 \mathrm{mg}$ along with two active comparators and placebo. Sixteen pharmaco-EEG parameters and 7 performance measures were assessed 5-6 times over an 8-hour period following each treatment. About 30 amisulpride-placebo differences were significant, mostly in a 
direction suggesting an activating effect. The most effective doses were the lowest, 12.5 and $25 \mathrm{mg}$.

\section{Effects of amisulpride $400 \mathrm{mg}$}

The initial $400 \mathrm{mg}$ dose had no significant effects on any performance parameter in psychomotor and cognitive tests. On Day 5 however, the subjects clearly performed less proficiently in several tests. The speed and accuracy of their continuous tracking performance were significantly worse after amisulpride $400 \mathrm{mg}$ than placebo in both CTT and DAT. In the latter test their reactions to occasional peripheral signals were also significantly retarded. Their symbol encoding in DSST was also generally slower after amisulpride $400 \mathrm{mg}$ than placebo, though only significantly at $6 \mathrm{~h}$ post dosing. At 3 and $6 \mathrm{~h}$ post dosing, the SR revealed a significant deterioration in the subjects' working memory. These mean differences were relatively small in magnitude but there was another that was large enough to signify an impairment of practical consequence. It was recorded in VIG at both times of testing, 4-5 and 7-8h, after the final dose of amisulpride $400 \mathrm{mg}$. In these $45 \mathrm{~min}$ tests, the subjects mean signal detection performance was about $33 \%$ lower after amisulpride than placebo. This change in performance, like every other one found to be significant, can be interpreted as showing that amisulpride reduced the subjects' level of arousal.

Indications that amisulpride possesses de-arousing properties should come as no surprise. The drugs' primary locus of activity is though to lie within the mesocorticolimbic projection system. Arising from dopaminergic cell bodies in the ventral tegmental area of the anterior reticular formation, that system provides nonspecific activation to telencephalic and limbic structures responsible for the organization of adaptive behaviors. ${ }^{37}$ Partial inhibition of this system does not preclude adaptive behavior since the brain possesses other activating monoaminergic projection systems that may reflexively compensate and, respond to an increase of in exteroceptive or corticofugal transmission with a temporary increase in activity, In the context of amisulpride's effects on subjects' performance in this study, it would seem that five days of treatment with amisulpride $400 \mathrm{mg}$ was sufficient for partially inhibiting the mesocorticolimbic system.

What amisulpride did not do is also of considerable theoretical and practical importance. It did not retard the subjects' speed of choice reaction times nor sensitize them to the influence of distracting stimuli in CRT. Apparently the drug's effects arousal are not such as to influence the ability to respond in a normal manner when the 
need to do so can be anticipated beforehand. Moreover, these results also indicate that amisulpride does not interfere with pyramidal motor functions. Neither did it generally interfere with the subjects' extrapyramidal motor functions. They showed no significant elevations in EPS or akathisia ratings at any time during the study. These results strongly confirm the drugs' relatively low level of activity within the basal ganglia even when its activity with the mesocorticolimbic system is strong enough to suppress normal waking arousal and presumably the pathophysiological process that causes schizophrenia.

Finally, rating scales of the subjects' affective function also failed to show any effects of amisulpride. Their mean scores on the HAMD, PANSS subscale for negative symptoms, SWN and ARCI did not differ significantly from those recorded during placebo treatment. Only PSE significantly distinguished one particular complaint which differed significantly in frequency and severity from replies given in the placebo condition: drowsiness. Certain adverse events were reported more frequently while the subjects were treated with amisulpride than placebo. Feelings of fatigue and apathy were the most frequent. However, feelings of restlessness accompanied by tremor were the most distressing. Two subjects experiencing them requested medical intervention and were treated with oral biperiden in $2 \mathrm{mg}$ doses.

\section{Comparison of amisulpride and haloperidol effects}

As mentioned, only haloperidol produced significant effects on Day 1. Haloperidol also affected every parameter significantly after dosing on Day 5, and amisulpride $400 \mathrm{mg}$, some of them. yet the former always caused the greater mean change from corresponding placebo levels and usually there were also significant differences between the drugs' effects. This was true in the DSST, SR, DAT (tracking) and CRT. Their effects were only comparable in a single test on Day 5; i.e. VIG. Mean ratings of EPS and akathisia were always significantly higher after haloperidol than amisulpride $400 \mathrm{mg}$, even before the final doses were given on Day 5. All of the parameters measured in the psychiatric interview were significantly more affected by haloperidol than amisulpride, except one. The psychiatrist's rating of subjects' drowsiness were slightly but not significantly higher when they had been taking amisulpride $400 \mathrm{mg}$ than haloperidol. More than five times as many subjects requested anticholinergic medication for the refief of akathisia during haloperidol than amisulpride treatment and the overall number of adverse events recorded in the former condition was almost 
double those in the latter. Finally, two subjects dropped out because of drug-related side-effects during haloperidol and none during amisulpride treatment.

This demonstration of amisulpride"s better tolerability deserves careful scrutiny for ensuring that it did not occur as a consequence of experimental bias. Any question about biasing due to the selection of inequivalent doses of amisulpride and haloperidol can be easily dismissed. The former has been shown to possess more antipsychotic efficacy than the latter in similarly designed studies involving acutely exacerbated schizophrenics. Four weeks of treatment with amisulpride $400 \mathrm{mg} / \mathrm{d}$ resulted in a marked reduction in positive symptoms (Freeman, 1997) whereas treatment over the same period with haloperidol $5 \mathrm{mg} / \mathrm{d}$ did not (Van Putten et al, 1992). Haloperidol is normally given in divided doses over the day and the fact that $4 \mathrm{mg}$ was given at one time of Days 1 and 5 may have intensified the drug's adverse effects on test performance. However, amisulpride is also given in divided doses so the chance of intensifying its effects beyond those normally seen was the same.

One undeniable confounding factor may have added disproportionately to some of haloperidol's effects. More subjects required anticholinergic comedication to cope with extrapyramidal disturbances after haloperidol than amisulpride. It is not known whether the drug (biperiden) in the doses given ( $2 \mathrm{mg}$ p.o.) affects cognitive and psychomotor functions. If it does, some of the impairments shown by the subjects during haloperidol treatment may have been partially attributable to the comedication. Yet as already mentioned, haloperidol's effects on performance were already severe 34h after the first dose, before any of the subjects had taken biperiden. For that reason we are inclined to think that the perpetuation of their impairments were mainly, if, not exclusively, attributable to haloperidol. Moreover, the comedication could have been confounding in the opposite respect. If it had somehow been possible to retain subjects in the study while denying them the use of an anticholinergic, they surely would have experienced worse EPS while taking haloperidol. All of the other test results might have reflected this confounding factor. For so long as antipsychotic drugs produce EPS it will be practically and ethically impossible to compare their repeated dose effects in either volunteers or patients without confounding by anticholinergics. That amisulpride was tolerated by most of the subjects without the need for comedication can be counted as one more indication of its better tolerability. 


\section{References}

Baddelley AD (1968). A three-minute test based on grammatical transfomation. Psychometr Science 72: $257-269$

Baldessarini R, Frankenburg FR. (1991). Clozapine, a novel antipsychotic agent. N Eng J Med 324 $746-754$

Bartfai A, Wiesel FA (1986). Effects of sulpiride on vigilance in healthy subjects. Int I Psychophysiol 4: $1-5$

Barnes TRE (1989). A rating scale for drug-induced akathisia. Br J Psychiatry 154:672-676.

Casey DE (1995). Motor and mental aspects of extrapyramidal syndromes. Int Clin Psychophamacol 10 (suppl 3): $105-114$

Fagan D, Scott DB, Mitchell M, Tiplady $B$ (1991). Effects of remoxipride on measures of psychological performance in healthy wolunteers. Psychopharmacology 105:225-229

Freeman IHL (1997). Amisulpride compared with standard neuroleptics in acute exabatations of schizophrenia: three efficacy studies. Int Clin Psychopharmacol 12 (suppl 2): 1.1-18.

Grünberger I, Saletu B, Linzmayer L, Stöhr H. Determination of pharmacokinetics and pharmacodynamics of anisulpride by pharmaco-EEG and psychometry (1985). In : Pichot $P$, Berner P, Wolf R, Thau eds. Psychiatry : the state of the art. New York, London. Plenum Press, pp 681-686.

Haertzen CA. Development of scales based on patterns of drug effects, using the Addiction Research Center Inventory (ARC). Psychological Reports 1966, 18:163-194

Hamilton $M(1976)$. Development of a rating scale for primary depressive illness. Br J Soc Clin Psychol 6: 278-296.

Jex HR, McDomell JD, Phatak AV, 1966. Critical tracking task for manual control research, MEEE Trans Human Fac Electron 7:138-145.

Kahn JP, Laxenaire M, Burnat G, Albaret C, Holm AC (1994). Remoxepride in acute psychosis: intramuscular followed by oral treatment compared to haloperidol, a double blind, multicenter trial. Hum Psychopharmacol 9: 79-92.

Kay SR (1991). Positive and negative symptoms in schizophrenia. New York, Brunner Mazel.

King DJ (1993). Measures of neuroleptic effects on cognition and psychomotor performance in healthy volunteers In: Hindmarch 1, Stonier PD, eds. Human Psychopharmacology Vol 4. West Sussex: John Wiley \& Sons Ltd, 195-2035

King D. (1994). Psychomotor disturbances induced by neuroleptics. Acta Psychiatr Scand 89 (suppl $380): 53-59$

King DJ, Best P, Lynch G, Mannion MF, Montgonery RC, Tiplady B, Yisak W (1995). The effects of remoxepride and chlorpromazine on eye movements and psychomotor performance in heallhy volunteers. J Psychopharmacol 2: 143-150.

King DJ (1997). BAP concensus statement: Guidelines for the use of antipsychotic drug studies in healthy volunteers. J Psychopharmacol 11:201-210.

Lader M (1993). Old problem, new challenge. J Psychopharmacoll 1993, 7: 392-393.

Le Moal M (1994). Mesocorticolimbic dopaminergic neurons: functional and regulatory rules. In: Bloom FE, Kupher DJ, eds. Psychopharmacology: the fourth generation of progress. New York: Raven Press, 283-294

Levander T (1994). Neuroleptics and the neuroleptic deficit syndrome. Acta Psychiatr Scand 89 (suppl 380$): 8-13$

Leysen JE, Gommeren W, Schotte A (1996). Serotonin receptor subtypes: possible roles and implications in antipsychotic drug action. In Kane IM, Möller HJ, Wouters FA, eds. Serotonin antipsychotic treatment. New York: Marcel Dekker, 1996: 51-75. 
Liljequist R, Linnoila M, Matrila MJ, Saario I, Seppälä T (1975). Effects of two weeks ${ }^{3}$ treatment with thioridazine, chlorpromazine, sulpiride and bromazepam, alone or in combination with alcohol, on learning and memory in man. Psychopharmacologia 1975, 44: 205-208.

Mattla MJ. Mattila ME, Konno K, Saariolho-Kere U (1988). Objective and subjective effects of remoxipride, alone and in combination with ethanol or diazepam, on performance in healthy subjects if of Psychopharmacol $2: 138-149$

Mattila MJ, Patat A, Seppalla T, Kalska H, Jalava ML, Vanakoski J, Lavanant C (1996). Single oral doses of amisulpride do not enhance the effects of alcohol on the performance and memory of healthy subjects. Eur J Clin Pharmacol 51: 161-166.

McClelland GR, Cooper SM, Pilgrim AJ (1990). A comparison of the central nervous system effects of haloperidol, chlorpromazine and supiride in normal volunteers. Br J Clin Pharmacol 30 : $795-803$

Meltzer HY (1994). Atypical antipsychotics. In: Bloom FE, Kupher DJ, eds. Psychopharmacology: the fourth generation of progress. New York: Raven Press, 1277-286

Mackworth NH (1950). Researches on the measurement of human performance. Medical Research Counsil Special Report No.268, HMSO, London

Moskowitz H (1973). laboratory studies on the effects of alcohol on some variables related to driving. Safiety Research 5: 185-1992

Naber D, Walther A, Kircher T, Hayek R, Holzbach R (1994). Subjective effects of neuroleptics predict compliance. In: Gaebel W, Awad R, eds. Prediction of Neuroleptic Treatment Outcome in Schizophrenia - Concepts and Methods. Heidelberg, Springer, 85-98.

Perrault GH, Depoortere R, Morel E, Sanger DI, Scatton B (1997). Psychopharmacological profile of amisulpride, an antipsychotic drug with selective presynaptic $D_{2} / D_{3}$ dopamine receptor antagonistic activity and limbic selectivity. J Pharmacoll Exp Ther 280:73-82.

Peretti CS, Danion JM, Kaufmann-Muller F, Grange D, Patat A, Rosenzweig P. Effects of haloperido] and amisulpride on motor and cognitive skill leaming in healthy volunteers. Psychopharmacology 131: 329-338.

Rammasyer T, Gallhofer V (1995). Remoxepride versus haloperidol in healthy volunteers: psychometric performance and subjective tolerance profiles. Int Clin Psychopharmacol 10: $31-37$

Rein W, Turjanski S (1997). Clinical update on amisulpride in deficit schizophrenia. Int Clin Psychophamacoi 12 (suppl 2): $19-36$.

Schiton B, Claustre Y, Cudennec A, Oblin A, Perrault G, Sanger DJ, Schoemaker H (1997). Amusulpride: from animal pharmacology to therapeutic action. Int Clin Psychopharmacol 12 (stupp/2): 29-36.

Schoemaker $\mathbb{H}$, Claustre $Y$, Fage D, Rouquier L, Chergui $K$, Curet O, Oblin A, Gonon $F_{*}$ Carter $C$, Benavides J, Scatton B (1997). Neurochemical characteristics of amisulpride, an atypicall $\mathrm{D}_{2} / \mathrm{D}_{3}$ receptor antigonist with both presynaptic and limbic selectivity. J Pharmacol Exp Ther 280:83-97

Simpson OM, Angus JW/S (1970). Drug induced extrapyramidal disorders: a rating scale for extrapyramidal effects. Acta Psychiatr Scand Suppl 212:11-19.

Van Putten T, Marder SR, Mintz I, Poland RE (1992). Haloperidol plasma levels and alinical response: a therapeutic window relationship. Am J Psychiatry 1992,49:500-505

Wechsier D (1981) The measurement and appraisal of adult intelligence. Baltimore: Williams and Wilkins.

Wing JK. Sturp E (1978). The PSE-IDEE CATEGO System: Supplementary Manual. Institute of Psychiatry, London.

Wing JK, Cooper $J(1974)$, Sartorius $\mathbb{N}$. The Measurement and Classification of $\mathbb{P}$ sychiatric Symptoms. Cambridge: Cambridge University Press. 


\title{
CHAPTER 8
}

\section{Antihistamine effects on actual driving performance in a standard test: A summary of Dutch experience.}

\begin{abstract}
The review summarizes the major results of eight double-blind, placebo-controlled, volunteer studies undertaken by three independent institutions for showing the effects on actual driving performance of "sedating" and "nonsedating" antihistamines (respectively, triprolidine, diphenhydramine, clemastine and terfenadine, loratadine, cetirizine, acrivastine, mizolastine, ebastine). A common, standardized test was used. that measures driving impairment from vehicular "weaving" (i.e. standard deviation of lateral position, SDLP). Logical relationships were found between impairment and dose, time after dosing and repeated doses over 4-5 days. The newer drugs were generally less impairing but differences existed among their effects and none was unimpairing at doses $1-2 \mathrm{x}$ the currently recommended levels. One or possibly two of the newer drugs possessed both performance enhancing and impairing properties, depending on dose, to suggest two mechanisms of action.
\end{abstract}

JF O'Hanlon, JG Ramaekers. Allergy 50:234-242, 1995 


\section{INTRODUCTION}

The appearance of astemizole and terfenadine on first European (1981) and later North American (1985) markets opened the era of $2^{\text {nd }}$ - generation or "nonsedating" antihistamines. In comparison to their predecessors, the new drugs were both more selective and less lipophilic. The older antihistamines rapidly penetrated the blood brain barrier to block histaminergic neurotransmission, now recognized as essential for the maintenance of normal wakefulness (Schwartz et al, 1991). To varying degrees they also blocked adrenergic, cholinergic and serotonergic neurotransmission, possibly interfering with a number of other mental functions.

The prototype "nonsedating" antihistamines have since been joined on the market by similarly selective and lipophobic drugs - acrivastine, cetirizine, ebastine and loratadine. Additions such as mizolastine are expected to appear there shortly. Respective manufacturers claim particular advantages for each drug, but all maintain that they should not cause sedation and performance impairment when taken in recommended doses.

It would be well to carefully examine this common assertion. In the strictest sense, onlly antihistamines that fail to cause sedation in nearly the entire patient population should be labeled as nonsedating. However, the assertion is never made in reference to post-marketing surveillance data, which if adequately collected, could conceivably show whether a small fraction of the total population were sedated by a particular drug. Rather it is made on the basis of data collected by the drug's manufacturer prior to its registration. There are two sources: clinical trials with patients and psychometric studies with healthy volunteers. But one should not rely exclusively upon either source for judging that a drug is definitely nonsedating. The prevalence of patients' spontaneous reports of feeling sedated in clinical trials is almost certainly an overly optimistic estimate of the actual occurrence. It is likely that many fail to recall mild and transient drowsiness or believe such feelings are unworthy of attention when questioned days or weeks after the event. Neither should this judgement be solely based upon the lack of significant impairment in the majority of psychometric studies wherein volunteers" performance is measured in simple laboratory tests after single therapeutic doses. Sample sizes in most psychometric studies are relatively small and could not include many individuals whose sensitivity to the drugs' sedative activity lies within the top $5-10 \%$ of the normal population. The occasional sensitive individual's 
reaction can easily be lost among the majority's failure to react. Dose-ranging psychometric studies have rarely been undertaken with newer antihistamines. Rarer still are those involving the administration of different doses over periods long enough for the drugs' plasma concentrations to achieve steady-state. Yet such studies are the best for determining whether antihistamines are really devoid of impaining properties. If a relatively small group shows performance impaiment after single or multiple doses at twice the therapeutic level, it may be assumed that at least some in the normal population will do the same after ordinary doses.

Study design is not the only questionable aspect of previous psychometric research on antihistamines: the methods employed for assessing the drugs' effects on performance also attract critical attention. It is a simple fact that no conventional test, or any collection in a battery, has ever been shown to predict medicinal drugs' effects on patients" behavior in real-life. This does not necessarily mean that all conventional tests used for drug screening lack predictive validity. Many possess two of the prerequisites; sensitively to low-level states of sedation and the degree of reliability that leads to highly reproducible results. Yet there is another prerequisite that none satisfies; a transfer function enabling the investigator to convert changes in test performance into some real-ife analog which varies through the range of acceptable impairment into the region of unacceptable hazard. Frustration with the seeming inability of laboratory-bound investigators to satisfy the third prerequisite led others to devise an actual driving test that avoids the necessity for a transfer function. It does this by measuring a real-life performance parameter, related to patients' safety, instead of a surrogate. The method has been independently applied by three groups working at different Dutch universities in eight double-blind, placebo-controlled volunteer studies for determining whether the forementioned "nonsedating" antihistamines are really" devoid of impairing properties after single and multiple doses, at and above their normal therapeutic levels.

The goal of this review is to summarize and integrate the Dutch effort for showing new and old antihistamine effects on driving performance. Specific objectives are to show what impairments occur after treatments with sedating antihistamines and how these compare with that caused by the only drug that is definitely known to cause traffic accidents (e.g. ethanol); and to indicate which among the new antihistamines seem the most and least likely to cause driving impairment. 


\section{THE COMMON METHOD}

The Dutch test for assessing drug effects on driving performance evolved from studies of driver fatigue conducted in the United States during the early 1970's (O'Hanlon \& Kelley, 1977). It was first applied in a 1981 pilot study for showing the acute effects or diazepam $10 \mathrm{mg}$ (O'Hanlon et al, 1982). The test was standardized shortly thereafter (O'Hanlon et al, 1986) and calibrated in a manner allowing specification of any sedating drug's effect in terms of the blood alcohol concentration [BAC] required to achieve the same level of impairment (Louwerens et al, 1987). It has not changed substantially in more than 50 studies spanning more than a decade.

Subjects perform the test in the company of a safety supervisor seated in the front passenger"s seat with access to redundant controls and a technician seated behind. The test involves driving over a $100 \mathrm{~km}$ (61 mi.) circuit while maintaining a constant speed $(95 \mathrm{~km} / \mathrm{h}, 58 \mathrm{mi} / \mathrm{h})$ and a steady lateral position within the boundaries of the slower traffic lane. Equipment aboard the vehicle continuously records speed and lateral position relative to lane-line delineation. The primary performance measure is standard deviation of lateral position (SDLP, $\mathrm{cm}$ ), an index of "weaving". SDLP is a very reliable characteristic of an individual's normal driving behavior. Test-retest reliability coefficients measured for unmedicated young and middle-aged adults over periods of days, weeks and even months are generally higher than $r=.75$ [5]. Moreover, SDLP is very sensitive to drug-induced sedation. For example, Ramaekers et al. (1992) showed the significant impairing effect of ethanol on SDLP while subjects' BAC levels declined from 0.4 to $0.2 \mathrm{mg} / \mathrm{mll}$ during the test.

\section{RESULTS}

Nine antihistamines' effects on driving are described in the following figures. Mean changes in SDLP from the same groups' corresponding placebo levels are plotted on the ordinates. Information given along the abscissa identifies the conditions of resting with respect to each of the following: hours since drug ingestion; days after the beginning of treatment; dose, formulation (when unusual), dosing regimen and numbers of male and female volunteers comprising the sample. Significant $(p<05)$ or nearly significant $(.05<\mathrm{p}<.10)$ mean SDLP changes, indicated in the figures, were in 
most cases reported as such by the investigators conducting the studies. Exceptions, noted below, occurred in two cases. The results of one study (Vuurman et al, 1994) were judged significant if satisfying the adjusted alpha-probability oriteria (po, for multiple mean-pair comparisons. That adjustment was ignored here for the sake of comparing this study's results with the majority which involved no adjustment. The results of another study (Brookhuis, 1993) did not provide test by test drug-placebo comparisons but only those involving data combined over several tests in the same series. Again for comparability, these data were reanalyzed using correlated-means ttests. The present authors accept sole responsibility for the accuracy of the results reported here for the first time.

\section{First Generation Antihistamines}

Triprolidine in doses of in either $5 \mathrm{mg}$ or $10 \mathrm{mg}$ (controlled release formulation, CR) has been used most frequently as an active control (Figure 1). Triprolidine 5 mg's acute

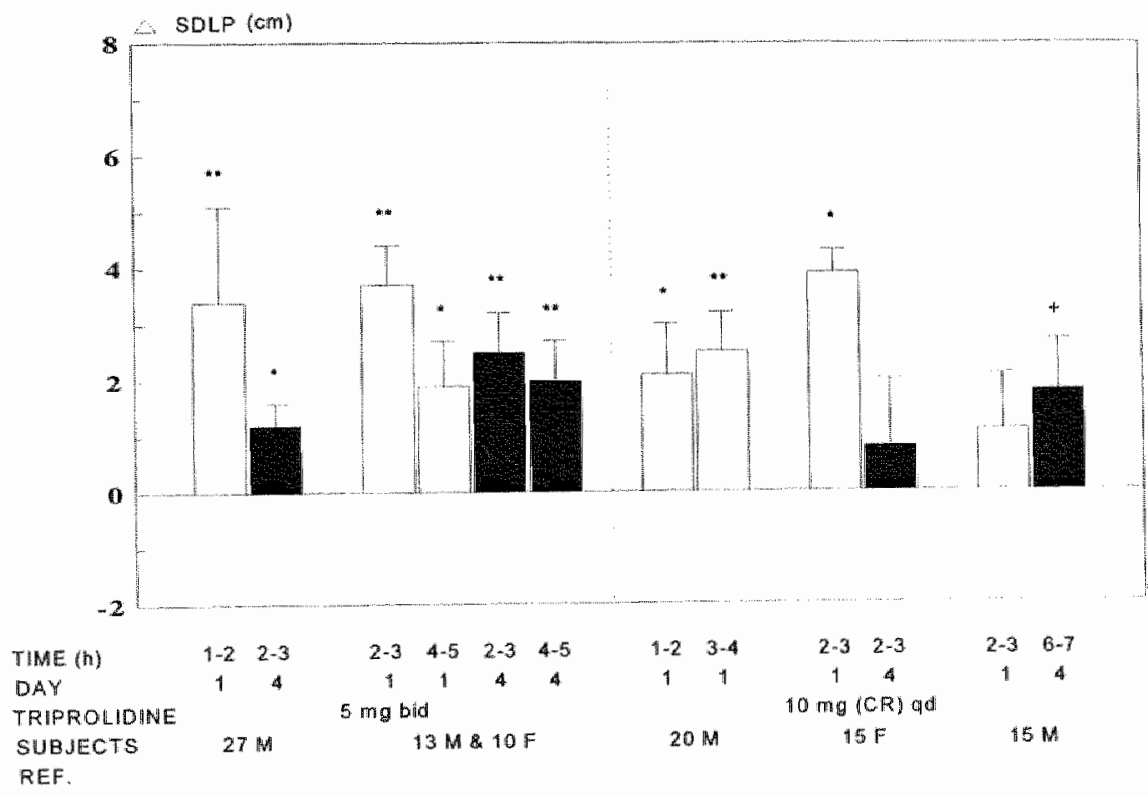

Figure 1 Mean ( \pm SE) $\triangle S D L P$ (drug-placebo) after trippolidine in normal (left) and controlled -release formulations (CR, right), as measured in separate stadios Significance of changes is indicated as follows: $+<0.10,<0.05, * 0.01)$ 
effects on SDLP were remarkably similar in the two studies where it was employed. A reduction in that effect was observed after four days of twice daily dosing in both cases, indicating tolerance for triprolidine's sedative activity. However, tolerance did not abohish the acute effect entirely: a significant effect was still present for 4-5 hours after the last dose. The effects of the controlled release formulation were appreciably less but still significant for up to 3-4 hours after the first dose. Substantial tolerance was seen after four consecutive daily doses in one study but not after five daily doses in another.

Single doses of diphenhydramine $50 \mathrm{mg}$ and clemastine $2 \mathrm{mg}$ were

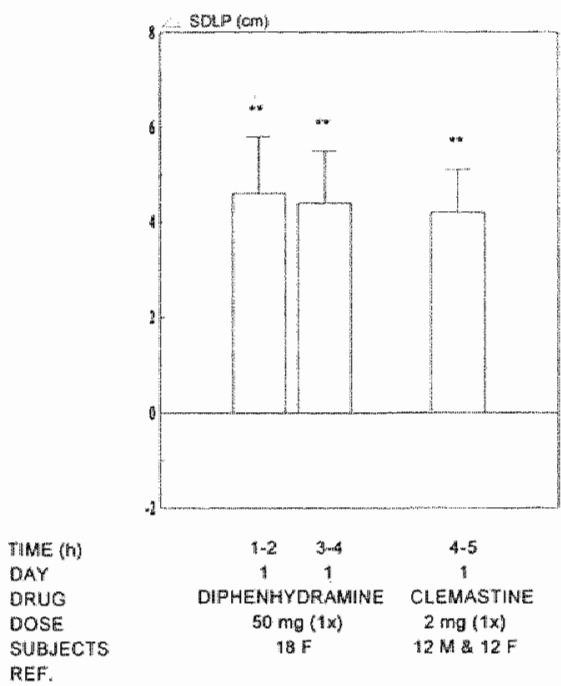

Figure 2 Mean (+SE) $\triangle S D L P$ after single doses of diphenhydramine and clemastine in separate studies. Significance of changes are as indicated for Figure 1. respectively given to females and a mixed-gender group in separate studies (Figure 2). Both drugs produced large elevations in SDLP. Interestingly, the women in the latter study reacted significantly $(\mathrm{p}<.05)$ more than their male counterparts to clemastine 2 mg; mean $\triangle S D L P$ for the former was $5.7 \mathrm{~cm}$, and for the latter, only $2.5 \mathrm{~cm}$.

These results seem representative for the adverse effects of $1^{\text {st }}$-generation antihistarnines on SDLP. Their clinical relevance can be judged in comparison to those of various blood alcohol concentrations measured in the alcohol-calibration study [4], mentioned above. Twenty-four male and female "social drinkers" drove sober and then after consuming enough alcohol to raise their BACs to $0.3,0.6,0.9$ and $1.2 \mathrm{mg} / \mathrm{ml}$ on separate occasions. Their mean $\triangle S D L P$ values increased systematically as an exponential function of $\mathrm{BAC}$ (mean correlation, $r=99$ ). This relationship was described by an equation which indicates that $\mathrm{BACs}$ of 0.5 and $1.0 \mathrm{mg} / \mathrm{ml}$ respectively produce $\triangle S D L P$ values of 2.2 and $5.5 \mathrm{~cm}$. All changes produced acutely by $1^{\text {si }}$ generation antihistamines fell within this range. The inference is that clinically important driving performance impairment can occur after $1^{\text {st }}$-generation antihistamines. 


\section{Terfenadine}

Terfenadine has been given in five separate studies in single doses up to $180 \mathrm{mg}$, and

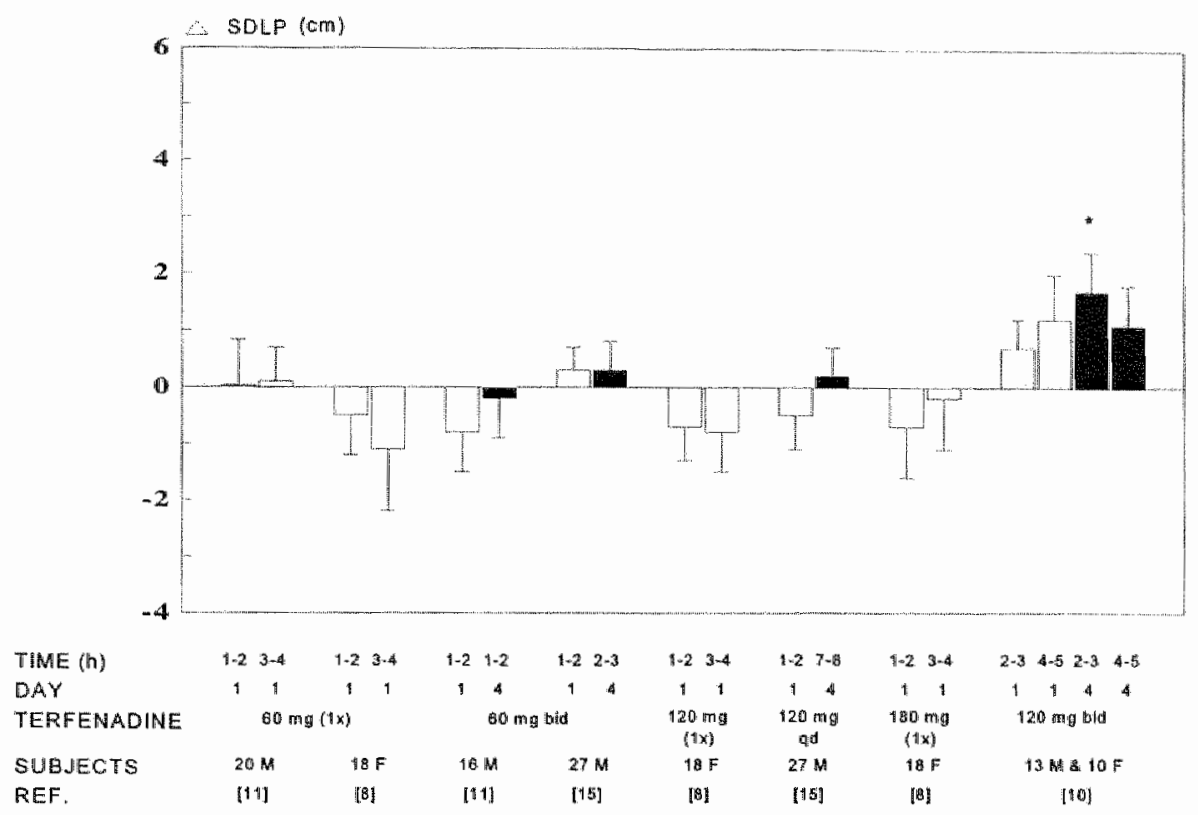

Figure 3 Mean $(+S E) \triangle S D L P$ after terfenadine. Significance of changes are as indicated for Figure 1.

multiple doses over four days, up to $120 \mathrm{mg}$ b.i.d. (Figure 3). No single-dose ever produced a significant rise in SDLP. On the contrary, there was a tendency for 60 and $120 \mathrm{mg}$ to produce a slight fall in SDLP suggesting a mild stimulating activity of the drug. Multiple doses of $60 \mathrm{mg}$ b.i.d. or $120 \mathrm{mg} \mathrm{q.d.} \mathrm{were} \mathrm{likewise} \mathrm{without} \mathrm{a} \mathrm{significant}$ effect. However, after subjects had been treated with twice the therapeutic dose, 120 mg b.i.d., for three days and tested after the morning dose on the fourth, terfenadine finally became significantly impairing.

\section{Loratadine}

Loratadine produced no significant rise in SDLP after single doses of 10 and $20 \mathrm{mg}$, or after multiple $10 \mathrm{mg}$ q.d. doses in four studies (Figure 4). Yet it too had a significant impairing effect when given over four days in twice the therapeutic dose, 20 mg q.d.. Mean $\triangle$ SDLP measured in morning and afternoon tests on the first and last treatment 


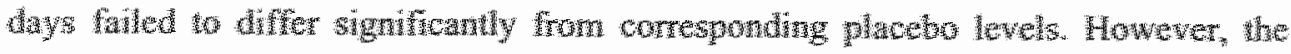

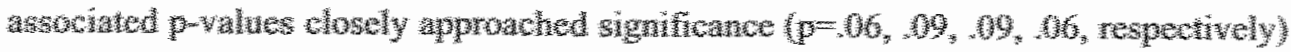
and the overall ang effect was signifeant $(p<05)$.

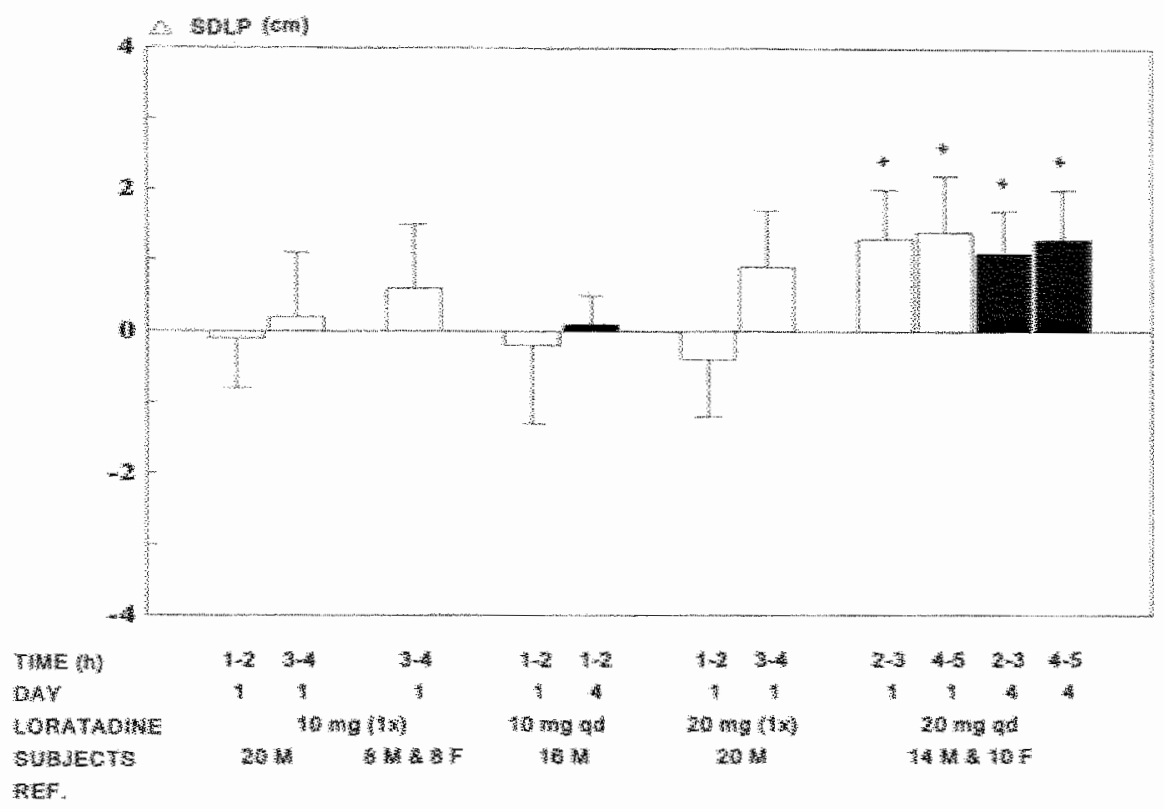

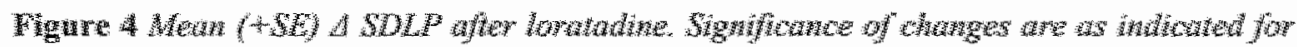
Figige 1 .

\section{Cetirizine}

Cetirizine's effect on SDLP is a matter of contention between different groups of investigators (Figure 5). One showed a significant impairing single-dose effect of cetirizine $10 \mathrm{mg}$ while the other found no effect of that dose on either the first or fourth days of repeated administration. However, differences in the composition of the respective subject samples and the times when they were tested may explain this disparity. The study showing an effect employed a mixed-gender sample who were tested 3-4 hours after drug administration. That showing no effect employed a male sample who were tested $1-2 \mathrm{~h}$ after the first dose and $7-8 \mathrm{~h}$ after the last. Though the 
former investigators were unable to measure a significant gender effect, possibly owing to the small numbers of each sex, the results mentioned above and below suggest that females are more sensitive to antihistaminest sedating activity. Moreover their subjects were tested closer to the time when cetirizine's pharmacodynamic effects in the wheel and flare test are maximum (Shall et al, 1989). It is therefore possible that the latter investigators failed to measure a significant drug effect due to the relative insensitivity of male subjects and an inappropriate time of testing, particularly on the $4^{\text {th }}$ treatment day.

\section{Acrivastine}

In Europe, acrivastine is available

alone in $8 \mathrm{mg}$ doses and combined with the decongestant, pseudoephedrine, in two fomulations: acrivastine $8 \mathrm{mg} /$ pseudoephedrine $60 \mathrm{mg}$ (instant release) and acrivastine $12 \mathrm{mg} /$ pseudoephedrine $90 \mathrm{mg}$ (slow release). Only the combination, acrivastine 8 $\mathrm{mg} /$ pseudoephedrine $60 \mathrm{mg}$ (instant release), is available in the United States.

Two studies were conducted to measure the effects of acrivastine alone in doses of 8,16 and $24 \mathrm{mg}$ and both combination preparations (Figure 6). Acrivastine $8 \mathrm{mg}$ had no effect on mean $\triangle S D L P$ in male subjects but a significantly impairing one in females. Moreover the women tended to drive worse as the doses ascended. The duration of their impaiment was also dose-related.

The addition of pseudoephedrine in the combination preparation had a salutary effect on driving performance. The women who were impaired after $8 \mathrm{mg}$ of acrivastine alone, were not affected by the same dose in combination with pseudoephedrine $60 \mathrm{mg}$. Moreover the males who were treated with that combination drove, after four days of treatment, with a significantly llower SDLP than following 
placebo. It would appear that pseudoephedrine's mild stimulating activity physiologically antagonizes acrivastine's correspondingly mild sedating activity, when present; and that the former predominates when the latter is low or absent.

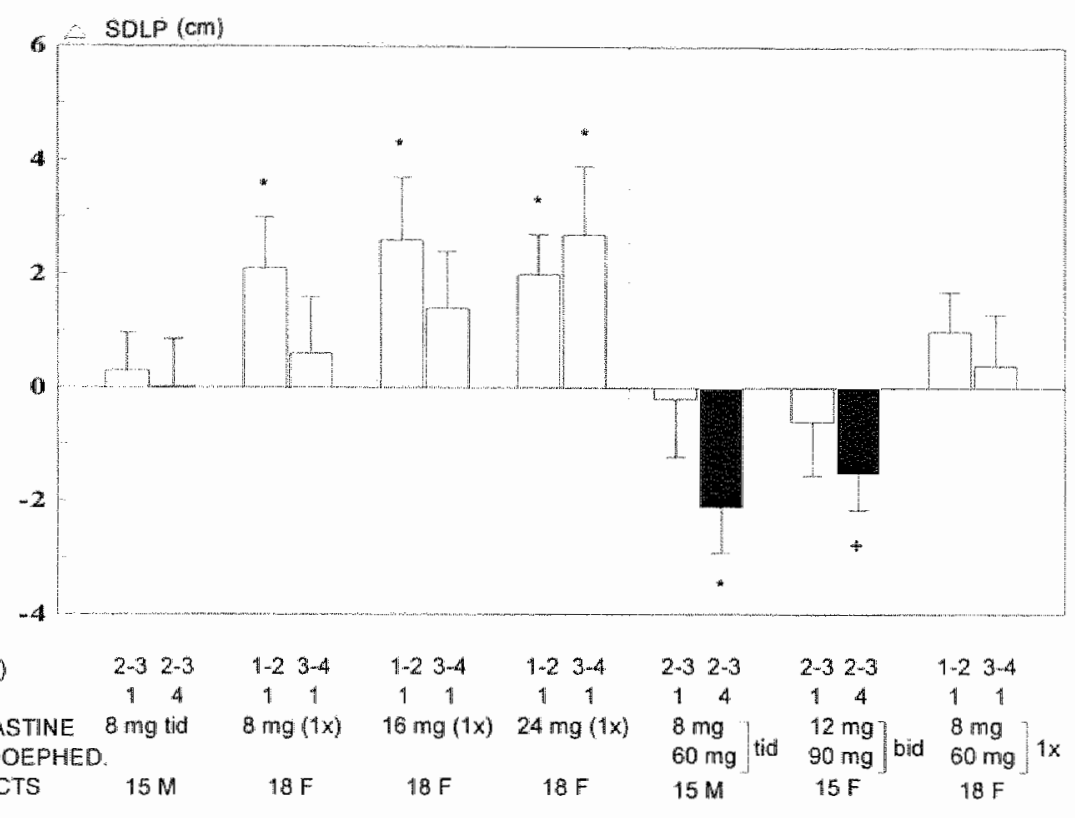

\begin{tabular}{|c|c|c|c|c|c|c|c|c|c|}
\hline TIME $(\mathrm{h})$ & $2-3 \quad-3$ & $\|-23-4$ & $1-2 \quad 3-4$ & 1.23 .4 & $2-3 \quad 2-3$ & & $2-32-3$ & & $1-23.4$ \\
\hline$D A Y$ & 4 & 1 & 11 & 1 & & & & & 11 \\
\hline $\begin{array}{l}\text { ACRIVASTINE } \\
\text { PSEUDOEPHED }\end{array}$ & $8 \mathrm{mg}$ t tid & $8 \pi \operatorname{tag}(1 x)$ & $16 \mathrm{mg}(1 \mathrm{x})$ & $24 m g(1 x)$ & $\left.\begin{array}{l}8 \mathrm{mg} \\
60 \mathrm{mg}\end{array}\right]$ & tid & $\begin{array}{l}12 \mathrm{mg} \\
90 \mathrm{mg}\end{array}$ & bid & $\begin{array}{l}8 \mathrm{mg} \\
60 \mathrm{mg}\end{array}$ \\
\hline $\begin{array}{l}\text { SUBJECTS } \\
\text { REF }\end{array}$ & $15 \mathrm{M}$ & $18 \mathrm{~F}$ & $18 \mathrm{~F}$ & $18 F$ & $15 M$ & & $15 F$ & & $18 \mathrm{~F}$ \\
\hline
\end{tabular}

Figure 6 Mean $(+S E) \triangle S D L P$ after acrivastine alone (left) and in combination with pseudoephedrine (right). Significance of changes are as indicated for Figure 1.

\section{Mizolastine}

Mizolastine is a relatively new astemizole derivative. It will be marketed in $10 \mathrm{mg}$ doses to be taken once daily. Mizolastine's effects on SDLP after single doses of 5, 10, 20 and $40 \mathrm{mg}$ were measured in a single study (Figure 7). As expected, 20 and $40 \mathrm{mg}$ doses had significantly impairing effects. How one judges the significance of the 10 $\mathrm{mg}$ dose effect depends upon his interpretation of the criterion. Originally an alphaprobability adjustment was used for multiple drug-placebo comparisons and the effects of $10 \mathrm{mg}$ failed to meet the significance criterion $\left(\mathrm{p}=.036 ; \mathrm{p} \alpha_{\mathrm{c}}=.025\right)$. However, it would appear from the well-defined dose-effect relationship that impairment begins after a single dose of about $10 \mathrm{mg}$. Whether or not one wishes to accept the original or 
present interpretation would depend upon his preference for avoiding a Type 1 or Type III error.

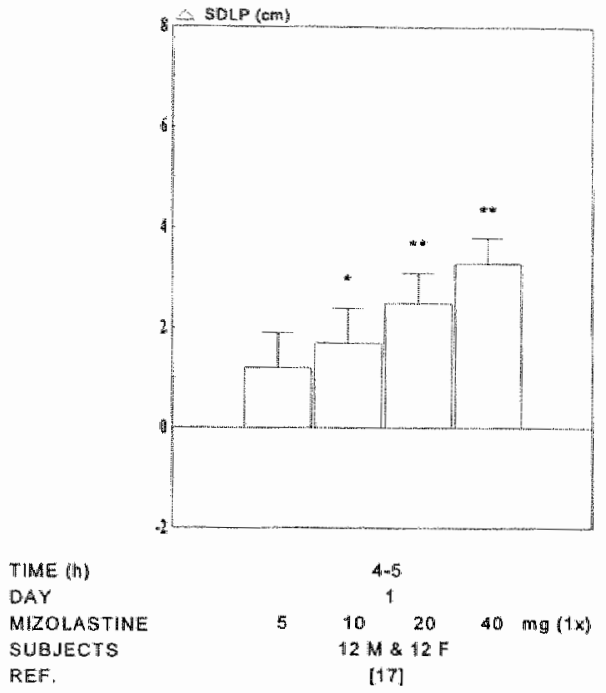

Figure 7 Mean ( + SE) $\triangle$ SDLP after single doses of mizolastine. Significance of changes are as indicated for Figure 1.

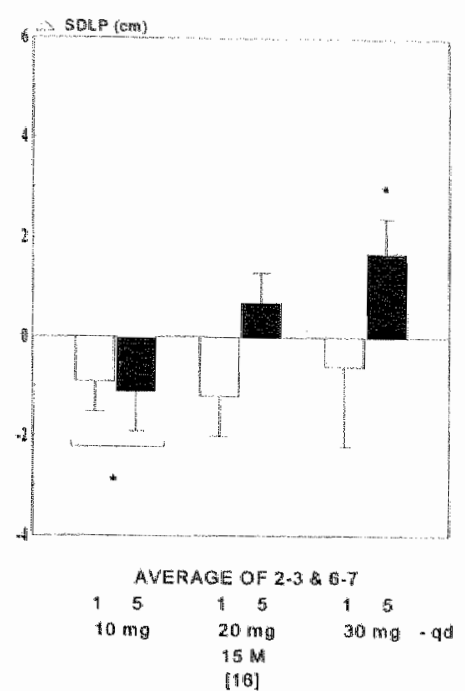

[1]

Figure 8 Mean $(+S E)$ A SDLP over two tests given on same days after ebasiline. Significance of changes are as indicated for Figure I.

\section{Ebastine}

Ebastine's chemical structure and metabolism closely resemble those of terfenadine. Both piperidine derivatives are pro-drugs almost entirely transformed into active acid metabolites during $1^{\text {st }}$-pass metabolism. Ebastine was registered for $10 \mathrm{mg}$ q.d. dosing in its country of origin (Spain) but doubts concerning that dose's efficacy may cause its registration for $20 \mathrm{mg} \mathrm{q}$.d. dosing elsewhere.

Fascinating results emerged from the single study involving ebastine (Figure 8). Male subjects were treated with ebastine 10,20 and $30 \mathrm{mg}$ q.d. for five days on separate occasions. They undertook the driving test twice on both the first and last days of each series. The results were published twice, first in a technical report [6] with limited distribution and later in the open literature [2]. The former report was the more comprehensive and is taken as the source of data for the following. 
Ebastine $10 \mathrm{mg}$ significantly lowered mean SDLP relative to placebo. Higher doses were said to have no significant effects but primarily because the investigators combined data from all tests for making the drug-placebo comparisons. Reanalysis of the data from the $5^{\text {th }}$ day of ebastine $30 \mathrm{mg}$ treatment showed that this dose was significantlly impairing.

The results shown in Figure 8 provide much food for thought. There was apparently a shift in ebastine"s CNS activity from stimulating to sedating as its brain concentration rose with the dose and/or accumulation. The effects of the $10 \mathrm{mg}$ dose were apparently stimulating on both test days. The $20 \mathrm{mg}$ dose lowered SDLP on the $1^{\text {st }}$ day, though not significantly, suggesting that it too might be stimulating. All suggestion of a stimulating effect was gone when this dose's effects were measured again on the $5^{\text {th }}$ day. The $30 \mathrm{mg}$ dose had little effect on mean $\triangle$ SDLP but a relatively large effect on the variance of individual values on the $1^{\text {st }}$ day. By the $5^{\text {th }}$ day, the highest dose's effects were clearly in the direction of sedation and a contraction of the variance showed that this was relatively consistent for all subjects.

\section{DISCUSSION}

The results of the Dutch effort are in general accord with the commonly observed difference in the impairing effects of $1^{\text {st }}$-generation and $2^{\text {nd }}$-generation antihistamines. Even when those studies showed a significant driving impairment after therapeutic doses of the newer antihistamines, its magnitude was always much less than effects of the older drugs. Except after doses that were 2-3x higher than currently recommended, no $2^{\text {nd }}$. generation antihistamines ever produced as much impairment as ethanol in a blood concentration of $0.5 \mathrm{mg} / \mathrm{ml}$. Obviously newer antihistamines are all much safer than their predecessors for use by patients who drive.

Yet an important message from the Dutch studies is that every $2^{\text {ndid-generation }}$ antihistamine possesses properties that can impair driving performance: none is truly non-sedating irrespective of the dose and duration of dosing. Therapeutic doses of some, like terfenadine and loratadine, are apparently unable to produce a significant effect in a sample of 20-30 healthy volunteers. However these drugs significantly impaired volunteers' driving performance after repeated doses that were only twice as 
high. It seems likely that normal doses would do the same in a small fraction of the total user population. All patients should be warned accordingly.

Other drugs - acrivastine, mizolastine and possibly cetirizine - appear to possess slightly greater sedating properties. For acrivastine this property can be overcome by the mild sympathomimetic effects of the decongestant with which it is presented in a combination preparation. A laboratory-based psychometric study (Gaillard \& Verduin, 1983) has shown that the combination of azatadine, a sedating antihistamine, with pseudoephedrine resulted in a net effect on performance that was indistinguishable from placebo's. The components in this case had the expected significant impairing and improving effects. Acrivastine $8 \mathrm{mg}$ combined with pseudoephedrine $60 \mathrm{mg}$ also, improved the driving performance of male subjects after four days of repeated dosing. The combination had no significant effect in females tested after a single dose, but might have similarly improved their driving performance after a multiple dose series.

Uncertainty regarding the impairing properties of cetirizine $10 \mathrm{mg}$ was not resolved by two driving studies providing conflicting results. An answer could emerge from a third study using the same approach for testing cetirizine's effects across a wide dose range but it might be available now from another source. Betts et al. (1989) measured 10 female volunteers' driving performance in a series of closed-course vehicle handing maneuvers such as driving through a slalom demarked by pylons and through a gap between pylons judged to be just wider than the vehicle. After a single dose of cetirizine $10 \mathrm{mg}$ these subjects' performance was little different than following placebo. After $20 \mathrm{mg}$, however, they struck significantly more pylons in both tests. Without bothering with the arid question of whose driving tests are the most sensitive, it is clear that both approaches provide about the same results when applicd for measuring the effects of a drug regarded clinically as sedating. It would be surprising therefore if application of the Dutch method failed to show a significantly impairing effect of cetirizine $20 \mathrm{mg}$. In that case, the present controversy about the effects of 10 mg would become largely irrelevant for the reason given above.

Ebastine's effects on driving performance are at once puzzling and provocative. No antihistamine should be intrinsically stimulating at one dose and sedating at another if it is solely an H1-receptor antagonist. The possibility exists that ebasine's metabolite, carebastine, is something more.

Post-synaptic $\mathrm{H} 1$ and $\mathrm{H} 2$ receptors have been located in the brain and also a presynaptic autoreceptor, H3 (Schwartz et al, 1991). An intense effort is now underway 
to develop ligands that bind as agonists or antagonists at the $\mathrm{H} 3$ receptor. According to current theory, H3 agonists should be sedating, and antagonists, stimulating. Carebastine is known to be an $\mathrm{H} 1$ ligand but it may also bind preferentially at the autoreceptor. This would nicely explain the driving test results; initial stimulation followed by eventual sedlation as the drug's rising brain carebastine concentration first antagonizes $\mathrm{H} 3$ autoreceptors and then post-synaptic $\mathrm{H} 1$ receptors. Whether carebastine acts in this manner should be determined by future research.

The suggestion from the results of several studies that females might be more susceptible to antihistamine-induced sedation should also be addressed in future research. Perhaps women's generally smaller volume of distribution that results in somewhat higher plasma drug concentrations after any dose is the responsible factor. But if any factor is operating to produce a gender difference in sensitivity, the usual choice of exclusively male samples for studying antihistamine and other drugs' effects on performance is an obvious mistake. The mere suspicion that this difference exists should henceforth alert researchers to employ either mixed-gender subject samples or those comprised exclusively of the gender which presently seems the more sensitive.

\section{CONCLUSIONS}

- All of the aforementioned $2^{\text {nd }}$ generation antihistamines are clearly less sedating and impairing than their predecessors.

- But none of them is entirely devoid of CNS activity.

- All produce driving performance impairment indicating a low level of sedating activity after single or multiple doses, $1-2 x$ those currently recommended.

- At least one has stimulating activity which gives way to sedating activity as its brain concentration rises with the administered dose and/or accumulation, and, its effect on driving performance varies accordingly.

- Combined therapeutic doses of sympathomimetic decongestants and mildly sedating $2^{\text {nd }}$ generation antihistamines have a net effect on driving performance that is determined by the components" physiologically antagonistic CNS activities. The average net effect for combination preparations so far studied was slightly performance enhancing or nil. Other combinations might have the same or different effects and individual reactions to all are likely to be less consistent than to either component separately. 
- Finally, precautionary warnings about antihistamines' possible adverse effects on driving and other potentially dangerous activities should not be waived for the $2^{\text {nd }}$-generation drugs. It is unlikely that the majority of patients taking recommended doses of any of these drugs will experience untoward reactions affecting their driving safety, but if any fraction will, all should receive an appropriate warning.

\section{References}

Betts $T$, Kenwood C, Dalby G, Hull B, Wild J (1989). A comparison of the effects of two nonsedating antihistamines (terfenadine and cetirizine) on tests of CNS function including driving. J Psychopharmacol 3/4: 101.

Brookhuis KA, De Vries G, De Waard D (1993). Acute and subchronic effects of the $\mathrm{H}_{1}$-histamine receptor antagonist ebastine in 10,20 and $30 \mathrm{mg}$ dose and triprolidine $10 \mathrm{mg}$ on car driving performance. Br J Clin Pharmacol 36: 67-70.

Gaillard AWK, Verduin CJ (1983). The combined effects of an antihistamine and pseudo-ephedrine on human performance. J Drug Res 8: 1929-1936.

Louwerens JW, Gloerich ABM, De Vries G, Brookhuis KA, O'Hanlon JF (1987). In: Noordzij PC, Roszbach R, eds. Alcohol, drugs and traffic safety - T86. Amsterdarn: Excerpta Medica, 183186.

O'Hanlon JF, Brookhuis KA, Louwerens JW, Volkerts ER (1986). In: OHanlon JF, De Gier JJ, eds. Drugs and driving. London: Taylor \& Francis, 311-327.

O'Hanlon JF, Haak T, Blaauw GJ, Riemersma JBJ (1982). Diazepam impairs lateral position control in highway driving. Science 217: 79-82.

O'Hanlon JF, Kelley GR (1977). In: Mackie RR, ed. Vigilance: theory, operational performance and physiological correlates. New York: Plenum Press, 189-201.

Ramaekers JG, O'Hanlon JF (1994). Acrivastine, terfenadine and diphenhydramine effects on several aspects of actual driving performance as a function of dose and time after dosing. Eur $\mathrm{J}$ Clin Pharmacol, 47: 261-266

Ramaekers JG, Uiterwijk MMC, OHanlon JF (1992). Effects of loratadine and cetirizine on aciual driving and psychometric test performance, and EEG during driving. Eur I Clin Plarmacol 42: 363-369.

Riedel WJ, Ramaekers IG, Uiterwijk M, O'Hanlon JF (1990). Higher doses of terfenadine and loratadine: acute and subchronic effects on psychomotor and actual driwing performance. Institute for Drugs, Safety and" Behavior, University of Limburg, Mastricht, NL. Techn. Rep, IGVG 90-08, ISBN 90-5147-009-6.

Riedel WJ, Schoenmakers EAM, O'Hanlon JF (1989). In: Kalinger MA, ed. Management of allergy in the 1990's. Toronto: Hans Huber, 38-49.

Robbe HJ, OHtanlon JF (1990). Effects of acrivastine, acrivastine plus pseudocphedrine and triprolidine on highway driving. Institute for Drugs, Safety and Behavior, University of Limburg, Maastricht, NL. Techn. Rep, IGVG 90-12, ISBN 90-5147-010-X.

Schwartz JC, Arrang JM, Garburg M, Pollard H, Ruat M (1991). Histaminergic transmission in the mammalian brain. Physiol Rev 71:2-51. 
Shall L, Barkley A, Millard LG (1989). H receptor antagonim of terfenadine, cetizizine and loratadine of histamine induced wheals in man. Proceedings, XIVth Congress of the European Academy of Allergology and Clinical Immunology (Berlin). Allergology B1366 Ep. 123 [Abstract].

Volkerts ER, Van Willigenburg APP, Van Laar MW, Maes RAA (1992). Does cetirizine belong to the new generation of antihistamines? An investigation into its acute ard subchronic effects on highway driving. psychometric test performance and daytime sleepiness. Hum Psychopharmacol 7: 227-238.

De Vries $\mathrm{G}$, De Waard D, Brookhuis KA (1989). A double blind study to compare the acute and subchronic effects of ebastine 10,20 and $30 \mathrm{mg} \mathrm{o.d.,} \mathrm{triprolidine} 10 \mathrm{mg}$ o.d. and placebo on car driving performance. Traffic Research Centre, University of Groningen, Groningen, NL. Techn. Rep, VK 89-22, ISBN 90-6807-165-3.

Vuurman EFPM, Uiterwijk MMC, Rosenzweig P, OHanlon JF (1994). Effects of mizolastine and clemastine on actual driving and psychomotor performance in healthy volunteers. Eur J Clin Pharmacol 47: 253-259. 


\section{CHAPTER 9}

\section{GENERAL DISCUSSION}

\section{Clinical significance of behavioral toxicity}

It is evident from the preceding chapters that behavioral side effects can significantly limit the usefulness of medicinal drugs. Sedation is a side effect produced by a great number of medicinal drugs in a variety of therapeutic classes: e.g anxiolytios, antidepressants, antipsychotics and antihistamines. Empirical studies presented in Chapters 3 through 8 demonstrate that the sedative activities of many of these drugs impair their users' performance in laboratory tests of psychomotor and cognitive skills, and in on-the-road tests of actual driving performance. If the nature of the patients" illness precludes normal activities, they may suffer no adverse consequences of being sedated. The relief it brings from anxiety or tedium might even be beneficial. Yet prolonged sedation can be highly detrimental in ambulant patients, like the group of depressed outpatients described in Chapter 6. Some of these patients' driving performance was severely impaired while using particular combinations of BZDs and antidepressants. Epidemiological surveys, reviewed in Chapter 2, furthermore demonstrated that sedative drugs can be the cause of injurious accidents or even death in common traffic, work or home situations.

Drugs may also induce side effects which appear similar to symptoms of the underlying disease. Blatantly sedative antidepressants such as mianserin and dothiepin, frequently produce drowsiness, fatigue and loss of energy (Chapters 3 and 4). SSRIs such as fluoxetine can cause concentration problems, nervousness and sleep disturbances (Chapters 4 and 6). Any of these side effects can easily be mistaken for genuine symptoms of depression. Complaints of sleep disturbance may even stimulate physicians to prescribe hypnotic comedication which could expose patients to an even greater risk of behavioral toxicity. Similarly, classic antipsychotics, can produce a number of undesirable, and it would seem unnecessary, side effects. These have been circumscribed by schizophrenic patients as "chemical strait jacketing" and "psychiatric assault" and frequently cause non-compliance with prescribed oral dose regimens (Van 
Putten, 1974; 1981). Not only do they suffer from extrapyramidal disturbances, they also complain of a number of mental aberrations that resemble the negative symptoms of schizophrenia. In Chapter 7, it was demonstrated that haloperidol produces feelings of depersonallization, lethargy, mental dullness and dysphoria in healthy volunteers. These feelings may or may not be the same as those attributable to the disease itself. But if not, they were indistinguishable from "true" negative symptoms on the most widely used clinical rating scale for assessing their severity. In any case, the ability of classic antipsychotics to exacerbate negative symptoms or inflict similarly appearing side effects, strictly limits their effectiveness to the partial control of positive symptoms.

It might be argued that treatment related side effects are a reasonable cost that a patient must bear to obtain any symptomatic relief. That particular view might even be shared by patients if their only prospect of recovering from a disabling disease completely depended on treatment with one of these so called 'behaviorally toxic' drugs. Fortunately this is rarely the case. The side effect profiles of drugs within practically every therapeutic class differ so widely that the well-informed physician can usually select a treatment that minimally impairs the patient. If different drugs provide equal efficacy, as they often do, their respective side effect profiles should be the major determining factor for prescribing one instead of another. Selection of the least impairing drug, would clearly contribute to the patients' desire to function in a normal and efficient manner within society.

\section{Selecting drugs in the light of experimental research}

Results from experimental studies presented in this dissertation demonstrated that behavioral side effects of many of the new agents can widely differ from those of older generations of drugs. Novel antidepressants, such as moclobemide, befloxatone or fluoxetine differed markedly from traditional antidepressants by producing little or no performance impairment. Moclobemide $200 \mathrm{mg}$ bid did not affect driving and psychomotor performance of healthy volunteers when tested after the first dose and after 8 days of repeated dosing. Befloxatone (20mg od for 10 days) had no impairing cffects in tests of psychomotor and cognitive functions. Neither did the drug interact with social doses of ethanol $(0.5$ and $0.8 \mathrm{~g} / \mathrm{kg})$ to cause any greater impairment than that of the latter alone. Finally, fluoxetine ( $20 \mathrm{mg}$ for 22 days) produced no measurable effects on driving performance, but slightly decreased vigilance test performance and 
CFF over 3 weeks of treatment. The relevance of the latter finding is unknown. It seems evident, however, that these novel antidepressants are preferable to the older drugs, which if taken in divided doses over the day, severely interfere with patients" behavioral competence.

This is not to say that behavioral toxicity could never occur with any of these drugs. An increasing body of evidence has shown that drugs inhibiting metabolizing enzymes of the cytochrome P450 system cause elevated plasma concentrations of comedicated drugs depending on the same enzyme for oxidation (Brosen, 1996). Fluoxetine is an inhibitor of CYP2D6 and CYP3A4 and has the potential for causing interactions with a number of $\mathrm{BZD}$ substrates of these particular isozymes. Moclobemide is a potent inhibitor of CYP2C19 implicated in the demethylation of diazepam, and the hydroxylation of its metabolite nordiazepam. The practical implication of such interactions was demonstrated in Chapter 6. Driving performance of a group of depressed out-patients treated with fluoxetine or moclobenida, deteriorated for those using co-medicated BZDs that are metabolized by a cytochrome P450 isozyme subject to inhibition by their particular antidepressant.

Neither is it to say that prescription of 'sedative' or behaviorally toxic antidepressants should always be avoided at any price. The study presented in Chapter 4 showed that daytime driving and vigilance performance during subchronic treatment with nocturnal doses of the 'sedative' antidepressant dothiepin was virtually indistinguishable from that during placebo treatment. Other studies have also demonstrated that nocturnal doses of dothiepin, and other sedative antidepressants such as amitriptyline, mianserin and mirtazepine have little effect on daytime performance (Lader et al, 1986; Allen et a1, 1988; Stille \& Herberg, 1989; Ramaekers et al, 1995). The implication is that nocturnal doses of sedative antidepressants could serve as an alternative to combined antidepressant $B Z D$ treatment in depressed patients who also suffer from insomnia. If a drug-drug interaction as described above is to be expected, the patient might be better off with noctumal doses of a sedative antidepressant.

Recent years have also witnessed the introduction of novel agents in the treatment of schizophrenia, that should provide liable alternatives for the classic antipsychotics. This was also demonstrated by the comparative study of the behavioral effects of a classic (haloperidol) and a novel (amisulpride) antipsychotic in healthy volunteers. Haloperidol $4 \mathrm{mg}$ severely impaired psychomotor and cognitive performance, throughout 5 days of treatment. It produced extrapyramidal disturbances 
in almost every subject, the most notably being akathisia and the most severe being acute dystonia in one case. It furthermore produced a number of mental disturbances, the most notably being negative symptoms. Amisulpride $400 \mathrm{mg}$ had several adverse effects on psychomotor and cognitive performance after 5 days of treatment, though generally less than haloperidol. Amisulpride generally produced no extrapyramidal disturbance, though some was measured in a low percentage of the subjects. Amisulpride also produced no signs of mental disturbances.

Side effects of amisulpride should thus be much less troublesome or behaviorally toxic to patients in comparison to classic antipsychotics, like haloperidol. Antipsychotics that do not induce EPS and mental disturbances should be very useful in most schizophrenic patients during acute phase and long-term maintenance treatment. They should increase compliance and increase the patients' quality of life and his/her overall functioning within society. However, in spite of the apparent advantages of novel drugs like amisulpride one should not imagine that they are some sort of final solution. Amisulpride's ability to impair psychomotor and cognitive function clearly reflects the drugs' potential for producing sedation. Some performance decrements brought about by amisulpride were almost comparable to those seen for amitriptyline or the hypnotic lorazepam in comparable studies (Robbe 1995; Vermeeren et al, 1996). The latter drugs' contributions to injurious accidents are well established.

Differences in side effect profiles of first and second generation antihistamines have also been well established. Results from the experimental studies in Chapter 8 indicate that second generation antihistamines possess a major advantage over the first generation in that they produce considerably less behavioral toxicity. In general, recommended doses of first generation antihistamines caused subjects to drive as badly as others had done with a blood alcohol concentration of $0.80 \mathrm{mg} / \mathrm{ml}$. None of the second generation antihistamines affected driving performance to such an extend. Yet several had significant effects, the equivalent of blood alcohol concentrations of $0.40 \mathrm{mg} / \mathrm{ml}$. Others did not have significant effects after being taken in recommended doses but had as least measurable effects after doses that were twice as high. In general, second generation antihistamines should always be preferred over their predecessors to minimize the risks on adverse behavioral effects. But again, physicians should not be misled or mislead their patients into believing that the former are entirely devoid of such properties. 


\section{Conclusion}

Medicinal drugs frequently produce side effects that prevent their users from performing everyday operations in an efficient and normal manner. As a consequence, they are at higher risk of becoming involved in accidents which in turn may lead to injuries and even worse, death. It is therefore of great importance for the safety and overall well-being of the patient to establish the behavioral side effects of all drugs. Experimental research on behavioral toxicity has provided much of this knowledge by comparing individual drugs' effects on performance of healthy volunteers or patients in well controlled, laboratory and real life conditions. Their results provide physicians with the opportunity to minimize the prevalence of behavioral toxicity by selecting those drugs with the most favorable side effect profile. Unfortunately, most experimental research has been confined to a few drug categories only, even though many others are suspected or known to produce adverse events. Extensive research on the behaviorally toxicity of medicinal drugs therefore remains badly needed, if we subscribe to the view that medical therapy should not only ameliorate symptoms and/or cure a disease but, in addition, should help the patient to function in a normal and proficient manner within society.

\section{References}

Allen D, Lader M, Curran V (1988). A comparative study of the interactions of alcohol with amitriptyline, fluoxetine and placebo in normal subjects. Prog Neuropsychopharmacol Biol Psychiatry 12:63-80

Brøsen K (1997). Are pharmacokinetic drug interactions with SSRIs an issue? Int Clin Pharmacol 11:23-27.

Lader M, Melluish A, Freka G, Fredrickson Owero K, Cristensen V (1986). The effects of citalopram in single and repeated doses and with alcohol on physiological and psychological measures in healthy subjects. Eur J Clin Pharmacol 31:183-190

Ramaekers JG, Muntjewerff ND, O'Hanlon JF (1995). Acute and subchronic effects of mirtazepine (15/30mg nocte) and mianserin $(30 / 60 \mathrm{mg}$ nocte) on psychomotor and actual driving performance. Eur Neuropsychopharmacol 5: 294

Robbe HWJ, O'flanton IF (1995). Acute and subchronic effects of paroxetine and amitriptyline on actual driving, psychomotor performance and subjective assessments in healthy volunteers. Eur Neuropsychopharmacol 5:35-42.

Stille G, Herberg KW (1989). Traffic safety during treatment with dosulepin. Fortschitte der Medizin 107: 75-78.

Van Putten T (1974) Why do schizophrenic patients refuse to take their drugs? Arch Gen Psychiat 31: 67-72

Van Putten T, May PRA, Marder SR, Wittman LA (1981). Subjective response to antipsychotic drugs. Arch Gen Psychiatry 38: 187-180. 
Vermeeren A, Jackson JL, MuntjewerfI ND, Quint PJ, Harrison EM, O'Hanlon JF (1995) Comparison of acute alprozolam $(0.25,0.50$ and $1.0 \mathrm{mg})$ effects versus those of lorazepam $2 \mathrm{mg}$ and placebo on memory in healthy volunteers using laboratory and telephone tests. Psychopharnacology 11: 1-9. 


\section{SUMMARY}

This dissertation deals with the adverse effects of medicinal drugs on behavior. Many drugs produce CNS side effects, such as sedation, sleep disturbances, motor and emotional disturbances and lethargy, which may diminish the patients' ability to cope with normal day to day activities, increase his/her risk on injurious accidents in common situations, and reduce overall quality of life. Those that do can be conceived of as behaviorally toxic.

Chapter 1 shortly provides the rationale for this thesis. Chapter 2 opens with a working definition of behavioral toxicity and reviews epidemiological and experimental research on the behavioral toxicity of anxiolytics, hypnotics, antidepressants, antipsychotics and antihistamines. Epidemiological studies consistently demonstrated causal relations between the use of certain types of medicinal drugs and injuries from falls, traffic and occupational accidents. The use of BZDs, sedative antidepressants and antipsychotics were implicated most frequently. Yet other drugs such as antihistamines or even novel antidepressant such as the SSRIs were found to increase their users' risk of occupational injuries and falls, respectively. Experimental research repeatedly demonstrated adverse drug effects on the performance of healthy volunteers and patients in number of laboratory test designed to measure psychomotor and cognitive function. The practical implications of such drug induced changes on "real life" performance such as driving has furthermore been demonstrated in a standard driving test on public roads in actual traffic. Most of these tests have been very useful for discriminating between behavioral effects of individual drugs with otherwise similar therapeutic indications. Such comparative studies of side effect profiles of individual drugs provide very useful information to physicians who wish to avoid or manage behavioral toxicity. Some of these insight offered in this chapter followed from empirical research described in the following chapters.

The study presented in Chapter 3 compares the behavioral effects of two antidepressants that widely differ in their pharmacological activities. Both antidepressants increase postsynaptic concentrations of monoamines. Moclobemide relieves depression by increasing monoamine release by inhibition of $\mathrm{MAO}-\mathrm{A}$, 
whereas mianserin enhances noradrenergic release by blocking presynaptic $a_{2}$ receptors. Yet, mianserin also possesses binding affinities for postsynaptic adrenergic, histaminergic and cholinergic receptors that are though to play a major role in the development of sedation.

The acute and subchronic effects of moclobemide and mianserin on driving and psychometric performance were compared to those of placebo in a double blind, crossover study involving 17 healthy volunteers. Mianserin ( $10 \mathrm{mg}$ ti.d), moclobemide (200 mg b.i.d) and placebo were administered according to a fixed schedule for eight consecutive days. Subjects' performance was measured on the $1^{\text {st }}$ and $8^{\text {th }}$ day of each treatment series. In addition, subjective sleep parameters, mood, and possible side effects were recorded each treatment day on questionnaires or visual analog scales. The results were highly consistent. Mianserin affected most of the performance measures while moclobemide affected none. Mianserin impaired driving and tracking performance and decreased CFF. Throughout its administration, subjects reported depressed levels of alertness, calmness and contentment. Sleep quality was unaffected, but sleep duration increased together with feelings of drowsiness and fatigue over the day. No statistical interactions between the factors Drugs and (Treatment) Days were found, indicating that little pharmacological tolerance developed over time during mianserin treatment. Mianserin's sedative properties are held responsible for all performance and subjective effects of the drug. Because moclobemide produced none of these effects it is concluded that this drug has no important sedative properties after twice daily administration of $200 \mathrm{mg}$.

Chapter 4 presents the results of a comparative study of the behavioral effects of dothiepin and fluoxetine. Dothiepin belongs to the group of TCAs that achieve their therapeutic effect through inhibition of reuptake of NA and 5-HT. Dothiepin is also an antagonist of cholinergic, adrenergic and histamine receptors which may cause sedation and consequenily behavioral impairment. Fluoxetine belongs to a different class of antidepressants, the SSRIs. It increases the availability of 5-HT in the synaptic cleft by inhibiting its neuronal reuptake. Fluoxetine generally produces less side effects than classic TCAs, and is generally regarded as a behaviorally safe drug, whereas dothiepin is classified as impairing because of its sedative effects.

The acute and subchronic effects of dothiepin $75 / 150 \mathrm{mg}$ and fluoxetine $20 \mathrm{mg}$ on critical fusion frequency (CFF), sustained attention and actual driving performance were compared to those of placebo in a double-blind, cross-over study involving 18 
healthy volunteers. Drugs and placebo were administered for 22 days in evening doses. Fluoxetine doses were constant but dothiepin doses increased on the evening of day 8 . Performance was assessed on days 1, 8 and 22 of each treatment series. Subjective sleep parameters and possible side effects were recorded on visual analogue scales on alternate treatment days. Dothiepin reduced sustained attention on day 1 by $6.67 \%$ and CFF on day 22 by $1.13 \mathrm{~Hz}$. Fluoxetine reduced sustained attention days 1,8 and 22 of treatment by $7.41,6.67$ and $6.48 \%$ respectively. CFF decreased linearly over days during fluoxetine treatment and significantly differed from placebo on day 22 with $1.24 \mathrm{~Hz}$. Neither drug significantly affected driving performance. Whilst receiving dothiepin, subjects complained of drowsiness on days 1-3 of treatment and slept 43 min longer. After receiving fluoxetine, they reported dizziness, shakiness, nausea and concentration problems in the second or third week of treatment. Spontaneously reported adverse events resembled the side effects recorded on visual analogue scales but differed less between drug treatments.

These results seem to indicate that both drugs possess similar but apparently small potentials for impairing performance. The failure to find any drug effect on driving performance furthermore indicates that the use of either dothiepin or fluoxetine would not be expected to seriously compromise patients' ability to undertake such activities in real life. This not say that either drug could never affect performance in an untoward manner. Dothiepin was given to the subjects in recommended, nocturnal doses because it possesses sedative properties. It would almost certainly cause sedation and performance impairment when taken over the day. Tolerance was apparently sufficient in the current study to largely attenuate the drug's potential sedative effects on perfornance. Dothiepin's relative mild effect on performance therefore do not contradict the current belief that it is sedating antidepressant, nor that under some conditions it can impair performance. These results rather indicate that the drug's sedative activity can be controlled as to minimize its effects on performance by gradually increasing therapeutic dosing regimen with noctumal drug administration.

The main purpose of the study presented in Chapter 5 was to determine whether befloxatone, another selective and reversible inhibition of $\mathrm{MAO}-\mathrm{A}$, potentiates the effects of ethanol on performance and mood. As for any other antidepressant, the effects of befloxatone, alone and in combination with ethanol should be assessed. Most of the drugs used for treating depression possess side effects that impair performance. Moreover these drugs" side effects generally potentiate or add to those of ethanol. It is 
well known that patients undergoing antidepressant drug therapy often consume ethanol for symptomatic relief, or simply, normal recreational purposes. The present study was designed to provide that information.

The effects of befloxatone ( $20 \mathrm{mg}$ od for 10 days) alone and in combination with ethanol on psychomotor performance, memory and mood were assessed in a randomized, double-blind, placebo controlled study. On treatment days 6,8 and 10 , subjects received $0.5,0.8 \mathrm{~g} / \mathrm{kg}$ ethanol and ethanol placebo in randomly assigned, balanced orders, 2 h post drug. Critical fusion frequency (CFF), choice reaction time (CRT), postural instability, critical tracking (CTT) and mood were measured $1 \mathrm{~h}$ before ethanol and 1, 3 and $5 \mathrm{~h}$ afterwards. Divided attention (DAT), sustained attention and memory (immediate and delayed recall) were also measured in single tests, $2-5.5 \mathrm{~h}$ post ethanol. Ethanol's effects were generally significant when blood alcohol concentrations (BAC) after both doses were the highest; i.e. 0.48-0.67 and 0.96-1.10 $\mathrm{mg} / \mathrm{ml}$. Those effects were virtually gone after the subjects mean BACs fell below 0.40 $\mathrm{mg} / \mathrm{ml}$. Befloxatone alone had no significant impairing effect in any test. Neither did it significantly interact with ethanol to cause any greater impairment than the latter alone. It was concluded that befloxatone does not potentiate the sedating and impairing effects of ethanol.

Chapter 6 presents the results of a study of the effects of moclobemide and fluoxetine on driving performance of depressed outpatients. One difference between patients and healthy volunteers is that the former are often receive comedication. Patients suffering from depression are often treated with an antidepressant and a BZD concurrently, particular when the latter has insomnia, anxiety or agitation among its side effects. The protocol of the present study allowed the patients entering the study to continue their longstanding use of BZDs as comedication.

This offered the opportunity of applying a post-hoc analysis to determine wether certain antidepressant - BZD interactions affect patients' driving performance. Moclobemide and fluoxetine are known to inhibit different isozymes of the cytochrome P450 system that are responsible for the metabolism of many BZDs. Some benzodiazepines are substrates of isozymes that are inhibited, and others are substrates of isozymes that are not inhibited by these particular antidepressants. The BZD comedication used by patients in the present study could thus either be metabolically competitive or noncompetitive with their particular antidepressant. 
The study was conducted according to a two-leg, double-blind, parallel-group design. Parallel groups of depressed (DSM III-R) outpatients received moclobemide (22) and fluoxetine (19), double blind, for 6 weeks. Respective starting doses were 150 $\mathrm{mg}$ bid and $20 \mathrm{mg}$ qam. These could be doubled after 3 weeks for greater efficacy. Chronic users of BZD anxiolytics continued taking them as comedication. Therapeutic and side effects were assessed using conventional rating scales. Beside the Hamilton Depression Rating Scale (HDRS), the Montgomery-Asberg Depression Rating Scale (MADRS), Beck's Depression Inventory (BDI), and a Clinical Global Impression (CGI) scale were used. The occurrence of side effects was checked using a standardized adverse events questionnaire. Actual driving performance was assessed during the week prior to therapy and at 1,3 and 6 weeks thereafter using a standlardized test that measures standard deviation of lateral position (SDLP).

Similar remissions in depressive symptoms and side effects occurred in both groups. Patients drove with normal and reliable $(r=.87)$ SDLPs before treatments. Most continued to do so but a few drove with progressively rising SDLPS and the overall trends were significant in both groups ( $p<.03$ ). A post hoc multiple regression analysis was applied for identifying factors that correlated with SDLP in separate tests after the beginning of therapy. Factors included were: Antidepressant, Double dose, Depression severity, BZD comedication, High doses of BZD, Competitive BZD, Sleep disturbances, Nervousness and Nausea. At 3 and 6 weeks there were significant $(p<.03)$ relationships involving the same factor: Patients who drove with progressively higher SDLPs appeared to be those using BZDs that are metabolized by a P450 isozyme subject to inhibition by their particular antidepressant.

These results indicate that outpatients suffering from Major Depression werc able to repeatedly perform the driving test in an essential normal manner, and that their driving performance did not improve with the remission of the depressive symptoms. The final tentative conclusion offered for heuristic purposes is that neither moclobemide nor fluoxetine affects the driving performance of depressed patients, excepts when used in combination with competitive BZD conedication, producing impairment.

The primary objective of the study presented in Chapter 7 was to compare the effects of amisulpride, an atypical benzamide antipsychotic, with those of haloperidol and placebo on healthy young volunteers" performance in a battery of cognitive, psychomotor and extrapyramidal tests and their mental status as assessed in a 
structured interview. Volunteers entered a four-way double-blind design where they were treated for 5 days on separate occasions, with amisulpride ( 50 and $400 \mathrm{mg} /$ day), haloperidol ( $4 \mathrm{mg} /$ day) and placebo. Subjects were institutionalized during treatment periods under 24 h medical supervision. They performed a series of psychomotor and cognitive tests $1 \mathrm{~h}$ before and 3 and $6 \mathrm{~h}$ after dosing on Days 1 and 5 . Their extrapyramidal disturbances and drug related feelings were assessed at the end of each replication. Psychiatric interviews and ratings of depression, subjective well-being and negative symptoms occurred on Day 4 . Amisulpride $50 \mathrm{mg}$ had no significant effect on any parameter. Amisulpride 400mg had several adverse effects on psychomotor and, though less, cognitive performance on the $5^{\text {th }}$ day only. Amisulpride 400 produced no significant extrapyramidal disturbances in the group as a whole, though it may have in some individuals. Also, it produced no signs of mental disturbances on clinical rating scales or during a structured psychiatric interview. Haloperidol ubiquitously impaired psychomotor and cognitive performance, similarly after the first and the final doses. It produced extrapyramidal disturbances in almost every subject, the most common being akathisia and the most severe, in the case of one individual, acute dystonia. Unlike amisulpride, haloperidol produced a number of mental disturbances, the most noteworthy being negative symptoms. Amisulpride appears to be a far better tolerated drug. Its side effects shouid be much less troublesome to patients using the drug chronically than those of classic antipsychotics, like haloperidol.

The review presented in Chapter 8 summarizes the major results of eight double-blind, placebo-controlled, volunteer studies undertaken by three independent institutions for showing the effects on actual driving performance of "sedating" and "nonsedating" antihistamines (respectively, triprolidine, diphenhydramine, clemastine and terfenadine, loratadine, cetirizine, acrivastine, mizolastine, ebastine). A common, standardized test was used that measures driving impairment from vehicular "weaving" (i.e. standard deviation of lateral position, SDLP). Logicall relationships were found between impairment and dose, time after dosing and repeated doses over 4-5 days. The newer drugs were generally less impairing but differences existed among their effects and none was unimpairing at doses $1-2 x$ the currently recommended levels. One or possibly two of the newer drugs possessed both performance enhancing and impairing properties, depending on dose, to suggest two mechanisms of action.

Chapter 9 concludes the dissertation with a general discussion of the clinical relevance of behavioral toxicity and the importance of aggregating knowledge on 
behavioral toxicity for optimizing treatment decisions. It is emphasized that current research on the behaviorally toxicity of medicinal drugs has been limited to a few drug categories only, even though other drugs classes are suspected to produce unwanted side effects as well. 


\section{SAMENVATTING}

Dit proefschrift handelt over de ongewenste effecten van geneesmiddelen op gedrag. Geneesmiddelen kunnen een reeks van ongewenste bijwerkingen veroorzaken, zoals sedatie, slaapstoornissen, motorische en emotionele stoornissen en lethargie, die ertoe kunnen leiden dat hun gebruikers minder goed functioneren in het dagelijkse leven of aan een hoger risico op ongevallen worden blootgesteld. Deze bijwerkingen kunnen dus schadelijk, cq toxisch, zijn voor het vermogen van een patiënt om op een normale en efficiênte manier te handelen. In zo'n geval kunnen we spreken van 'gedragstoxicologie'.

Hoofdstuk 1 geeft kort de rationale van het proefschrift weer. Hoofdstuk 2 opent met een werkdefinitie van gedragstoxicologie. Het vervolgt met een overzicht van epidemiologisch en experimenteel onderzoek naar de gedragstoxicologie van kalmeringsmiddelen, slaapmiddelen, antidepressiva, antipsychotica en antihooikoortsmiddelen, geeft aan wat bekend is over de onderliggende farmacologische processen en geeft inzicht in de manier waarop gedragstoxicologie beheerst of vermeden kan worden. Epidemiologische studies hebben duidelijk aangetoond dat het gebruik van bovengenoemde geneesmiddelen is geassocieerd met een toename van het risico op vallen of om bij verkeers- en bedrijfsongevallen betrokken te raken. Empirische studies, hebben bij herhaling laten zien dat geneesmiddelen de prestaties van gezonde vrijwilligers en patiènten op een aantal laboratorium tests van psychomotore en cognitieve functies verminderen. De praktische relevantie van zulke gedragsveranderingen voor dagelijkse activiteiten zoals autorijden is bovendien aangetoond in een standaard rijvaardigheidstest die wordt uitgevoerd op de snelweg onder normale omstandigheden. De meeste van deze tests zijn zeer gevoelig voor de effecten van geneesmiddelen en uitermate geschikt om verschillen tussen bijwerkingen van afzonderlijke geneesmiddelen naar aard en intensiteit te classificeren. Zulk vergelijkingsmaterial kan waardevolle informatie verschaffen aan de arts in diens keuze voor een geneesmiddel. Deze bepaalt in belangrijke mate of patiënten hinder ondervinden van ongewenste bijwerkingen. 
De studie uit Hoofdstuk 3 vergelijkt de effecten van twee, farmacologisch verschillende, antidepressiva op een aantal gedragsparameters. Uit literaturgegevens is bekend dat beide antidepressiva hun therapeutische werking bewerkstelligen door een toename van post-synaptische concentraties van monoanines in de hersenen. Moclobemide veroorzaakt een hogere afgifte van monoamines als gevolg van MAO-A. inhibitie en mianserine veroorzaakt hogere noradrenaline concentraties middels blokkade van pre-synaptische adrenergische $\left(\alpha_{2}\right)$ receptoren. Echter, mianserine beschikt ook over een aantal farmacologische eigenschappen die niet direct relevant zijn voor het beoogde therapeutische effect. Met name haar werking op postsynaptische adrenergische $\left(\alpha_{1}\right)$, histaminergische en cholinergische receptoren wordt in verband gebracht met versuffende bijwerkingen.

Acute en subchronische effecten van moclobemide (200mg bid) en mianserine (10mg tid) op rijvaardigheid en psychomotorische vaardigheden werden vergeleken met die van placebo. Geneesmiddelen werden dubbel-blind en in een gerandomiseerde volgorde toegediend aan 18 gezonde vrijwilligers gedurende periodes van 8 dagen. Hun rijvaardigheid en psychomotore functies werden gemeten op dag 1 en 8 van iedere periode. Bovendien, werden hun subjectieve beoordelingen van de slaap, stemming en bijwerkingen geregistreerd op visuele analoge schalen. De resultaten waren bijzonder consistent. Mianserine beïnvloedde de meeste gedragsparameters en moclobemide geen enkele. Mianserine verminderde de rijvaardigheid en psychomotore functies. Tijdens de gehele medicatieperiode maakten de vrijwilligers gewag van verminderde alertheid, suf- en vermoeidheid. De ernst van deze bijwerkingen bleven min of meer constant gedurende de gehele medicatieperiode. Dit geeft aan dat er in het geval van mianserine niet of nauwelijks farmacologische gewenning optreedt aan haar sedatieve eigenschappen. Deze laatste worden dan ook verantwoordelijk geacht voor de nadelige effecten van mianserine op prestaties en gedrag. Omdat moclobemide geen van deze effecten veroorzaakte kan worden geconcludeerd dat dit geneesmiddel geen sedatieve eigenschappen heeft bij doseringen van $200 \mathrm{mg}$ bid.

Hoofdstuk 4 presenteert de resultaten van een vergelijkende studie van de effecten van dosulepine en fluoxetine op gedrag. Dosulepine behoort tor de groep van tricyclische antidepressiva die een therapeutische effect bereiken middels inbibitie van neuronale heropname wan noradrenaline en serotonine. Dosulepine heeft ook een antagonistische werking op cholinerge, adrenerge en histaminerge receptoren die sedatie kan veroorzaken en verstoring van gedrag tot gevolg kan hebben. Fluoxetine 
behoort tot een andere groep antidepressiva, de SSRIs, die serotonine concentraties in de synaptische spleet verhogen middels een selectieve inhibitie van hun heropname. Fluoxetine produceert in het algemeen minder bijwerkingen dan de traditionele tricyclische antidepressiva, en wordt over het algemeen beschouwd als een zeer veilig geneesmiddel. Dosulepine daarentegen wordt algemeen gezien als een geneesmiddel dat gedrag kan ontregelen vanwege zijn sedatieve eigenschappen.

De acute en subchronische effecten van dosulepine (75/150mg) en fluoxetine (20mg) op psychomotore functies (CFF, vigilantie) en rijvaardigheid van 18 gezonde vrijwilligers werden vergeleken met die van placebo. Geneesmiddelen en placebo werden gedurende periodes van 22 dagen als avonddosering toegediend. Fluoxetine doseringen bleven gedurende de gehele periode constant, maar die van dosulepine verdubbelde van 75 naar 150 op dag 8 . Psychomotoriek en rijvaardigheid werden gemeten op dag 1, 8 en 22 van iedere medicatieperiode. Subjectieve beoordelingen van slaap en bijwerkingen werden vastgelegd op visuele analoge schalen. Dosulepine verminderde vigilantie op dag 1 met $6.67 \%$ en CFF met $1.13 \mathrm{~Hz}$ op dag 22. Fluoxetine verminderde vigilantie op dagen 1,8 en 22 met respectievelijk $7.41,6.67$ en $6.48 \%$. $\mathrm{CFF}$ daalde lineair over de tijd gedurende behandeling met fluoxetine en verschilde significant van placebo op dag 22. Dosulepine veroorzaakte sufheid gedurende de eerste drie medicatiedagen en verlengde de slaapduur met 45 min. Vrijwilligers rapporteerden duizeligheid, misselijkheid en concentratieproblemen tijdens het gebruik van fluoxetine.

Deze resultaten geven aan dat beide geneesmiddelen een gelijke, kleine verstoring van gedragsfuncties veroorzaken bij gezonde vrijwilligers. De mate van interferentie was echter gering en niet van dien aard dat patiènten ernstig beperkt zullen worden in het normale, dagelijks functioneren. Dat wil niet zeggen dat deze geneesmiddelun nooit van negatieve invloed kunnen zijn. Dosulepine werd in de studie toegediend in avonddoseringen, juist vanwege z'n sedatieve kenmerken. Deze zouden zo goed als zeker van invloed zijn geweest op de prestaties van vrijwilligers indien het geneesmiddel was toegediend gedurende de dag. Tolerantie voor de sedatieve werking van dosulepine was in de huidige studie blijkbaar voldoende om de negatieve effecten op prestatievermogen en gedrag tot een minimum te beperken. Het relatief milde effect van dosulepine op gedrag is dan ook niet in tegenspraak met de huidige opvatting dat dosulepine een sedatief geneesmiddel is. Veeleer geeft het aan, dat de schadelijke 
gevolgen beperkt kunnen worden wanneer het geneesmiddel als wonddosering wordt voorgeschreven.

De studie in Hoofdstuk 5 wilde vaststellen of befloxatone, ook een rewersibele MAO-A remmer, de nadelige effecten van alcohol op gedrag en stemming zou kunnen beïnvloeden. Dit is van belang omdat patienten naast medicatie vaak alcohol gebruiken, soms voor recreatieve doeleinden en soms als symptoombestrijding. Een interactie tussen het geneesmiddel en alcohol zou ertoe kunnen leiden dat gelijktijdig gebruik van grotere invloed is voor gedrag dan op grond van de bijwerkingen van alcohol en een geneesmiddel afzonderlijk verwacht zou kumnen worden.

De effecten van befloxatone $(20 \mathrm{mg})$ met en zonder een dosering alcohol, op psychomotoriek, geheugen en stemming werden gemeten in een gerandomiseerd, dubbel-blind onderzoek. Op dag 6, 8 en 10 van iedere medicatieperiode ontvingen proefpersonen $0.5,0.8 \mathrm{~g} / \mathrm{kg}$ alcohol en alcohol placebo in eem gerandomiseerde en gebalanceerde volgorde, 2 uur na inname van medicatie. Psychomotoriek, geheugen en stemming werden middels een aantal laboratorium testsw gemeten voor imname en, bij herhaling, tussen 1 en 6 uur na inname van medicatie. De effecten van beide doseringen alcohol op psychomotorische en cognitieve gedragsparameters waren over het algemeen het duidelijkst meetbaar op tijdstippen dat de bloed alcohol concentraties (BACs) het groots waren; dwz tussen 0.48-0.67 en 0.96-1.1 $\mathrm{mg} / \mathrm{ml}$. Befloxatone had geen nadelige effecten in geen enkele test. De combinatie van befloxatone met alcohol veroorzaakte geen grotere effecten op gedragsparameters dan het gebruik van alcohol alleen. Daaruit werd de conclusie getrokken dat befloxatone de sedatieve werking van alcohol niet versterkt.

Hoofdstuk 6 presenteert de resultaten van een studie naar de effecten van moclobemide en fluoxetine op rijwaardigheid van ambulante, depressieve patiènten. Een verschil tussen patiënten en gezonde vrijwilligers is dat de eerste vaak comedicatie imnemen. Patiënten die lijden aam een depressie worden vaak behandeld met een antidepressivum alswel een BZD, met name wanneer bij deze laatste slapeloosheid, psychische angst of geagiteerdheid onder de bekende bijwerkingen horen. Het protocol van de huidige studie stond toe dat de patiènten die aan de studie meededen hun reeds langdurende gebruik van BZDs als co-medicatie konden voortzetten.

Dit bood de kans om, door middel van een post-hoc analyse, te bepalen of het gebruik van combinaties van antidepressiva en BZDs de rijvaardigheid van patienten 
beïnvloeden. Van moclobemide en fluoxetine is bekend dat zij werschillende isozymen van het cytochrome P450 systeem beïnvloeden welke verantwoordelijk zijn woor het metabolisme van veel BZDs. Enkele benzodiazepines zijn substraten van isozymen die wel, en andere zijn substraten van isozymen die niet onderdrukt worden door deze specifieke antidepressiva. De BZD co-medicatie die gebruikt werd door de patiënten in de huidige studie kon clarom compatibel of niet-compatibel zijn met hun specifieke antidepressiva.

De studie werd uitgevoerd volgens een 2-weg, dubbel-blind onderzoek. Parallelle groepen depressieve (DSM III-R) patiënten kregen moclobemide (N=22) en fluoxetine $(\mathrm{N}=19)$, toegediend gedurende een periode van 6 weken. De respectievelijke start-doseringen waren $150 \mathrm{mg}$ bid en $20 \mathrm{mg}$ qam. Deze doseringen konden verdubbeld worden na 3 weken indien effectiviteit achterwege bleef. Chronische gebruikers van BZDs bleven deze gebruiken als co-medicatie. Therapeutische werkingen en bijwerkingen werden gemeten met behulp van conventionele beoordelingsschalen. Naast de 'Hamilton Depression Rating Scale' (HDRS) werden de 'MontgomeryAsberg Depression Rating Scale” (MADRS), 'Beck's Depression Inventrory” (BDI), en een 'Clinical Global Impression' (CGI) schaal gebruikt. Het optreden van bijwerkingen werd gecontroleerd met behulp van een gestandaardiseerde vragenlijst voor ongewenste bijwerkingen. De rijvaardigheid werd één week voor de therapie getest en 1,3 en 6 weken daarna met behulp van een gestandaardiseerde test.

Depressieve symptomen verminderden gedurende behandeling in beiden groepen. Voorafgaande aan de medicatieperiode reden patiënten op een normale en statistisch betrouwbare manier. De meeste bleven dit doen tijdens de medicatieperiode, maar in enkele gevallen werd een daling van de rijvaardigheid geconstateerd. Vervolgens werd een post hoc multiple regressie analyse toegepast om die factoren te identificeren die correleerden met hun prestaties in de rijtest. De volgende factoren werden onderzocht op hun invloed op de rijwaardigheid: Gebruik van antidepressiva, Dubbele dosis, Mate van Depressie, BZD co-medicatie, Hoge doseringen BZD, Incompatibele BZDS, Slaapstoornissen, Nervositeit en Misselijkheid. De resultaten toonden aan dat een factor in het bijzonder van invloed was op rijvaardigheid. Patienten wier rijwaardigheid afnam gedurende therapie bleken juist die patiënten te zijn die incompatibele combinaties van een antidepressivum en BZD gebruikten.

Het doel van de studie in Hoofdstuk 7 was de effecten van amisulpride, een atypisch antipsychoticum, en haloperidol, een klassiek antipsychoticum, op 
psychomotore, cognitieve, extrapyramidale en affectieve functies to vergelijken met die van placebo. Gezonde vrijwilligers werden volgens een 4-wegs, dubbel-blinde onderzoeksprocedure gedurende periodes van 5 dagen behandeld met: placebo, amisulpride 50 en $400 \mathrm{mg}$ en haloperidol $4 \mathrm{mg}$. Gedurende medicatieperiodes werden deelnemers ondergebracht op een gesloten afdeling onder continue medische supervisie. Psychomotoriek, cognitie en extrapyramidale functies werden gemeten op dag 1 en 5 wan iedere periode. Depressie, subjectieve gevoelens van welbehagen, en negatieve symptomen van schizofrenie werden gemeten middels een aantal gevalideerde, klinische beoordelingsschalen en tijdens een psychiatrisch interview op dag 4. Amisulpride $50 \mathrm{mg}$ had geen enkel effect op de onderzoeksvariabelen. Amisulpride $400 \mathrm{mg}$ veroorzaakte verschillende effecten op psychomotoriek en cognitie, maar alleen op dag 5 . Het had in het algemeen geen invloed op extrapyramidale en affectieve functies van de proefpersonen, alhoewel in sommige individuen wel extrapyramidale stoornissen meetbaar waren. Haloperidol had een nadelige invloed op zowat iedere psychomotorische en cognitieve gedragsvariabele, zowel op dag 1 en 5 van medicatie. Het produceerde extrapyramidale stoornissen bij vrijwel iedere proefpersoon. Meestal bleven deze beperkt tot akathisie, maar in het ernstigste geval leidde dit tot een acute dystonie. Haloperidol veroorzaakte ook een aantal mentale stoomissen die avereenkomen of lijken op de negatieve symptomen van schizofrenie. De nadelige gedragseffecten van amisulpride waren dus minder in getal en lichter van aard dan die van haloperidol. Er werd geconcludeerd dat bijwerkingen van amisulpride daardoor draaglijker moeten zijn voor patiënten dan die van klassieke antipsychotica, zoals haloperidol.

Het overzichtsartikel in Hoofdstuk 8 vat de belangrijkste resultaten samen van 8 dubbel-blinde, placebo gecontroleerde studies naar de effecten van "sedatieve" en zogeheten "niet-sedatieve" antihistaminica (respectievelijk: triprolidine, diphenhydramine, clemastine, terfenadine, loratadine, ceterizine, acrivastine, mizolastine, ebastine) op rijvaardigheid. Deze studies werden uitgevoerd in drie Nederlandse studiecentra die elk gebruik maakten van dezelfde gestandaardiseerde methode volgens welke rijvaardigheid wan een persoon kan worden bepaald aan de hand van zijn/haar slingergedrag gedurende een snelweg rit van een uur. De mate van slingering wordt tot uitgedrukt in een gemiddelde standard deviatie van de laterale positie (SDLP) van het voertuig gedurende de test. Er werden duidelijke relaties gevonden tussen de mate van slingergedrag en de hoogte van doseringen, tijd na 
medicatie inname en de duur van medicatie inname. De nieuwere "niet-sedatieve" middelen hadden minder effect op de rijvaardigheid dan oudere, sedatieve antihistaminica. Sommige veroorzaakten zelfs geen nadelig effect op de rijvaardigheid. Echter, alle 'niet-sedatieve' antihistaminica verminderden de rijvaardigheid bij doseringen die eens of tweemaal zo hoog waren dan de aanbevolen dosering. Een, wellicht twee, van de nieuwere antihistaminica veroorzaakte zowel een lichte verbetering als een verslechtering van de rijvaardigheid afhankelijk van de hoogte van de dosering.

Hoofdstuk 9 eindigt dit proefschrift met een algemene discussie over de klinische relevantie van ongewenste effecten van geneesmiddelen op gedrag, en het belang van kennis daaromtrent bij de keuze tussen verschillende geneesmiddelen. $\mathrm{Er}$ wordt benadrukt dat onderzoek naar nadelige effecten van geneesmiddelen op gedrag zich tot op heden beperkt heeft tot een klein aantal groepen van geneesmiddelen, terwijl gedragstoxicologische effecten bij meerdere categorieën verwacht kunnen worden. 


\section{DANKWOORD}

Velen droegen bij aan de totstandkoming van dit proefschrift. Een aantal van hen wil ik met name noemen.

Allereerst mijn promotoren Jim O'Hanlon en Jelle Jolles. Jim O'Hanlon, hoogleraar Psychofarmacologie aan de Universiteit Maastricht en voormalig directeur van het Instituut voor Humane Psychofarmacologie (IHP) ben ik zeer erkentelijk woor zijn nimmer tanend enthousiasme, zijn kritische begeleiding maar vooral ook voor de talloze gesprekken die we voerden over psychofarmacologie, behoudens die op zondagochtend. Jelle Jolles, hoogleraar Neuropsychologie en directeur van de onderzoeksschool Hersenen \& Gedrag van de Universiteit Maastricht, dank ik voor zijn commentaar en adviezen die bijdroegen aan de kwaliteit van het proefschrift.

Nienke Muntjewerff, Cees van Leeuwen ('An Apple a day keeps Cees away'), Henriëtte Swijgman, Henk Milius, Arthur de Bie en Jan Willem Louwerens dank ik voor hun bekwame medische ondersteuning tijdens de verschillende studies.

De rij-instructeurs, in het bijzonder Henk Brauers, die tijdens de rijtesten zorg droegen voor de (verkeers)veiligheid van de proefpersonen, en Irma Brauers die de planning van vele 'ritten' coördineerde, wil ik bedanken voor hun inzet en waakzaamheid.

Verder dank ik de overige oud-collega's van het IHP voor de prettige sfeer waarin we konden samenwerken. Marcel Hendrickx, Ron Hellebrand, Veronique van der Varst wil ik bedanken voor hun technische en secretariële ondersteuning. Marius Bassie, Mir Uiterwijk en Loe van Veggel dank ik voor hun diverse waardevolle bijdragen. Ook alle assistenten die mij geholpen hebben bij het verzamelen van gegevens ben ik zeer erkentelijk voor hun grote inzet.

Familie en vrienden wil ik bedanken voor hun interesse in mijn werk. Mijn ouders dank ik voor hun aanhoudende steun. Bovenal dank ik Judy en Arthur. 


\section{CURRICULUM VITAE}

Jan Ramaekers werd geboren op 5 juni 1963 te Heerlen. In 1982 behaalde hij het Atheneum-A diploma aan het Bernardinus College in diezelfde stad. Aansluitend begon hij aan de studie Psychologie aan de Rijksuniversiteit Groningen. Na zijn afstuderen in de psychologische functieleer in 1988 was hij als onderzoeker werkzaam bij het Instituut voor Humane Psychofarmacologie van de Universiteit Maastricht, alwaar hij onderzoek verrichtte naar de effecten wan geneesmiddelen op menselijk gedrag. Sinds 1996 is hij tevens als universitair docent verbonden aan de Faculteit Psychologie van de Universiteit Maastricht. Nu, twee jaar later, bekleedt hij deze functie voltijds. 
